\title{
Platelets in atherothrombosis : roles of CD36 and P2Y12 receptors
}

Citation for published version (APA):

Unal - Nergiz, R. (2011). Platelets in atherothrombosis : roles of CD36 and P2Y12 receptors. [Doctoral Thesis, Maastricht University]. Maastricht University. https://doi.org/10.26481/dis.20110623ru

Document status and date:

Published: 01/01/2011

DOI:

10.26481/dis.20110623ru

Document Version:

Publisher's PDF, also known as Version of record

\section{Please check the document version of this publication:}

- A submitted manuscript is the version of the article upon submission and before peer-review. There can be important differences between the submitted version and the official published version of record.

People interested in the research are advised to contact the author for the final version of the publication, or visit the DOI to the publisher's website.

- The final author version and the galley proof are versions of the publication after peer review.

- The final published version features the final layout of the paper including the volume, issue and page numbers.

Link to publication

\footnotetext{
General rights rights.

- You may freely distribute the URL identifying the publication in the public portal. please follow below link for the End User Agreement:

www.umlib.nl/taverne-license

Take down policy

If you believe that this document breaches copyright please contact us at:

repository@maastrichtuniversity.nl

providing details and we will investigate your claim.
}

Copyright and moral rights for the publications made accessible in the public portal are retained by the authors and/or other copyright owners and it is a condition of accessing publications that users recognise and abide by the legal requirements associated with these

- Users may download and print one copy of any publication from the public portal for the purpose of private study or research.

- You may not further distribute the material or use it for any profit-making activity or commercial gain

If the publication is distributed under the terms of Article $25 \mathrm{fa}$ of the Dutch Copyright Act, indicated by the "Taverne" license above, 
Platelets in atherothrombosis

Roles of CD36 and $P 2 Y_{12}$ receptors 


\section{Platelets in atherothrombosis}

Roles of CD36 and $P 2 Y_{12}$ receptors

Thesis Universiteit Maastricht

ISBN 978-90-817320-0-0

(C) R. Nergiz Ünal, Maastricht 2011

Printed by Palme Publications

Layout and Cover by Ahmet Akay (Palme Publications) \& Reyhan Nergiz Ünal 


\title{
Platelets in atherothrombosis
}

\author{
Roles of CD36 and $\mathrm{P} 2 \mathrm{Y}_{12}$ receptors
}

PROEFSCHRIFT

ter verkrijging van de graad van doctor aan de Universiteit

Maastricht, op gezag van de Rector Magnificus,

Prof. mr. G.P.M.F. Mols, volgens het besluit van het

College van Decanen, in het openbaar te verdedigen op

donderdag 23 juni 2011 om 10.00 uur

door

Reyhan Nergiz Ünal 


\section{Promotor}

Prof. dr. J.W.M. Heemskerk

\section{Copromotor}

Dr. J.M.E.M. Cosemans

\section{Beoordelingscommissie}

Prof. dr. A. Bast (voorzitter)

Prof. dr. E.A.L. Biessen

Prof. dr. H. ten Cate

Dr. M. van Greevenbroek

Dr. S.J.A. Korporaal (Universitair Medisch Centrum, Leiden)

Financial support by the Netherlands Heart Foundation for the publication of this thesis is gratefully acknowledged.

Additional financial support for the publication of this thesis by Helvacızade Food, Drug and Chemicals Inc. is gratefully acknowledged.

Additional financial support for the publication of this thesis by Stichting Hartsvrienden RESCAR is gratefully acknowledged. 


\section{Gerçek Değer}

Gerçek değer gelmesi boşluk dolduran değil; Gitmesi boşluk yaratandır.

\section{Real Value}

Real value is not what fills a gap when it comes; It is what creates a gap when it goes.

(Özdemir Asaf) 



\section{Contents}

Chapter 1 General Introduction 9

Chapter 2 CD36 as a multiple-ligand signaling receptor in atherothrombosis

Chapter 3 Signaling role of CD36 in platelet activation and thrombus formation on immobilized thrombospondin or oxidized LDL

Chapter 4 Subtle roles of platelet CD36 and thrombospondin-1 in murine thrombus formation on collagen

Chapter 5 Complementary roles of platelets and coagulation in thrombus formation on plaques acutely ruptured by targeted ultrasound treatment: a novel intravital model

Chapter 6 Stabilizing role of platelet $\mathrm{P}_{2} \mathrm{Y}_{12}$ receptors in shear-dependent thrombus formation on ruptured plaques

Chapter 7 Effect of dietary walnut on atherosclerosis and coagulant state in ApoE-deficient mice

Chapter 8 General Discussion

Summary

Samenvatting

Özet

Curriculum vitae

List of Publications 174

Acknowledgements 



\section{Introduction}

Cardiovascular diseases are the underlying cause of one third of all deaths globally (17.1 million people a year). The majority of these deaths are due to thrombotic disorders such as coronary heart disease and stroke ${ }^{1}$. Herein, thrombosis is due to (downstream) occlusion of an affected artery as the consequence of rupture or erosion of an atherosclerotic plaque. In spite of all current treatment options, further research to reduce the incidence of these thrombotic disorders is highly needed. In this thesis the role of several platelet receptors in the thrombus-forming process is studied either in vivo on ruptured murine atherosclerotic plaques or in model tests in vitro. In addition, the possible involvement of nutrition in atherosclerosis and onset of thrombosis is studied. The paragraphs below give relevant background information on the platelet receptors and activation processes that contribute to thrombus formation.

\section{Platelet responses in thrombus formation}

Platelets have an essential function in hemostasis, but are deleterious in atherothrombosis. They rapidly adhere to the arterial vessel wall at sites of endothelial cell damage, and thereby contribute the development of chronic atherosclerotic lesions ${ }^{2,3}$. In large arteries, including the aortic arch and the coronary and carotid arteries, the rupture or denudation of an atherosclerotic plaque causes massive adhesion and aggregation of platelets to form a growing thrombus ${ }^{4,5}$. Several recent reviews extensively describe current knowledge regarding the molecular mechanisms of thrombus formation ${ }^{6-8}$. Only those pathways relevant to this thesis are discussed here.

Collagen fibers in an atherosclerotic plaque constitute the principal platelet-adhesive component ${ }^{9,10}$. When exposed to flowing blood, type I and III collagens potently support platelet adhesion and robustly trigger platelet activation via the signaling collagen receptor glycoprotein (GP)VI and the adhesive collagen receptor integrin $\alpha_{2} \beta_{1}$ (Figure $1.1)^{11,12}$. At arterial, high-shear flow conditions, collagen-bound von Willebrand factor assists in the initial platelet adhesion via GPIb-IX-V. Collagen-adhered platelets become activated and then recruit other platelets via secretion of several autocrine agents, such as ATP, ADP, thrombopondin-1 (TSP1). In addition, the activated platelets release short-living phospholipid-derived eicosanoids like thromboxane $A_{2}$, which interacts with neighboring TP receptors. The released ATP interacts with the rapidly desensitizing $P 2 X_{1}$ receptors ${ }^{13,14}$. The autocoid ADP is secreted from dense granules, and it activates nearby platelets via the $\mathrm{P} 2 \mathrm{Y}_{1}$ and $\mathrm{P}_{2} \mathrm{Y}_{12}$ receptors, both of which play an important role in platelet aggregate formation ${ }^{15,16}$. Although in vitro studies show the importance of these receptors in platelet activation, their contribution to the process of thrombus formation after plaque rupture has not been studied. Even more unclear is the role of thrombospondin-1, which is abundantly released from platelet alpha granules ${ }^{17,18}$.

Whereas many of the collagen-adhered platelets assemble into aggregates, some of the platelets expose phosphatidylserine at their outer membrane. Phosphatidylserine serves as a procoagulant phospholipid surface accelerating the activation of coagulation factors, in particular the conversion of prothrombin into thrombin ${ }^{19,20}$. Thrombin, in turn, acts as a strong platelet agonist on human platelets via the protease-activated receptors, 
PAR-1 and PAR-4, and on murine platelets via PAR-3 and PAR-421,22. Locally formed thrombin, in addition, operates as a feedback activator of several coagulation factors, and it furthermore cleaves fibrinogen into fibrin monomers which after polymerization stabilize the growing thrombus (Figure 1.1) ${ }^{23}$.

Recent evidence indicates that rupture of a plaque evokes stimulation of both the extrinsic and intrinsic coagulation cascades. Regarding the first pathway, tissue factor, in plaques particularly expressed on macrophages, stimulates factor VII-dependent thrombin generation 924,25 . Plaque-derived collagen triggers the intrinsic pathway of thrombin generation via activation of factor $\mathrm{XII}^{26}$. A role of exposed plaque material in coagulation is furthermore likely, since plaques derived from autopsies contain all key coagulation factors ${ }^{27}$. Accordingly, current findings suggest that during thrombus formation on atherosclerotic plaques, the processes of platelet activation and coagulation are activated in a joint fashion ${ }^{19,28,29}$.

\section{Platelet activation by signaling and adhesive receptors}

Platelets contain high amounts of both adhesive and signaling receptors. In general, the typical adhesion receptors are expressed at much higher copy numbers than the

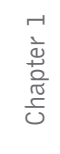

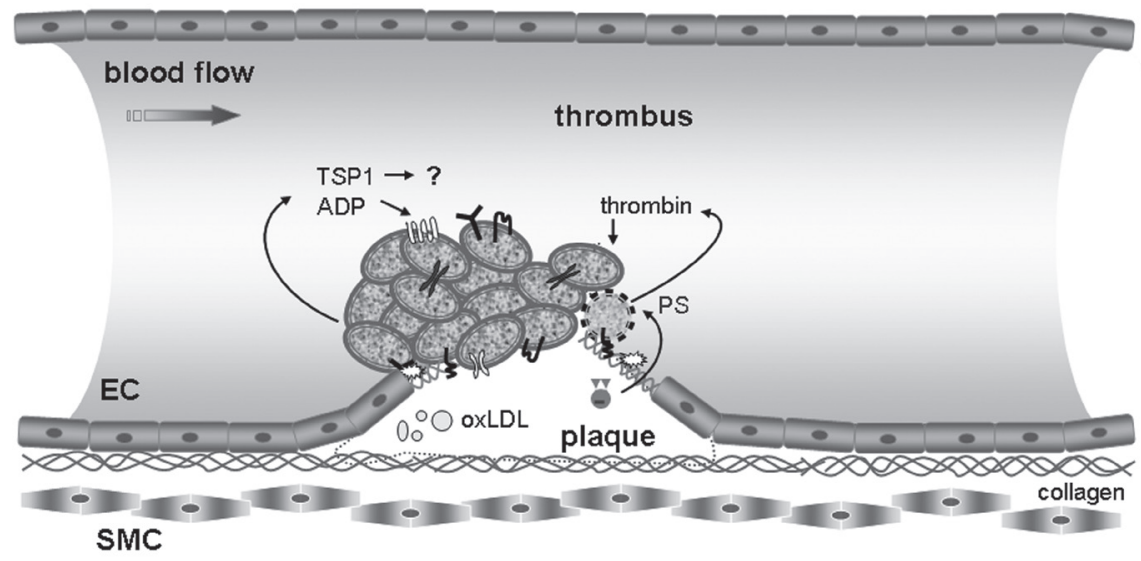

\begin{tabular}{|c|c|c|c|c|c|}
\hline$Y_{\text {GPIb-IX-V }}$ & $\int \alpha_{2} \beta_{1}$ & $x^{3}$ & WWF & M CD36 & || phosphatidylserine \\
\hline 3 GPVI & )$\left(\alpha_{11 b} \beta_{3}\right.$ & 1000 & $\mathrm{P} 2 \mathrm{Y}_{1112}$ & TF & \\
\hline
\end{tabular}

Figure 1.1. General scheme of arterial thrombus formation. Rupture of an atherosclerotic plaque exposes a thrombogenic surface with collagen, oxidized LDL (oxLDL) and tissue factor (TF). Flowing platelets adhere to collagen-bound von Willebrand factor (vWF) via GPIb-IX-V, and to collagen via GPVI and integrin $\alpha_{2} \beta_{1}$. After activation, they secrete autocrine mediators such as ADP and thrombospondin-1 (TSP1). These agents interact with receptors on the surface of nearby platelets to form a thrombus. Tissue factor, e.g. exposed by macrophages, triggers the extrinsic coagulation cascade which is responsible for the generation of thrombin on the surface of procoagulant platelets exposing phosphatidylserine (PS). Thrombin potentiates thrombus formation and cleaves fibrinogen into fibrin, which stabilizes the growing thrombus. Note that only events relevant to this thesis are indicated. Abbreviations: EC, endothelial cells; SMC, smooth muscle cells. 
- Table 1.1. Expression of key adhesive and signaling receptors on human platelets. Copy numbers of those platelet receptors are given, with their corresponding ligands, which are relevant for this thesis ${ }^{8,15,30,31,78-80}$.

\begin{tabular}{llc}
\hline Platelet receptor & Ligand / agonist & Copies per platelet \\
\hline$\alpha_{\text {IIb }} \beta_{3}$ (GPIIb-IIIa) & fibrinogen, vWF & $80,000-100,000$ \\
GPIb-IX-V & VWF, thrombospondin-1 & $20,000-30,000$ \\
CD36 & (this thesis) & $10,000-25,000$ \\
$\alpha_{2} \beta_{1}$ (GPIa-IIa) & collagen & $2000-4000$ \\
GPVI & collagen & $1000-2000$ \\
P2Y & ADP & $500-1000$ \\
P2Y & ADP & $500-1000$ \\
TP & thromboxane $A_{2}$ & $200-500$ \\
PAR-1 & thrombin & $1500-3000$ \\
PAR-4 & thrombin & $<1500$ \\
\hline
\end{tabular}

signaling receptors ${ }^{30}$. Table 1.1 summarizes this for those receptors relevant for the present thesis. The most abundant adhesive receptors are integrin $\alpha_{\mathrm{IIb}} \beta_{3}$ and GPIbIX-V, which bind fibrinogen and von Willebrand factor, respectively. Both are of key importance in platelet aggregation and thrombus formation under shear conditions. Typical signaling receptors are expressed at only 500-3000 copies per cell. This holds for the immunoglobulin-type receptor, GPVI, and for the G-protein coupled receptors, P2Y ${ }_{11}$ P2Y ${ }_{12}$ TP, PAR-1 and PAR-4 (Table 1.1).

Since a number of years, it is becoming more and more clear that the classical distinction between adhesive and signaling receptors is artificial. Some typical adhesive receptors also appear to have a signaling function and vice versa. For instance, ligandoccupied integrin $\alpha_{\mathrm{IIb}} \beta_{3}$, when in the activated form and clustered, can transduce signals itself via a so-called outside-in signaling mechanism ${ }^{8,31}$. This outside-in signaling leads to the spreading of platelets on immobilized fibrinogen and the retraction of platelets within a fibrin clot. The clustering of fibrinogen-bound $\alpha_{\mathrm{II}} \beta_{3}$ results in activation of a cascade of protein tyrosine kinases, involving Src kinase and recruited Syk kinase, the latter of which phosphorylates and activates phospholipase C (Figure 1.2). The result of this is formation of inositol 1,4,5-trisphosphate, which mobilizes cytosolic $\mathrm{Ca}^{2+}$, and of diacylglycerol, which activates protein kinase $C^{31,32}$. An alternative pathway has also been proposed, involving $\alpha_{\mathrm{IIb}} \beta_{3}$-dependent complex formation of Src with focal adhesion kinase, which provokes Syk-independent downstream responses. There is also evidence for signaling responses due to GPIb-IX-V interaction with von Willebrand factor, in part again through $\mathrm{Ca}^{2+}$ mobilization ${ }^{32,33}$. Whether other platelet adhesive receptors can operate in signaling mode has to be established.

\section{Unclear role of CD36 in platelet activation}

An abundant receptor, expressed at 10,000-25,000 copies per platelet, is CD36 (Table 1.1). Although this high expression is suggestive for an important role of CD36 


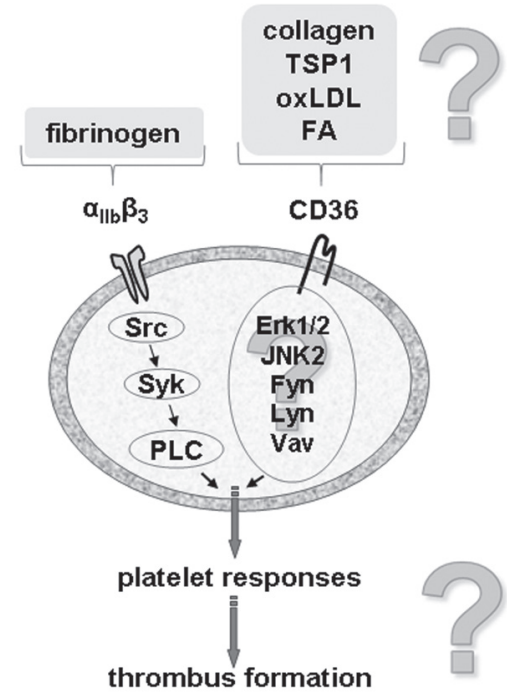

- Figure 1.2. Mechanisms of platelet activation by the abundant adhesive receptors $\alpha_{\mathrm{II}} \beta_{3}$ and CD36. Operating in the outside-in signaling mode, fibrinogenoccupied integrin $\alpha_{\mathrm{II}} \beta_{3}$ activates a protein tyrosine kinase signaling pathway, involving Src and Syk kinases. Important downstream effectors are phospholipase $C$ (PLC) $\gamma$-isoforms. In research with other cell types, the adhesive and scavenging receptor CD36 is reported to trigger different signaling routes. Several ligands of CD36 are described, including collagen, thrombospondin-1 (TSP1), oxidized LDL (oxLDL) and long-chain fatty acids (FA). Ligand-bound CD36 was found to activate serine/threonine and tyrosine protein kinases, including as Erk1/2, JNK2, Fyn and Lyn, as well as the guanine nucleotide exchange factor, Vav. Which of these agents activate platelets via CD36, and through which signaling pathways, is not clear.

in platelet activation, it has appeared difficult to discover such function ${ }^{34-36}$. Several ligands of CD36 have been identified in different cell types, the most important of which are collagen, TSP1, oxidized low-density lipoproteins (oxLDL), oxidized phospholipids (oxPL), and long-chain fatty acids (Figure 1.2) 37,38 . With this knowledge, CD36 has been categorized as an adhesive, scavenger or fatty acid binding receptor.

Early reports, using blocking anti-CD36 antibodies, suggested that CD36 operates in platelet adhesion to collagen and subsequent platelet activation ${ }^{39,40}$. However, this role could not be confirmed in studies with platelets from CD36-deficient patients, responding normally to collagen in terms of integrin activation, secretion and aggregation ${ }^{41,42}$. This questions a collagen-dependent role of CD36 in thrombus formation. Whether and how other ligands such as TSPI and oxidized LDL contribute to platelet activation via CD36 is also unclear (Figure 1.2). TSPI is secreted by activated platelets and endothelial cells into the blood stream and the extracellular matrix ${ }^{18,43,44}$. A role for TSPI has been proposed in platelet activation under high shear conditions, but this depended on interaction with GPIb-IX-V rather than CD36 ${ }^{45}$. Other authors have reported a functional interaction of TSPI with platelet integrins ${ }^{46,47}$.

In platelets, oxLDL can bind to CD36 and another class B scavenger receptor, $\mathrm{SR}-\mathrm{BI}^{48,49}$. Platelet treatment with $\mathrm{x} L \mathrm{LD}$ or $\mathrm{x} \mathrm{PL}$, partly via CD36, is supposed to result in activation of a number of protein kinases, such as Erk1/2, JNK2, Fyn, and Lyn (Figure 1.2) 38,50 . Which of these signals exclusively rely on CD36 and how these signals determine a possible role of CD36 in platelet adhesion and activation is still a matter of debate.

\section{Platelet $\mathrm{P}_{2} \mathrm{Y}_{12}$ receptors and thrombus formation}

The signaling pathways downstream of the $A D P$ receptors, $P 2 Y_{1}$ and $P 2 Y_{12}$, are well documented. Platelet stimulation with ADP via $P 2 Y_{1}$ causes shape change and initiates the 
aggregation process, while stimulation via $\mathrm{P}_{2} \mathrm{Y}_{12}$ is required for a complete aggregation response ${ }^{15}$. Signaling by $P 2 Y_{1}$ occurs via the conventional pathway of phospholipase $C$ and protein kinase $C$, which is discussed in detail elsewhere ${ }^{15,16}$. As summarized in Figure 1.3, the $\mathrm{P} 2 \mathrm{Y}_{12}$ receptors couple to $\mathrm{Gi}$ and inhibit adenylyl cyclase, an enzyme that produces CAMP and activates protein kinase A. Signaling via Gi furthermore leads to stimulation of phosphoinositide 3-kinase isoforms, which produce phosphatidylinositol 3,4,5-triphosphate to activate downstream signaling targets including Raplb, to result in $\alpha_{\text {IIb }} \beta_{3}$ activation ${ }^{51-53}$. It was shown by our group and others that continuous signaling via $A D P$ and $P 2 Y_{12}$ is required to maintain $\alpha_{I I b} \beta_{3}$ in its active conformation and to prevent disaggregation of a platelet thrombus ${ }^{54,55}$.

Since several years, the $\mathrm{P} 2 \mathrm{Y}_{12}$-directed prodrug clopidogrel is used to prevent secondary thrombotic events, for instance in patients with myocardial infarction or stroke ${ }^{56,57}$. Recent clinical studies performed with the new, irreversible $\mathrm{P}_{2} \mathrm{Y}_{12}$ inhibitor prasugrel $^{58}$ and the reversible $\mathrm{P}_{2} \mathrm{Y}_{12}$ inhibitor ticagrelor ${ }^{59}$ have provided even more promising results in the treatment of acute coronary syndrome. However, the clinical application of $\mathrm{P}_{2} \mathrm{Y}_{12}$ antagonists has disadvantages such as an increased risk of minor or major bleeding ${ }^{16}$.

Research to the efficacy of such drugs is greatly facilitated by the availability of in vivo animal models. In recent years, several murine thrombosis models have been developed to study thrombus formation in microvessels of the mesentery, and also in large vessels such as the carotid artery 29,60 . However, in most models healthy blood vessels, rather than atherosclerotic vessels, are damaged for thrombus induction (e.g. by manually squeezing, ligation, or application of free radical-generating agent). Research into atherothrombosis is thereby lacking a suitable animal model for realtime investigation of the process of thrombus formation upon acute plaque rupture. In the present thesis, we aimed to establish such a model, and use it to assess the antithrombotic effects of new $\mathrm{P} 2 \mathrm{Y}_{12}$ antagonists.

\section{- Figure 1.3. General scheme of $P 2 Y_{12}$-induced signaling in} platelets. While the ADP receptor $\mathrm{P} 2 \mathrm{Y}_{1}$ couples to $\mathrm{Gq}$, the ADP receptor $\mathrm{P}_{2} \mathrm{Y}_{12}$ is linked to $\mathrm{Gi}$ upon ligand occupation. Activated Gi stimulates phosphoinositide 3-kinase (PI3K) isoforms, which activate the low-molecular weight GTP-binding protein Rap1b. The latter is an important step in the cytoskeleton-dependent integrin $\alpha_{\mathrm{II}} \beta_{3}$ activation. In addition, Gi inhibits cAMP formation via adenylyl cyclase (AC); this shuts off protein kinase A (PKA), i.e. a platelet-inhibiting kinase. Together, both signaling pathways downstream of $\mathrm{Gi}$ are considered to mediate all $\mathrm{P} 2 \mathrm{Y}_{12}$-dependent platelet responses in thrombus formation.

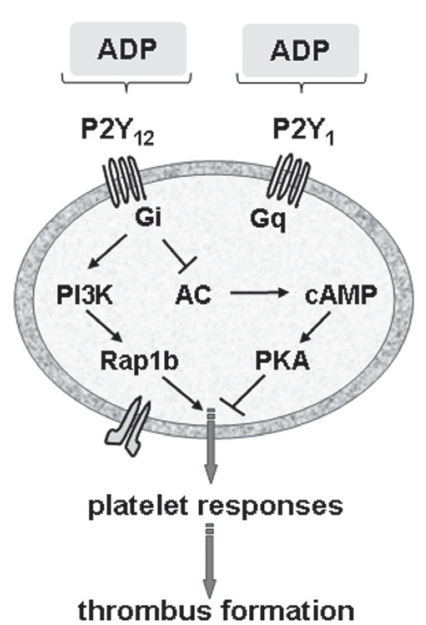




\section{Dietary effect on atherothrombosis}

Hyperlipidemia, in addition to hypertension, obesity and diabetes, is a major risk factor for atherothrombosis. Hence, a lipid-lowering diet can be helpful to retard plaque formation and delay the clinical manifestations of atherosclerosis and thrombosis ${ }^{61}$. Dietary components that are typically associated with lipid normalization and increased cardiovascular health are $n-3$ polyunsaturated fatty acids ( $n-3$ PUFA) and antioxidants ${ }^{62-64}$.

The World Health Organization recommends a daily ingestion of $n-3$ PUFA in the range of $6-10 \%$ of the total daily energy intake for an adequate promotion of cardiovascular health ${ }^{65}$. Dietary effects of $n-3$ PUFA have most extensively been examined in supplementation studies of fatty fish or fish oil. In several murine studies, it was demonstrated that supplementation of fish oil-derived n-3 PUFA had an antithrombotic effect by reducing the plasma levels of lipids and key coagulation factors, but with no more than little effect on platelet function ${ }^{63,66}$. Similarly, in patients with hyperlipidemia or diabetes mellitus, dietary fish oil reduced plasma levels of triglycerides as well as fibrinogen and factor $V^{67}$. Whether other sources of $n-3$ PUFA (non-marine or plantderived) act similarly is unknown.

Marked cholesterol- and lipid-lowering effects have been ascribed to the intake of antioxidant polyphenols, such as proanthocyanidin present in grape seeds ${ }^{68,69}$. Feeding rabbits a grape seed extract resulted in lowering of the plasma cholesterol, which was accompanied by a slower development of atherosclerosis ${ }^{70}$. In human, grape seed extracts were shown to inhibit platelet activation in vitro, and thrombus formation ex vivo $^{71,72}$.

Walnuts are much consumed in the Eastern Mediterranean including Turkey. Albeit being energy rich, walnuts may form a healthy nutritional supplement, since they contain high levels of n-3 PUFA as well as considerable amounts of antioxidant polyphenols. Furthermore, as a non-marine n-3 PUFA source, walnut oil does not contain cholestero ${ }^{73}$. Epidemiologic studies have pointed to a clear association between high walnut consumption, reduced plasma lipid levels and a diminished risk of coronary heart disease ${ }^{74,75}$. However, studies so far are inconsistent whether walnut consumption reduces platelet activation or not ${ }^{76,77}$. Taken together, this raises the question whether walnuts, by the combined presence of $n-3$ PUFA and antioxidants, are able to affect the process of atherosclerosis and thrombosis. From this perspective, it is interesting to make a comparison between dietary supplementation with whole walnuts, with $n-3$ PUFA-containing walnut oil only, and with a source of antioxidant polyphenols, such as in grape seeds.

\section{Aims and outline of this thesis}

In this thesis, new mechanisms are studied of platelet activation in thrombus formation, in particular in relation to atherothrombosis. Chapter 1 provides a brief synopsis of key platelet activation processes that contribute to the process of thrombus formation. The focus is on two receptor proteins studied most extensively in this thesis, CD36 and P2 $Y_{12}$. The possible roles of nutrition in atherosclerosis and thrombosis are also discussed. In 
chapter 2, a detailed overview is given on the proposed action mechanisms of CD36 in various cells of the cardiovascular system, with a focus on platelets and atherothrombosis. In the experimental chapter 3 the role of human CD36 in platelet activation and thrombus formation under flow conditions is examined. Starting point is the early evidence that this glycoprotein may act as a receptor for collagen, thrombospondin-1, oxidized LDL and long-chain fatty acids. Knowing that these substances accumulate in the subendothelial matrix of the vessel wall, it is investigated whether and how platelet activation by surface-immobilized collagen, thrombospondin- 1 and oxidized LDL relies on CD36 activity. Chapter 4 extends this work to the contribution of murine CD36 in platelet activation and thrombus formation by using $\mathrm{Cd}_{3} 6^{-/}$mice. Furthermore, using $\mathrm{Tsp}^{1-\text { - }}$, we aim to determine whether platelet-derived thrombospondin-1 acts herein as main ligand of CD36.

The next chapters study more directly the thrombotic process under conditions of atherosclerosis in Apoe ${ }^{-/}$mice, fed a cholesterol-rich Western-type diet. Chapter $\mathbf{5}$ starts with the recognition that a mouse model of plaque rupture-induced arterial thrombosis is still lacking. The development and validation of such a model is described here. Mouse plaques are acutely ruptured by using targeted ultrasound treatment. The mechanism of thrombus growth and stability on such ruptured plaques is extensively investigated in this paper. In the ensuing chapter 6, same in vivo model is used to assess the role of platelet $\mathrm{P} 2 \mathrm{Y}_{12}$ receptors in atherothrombosis. Confirmative evidence for a key function of $\mathrm{P}_{2} \mathrm{Y}_{12}$ in this process is also gathered by ex vivo perfusion experiments, where whole blood is flowed over immobilized collagen or plaque material. The nutritional studies of chapter 7 aim to determine the alleged anti-atherothrombotic effects of walnut and grape seed, with a focus on two dietary components, n-3 PUFA and polyphenolic antioxidants. In Apoe $e^{-/}$mice, the consequences of dietary supplementation of walnut or grape seed extracts are resolved with regard to plaque progression, CD36 accumulation and thrombotic activity of the plasma. Finally, in chapter 8 the principle findings of this thesis are discussed in a broader perspective. 


\section{References}

1. World Health Organization. Cardiovascular diseases. Fact sheet No: 317. 2011: http://www. who.int/mediacentre/factsheets/fs317/en/index.html.

2. Davi G, Patrono C. Platelet activation and atherothrombosis. N Engl J Med. 2007;357:24822494.

3. Mackman N. Triggers, targets and treatments for thrombosis. Nature. 2008;451:914-918.

4. Gawaz M. Platelets in the onset of atherosclerosis. Blood Cells Mol Dis. 2006;36:206-210.

5. Gawaz M, Langer H, May AE. Platelets in inflammation and atherogenesis. J Clin Invest. 2005; 115:3378-3384.

6. Jackson SP. The growing complexity of platelet aggregation. Blood. 2007;109:5087-5095.

7. Ruggeri ZM. Platelets in atherothrombosis. Nat Med. 2002;8:1227-1234.

8. Cosemans JM, Iserbyt BF, Deckmyn H, Heemskerk JW. Multiple pathways to switch platelet integrins on and off. J Thromb Haemost. 2008;6:1253-1261.

9. Cosemans JM, Kuijpers MJ, Lecut C, Loubele ST, Heeneman S, Jandrot-Perrus M, Heemskerk JW. Contribution of platelet glycoprotein VI to the thrombogenic effect of collagens in fibrous atherosclerotic lesions. Atherosclerosis. 2005;181:19-27.

10. Penz S, Reininger AJ, Brandl R, Goyal P, Rabie T, Bernlochner I, Rother E, Goetz C, Engelmann B, Smethurst PA, Ouwehand WH, Farndale R, Nieswandt B, Siess W. Human atheromatous plaques stimulate thrombus formation by activating platelet glycoprotein VI. Faseb J. 2005; 19:898-909.

11. Auger JM, Kuijpers MJ, Senis YA, Watson SP, Heemskerk JW. Adhesion of human and mouse platelets to collagen under shear: a unifying model. Faseb J. 2005; 19:825-827.

12. Heemskerk JW, Kuijpers MJ, Munnix IC, Siljander PR. Platelet collagen receptors and coagulation. A characteristic platelet response as possible target for antithrombotic treatment. Trends Cardiovasc Med. 2005;15:86-92.

13. Jackson SP, Nesbitt WS, Kulkarni S. Signaling events underlying thrombus formation. J Thromb Haemost. 2003;1:1602-1612.

14. Vial C, Pitt SJ, Roberts J, Rolf MG, Mahaut-Smith MP, Evans RJ. Lack of evidence for functional ADP-activated human P2XI receptors supports a role for ATP during hemostasis and thrombosis. Blood. 2003;102:3646-3651.

15. Gachet C. P2 receptors, platelet function and pharmacological implications. Thromb Haemost. 2008;99:466-472.

16. Cattaneo M. Advances in antiplatelet therapy: overview of the $P 2 Y_{12}$ receptor antagonists in development. Eur Heart J. 2008;10:Suppl. I33-I37.

17. Tan K, Lawler J. The interaction of thrombospondins with extracellular matrix proteins. J Cell Commun Signal. 2009;3:177-187.

18. Bornstein P. Thrombospondins as matricellular modulators of cell function. J Clin Invest. 2001;107:929-934.

19. Heemskerk JW, Bevers EM, Lindhout T. Platelet activation and blood coagulation. Thromb Haemost. 2002;88:186-193.

20. Munnix IC, Kuijpers MJ, Auger J, Thomassen CM, Panizzi P, van Zandvoort MA, Rosing J, Bock PE, Watson SP, Heemskerk JW. Segregation of platelet aggregatory and procoagulant microdomains in thrombus formation: regulation by transient integrin activation. Arterioscler Thromb Vasc Biol. 2007;27:2484-2490.

21. Kahn ML, Nakanishi-Matsui M, Shapiro MJ, Ishihara H, Coughlin SR. Protease-activated receptors 1 and 4 mediate activation of human platelets by thrombin. J Clin Invest. 1999; 103:879-887.

22. Coughlin SR. Protease-activated receptors in hemostasis, thrombosis and vascular biology. $J$ Thromb Haemost. 2005;3:1800-1814.

23. Munnix ICA, Cosemans J M EM, Auger J M, Heemskerk JWM. Platelet response heterogeneity in thrombus formation. Thromb Haemost. 2009;102:1149-1156. 
24. Reininger AJ, Bernlochner I, Penz SM, Ravanat C, Smethurst P, Farndale RW, Gachet C, Brandl R, Siess W. A 2-step mechanism of arterial thrombus formation induced by human atherosclerotic plaques. J Am Coll Cardiol. 2011;55:1147-1158.

25. Smid M, Dielis AW, Winkens M, Spronk HM, van Oerle R, Hamulyak K, Prins MH, Rosing J, Waltenberger $\mathrm{JL}$, ten Cate $\mathrm{H}$. Thrombin generation in patients with a first acute myocardial infarction. J Thromb Haemost. 2011;9:450-456.

26. Van der Meijden PE, Munnix IC, Auger JM, Govers-Riemslag JW, Cosemans JM, Kuijpers MJ, Spronk HM, Watson SP, Renné T, Heemskerk JW. Dual role of collagen in factor XIIdependent thrombus and clot formation. Blood. 2009;114:881-890.

27. Borissoff JI, Heeneman S, Kilinc E, Kassak P, van Oerle R, Winckers K, Govers-Riemslag JW, Hamulyak K, Hackeng TM, Daemen MJ, ten Cate H, Spronk HM. Early atherosclerosis exhibits an enhanced procoagulant state. Circulation. 2010;122:821-830.

28. Van der Meijden PE, Feijge MA, Giesen $P L$, Huijberts $M$, van Raak EP, Heemskerk JW. Platelet $P 2 Y_{12}$ receptors enhance signalling towards procoagulant activity and thrombin generation: a study with healthy subjects and patients at thrombotic risk. Thromb Haemost. 2005;93:1128-1137.

29. Kuijpers MJ, Munnix IC, Cosemans JM, van Vlijmen BJ, Reutelingsperger CP, oude Egbrink $M G$, Heemskerk JW. Key role of platelet procoagulant activity in tissue factor-and collagendependent thrombus formation in arterioles and venules in vivo. Differential sensitivity to thrombin inhibition. Microcirculation. 2008;15:269-282.

30. Ruggeri ZM, Mendolicchio GL. Adhesion mechanisms in platelet function. Circ Res. 2007;100:1673-1685.

31. Shattil SJ, Newman PJ. Integrins: dynamic scaffolds for adhesion and signaling in platelets. Blood. 2004;104:1606-1615.

32. Watson SP, Auger JM, McCarty 0J, Pearce AC. GPVI and integrin $\alpha_{\mathrm{IIb}} \beta_{3}$ signaling in platelets. J Thromb Haemost. 2005;3:1752-1762.

33. Li S, Wang Z, Liao Y, Zhang W, Shi Q, Yan R, Ruan C, Dai K. The glycoprotein Ibo-von Willebrand factor interaction induces platelet apoptosis. J Thromb Haemost. 2010;8:341350.

34. Yamashita S, Hirano K, Kuwasako T, Janabi M, Toyama $Y$, Ishigami M, Sakai N. Physiological and pathological roles of a multi-ligand receptor CD36 in atherogenesis: insights from CD36-deficient patients. Mol Cell Biochem. 2007;299:19-22.

35. Febbraio M, Silverstein RL. CD36: implications in cardiovascular disease. Int J Biochem Cell Biol. 2007;39:2012-2030.

36. Shattil SJ, Brugge JS. Protein tyrosine phosphorylation and the adhesive functions of platelets. Curr Opin Cell Biol. 1991;3:869-879.

37. Glatz JF, Luiken JJ, Bonen A. Membrane fatty acid transporters as regulators of lipid metabolism: implications for metabolic disease. Physiol Rev. 2010;90:367-417.

38. Silverstein RL, Febbraio M. CD36, a scavenger receptor involved in immunity, metabolism, angiogenesis, and behavior. Sci Signal. 2010;2:re3.

39. Beer JH, Rabaglio M, Berchtold P, von Felten A, Clemetson KJ, Tsakiris DA, Kehrel B, Brandenberger S. Autoantibodies against the platelet glycoproteins (GP) IIb/IIIa, Ia/IIa, and IV and partial deficiency in GPIV in a patient with a bleeding disorder and a defective platelet collagen interaction. Blood. 1993;82:820-829.

40. Diaz-Ricart M, Tandon NN, Gomez-Ortiz G, Carretero M, Escolar G, Ordinas A, Jamieson GA. Antibodies to CD36 (GPIV) inhibit platelet adhesion to subendothelial surfaces under flow conditions. Arterioscler Thromb Vasc Biol. 1996;16:883-888.

41. Yamamoto N, Akamatsu N, Yamazaki H, Tanoue K. Normal aggregations of glycoprotein IV (CD36)-deficient platelets from seven healthy Japanese donors. Br J Haematol. 1992;81:869242. Kehrel B, Wierwille S, Clemetson KJ, Anders 0, Steiner M, Knight CG, Farndale RW, Okuma M, Barnes MJ. Glycoprotein VI is a major collagen receptor for platelet activation: 
it recognizes the platelet-activating quaternary structure of collagen, whereas CD36, glycoprotein IIb/IIIa, and von Willebrand factor do not. Blood. 1998;91:491-499.

43. Esemuede N, Lee T, Pierre-Paul D, Sumpio BE, Gahtan V. The role of thrombospondin- 1 in human disease. J Surg Res. 2004;122:135-142.

44. Bonnefoy A, Hantgan R, Legrand C, Frojmovic MM. A model of platelet aggregation involving multiple interactions of thrombospondin-1, fibrinogen, and GPIIb/IIIa receptor. J Biol Chem. 2001;276:5605-5612.

45. Jurk K, Clemetson KJ, de Groot PG, Brodde MF, Steiner M, Savion N, Varon D, Sixma JJ, Van Aken $H$, Kehrel BE. Thrombospondin-1 mediates platelet adhesion at high shear via glycoprotein Ib (GPIb): an alternative/backup mechanism to von Willebrand factor. Faseb J. 2003;17:1490-1492.

46. Chung J, Gao AG, Frazier WA. Thrombospondin acts via integrin-associated protein to activate the platelet integrin $\alpha_{\text {II }} \beta_{3}$. J Biol Chem. 1997;272:14740-14746.

47. Kowalska MA, Tuszynski GP. Interaction of thrombospondin with platelet glycoproteins GPIa/IIa and GPIIb/IIIa. Biochem J. 1993;295:725-730.

48. Korporaal SJ, van Eck M, Adelmeijer J, IJsseldijk M, Out R, Lisman T, Lenting PJ, van Berkel TJ, Akkerman JW. Platelet activation by oxidized low density lipoprotein is mediated by CD36 and scavenger receptor-A. Arterioscler Thromb Vasc Biol. 2007;27:2476-2483.

49. Gao D, Ashraf MZ, Kar NS, Lin D, Sayre LM, Podrez EA. Structural basis for the recognition of oxidized phospholipids in oxidized low density lipoproteins by class B scavenger receptors CD36 and SR-BI. J Biol Chem. 2010;285:4447-4454.

50. Korporaal SJ, Gorter G, van Rijn HJ, Akkerman JW. Effect of oxidation on the plateletactivating properties of low-density lipoprotein. Arterioscler Thromb Vasc Biol. 2005;25:867872.

51. Gilio K, Munnix IC, Mangin P, Cosemans JM, Feijge MA, van der Meijden PE, Olieslagers S, Chrzanowska-Wodnicka MB, Lillian R, Schoenwaelder S, Koyasu S, Sage SO, Jackson $\mathrm{SP}$, Heemskerk JW. Non-redundant roles of phosphoinositide 3-kinase isoforms $\alpha$ and $\beta$ in glycoprotein VI-induced platelet signaling and thrombus formation. J Biol Chem. 2009;285:33750-33762.

52. Schoenwaelder SM, Ono A, Sturgeon S, Chan SM, Mangin P, Maxwell MJ, Turnbull S, Mulchandani M, Anderson K, Kauffenstein G, Rewcastle GW, Kendall J, Gachet C, Salem HH, Jackson SP. Identification of a unique co-operative phosphoinositide 3-kinase signaling mechanism regulating integrin $\alpha_{\mathrm{II}} \beta_{3}$ adhesive function in platelets. J Biol Chem. 2007;282:28648-28658.

53. Woulfe DS. Platelet G protein-coupled receptors in hemostasis and thrombosis. J Thromb Haemost. 2005;3:2193-2200.

54. Cosemans JM, Munnix IC, Wetzker R, Heller R, Jackson SP, Heemskerk JW. Continuous signaling via phosphoinositide 3-kinase isoforms $\beta$ and $\gamma$ is required for platelet ADP receptor function in dynamic thrombus stabilization. Blood. 2006;108:3045-3052.

55. Goto S, Tamura N, Ishida H, Ruggeri ZM. Dependence of platelet thrombus stability on sustained glycoprotein IIb/IIIa activation through adenosine $5^{\prime}$-diphosphate receptor stimulation and cyclic calcium signaling. J Am Coll Cardiol. 2006;47:155-162.

56. Storey RF, Angiolillo DJ, Patil SB, Desai B, Ecob R, Husted S, Emanuelsson H, Cannon $\mathrm{CP}$, Becker RC, Wallentin L. Inhibitory effects of ticagrelor compared with clopidogrel on platelet function in patients with acute coronary syndromes: the PLATO (Platelet inhibition and patient outcomes) PLATELET substudy. J Am Coll Cardiol. 2010;56:1456-1462.

57. Gurbel PA, Tantry US. Drug insight: clopidogrel nonresponsiveness. Nat Clin Pract Cardiovasc Med. 2006;3:387-395.

58. Wiviott SD, Braunwald E, McCabe CH, Montalescot G, Ruzyllo W, Gottlieb S, Neumann FJ, Ardissino D, De Servi S, Murphy SA, Riesmeyer J, Weerakkody G, Gibson CM, Antman EM. Prasugrel versus clopidogrel in patients with acute coronary syndromes. N Engl J Med. 2007;357:2001-2015. 
59. Wallentin L, Becker RC, Budaj A, Cannon CP, Emanuelsson H, Held C, Horrow J, Husted S, James S, Katus H, Mahaffey KW, Scirica BM, Skene A, Steg PG, Storey RF, Harrington RA, Freij $A$, Thorsen $M$. Ticagrelor versus clopidogrel in patients with acute coronary syndromes. N Engl J Med. 2009;361:1045-1057.

60. Falati S, Gross P, Merrill-Skoloff G, Furie BC, Furie B. Real-time in vivo imaging of platelets, tissue factor and fibrin during arterial thrombus formation in the mouse. Nat Med. 2002;8:1175-1181.

61. Insull W. The pathology of atherosclerosis: plaque development and plaque responses to medical treatment. Am J Med. 2009;122:S3-S14.

62. Ros E, Mataix J. Fatty acid composition of nuts: implications for cardiovascular health. Br J Nutr. 2006;96:S29-35.

63. Vanschoonbeek K, de Maat MP, Heemskerk JW. Fish oil consumption and reduction of arterial disease. J Nutr. 2003;133:657-660.

64. Ghosh D, Scheepens A. Vascular action of polyphenols. Mol Nutr Food Res. 2009;53:322331.

65. World Health Organization. Expert consultation on fats and fatty acids in human nutrition FAO/WHO, Geneva. 2008:10-14.

66. Nieuwenhuys CM, Feijge MA, Vermeer $C$, Hennissen AH, Beguin S, Heemskerk JW. Vitamin K-dependent and vitamin K-independent hypocoagulant effects of dietary fish oil in rats. Thromb Res. 2001;104:137-147.

67. Vanschoonbeek K, Feijge MA, Paquay M, Rosing J, Saris W, Kluft C, Giesen PL, de Maat MP, Heemskerk JW. Variable hypocoagulant effect of fish oil intake in humans: modulation of fibrinogen level and thrombin generation. Arterioscler Thromb Vasc Biol. 2004;24:17341740.

68. Baiges I, Palmfeldt J, Blade C, Gregersen N, Arola L. Lipogenesis is decreased by grape seed proanthocyanidins according to liver proteomics of rats fed a high fat diet. Mol Cell Proteomics. 2010;9:1499-1513.

69. Jiao R, Zhang Z, Yu H, Huang Y, Chen ZY. Hypocholesterolemic activity of grape seed proanthocyanidin is mediated by enhancement of bile acid excretion and up-regulation of CYP7A1. J Nutr Biochem. 2010;21:1134-1139.

70. Frederiksen H, Mortensen A, Schroder M, Frandsen H, Bysted A, Knuthsen P, Rasmussen SE. Effects of red grape skin and seed extract supplementation on atherosclerosis in Watanabe heritable hyperlipidemic rabbits. Mol Nutr Food Res. 2007;51:564-571.

71. Polagruto JA, Gross HB, Kamangar F, Kosuna K, Sun B, Fujii H, Keen CL, Hackman $\mathrm{RM}$. Platelet reactivity in male smokers following the acute consumption of a flavanol-rich grapeseed extract. J Med Food. 2007;10:725-730.

72. Olas B, Wachowicz B, Tomczak A, Erler J, Stochmal A, Oleszek W. Comparative anti-platelet and antioxidant properties of polyphenol-rich extracts from: berries of Aronia melanocarpa, seeds of grape and bark of Yucca schidigera in vitro. Platelets. 2008;19:70-77.

73. Feldman EB. The scientific evidence for a beneficial health relationship between walnuts and coronary heart disease. J Nutr. 2002;132:1062S-1101S.

74. Banel DK, Hu FB. Effects of walnut consumption on blood lipids and other cardiovascular risk factors: a meta-analysis and systematic review. Am J Clin Nutr. 2009;90:56-63.

75. Olmedilla-Alonso B, Granado-Lorencio F, Herrero-Barbudo C, Blanco-Navarro I, BlazquezGarcia S, Perez-Sacristan B. Consumption of restructured meat products with added walnuts has a cholesterol-lowering effect in subjects at high cardiovascular risk: a randomised, crossover, placebo-controlled study. J Am Coll Nutr. 2008;27:342-348.

76. Canales A, Bastida S, Librelottto J, Nus M, Sanchez-Muniz FJ, Benedi J. Platelet aggregation, eicosanoid production and thrombogenic ratio in individuals at high cardiovascular risk consuming meat enriched in walnut paste. A crossover, placebo-controlled study. Br J Nutr. 2009;102:134-141. 
77. Guyton JR, Klemp KF. Development of the lipid-rich core in human atherosclerosis. Arterioscler Thromb Vasc Biol. 1996;16:4-11.

78. Nieswandt B, Watson SP. Platelet-collagen interaction: is GPVI the central receptor? Blood. 2003;102:449-461.

79. Liel N, Mais DE, Halushka PV. Binding of a thromboxane $A_{2} /$ prostaglandin $\mathrm{H}_{2}$ agonist $\left[{ }^{3} \mathrm{H}\right]$ U46619 to washed human platelets. Prostaglandins. 1987;33:789-797.

80. Kattelman EJ, Venton DL, Le Breton GC. Characterization of U 46619 binding in unactivated, intact human platelets and determination of binding site affinities of four $T X A_{2} / P_{1} H_{2}$ receptor antagonists (13-APA, BM 13177, ONO 3708 and SQ 29548). Thromb Res. 1986;41:471481. 


\section{CHAPTER 2}

\section{CD36 as a multiple-ligand}

signaling receptor in atherothrombosis

Reyhan Nergiz-Unal, Timo Rademakers, Judith M.E.M. Cosemans, Johan W.M. Heemskerk

Cardiovasc Hematol Agents Med Chem 2011; 9: 42-55

Reprinted with permission 


\title{
CD36 as a multiple-ligand signaling receptor in atherothrombosis
}

\begin{abstract}
The glycoprotein CD36, also known as glycoprotein IIIb/IV or FAT, is expressed on the surface of platelets, monocytes, microvascular endothelial cells, smooth muscle cells, cardiomyocytes and other cells of the cardiovascular system. In spite of its abundant presence, CD36 has remained for long a mysterious protein with a poorly understood role. In this paper, we review how CD36 can affect cellular responses by interaction with a variety of ligands, in particular thrombospondin-1, oxidized lipoproteins and fatty acids. Furthermore, given the structure of CD36 with two transmembrane domains and short cytoplasmic tails, we consider how this receptor can induce intracellular signaling, likely in junction with other cellular receptors or associated proteins in the membrane. Current literature points to activation of Src-family and mitogen-activated protein kinases, as well as to activation of the NFKB and Rho pathways. The new insights make CD36 attractive as a therapeutic target to suppress platelet and monocyte/macrophage function and thereby atherothrombosis.
\end{abstract}




\section{Introduction}

The membrane protein CD36, also known as scavenger receptor, glycoprotein IIIb, glycoprotein IV, GP88, FAT, SCARB3 or PASIV, is expressed on the surface of most cells of the cardiovascular system, such as platelets, megakaryocytes, monocytes, microvascular endothelial cells, smooth muscle cells and cardiomyocytes. Its relatively simple structure as a glycoprotein with two transmembrane domains, suggests a receptorlike or regulatory function rather than a role as transporter or carrier protein. In spite of the recent elucidation of its ligands, CD36 has remained a mysterious glycoprotein with often distinct proposed roles in different cell types. This paper provides an overview of the cellular responses triggered by occupation of CD36 with currently known physiological ligands - collagen, thrombospondin-1 (TSP1), oxidized phospholipids (oxPL), oxidized lipoproteins and long-chain fatty acids -, as well as the responses evoked by CD36 ligand peptides - hexarelin and EP80317. We propose a model how CD36 can trigger, via a limited number of signal transduction pathways, various (patho)physiological processes, such as platelet activation, thrombosis, atherosclerosis, inflammation, glucose and lipid metabolism.

\section{Structure of CD36 and ligand binding sites}

As an integral membrane protein, CD36, belongs to the class $B$ scavenger receptor family, which also include the scavenger receptor BI (SR-BI/CLA-1) and the lysosomal integral membrane protein 2 (LIMP-II). The class B scavenger receptors have in common the binding of modified forms of lipoproteins and lipids. The human CD36 gene is located on chromosome 7 (7q11.2). It encodes for 15 exons extending over 32 kilobases, which by alternative splicing produce at least two mRNA species. The CD36 protein consists of a single peptide chain of 472 amino acids and has a molecular weight of 80-90 kDa, which varies with the extent of glycosylation. It is expressed on the surface of many cells of the cardiovascular system, including platelets, monocytes, smooth and skeletal muscle cells, microvascular endothelial cells and cardiomyocytes ${ }^{1-5}$. On platelets CD36 is one of the most common glycoproteins with 10,000-25,000 molecules present per single platelet $t^{6,7}$.

The CD36 protein has a 'hairpin-like' configuration, containing two transmembrane domains, one near the $\mathrm{N}$-terminus and the other near the $\mathrm{C}$-terminus, which are separated by a large, glycosylated extracellular loop (Figure 2.1A). Its structure is similar to that of human SR-BI and LIMP II, and resembles the structure of the Drosophila epithelial membrane protein, Emp ${ }^{8-10}$. The second transmembrane domain shows homology with the $A B C$ transporter (a permease protein) of Streptococcus. The hydropathy plot of CD36 shows two relatively hydrophobic regions within the extracellular loop around amino acid residues 140 and 190, the second of which is supposed to be membraneassociated (Figure 2.1B).

The extracellular loop further contains multiple $\mathrm{N}$-linked glycosylation sites. The extensive glycosylation appears to be needed for efficient intracellular trafficking of the newly synthesized CD36 protein to the cell surface ${ }^{11}$. Similarly, disulfide linkages between cysteine residues in the extracellular loop are required for its transport to the 
A

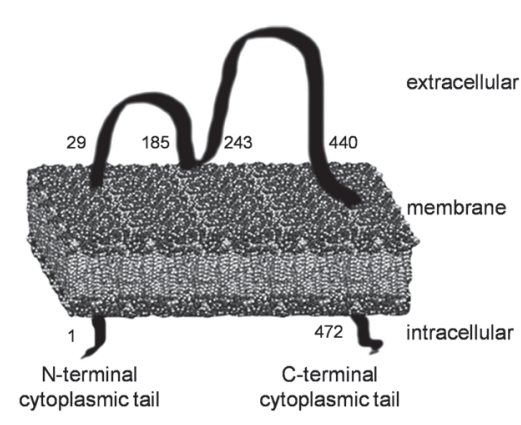

B

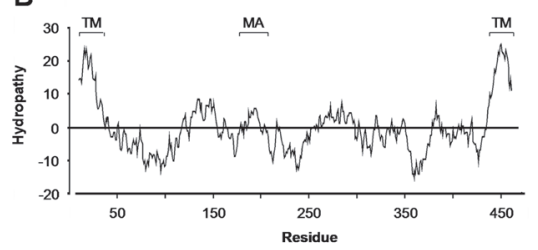

C
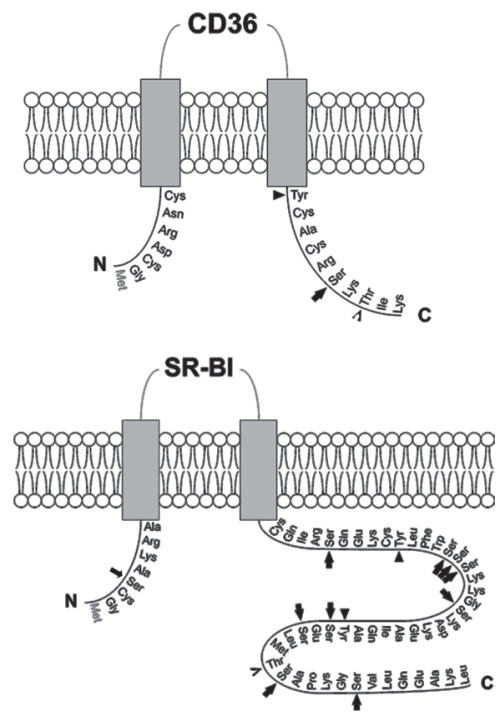

- Figure 2.1. Overall structure and membrane topology of CD36. (A) Schematic representation of CD36 in the membrane bilayer. (B) Hydropathy plot of CD36 amino acid residues with transmembrane (TM) and putative membrane-associated (MA) regions. (C) Similarity in structure of the homologous proteins CD36 and SR-BI. Closed arrows indicate Ser, open arrows Thr, and arrow heads Tyr residues, as potential phosphorylation sites.

plasma membrane ${ }^{12}$. The disulfide bonds are formed between the cysteine residues 243 $311,272-333$ and 313-322. The remaining cytosolic cysteines $(3,7,464,466)$, two at each terminus, are consensus palmitoylation sites for stabilization of the interaction of CD36 with the cell membrane ${ }^{1,11,13,14}$. The sugar groups and cysteine linkages are likely required for proper folding and ligand recognition, but this has not been investigated. The two cytoplasmic tails are remarkably short, 6 residues $N$-terminally and 12 residues C-terminally 1,13,15,16.

Ligands of CD36 identified so far include TSP1, oxPL, oxidized low-density lipoproteins (oxLDL), hexarelin and long-chain fatty acids (Figure 2.2). In addition, on red blood cells CD36 serves as a receptor for the malaria parasite, Plasmodium falciparum. The binding site for TSPI has been termed CLESH-1 domain (for $\underline{\text { CD } 36}$ LIMP II Emp structural homology-1), and resides within the amino acid sequence 93 155 , more precisely in the regions $93-120$ and 139-155 $17-20$. A nearby part of the protein

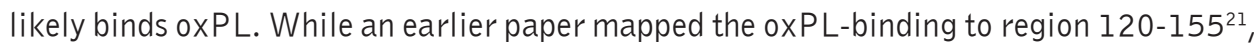
recent evidence shows that the core of OXPL binding is located in the sequence 157-171, while the two lysines at $164 / 166$ are indispensable for this interaction ${ }^{22}$. The binding of oxLDL has been located at the residues $155-183^{23}$, while also the synthetic hexapeptide ligand, hexarelin, binds in this region (amino acids 132-177) 24, 25. The CD36 interaction site of long-chain fatty acids is only poorly mapped to the extracellular stretch of amino acids 127-27926, 27. Further downstream, the large proline- and cysteine-rich region of the extracellular loop (243-375) likely is important for proper folding and may not 


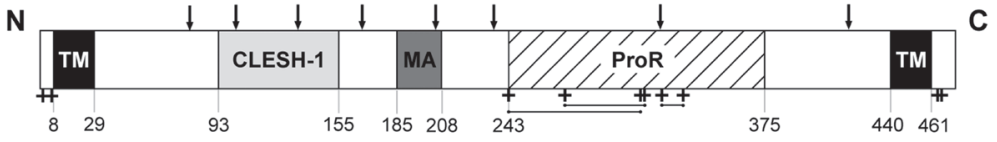

TSP-1

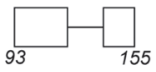

oxPL

oxLDL

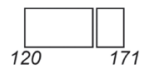

Hexarelin

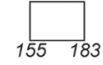

Fatty acids (long chain)

Plasmodium falciparum
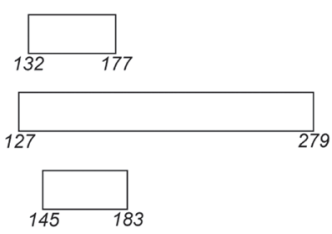

Figure 2.2. Domain structure of CD36 and proposed ligand binding sites. Indicated regions are: the transmembrane (TM) and membrane-associated (MA) domains; and the CLESH-1 and proline-rich (ProR) regions. Arrows show predicted $N$-linked glycosylation sites; crosses indicate 10 cysteine residues with established cystein bridges. Boxes next to ligands show proposed ligand binding sites.

directly participate in ligand interaction ${ }^{1,11}$. Taken together, most or all known CD36 ligands seem to bind to a common part of the protein, starting at the CLESH-1 domain and extending to around amino acid 183.

The C-terminal cytoplasmic domain of CD36 is with 10 amino acids much shorter than that of its family member SR-BI (Figure 2.1C). As a consequence, CD36 lacks most of the potential phosphorylation sites in SR-BI, which have been considered as interaction sites for signaling proteins ${ }^{28}$. In fact, the C-terminal part of CD36 contains only one consensus phosphorylation site, TIK (Thr-Ile-Lys). Evidence for phosphorylation of this site upon ligand binding is still lacking. On the other hand, the $\mathrm{N}$-terminal cytoplasmic domains of CD36 and SR-BI are similar in size (7-8 amino acids) and do not contain consensus phosphorylation sites. So far, there are no strong indications for clustering or multimerization of CD36 in the cell membrane, although one paper describes that CD36 can dimerize upon binding of $\mathrm{TSP}^{29}$. Since recent data point to a clear signaling role of CD36 (see below), it is likely that the protein interact with other signaling components in or near the plasma membrane. How these interactions take place is still a matter of speculation. Interestingly, early data suggest extracellular phosphorylation of platelet CD36 by an ectoprotein kinase ${ }^{30}$, but the function of this is fully unclear.

\section{CD36-induced cellular responses and signaling events}

In early years, CD36 was mostly recognized as a scavenging receptor implicating a role in endocytosis of bound ligands such as oxLDL. Other papers pointed to a role as fatty acid import protein (FAT/CD36). However, with the new knowledge of CD36 ligands and the signaling consequences of ligand binding, it is becoming clear that the protein acts in a receptor-type of manner. In many cases, CD36 ligandation causes a 
stress-like effect, enhancing defensive responses such as thrombus formation (platelets), production of inflammatory markers (endothelial cells, monocytes) and development of foam cells (macrophages). An overview of the various responses is given in Table 2.1, with emphasis on cells of the cardiovascular system. Not surprisingly, the CD36mediated signaling events are similar to those of other 'stress' agonists, and involve activation of the pathways of mitogen-activated protein kinase (MAPK), nuclear factor $\kappa B(N F \kappa B)$ and Rho kinase. Currently available evidence for CD36-mediated signaling

\section{Table 2.1. Reported ligands and responses of CD36 in different cell types}

\begin{tabular}{|c|c|c|c|}
\hline Cell type & Ligand & Response & References \\
\hline \multirow[t]{10}{*}{ Platelets } & collagen type I & platelet adhesion & $31-34$ \\
\hline & TSP1 & & 51 \\
\hline & oxLDL, oxPL & & 82,83 \\
\hline & $0 \times L D L, 0 \times P L$ & platelet degranulation & $79,82,93$ \\
\hline & collagen type $\mathrm{V}$ & platelet aggregation & 45 \\
\hline & TSPl & & 50,62 \\
\hline & ABT-510 & & 69 \\
\hline & oxLDL, oxPL & $\begin{array}{l}\text { platelet aggregation, thrombus } \\
\text { formation }\end{array}$ & $\begin{array}{l}4,72,79,82, \\
89,151\end{array}$ \\
\hline & VLDL & & 118 \\
\hline & microparticles (PS) & & 91,157 \\
\hline \multirow[t]{7}{*}{ Monocytes, macrophages } & oxLDL, oxPL & production of inflammatory & $76,79,84,151$ \\
\hline & & markers, foam cell formation & 156,158 \\
\hline & $\mathrm{NO}_{2}-\mathrm{OxLDL}$ & & 77,155 \\
\hline & hexarelin, EP80307 & & $96,97,159$ \\
\hline & oxLDL & endocytosis, foam cell formation & $\begin{array}{l}73,75,86,89,92, \\
123,132,154\end{array}$ \\
\hline & oxHDL & & 90 \\
\hline & collagen type I & cell adhesion & 46 \\
\hline \multirow[t]{4}{*}{ Endothelial cells } & oxLDL & $\begin{array}{l}\text { production of inflammatory } \\
\text { markers, cell activation }\end{array}$ & $160-162$ \\
\hline & oxPL & tissue factor expression & 163 \\
\hline & fatty acids & NO production & 104 \\
\hline & P. falciparum & endocytosis & 164,165 \\
\hline \multirow[t]{2}{*}{ Smooth muscle cells } & TSPI & proliferation & 68,166 \\
\hline & & fatty acid uptake & 106 \\
\hline \multirow[t]{4}{*}{ Cardiomyocytes } & hexarelin & coronary vasospasm & 24,167 \\
\hline & fatty acids & coronary vasospasm & 76 \\
\hline & & fatty acid uptake & $105-107,168$ \\
\hline & & glucose uptake & $76,100,131$ \\
\hline \multirow[t]{3}{*}{ Adipocytes, myocytes } & fatty acids & glucose uptake & 99,169 \\
\hline & & fatty acid uptake & 107,108 \\
\hline & & fat deposition & $142,170-172$ \\
\hline Fibroblasts & TSPI & cell adhesion & 52 \\
\hline
\end{tabular}

Abbreviations: HDL, high density lipoproteins; oxLDL, oxidized low density lipoproteins; oxPL, oxidized phospholipids; PS, phosphatidyl serine; TSP1, thrombospondin 1 ; VLDL, very low density lipoproteins. 
events in these cells is summarized in Table 2.2. Below, the cellular responses are described per ligand type.

\section{A. CD36 as collagen receptor}

In platelets, CD36 is also known as glycoprotein IV or glycoprotein IIIa. Introduced as early as in 1989, it is one of the first proposed collagen receptors on platelets ${ }^{31}$. Evidence for such a role came from studies with anti-CD36 antibodies, which interfered with platelet adhesion to collagen ${ }^{32-34}$. Later, it was established that not CD36 but glycoprotein VI is the main signaling receptor for fibrillar collagen (types I and III) of platelets ${ }^{35,36}$. Glycoprotein VI in cross-talk with the adhesive collagen receptor, integrin $\alpha_{2} \beta_{1}$, mediates the vast majority of collagen-induced platelet responses such as secretion, aggregation and procoagulant activity ${ }^{37-39}$. Hence, a function of CD36 as receptor for fibrillar collagens is no longer considered ${ }^{40}$. Indeed, platelets from CD36-

Table 2.2. Signaling pathways evoked by CD36 ligands in different cell types

\begin{tabular}{|c|c|c|c|}
\hline Cell type & Ligand & Signaling mode & References \\
\hline \multirow[t]{8}{*}{ Platelets } & TSPI & $\mathrm{Ca}^{2+}$ & 173 \\
\hline & & cGMP & 62,69 \\
\hline & & ectoprotein kinase $A$ & 30 \\
\hline & oxLDL & SFK, JNK & 89 \\
\hline & & p38 MAPK & 83,93 \\
\hline & not determined & SFK & 174,175 \\
\hline & & TyrK & 6,66 \\
\hline & & SFK, Chk & 176 \\
\hline \multirow[t]{7}{*}{$\begin{array}{l}\text { Monocytes/ } \\
\text { macrophages }\end{array}$} & hexarelin & SKF, Pyk2 & 159 \\
\hline & & PPAR $\gamma$ & 97 \\
\hline & oxLDL & SFK, JNK & $92,153,154,157$ \\
\hline & & Erk, p38 MAPK, JNK & 87 \\
\hline & & Rho & 92 \\
\hline & & $N F K B$ & 76 \\
\hline & microbial lipopeptide & Toll-like receptor 2 & 177 \\
\hline Smooth muscle cells & TSPI & SFK, cGMP & $68,69,106$ \\
\hline \multirow[t]{3}{*}{ Endothelial cells } & TSPI & SFK, cGMP & 68,106 \\
\hline & oxPL & Erk, NFKB, NFAT & 163 \\
\hline & fatty acids & AMPK, eNOS & 104 \\
\hline \multirow[t]{2}{*}{ Cardiomyocytes } & hexarelin & altered gene expression & 167 \\
\hline & fatty acids & GLUT4 translocation & 100 \\
\hline
\end{tabular}

Abbreviations: cGMP, cyclic guanosine monophosphate; SFK, Src family kinases; JNK, c-Jun N-terminal kinases; MAPK, mitogen-activated protein kinase; TyrK, tyrosine kinases; Pyk2, proline-rich tyrosine kinase 2; PPAR $\gamma$, peroxisome proliferator-activated receptor gamma; NFKB, nuclear factor kappa B; NFAT, nuclear factor of activated T cells; AMPK, AMP-activated protein kinase; NOS, nitric oxide synthase; GLUT4, glucose transporter 4. See further Table 2.1. 
deficient patients respond normally to collagen stimulation ${ }^{41-44}$. Only CD36 binding to the non-fibrillar type $V$ collagen is documented ${ }^{45}$. Interestingly, though, monocytederived macrophages from CD36-deficient patients show reduced adhesion to collagen type $\mathrm{I}^{46}$. Overall, the data do not support a direct function as primary collagen receptor, but CD36 may still have an assistant role in collagen interaction, e.g. by binding to collagen-associated proteins.

\section{B. CD36 as thrombospondin receptor}

Thrombospondins belong to a family of modular glycoproteins with incompletely described cell-adhesive and signaling functions. The multimer forms TSP1 and TSP2 have a role in platelet activation ${ }^{47,}{ }^{48}$. While TSP1 and not TSP2 is massively stored in platelet granules, only TSP2 null mice display a bleeding diathesis, and only platelets from these mice are reduced in aggregate formation ${ }^{49}$. On the other hand, TSPI acts as a ligand for CD36 not only in platelets, but also in fibroblasts, endothelial cells and smooth muscle cells ${ }^{50-53}$. Since TSPI is secreted by activated platelets and other blood cells, it deposits at sites of a damaged vessel wall and in atherosclerotic plaques ${ }^{54-56}$.

Studies with anti-CD36 antibodies suggest that CD36 is a main but not the only receptor for TSPI on platelets ${ }^{50,51}$. Evidence for a role as TSPI receptor comes from the use of recombinant CD36 peptides, corresponding to the amino acid sequences 93 110 and 139-155 of CD36, which suppress TSP1-induced platelet activation ${ }^{19,57,58 .}$ Under conditions of high-shear flow, both glycoprotein Ib-V-IX and CD36 contribute to the $\mathrm{Ca}^{2+}$-dependent adhesion of platelets to TSP1 ${ }^{51,59,60}$. Yet, platelets also express other TSP1-binding proteins. For instance, CD47 (integrin-associated protein or IAP) is recognized as a co-receptor for TSP161,62. In the absence of CD36, even integrin $\alpha_{\text {IIb }} \beta_{3}$ can mediate platelet interaction with $\mathrm{TSPl}^{63}$. The TSP1-induced signaling via CD36 relies on the FCR $\gamma$-chain and involves activation of the Src family and Syk kinases ${ }^{64,65}$. Again in platelets, CD36 is reported to associate with the tetraspannin protein, CD9, next to integrins ${ }^{66}$. In plasma, the protease ADAMTS-13, containing eight TSP1 repeats, is known to binds to $\mathrm{CD} 36^{67}$, but whether this leads to cell activation is unknown.

In platelets and smooth muscle cells, TSPI binding to CD36 may inhibit cGMP or CAMP elevation and consequent activation of the CGMP/CAMP-dependent protein kinases $^{68-70}$. The importance of this finding still needs to be determined. On endothelial cells, TSP1 interaction with CD36 has a typical anti-angiogenic effect, which is mimicked by the peptide derivative ABT-510. Used as an anti-angiogenic CD36 ligand, this peptide appears to suppress tumor growth in animal model studies ${ }^{69,71}$. Effects of ABT-510 on platelet function have not been determined.

\section{CD36 as scavenger receptor for oxLDL and oxPL}

As a scavenger receptor, CD36 avidly binds oxidized lipoproteins, in particular ox LD L, and mediates its internalization via the classical clathrin-mediated endocytosis pathway ${ }^{72-75}$. In macrophages, CD36 is considered to be responsible for half of the $0 x L^{2} L$ binding ${ }^{76}$, and for most of the uptake of $\mathrm{NO}_{2}$-modified $0 x \mathrm{LDL}$ and of oxidized high density lipoprotein $(\mathrm{oxHDL})^{75,77}$. In development of murine atherosclerotic plaques, CD36 hence plays a 
major role in the conversion of macrophages to foam cells. The CD36-binding components of oxLDL have recently been identified. These are oxidized forms of phospholipids (oxPL), in particular oxidized derivatives of choline glycerophospholipids ${ }^{78,79}$. Such oxPL appear to accumulate in plasma from hyperlipidemic mice and from subjects with low HDL levels. Under conditions of hyperlipidemia, binding of oxPL to platelet CD36 leads to increased platelet activation. In macrophages, oxPL interaction with CD36 can trigger the phagocytosis of PS-expressing apoptotic cells ${ }^{80}$. However, a recent paper shows that oxPL also binds to the CD36-related receptor, SR-BI ${ }^{81}$.

In platelets at least, $\mathrm{CD} 36$ is considered to be the predominant receptor for oxLDL ${ }^{82-84}$. For instance, experiments with the blocking anti-CD36 antibody FA6-152 showed that prior oxidation of LDL is required for CD36-dependent platelet responses such as adhesion, secretion and aggregation. Signaling events involved are activation of Src family and Syk kinases, $\mathrm{Ca}^{2+}$ fluxes, as well as activation of cytoskeletal-associated RhoA and the $\mathrm{p} 38$ MAPK $^{83,85,86}$. However, oxLDL also activates platelet p38 MAPK via the scavenger receptor $A(S R-A)$, while native $L D L$ modulates platelet activity via the apolipoprotein E receptor $2^{\prime}\left(\operatorname{apoER} 2^{\prime}\right)^{83}$.

In macrophages, CD36-mediated activation of p38 MAPK can generate a feedforward loop by increasing CD36 expression by activation of the nuclear receptor, peroxisome proliferator-activated receptor $\gamma$ (PPAR $\gamma)^{87,88}$. In addition to p38 MAPK, oxLDL-CD36 interaction stimulates other MAPK pathways, i.e. those of Erk and c-Jun $N$-terminal kinase (JNK) isoforms (Table 2.2). In platelets, oxLDL binding to CD36 activates the JNK2 isoform via a pathway involving SrC family kinases and MKK $4^{89}$. The importance of this signaling route is shown in hyperlipidemic mice, where CD36 promotes thrombus formation in vivo in part via JNK phosphorylation. Studies using antiCD36 antibodies indicate that also oxHDL and endothelial cell-derived microparticles may activate platelets via CD3690,91.

Signaling events mediated by oxLDL and CD36 have also been studied in monocytes and macrophages. In macrophages from CD36-deficient patients, reduced activation of NFKB in response to oxLDL was observed, which was accompanied by diminished release of the inflammatory mediators, interleukin $1 \beta$ and tumor necrosis factor- $\alpha$, suggesting control of these events by CD36 signaling ${ }^{76}$. Internalization of oxLDL via CD36 is accompanied by a signaling pathway involving Src and Rho family kinases and JNK, as well as by reassembly of the actin cytoskeleton ${ }^{92}$. Endocytosis via CD36 is reported to be clathrin-dependent ${ }^{92}$.

Taken together, in various cell types, oxLDL binding to CD36 seems to trigger similar sets of signaling events, starting with activation of Src family kinases and extending to activation of other tyrosine kinases and MAPK family members, including Erk, p38 and JNK (Table 2.2). At least in macrophages, also the NFKB pathway is activated with consequent release of cytokines. It is unclear so far whether or not these signaling events rely on phosphorylation of the short intracellular CD36 domains. It is also unclear to which extent oxPL can fully mimic the signaling events evoked by oxidized lipoproteins. Current understanding is that the oxLDL-induced signaling of CD36 in macrophages and platelets contributes to atherosclerosis and thrombosis. 


\section{CD36 as receptor for native lipoproteins}

At least in platelets, CD36 may also interact with native, non-oxidized forms of LDL and VLDL although with mostly small effects ${ }^{86,93,94}$. Blocking antibodies against CD36 inhibit the binding of VLDL, LDL and HDL to cultured cells, such as C32 (melanoma) and COS-7 (kidney) cells ${ }^{95}$. In macrophages, CD36 impedes the uptake of LDL ${ }^{84}$. Thus, while CD36 may interact with these native lipoproteins, the intracellular effects seem to be small or opposite to those triggered by binding of the oxidized lipoprotein forms.

\section{E. CD36 as receptor for hexarelin and related synthetic peptides}

Photo-affinity cross-linking studies with the synthetic growth hormone-releasing peptide, His-D-Trp-Ala-Trp-D-Phe-Lys, also termed hexarelin, have shown that this hexapeptide can act as an inhibitory CD36 ligand, binding to the region around Met ${ }^{169}$ 25 , which corresponds to the oxLDL-binding sequence (Figure 2.2). Evidence for a CD36-dependent role of hexarelin came from the observation that the hexapeptide dose-dependently increased the perfusion pressure due to vasoconstriction in hearts from control mice, but not in hearts from $C d 36^{-1}$ mice ${ }^{24}$. Given the overlap in CD36 binding site of hexarelin and $0 \times L D L$, it was suggested that in macrophages the hexapeptide interferes with CD36-mediated uptake of modified lipoproteins ${ }^{25}$. This might explain the anti-atherosclerotic effect of growth hormone-releasing peptides in Apoe $^{-/}$mice. So far, hexarelin is not much used in studies of CD36-induced cell activation. Similarly to hexarelin, its synthetic analogue, EP80317 (Haic-D-Me-Trp$D$-Lys-Trp-D-Phe-Lys) which lacks growth hormone-releasing activity, was shown to suppress plaque development in $\mathrm{Apoe}^{-1-} \mathrm{Cd} 36^{+/+}$mice, but not in corresponding $\mathrm{Cd}_{3} 6^{-1}$ mice ${ }^{96}$. The peptide, possibly by interacting with CD36 of macrophages, increased the transcriptional activation and phosphorylation of the fat transport-regulating genes, in particular PPAR $\gamma^{96,97}$. Likely by this mechanism, inhibitory CD36 peptide ligands suppress macrophage foam cell formation by stimulating PPAR $\gamma$-mediated cholesterol efflux, resulting in less atherosclerotic plaque formation and reduced atherothrombosis. On the other hand, PPAR $\gamma$ agonists can up-regulate CD36 expression ${ }^{98}$. How EP80317 affects responses of platelets and other CD36-expressing cells is unclear.

\section{F. CD36 as fatty acid receptor and importer}

In a variety of cells and tissues expressing CD36, a role of this protein is described in the binding and uptake of long-chain fatty acids, and thereby in the control of fatty acid metabolism ${ }^{99-101}$. Referring to this function, it is often indicated as FAT/CD36. Remarkably, the binding site for long-chain fatty acids in CD36 is only poorly mapped to somewhere in the 127-279 region of the extracellular loop ${ }^{102}$. Since CD36 does not seem to have the structure of a transporter protein, the mechanism how fatty acid binding is linked to uptake is unclear. One possibility is that CD36-associated membrane proteins are involved in fatty acid incorporation.

Fatty acid transport regulated by CD36 occurs in variety of cell types, including monocytes/macrophages ${ }^{76,103}$, microvascular endothelial cells ${ }^{104}$, cardiomyocytes ${ }^{105,106}$ adipocytes and skeletal muscle cells ${ }^{107,108}$, enterocytes ${ }^{109}$, and taste bud cells $s^{110,111}$. 
In skeletal muscle cells and cardiomyocytes from $\mathrm{Cd} 36^{-}$mice, fatty acid uptake was reduced by $50-80 \%{ }^{99}$. In skeletal muscle cells and fibroblasts, conversely, transfection of CD36 was accompanied by an increased uptake rate of fatty acids ${ }^{102,112,113}$. However, in $\mathrm{CHO}$ cells, transfection of CD36 alone was insufficient to control oleic acid uptake ${ }^{114}$. Surprisingly, for platelets, no information is available.

Especially in cardiomyocytes, the reactive fatty acid derivate, sulfo- $N$-succinimidyl oleate (SSO), which cross-links to CD36, has been used as a blocking tool to demonstrate a role of CD36 in fatty acid uptake. Treatment with SSO suppressed fatty acid uptake in skeletal and heart muscle with 50-80\%, but was without effect on hepatocytes which do not express CD36 105,108 .

In endothelial cells a link could be established between TSPI binding to CD36 and fatty acid (myristic acid) uptake ${ }^{106}$. Treatment with TSP1 or anti-CD36 antibody inhibited both the uptake of myristate and the myristate-induced stimulation of eNOS and subsequent cGMP accumulation. However, part of the TSPI effects involved integrin-associated protein CD47 rather than CD36. Using anti-CD36 antibodies, another report claimed that the uptake of myristate via CD36 provoked stimulation of eNOS via activation of AMP-activated protein kinase ${ }^{104}$. In spite of these findings, CD36 is not the only known membrane protein regulating fatty acid transport ${ }^{102}$. It is considered that CD36 - directly or indirectly - by regulating fatty acid uptake controls a variety of physiological responses, such as vascular contraction, neo-vessel formation (angiogenesis) and tissue glucose metabolism (Table 2.1). The precise link between CD36 as a receptor for long-chain fatty acids and the uptake of fatty acids still need to be established.

\section{G. CD36 as scavenging receptor for other proteins}

As a scavenging receptor, CD36 on macrophages and other phagocytic cells also sequesters red blood cells infected by Plasmodium falciparum ${ }^{98,115}$. Binding of the parasite to CD36 involves a malarial variant antigen, i.e. the cysteine-rich domain of $P$. falciparum erythrocyte membrane protein 1 (PfEMP1) ${ }^{116}$. Another reported 'scavenging' ligand of CD36 is amyloid $A \beta$ peptide ${ }^{58}$, the binding of which results in proinflammatory cytokine production through activation of JNK and other MAPK isoforms ${ }^{92}$.

\section{Genetic deficiencies and mutations in CD36}

Early 1999, it was reported that the NIH strain of spontaneously hypertensive rats ( $\mathrm{SHR}$ ) harbor a deletion mutation in the CD36 gene, which associated with an impaired fatty acid metabolism ${ }^{117}$. Platelets from these rats were deficient in VLDL binding and showed enhanced collagen-induced aggregation ${ }^{118}$. It later appeared that the hypertension was caused by linkage of another gene to CD36, and that the deletion variant of CD36 was not critical to the hypertension in the SHR model ${ }^{119}$. The role of this protein could be studied more extensively after selective genetic knockdown of CD36 in mice. This resulted in elevated plasma levels of free fatty acids and insulin, in impaired metabolism of fatty acids, and a higher perfusion pressure in the heart $24,99,120,121$. In CD36-deficient mouse macrophages, binding and internalization of ox LDL was severely 
impaired, while CD36-deficient adipocytes showed a diminished fatty acid uptake ${ }^{122}$. Furthermore, in atherosclerotic Apoe ${ }^{-/}$mice, genetic knockdown of CD36 resulted in a decreased plaque development ${ }^{123}$. Although Apoe $^{-/} \mathrm{Cd} 36^{-/}$mice did not bleed, they showed reduced platelet reactivity and experimental arterial thrombosis, especially in response to hyperlipidemia-associated $0 \times \mathrm{PL}^{79}$.

In human, a number of mutations in the CD36 gene have been described that associate with diminished protein expression levels ${ }^{124-128}$. Two mutation types are distinguished, i.e. those that lead to absence of CD36 in many cell types, including monocytes and platelets (type I deficiency), and those that cause deficiency in only platelets (type II deficiency) ${ }^{129-132}$. Especially in the Japanese population, the frequency of type I and II deficiencies is relatively high, amounting $0.3 \%$ and $4 \%$, respectively ${ }^{1,126}$. Type II deficiency is also observed in a minority of African-Americans (3-4\%) and Caucasians $(<0.3 \%)$.

The physiological consequences of type I and II deficiencies have only partly been clarified. Type II patients with so-called Naka-negative platelets do not have a bleeding diathesis, suggesting normal platelet function ${ }^{41,133}$. However, these patients relatively often suffer from cardiomyopathy ${ }^{134,135}$, hyperlipidemia (LDL) with impaired utilization of free fatty acids ${ }^{136}$, insulin resistance with impaired glucose metabolism ${ }^{131,137,138}$, and mild hypertension similarly as in hypertensive rats $^{76}$. Although patient numbers are still small, these observations led to the supposition that CD36 deficiency is linked to metabolic syndrome and coronary heart disease ${ }^{76,132}$. Interestingly, at young age, there is no evidence for increased heart disease in these patients, which suggests the presence of compensating effects ${ }^{135}$. All together it is unclear whether the observed (patho) physiological effects of human CD36 deficiency are a direct consequence of paucity in CD36-induced cell signaling/activation or long-term, compensating effects, e.g. due to higher plasma lipid levels.

\section{Signaling roles of CD36 in atherothrombosis and related diseases}

As reviewed by others, pharmacological and genetic knock-out studies point to an adverse role of CD36 in lipid-modifiable diseases like metabolic syndrome, atherosclerosis and thrombosis ${ }^{5}$. Using a molecular approach, below we concentrate on the role of specific ligand-CD36 interactions and signaling events in the pathophysiology of these diseases.

\section{A. CD36 in regulation of lipid metabolism}

In animals, the amount or type of dietary fatty acid appears to influence the cellular expression of CD36. For instance, administration of fish oil, rich in n-3 polyunsaturated fatty acids, increased mRNA levels of CD36 in rat ${ }^{101}$. On the other hand, murine CD36 appeared to control fatty acid absorption by enterocytes in proximal segments of the intestine, which was linked to optimal secretion of triglyceride-containing chylomicrons ${ }^{109,139,140}$. In $C d 36^{-1-}$ mice, reduced chylomicron secretion was accompanied by impaired clearance of chylomicrons from plasma ${ }^{141}$. CD36 deficiency hence resulted in hypertriglyceridemia.

A similar role of CD36 in binding and uptake of long-chain fatty acids is reported for a range of cells of the cardiovascular system (Table 2.1). In various tissues, the 
role of CD36 seems to be aggravated by its up-regulation in pathological situations as obesity and diabetes ${ }^{142,143}$. How this positive feed-forward mechanism works is largely unresolved. In endothelial cells, fatty acids may activate nitric oxide synthase (eNOS) via a pathway involving AMP kinase, which controls the cellular energy metabolism ${ }^{104}$. In cardiac myocytes, AMP kinase regulates the contraction-dependent translocation of CD36 and GLUT4 ${ }^{144}$.

\section{B. CD36 in regulation of glucose metabolism}

A consistent finding is that the CD36-dependent uptake of fatty acids is accompanied with an altered intracellular glucose metabolism ${ }^{100}$. A proposed mechanism is the CD36mediated or -stimulated translocation of the GLUT4 glucose transporter to the plasma membrane and, as a consequence, higher glucose uptake. CD36 deficiency in mouse can hence lead to reduced glucose uptake, hyperinsulinemia and insulin resistance ${ }^{76,137,145}$, or in human to a compensatory increased glucose uptake ${ }^{131}$. As indicated above, the precise signaling events still need to be resolved.

Recently, a cleaved fragment of CD36 has been identified in human plasma ${ }^{146}$. The level of this soluble CD36 is increased in plasma from patients with insulin resistance or advanced atherosclerosis ${ }^{147-149}$. Since causal relations with disease are not established, this fragment is considered as a marker of impaired glucose tolerance. How soluble CD36 links to the expression level and signaling function of cellular CD36 is unknown. Interestingly, one report suggests it can co-activate Toll-like receptors ${ }^{150}$.

\section{CD36 in atherosclerosis and thrombosis}

The proposed 'scavenger' role of CD36 in atherogenesis largely comes from the evidence that intra-plaque macrophages form foam cells in a CD36-dependent way. The likely mechanism is binding and uptake of lipids (oxLDL) via CD36 with as result intracellular lipid accumulation $76,79,84,123,151$. Signaling via CD36 during lipid uptake is expected, given the fact that blockage of the p38 MAPK pathway attenuated oxLDL-induced foam cell formation ${ }^{87}$. Several papers point to a positive feedback in that oxLDL mediates the up-regulation of CD36 expression via PPAR $\gamma$ signaling ${ }^{87,152}$. On the other hand, in atherosclerotic mice, CD36 signaling to Src-family kinase and JNK isoforms has been implicated in foam cell formation ${ }^{153,154}$. However, since in double knockout mice, lacking $L D L$ receptors and CD36, atherosclerotic lesion development and macrophage foam cell formation are only incompletely abolished, it is likely that other scavenger receptors contribute to lipid uptake as well. Evidence for a pro-inflammatory role of CD36 in atherogenesis comes from observations, again with mice, that the CD36-dependent JNK phosphorylation is accompanied by higher circulating levels of cytokines ${ }^{155}$. Along the same line, in human macrophages CD36 expression correlates with NFKB expression and $0 \times L D L$-induced IL-1 $\beta$ formation ${ }^{156}$. The currently understood mechanism is that oxLDL uptake as well as signaling via CD36 enhances foam cell formation, which aggravates atherosclerotic plaque formation.

Given the fundamental role of platelets in intra-vascular thrombus formation, the abundant presence of CD36 on these cells (10,000-25,000 copies/platelet) suggests that 
CD36 contributes to the thrombotic process. For long, this role has remained uncertain, but recent evidence does point to a prothrombotic function of CD36 in hyperlipidemia. Thus, studies with Apoe-- mice show that CD36 deficiency protects from hyperlipidemiaassociated thrombosis, under conditions where oxLDL (containing oxPL) is a primary thrombotic trigger ${ }^{79,84}$. Binding of oxidized lipid or even microparticles to CD36 on platelets can increase thrombus formation ${ }^{157}$. Hence, under conditions of hyperlipidemia, platelet CD36 may principally act as ligand for oxLDL and oxPL. Taken together, these findings provide a rationale for interfering in the oxLDL-CD36 interaction to prevent atherosclerosis-linked thrombosis.

\section{Conclusions}

It is clear that CD36 is involved in multiple, often cell-specific functional responses. Detailed analysis of the various ligands and responses of CD36 provides better insight into its different signaling modes, namely: (i) the proposed ligands of CD36 (TSP1, oxLDL, oxPL, fatty acids) appear to bind to one region in or near the CLESH-1 domain; (ii) the CD36 ligands trigger similar signaling cascades; (iii) most signals and responses induced by CD36 ligands are redundant with those of other receptors (scavenger receptors, fatty acid-binding receptors, CD47, etc.); (iv) phosphorylation-dependent signaling events such as for growth factor receptors have not been described. Taking this together, it is unlikely that CD36 signals on its own, e.g. by directly activating protein kinases. Probably, ligand-bound CD36 interacts with a range of associated proteins in the membrane to transmit further signals. These include tetraspannins, integrins, clathrin-binding proteins, Toll-like receptors and other proteins that are still unknown. Such effector protein mediate further signaling events. This scheme, as presented in Figure 2.3, can explain why responses of various cell types are variable, but mostly include secretion (cytokines, granular contents) and gene expression regulation.

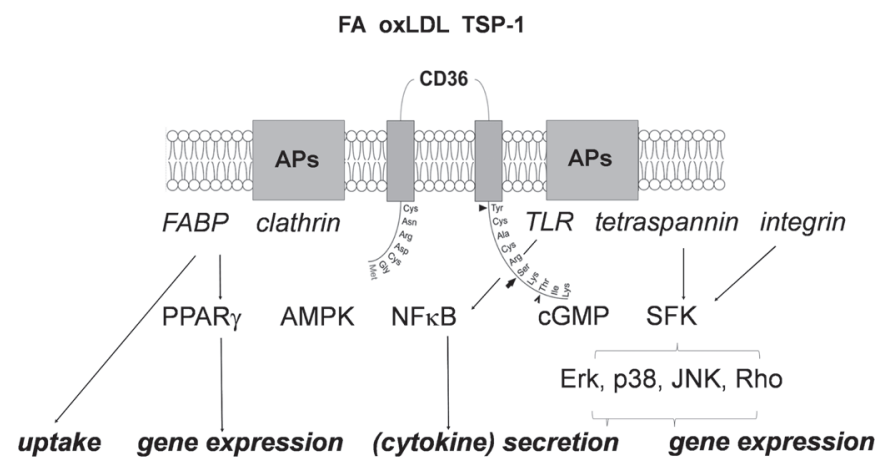

Figure 2.3. Tentative scheme of CD36-induced signaling. Several associated proteins (APs) may assist in uptake of fatty acids (FABP, fatty acid binding proteins), endocytosis of oxLDL (clathrinbinding proteins) or metabolic regulation (via PPAR $\gamma$ and AMPK). Likely different proteins (Toll-like receptors: TLR, tetraspannins and integrins) trigger conventional signaling pathways to activate $\mathrm{NF \kappa B}$, Src-family kinases (SFK: Lyn, Fyn), MAPK (Erk, p38 and JNK), and cytoskeleton-associated Rho kinase. Described CD36-mediated responses are fatty acid uptake, secretion (cytokines, granular contents) and gene expression regulation. 
Based on this scheme, CD36 in monocytes/macrophages, acting as a scavenger receptor, mediates endocytosis via clathrin vesicles and proinflammatory signaling via NFKB and MAPK isoforms. In platelets, CD36 occupied by TSPI or oxLDL may signal jointly with GPIb-V-IX, integrins and CD47 to activate Src-family kinases and further downstream protein kinase events. Likewise, in smooth muscle cells, endothelial cells and fibroblasts, TSPl-evoked signaling routes are triggered, putatively by interaction of CD36 with associated proteins. In this light CD36 becomes an attractive therapeutic target to suppress platelet and monocyte/macrophage function and thereby atherothrombosis. However, given the compensatory adverse effects of genetic CD36 deficiency, a short-term targeting of CD36 may be most promising.

\section{Acknowledgements}

We acknowledge grant support from the Hacettepe University (Ankara, Turkey) and the Netherlands Organization for Scientific Research (ZonMW 11.400.0076). 


\section{References}

1. Greenwalt, D. E.; Lipsky, R. H.; Ockenhouse, C. F.; Ikeda, H.; Tandon, N. N.; Jamieson, G. A., Membrane glycoprotein CD36: a review of its roles in adherence, signal transduction, and transfusion medicine. Blood 1992, 80, (5), 1105-15.

2. Ikeda, H., Platelet membrane protein CD36. Hokkaido Igaku Zasshi 1999, 74, (2), 99-104.

3. Febbraio, M.; Silverstein, R. L., CD36: implications in cardiovascular disease. Int J Biochem Cell Biol 2007, 39, (11), 2012-30.

4. Valiyaveettil, M.; Podrez, E. A., Platelet hyperreactivity, scavenger receptors and atherothrombosis. J Thromb Haemost 2009, 7 Suppl 1, 218-21.

5. Silverstein, R. L.; Febbraio, M., CD36, a scavenger receptor involved in immunity, metabolism, angiogenesis, and behavior. Sci. Siganl. 2010, 2, 272 re3.

6. Shattil, S. J.; Brugge, J. S., Protein tyrosine phosphorylation and the adhesive functions of platelets. Curr Opin Cell Biol 1991, 3, (5), 869-79.

7. Berger, G.; Caen, J. P.; Berndt, M. C.; Cramer, E. M., Ultrastructural demonstration of CD36 in the alpha-granule membrane of human platelets and megakaryocytes. Blood 1993, $82,(10), 3034-44$.

8. Vega, M. A.; Segui-Real, B.; Garcia, J. A.; Cales, C.; Rodriguez, F.; Vanderkerckhove, J.; Sandoval, I. V., Cloning, sequencing, and expression of a cDNA encoding rat LIMP II, a novel $74-k D a$ lysosomal membrane protein related to the surface adhesion protein CD36. J Biol Chem 1991, 266, (25), 16818-24.

9. Hart, K.; Wilcox, M., A Drosophila gene encoding an epithelial membrane protein with homology to CD36/LIMP II. J Mol Biol 1993, 234, (1), 249-53.

10. Acton, S.; Rigotti, A.; Landschulz, K. T.; Xu, S.; Hobbs, H. H.; Krieger, M., Identification of scavenger receptor SR-BI as a high density lipoprotein receptor. Science 1996, 271, (5248), 518-20.

11. Hoosdally, S. J.; Andress, E. J.; Wooding, C.; Martin, C. A.; Linton, K. J., The human scavenger receptor CD36: glycosylation status and its role in trafficking and function. J Biol Chem 2009, 284, (24), 16277-88.

12. Gruarin, P.; Sitia, R.; Alessio, M., Formation of one or more intrachain disulphide bonds is required for the intracellular processing and transport of CD36. Biochem J 1997, 328, 635-42.

13. Tao, N.; Wagner, S. J.; Lublin, D. M., CD36 is palmitoylated on both N- and C-terminal cytoplasmic tails. J Biol Chem 1996, 271, (37), 22315-20.

14. Rasmussen, J. T.; Berglund, L.; Rasmussen, M. S.; Petersen, T. E., Assignment of disulfide bridges in bovine CD36. Eur J Biochem 1998, 257, (2), 488-94.

15. Collot-Teixeira, S.; Martin, J.; McDermott-Roe, C.; Poston, R.; McGregor, J. L., CD36 and macrophages in atherosclerosis. Cardiovasc Res 2007, 75, (3), 468-77.

16. Asch, A. S.; Liu, I.; Briccetti, F. M.; Barnwell, J. W.; Kwakye-Berko, F.; Dokun, A.; Goldberger, J.; Pernambuco, M., Analysis of CD36 binding domains: ligand specificity controlled by dephosphorylation of an ectodomain. Science 1993, 262, (5138), 1436-40.

17. Prater, C. A.; Plotkin, J.; Jaye, D.; Frazier, W. A., The properdin-like type I repeats of human thrombospondin contain a cell attachment site. J Cell Biol 1991, 112, (5), 1031-40.

18. Pearce, S. F.; Wu, J.; Silverstein, R. L., A carboxyl terminal truncation mutant of CD36 is secreted and binds thrombospondin: evidence for a single transmembrane domain. Blood $1994,84,(2), 384-9$.

19. Frieda, S.; Pearce, A.; Wu, J.; Silverstein, R. L., Recombinant GST/CD36 fusion proteins define a thrombospondin binding domain. Evidence for a single calcium-dependent binding site on CD36. J Biol Chem 1995, 270, (7), 2981-6.

20. Simantov, R.; Febbraio, M.; Crombie, R.; Asch, A. S.; Nachman, R. L.; Silverstein, R. L., Histidine-rich glycoprotein inhibits the antiangiogenic effect of thrombospondin-1. J Clin Invest 2001, 107, (1), 45-52. 
21. Febbraio, M.; Hajjar, D. P.; Silverstein, R. L., CD36: a class B scavenger receptor involved in angiogenesis, atherosclerosis, inflammation, and lipid metabolism. J Clin Invest 2001, $108,(6), 785-91$.

22. Kar, N. S.; Ashraf, M. Z.; Valiyaveettil, M.; Podrez, E. A., Mapping and characterization of the binding site for specific oxidized phospholipids and oxidized low density lipoprotein of scavenger receptor CD36. J Biol Chem 2008, 283, (13), 8765-71.

23. Puente Navazo, M. D.; Daviet, L.; Ninio, E.; McGregor, J. L., Identification on human CD36 of a domain (155-183) implicated in binding oxidized low-density lipoproteins (0x-LDL). Arterioscler Thromb Vasc Biol 1996, 16, (8), 1033-9.

24. Bodart, V.; Febbraio, M.; Demers, A.; McNicoll, N.; Pohankova, P.; Perreault, A.; Sejlitz, T.; Escher, E.; Silverstein, R. L.; Lamontagne, D.; Ong, H., CD36 mediates the cardiovascular action of growth hormone-releasing peptides in the heart. Circ Res 2002, 90, (8), 844-9.

25. Demers, A.; McNicoll, N.; Febbraio, M.; Servant, M.; Marleau, S.; Silverstein, R.; Ong, H., Identification of the growth hormone-releasing peptide binding site in CD36: a photoaffinity cross-linking study. Biochem J 2004, 382, (Pt 2), 417-24.

26. Abumrad, N. A.; el-Maghrabi, M. R.; Amri, E. Z.; Lopez, E.; Grimaldi, P. A., Cloning of a rat adipocyte membrane protein implicated in binding or transport of long-chain fatty acids that is induced during preadipocyte differentiation. Homology with human CD36. J Biol Chem 1993, 268, (24), 17665-8.

27. Baillie, A. G.; Coburn, C. T.; Abumrad, N. A., Reversible binding of long-chain fatty acids to purified FAT, the adipose CD36 homolog. J Membr Biol 1996, 153, (1), 75-81.

28. Rhainds, D.; Brissette, L., The role of scavenger receptor class B type I (SR-BI) in lipid trafficking. defining the rules for lipid traders. Int J Biochem Cell Biol 2004, 36, (1), 39-77.

29. Daviet, L.; Malvoisin, E.; Wild, T. F.; McGregor, J. L., Thrombospondin induces dimerization of membrane-bound, but not soluble CD36. Thromb Haemost 1997, 78, (2), 897-901.

30. Hatmi, M.; Gavaret, J. M.; Elalamy, I.; Vargaftig, B. B.; Jacquemin, C., Evidence for cAMPdependent platelet ectoprotein kinase activity that phosphorylates platelet glycoprotein IV (CD36). J Biol Chem 1996, 271, (40), 24776-80.

31. Tandon, N. N.; Kralisz, U.; Jamieson, G. A., Identification of glycoprotein IV (CD36) as a primary receptor for platelet-collagen adhesion. J Biol Chem 1989, 264, (13), 7576-83.

32. Diaz-Ricart, M.; Tandon, N. N.; Carretero, M.; Ordinas, A.; Bastida, E.; Jamieson, G. A., Platelets lacking functional CD36 (glycoprotein IV) show reduced adhesion to collagen in flowing whole blood. Blood 1993, 82, (2), 491-6.

33. Beer, J. H.; Rabaglio, M.; Berchtold, P.; von Felten, A.; Clemetson, K. J.; Tsakiris, D. A.; Kehrel, B.; Brandenberger, S., Autoantibodies against the platelet glycoproteins (GP) IIb/ IIIa, Ia/IIa, and IV and partial deficiency in GPIV in a patient with a bleeding disorder and a defective platelet collagen interaction. Blood 1993, 82, (3), 820-9.

34. Matsuno, K.; Diaz-Ricart, M.; Montgomery, R. R.; Aster, R. H.; Jamieson, G. A.; Tandon, N. N., Inhibition of platelet adhesion to collagen by monoclonal anti-CD36 antibodies. Br J Haematol 1996, 92, (4), 960-7.

35. Nieswandt, B.; Brakebusch, C.; Bergmeier, W.; Schulte, V.; Bouvard, D.; Mohtari-Nejad, R.; Lindhout, T.; Heemskerk, J. W. M.; Zirngibl, H.; Fässler, R., Glycoprotein VI but not $\alpha 2 \beta 1$ integrin is essential for platelet interaction with collagen. EMBO J. 2001, 20, 21202130.

36. Lecut, C.; Schoolmeester, A.; Kuijpers, M. J. E.; Broers, J. L. V.; van Zandvoort, M. A. M. J.; Vanhoorelbeke, K.; Deckmyn, H.; Jandrot-Perrus, M.; Heemskerk, J. W. M., Principal role of glycoprotein $V I$ in $\alpha 2 \beta 1$ and $\alpha \operatorname{IIb} \beta 3$ activation during collagen-induced thrombus formation. Arterioscler. Thromb. Vasc. Biol. 2004, 24, 1727-1733.

37. Siljander, P. R. M.; Munnix, I. C. A.; Smethurst, P. A.; Deckmyn, H.; Lindhout, T.; Ouwehand, W. H.; Farndale, R. W.; Heemskerk, J. W. M., Platelet receptor interplay regulates collagen-induced thrombus formation in flowing human blood. Blood 2004, 103, 1333-1341. 
38. Munnix, I. C.; Kuijpers, M. J.; Auger, J.; Thomassen, C. M.; Panizzi, P.; van Zandvoort, M. A.; Rosing, J.; Bock, P. E.; Watson, S. P.; Heemskerk, J. W., Segregation of platelet aggregatory and procoagulant microdomains in thrombus formation: regulation by transient integrin activation. Arterioscler Thromb Vasc Biol 2007, 27, (11), 2484-90.

39. Kuijpers, M. J. E.; Pozgajova, M.; Cosemans, J. M. E. M.; Munnix, I. C. A.; Eckes, B.; Nieswandt, B.; Heemskerk, J. W. M., Role of murine integrin $\alpha 2 \beta 1$ in thrombus stabilization and embolization: contribution of thromboxane $A_{2}$. Thromb. Haemost. 2007, 98, $1072-$ 1080.

40. Nieswandt, B.; Watson, S. P., Platelet-collagen interaction: is GPVI the central receptor? Blood 2003, 102, 449-461.

41. Yamamoto, N.; Akamatsu, N.; Yamazaki, H.; Tanoue, K., Normal aggregations of glycoprotein IV (CD36)-deficient platelets from seven healthy Japanese donors. $\mathrm{Br} J$ Haematol 1992, 81, (1), 86-92.

42. Saelman, E. U.; Kehrel, B.; Hese, K. M.; de Groot, P. G.; Sixma, J. J.; Nieuwenhuis, H. K., Platelet adhesion to collagen and endothelial cell matrix under flow conditions is not dependent on platelet glycoprotein IV. Blood 1994, 83, (11), 3240-4.

43. Daniel, J. L.; Dangelmaier, C.; Strouse, R.; Smith, J. B., Collagen induces normal signal transduction in platelets deficient in CD36 (platelet glycoprotein IV). Thromb Haemost $1994,71,(3), 353-6$.

44. Kehrel, B.; Wierwille, S.; Clemetson, K. J.; Anders, 0.; Steiner, M.; Knight, C. G.; Farndale, R. W.; Okuma, M.; Barnes, M. J., Glycoprotein VI is a major collagen receptor for platelet activation: it recognizes the platelet-activating quaternary structure of collagen, whereas CD36, glycoprotein IIb/IIIa, and von Willebrand factor do not. Blood 1998, 91, (2), 491-9.

45. Kehrel, B.; Kronenberg, A.; Rauterberg, J.; Niesing-Bresch, D.; Niehues, U.; Kardoeus, J.; Schwippert, B.; Tschope, D.; van de Loo, J.; Clemetson, K. J., Platelets deficient in glycoprotein IIIb aggregate normally to collagens type I and III but not to collagen type $\mathrm{V}$. Blood 1993, 82, (11), 3364-70.

46. Janabi, M.; Yamashita, S.; Hirano, K.; Matsumoto, K.; Sakai, N.; Hiraoka, H.; Kashiwagi, H.; Tomiyama, Y.; Nozaki, S.; Matsuzawa, Y., Reduced adhesion of monocyte-derived macrophages from CD36-deficient patients to type I collagen. Biochem Biophys Res Commun 2001, 283, (1), 26-30.

47. Tan, K.; Lawler, J., The interaction of Thrombospondins with extracellular matrix proteins. J Cell Commun Signal 2009, in press.

48. Bornstein, P., Thrombospondins as matricellular modulators of cell function. J Clin Invest $2001,107,(8), 929-34$.

49. Kyriakides, T. R.; Zhu, Y. H.; Smith, L. T.; Bain, S. D.; Yang, Z.; Lin, M. T.; Danielson, K. G.; Iozzo, R. V.; LaMarca, M.; McKinney, C. E.; Ginns, E. I.; Bornstein, P., Mice that lack thrombospondin 2 display connective tissue abnormalities that are associated with disordered collagen fibrillogenesis, an increased vascular density, and a bleeding diathesis. J Cell Biol 1998, 140, (2), 419-30.

50. Aiken, M. L.; Ginsberg, M. H.; Byers-Ward, V.; Plow, E. F., Effects of OKM5, a monoclonal antibody to glycoprotein IV, on platelet aggregation and thrombospondin surface expression. Blood 1990, 76, (12), 2501-9.

51. Jurk, K.; Clemetson, K. J.; de Groot, P. G.; Brodde, M. F.; Steiner, M.; Savion, N.; Varon, D.; Sixma, J. J.; Van Aken, H.; Kehrel, B. E., Thrombospondin-1 mediates platelet adhesion at high shear via glycoprotein Ib (GPIb): an alternative/backup mechanism to von Willebrand factor. Faseb J 2003, 17, (11), 1490-2.

52. Stomski, F. C.; Gani, J. S.; Bates, R. C.; Burns, G. F., Adhesion to thrombospondin by human embryonic fibroblasts is mediated by multiple receptors and includes a role for glycoprotein 88 (CD36). Exp Cell Res 1992, 198, (1), 85-92.

53. Esemuede, N.; Lee, T.; Pierre-Paul, D.; Sumpio, B. E.; Gahtan, V., The role of thrombospondin-1 in human disease. J Surg Res 2004, 122, (1), 135-42. 
54. Moura, R.; Tjwa, M.; Vandervoort, P.; Van Kerckhoven, S.; Holvoet, P.; Hoylaerts, M. F., Thrombospondin- 1 deficiency accelerates atherosclerotic plaque maturation in Apo $\mathrm{E}^{-/}$mice. Circ Res 2008, 103, (10), 1181-9.

55. Wight, T. N.; Raugi, G. J.; Mumby, S. M.; Bornstein, P., Light microscopic immunolocation of thrombospondin in human tissues. J Histochem Cytochem 1985, 33, (4), 295-302.

56. Bonnefoy, A.; Hoylaerts, M. F., Thrombospondin-1 in von Willebrand factor function. Curr Drug Targets 2008, 9, (10), 822-32.

57. Leung, L. L.; Li, W. X.; McGregor, J. L.; Albrecht, G.; Howard, R. J., CD36 peptides enhance or inhibit CD36-thrombospondin binding. A two-step process of ligand-receptor interaction. J Biol Chem 1992, 267, (25), 18244-50.

58. Baranova, I. N.; Bocharov, A. V.; Vishnyakova, T. G.; Kurlander, R.; Chen, Z.; Fu, D.; Arias, I. M.; Csako, G.; Patterson, A. P.; Eggerman, T. L., CD36 is a novel serum amyloid A (SAA) receptor mediating SAA binding and SAA-induced signaling in human and rodent cells. $J$ Biol Chem 2010, 285, (11), 8492-506.

59. Agbanyo, F. R.; Sixma, J. J.; de Groot, P. G.; Languino, L. R.; Plow, E. F., Thrombospondinplatelet interactions. Role of divalent cations, wall shear rate, and platelet membrane glycoproteins. J Clin Invest 1993, 92, (1), 288-96.

60. Bonnefoy, A.; Hantgan, R.; Legrand, C.; Frojmovic, M. M., A model of platelet aggregation involving multiple interactions of thrombospondin-1, fibrinogen, and GPIIbIIIa receptor. J Biol Chem 2001, 276, (8), 5605-12.

61. Chung, J.; Wang, X. Q.; Lindberg, F. P.; Frazier, W. A., Thrombospondin-1 acts via IAP/ CD47 to synergize with collagen in $\alpha \mathrm{II} \beta 1$-mediated platelet activation. Blood 1999, 94, (2), 642-8.

62. Isenberg, J. S.; Romeo, M. J.; Yu, C.; Yu, C. K.; Nghiem, K.; Monsale, J.; Rick, M. E.; Wink, D. A.; Frazier, W. A.; Roberts, D. D., Thrombospondin-1 stimulates platelet aggregation by blocking the antithrombotic activity of nitric oxide/cGMP signaling. Blood 2008, 111, (2), 613-23.

63. Saumet, A.; de Jesus, N.; Legrand, C.; Dubernard, V., Association of thrombospondin-1 with the actin cytoskeleton of human thrombin-activated platelets through an $\alpha \operatorname{IIb} \beta 3$ - or CD36independent mechanism. Biochem J 2002, 363, (Pt 3), 473-82.

64. Nergiz-Unal, R.; Kuijpers, M. J.; Munnix, I. C.; Glatz, J. F.; Heemskerk, J. W., Outside-in signaling induced by thrombospondin- 1 enhances thrombus formation: involvement of CD36. J Thromb Haemost 2009, 7, Suppl 2, PP-TH-012.

65. Tulasne, D.; Judd, B. A.; Johansen, M.; Asazuma, N.; Best, D.; Brown, E. J.; Kahn, M.; Koretzky, G. A.; Watson, S. P., C-terminal peptide of thrombospondin-1 induces platelet aggregation through the Fc receptor $\gamma$-chain-associated signaling pathway and by agglutination. Blood 2001, 98, (12), 3346-52.

66. Miao, W. M.; Vasile, E.; Lane, W. S.; Lawler, J., CD36 associates with CD9 and integrins on human blood platelets. Blood 2001, 97, (6), 1689-96.

67. Davis, A. K.; Makar, R. S.; Stowell, C. P.; Kuter, D. J.; Dzik, W. H., ADAMTS13 binds to CD36: a potential mechanism for platelet and endothelial localization of ADAMTS13. Transfusion 2009, 49, (2), 206-13.

68. Isenberg, J. S.; Wink, D. A.; Roberts, D. D., Thrombospondin-1 antagonizes nitric oxidestimulated vascular smooth muscle cell responses. Cardiovasc Res 2006, 71, (4), 785-93.

69. Isenberg, J. S.; Yu, C.; Roberts, D. D., Differential effects of ABT-510 and a CD36-binding peptide derived from the type 1 repeats of thrombospondin- 1 on fatty acid uptake, nitric oxide signaling, and caspase activation in vascular cells. Biochem Pharmacol 2008, 75, (4), 875-82.

70. Roberts, W.; Magwenzi, S.; Aburima, A.; Naseem, K. M., Thrombinspondin-1 induces platelet activation through CD36-dependent inhibition of the CAMP/protein kinase A signaling cascade. Blood 2010, in press. 
71. Yang, Q.; Tian, Y.; Liu, S.; Zeine, R.; Chlenski, A.; Salwen, H. R.; Henkin, J.; Cohn, S. L., Thrombospondin-1 peptide ABT-510 combined with valproic acid is an effective antiangiogenesis strategy in neuroblastoma. Cancer Res 2007, 67, (4), 1716-24.

72. Endemann, G.; Stanton, L. W.; Madden, K. S.; Bryant, C. M.; White, R. T.; Protter, A. A., CD36 is a receptor for oxidized low density lipoprotein. J Biol Chem 1993, 268, (16), $11811-6$.

73. Sun, B.; Boyanovsky, B. B.; Connelly, M. A.; Shridas, P.; van der Westhuyzen, D. R.; Webb, N. R., Distinct mechanisms for oxLDL uptake and cellular trafficking by class $B$ scavenger receptors CD36 and SR-BI. J Lipid Res 2007, 48, (12), 2560-70.

74. Martin, C. A.; Longman, E.; Wooding, C.; Hoosdally, S. J.; Ali, S.; Aitman, T. J.; Gutmann, D. A.; Freemont, P. S.; Byrne, B.; Linton, K. J., CD36, a class B scavenger receptor, functions as a monomer to bind acetylated and oxidized low-density lipoproteins. Protein Sci 2007, 16, (11), 2531-41.

75. Thorne, R. F.; Mhaidat, N. M.; Ralston, K. J.; Burns, G. F., CD36 is a receptor for oxidized high density lipoprotein: implications for the development of atherosclerosis. Febs Lett 2007, 581, (6), 1227-32.

76. Yamashita, S.; Hirano, K.; Kuwasako, T.; Janabi, M.; Toyama, Y.; Ishigami, M.; Sakai, N., Physiological and pathological roles of a multi-ligand receptor CD36 in atherogenesis: insights from CD36-deficient patients. Mol Cell Biochem 2007, 299, (1-2), 19-22.

77. Podrez, E. A.; Febbraio, M.; Sheibani, N.; Schmitt, D.; Silverstein, R. L.; Hajjar, D. P.; Cohen, P. A.; Frazier, W. A.; Hoff, H. F.; Hazen, S. L., Macrophage scavenger receptor CD36 is the major receptor for LDL modified by monocyte-generated reactive nitrogen species. J Clin Invest 2000, 105, (8), 1095-108.

78. Podrez, E. A.; Poliakov, E.; Shen, Z.; Zhang, R.; Deng, Y.; Sun, M.; Finton, P. J.; Shan, L.; Gugiu, B.; Fox, P. L.; Hoff, H. F.; Salomon, R. G.; Hazen, S. L., Identification of a novel family of oxidized phospholipids that serve as ligands for the macrophage scavenger receptor CD36. J Biol Chem 2002, 277, (41), 38503-16.

79. Podrez, E. A.; Byzova, T. V.; Febbraio, M.; Salomon, R. G.; Ma, Y.; Valiyaveettil, M.; Poliakov, E.; Sun, M.; Finton, P. J.; Curtis, B. R.; Chen, J.; Zhang, R.; Silverstein, R. L.; Hazen, S. L., Platelet CD36 links hyperlipidemia, oxidant stress and a prothrombotic phenotype. Nat Med 2007, 13, (9), 1086-95.

80. Greenberg, M. E.; Sun, M.; Zhang, R.; Febbraio, M.; Silverstein, R.; Hazen, S. L., Oxidized phosphatidylserine-CD36 interactions play an essential role in macrophage-dependent phagocytosis of apoptotic cells. J Exp Med 2006, 203, (12), 2613-25.

81. Gao, D.; Ashraf, M. Z.; Kar, N. S.; Lin, D.; Sayre, L. M.; Podrez, E. A., Structural basis for the recognition of oxidized phospholipids in oxidized low density lipoproteins by class $B$ scavenger receptors CD36 and SR-BI. J Biol Chem 2010, 285, (7), 4447-54.

82. Hartwich, J.; Dembinska-Kiec, A.; Gruca, A.; Motyka, M.; Partyka, L.; Skrzeczynska, J.; Bzowska, M.; Pryjma, J.; Huber, J.; Leitinger, N.; Schmitz, G., Regulation of platelet adhesion by oxidized lipoproteins and oxidized phospholipids. Platelets 2002, 13, (3), 14151.

83. Korporaal, S. J.; Van Eck, M.; Adelmeijer, J.; Ijsseldijk, M.; Out, R.; Lisman, T.; Lenting, P. J.; Van Berkel, T. J.; Akkerman, J. W., Platelet activation by oxidized low density lipoprotein is mediated by CD36 and scavenger receptor-A. Arterioscler Thromb Vasc Biol 2007, 27, (11), 2476-83.

84. Luangrath, V.; Brodeur, M. R.; Rhainds, D.; Brissette, L., Mouse CD36 has opposite effects on LDL and oxidized LDL metabolism in vivo. Arterioscler Thromb Vasc Biol 2008, 28, (7), 1290-5.

85. Maschberger, P.; Bauer, M.; Baumann-Siemons, J.; Zangl, K. J.; Negrescu, E. V.; Reininger, A. J.; Siess, W., Mildly oxidized low density lipoprotein rapidly stimulates via activation of the lysophosphatidic acid receptor Src family and Syk tyrosine kinases and $\mathrm{Ca}^{2+}$ influx in human platelets. J Biol Chem 2000, 275, (25), 19159-66. 
86. Korporaal, S. J.; Gorter, G.; van Rijn, H. J.; Akkerman, J. W., Effect of oxidation on the platelet-activating properties of low-density lipoprotein. Arterioscler Thromb Vasc Biol 2005, 25, (4), 867-72.

87. Zhao, M.; Liu, Y.; Wang, X.; New, L.; Han, J.; Brunk, U. T., Activation of the p38 MAP kinase pathway is required for foam cell formation from macrophages exposed to oxidized LDL. Apmis 2002, 110, (6), 458-68.

88. Lim, H. J.; Lee, S.; Lee, K. S.; Park, J. H.; Jang, Y.; Lee, E. J.; Park, H. Y., PPARgamma activation induces CD36 expression and stimulates foam cell like changes in rVSMCs. Prostaglandins Other Lipid Mediat 2006, 80, (3-4), 165-74.

89. Chen, K.; Febbraio, M.; Li, W.; Silverstein, R. L., A specific CD36-dependent signaling pathway is required for platelet activation by oxidized low-density lipoprotein. Circ Res 2008, 102, (12), 1512-9.

90. Assinger, A.; Schmid, W.; Eder, S.; Schmid, D.; Koller, E.; Volf, I., Oxidation by hypochlorite converts protective HDL into a potent platelet agonist. Febs Lett 2008, 582, (5), 778-84.

91. Ghosh, A.; Li, W.; Febbraio, M.; Espinola, R. G.; McCrae, K. R.; Cockrell, E.; Silverstein, R. L., Platelet CD36 mediates interactions with endothelial cell-derived microparticles and contributes to thrombosis in mice. J Clin Invest 2008, 118, (5), 1934-43.

92. Collins, R. F.; Touret, N.; Kuwata, H.; Tandon, N. N.; Grinstein, S.; Trimble, W. S., Uptake of oxidized low density lipoprotein by CD36 occurs by an actin-dependent pathway distinct from macropinocytosis. J Biol Chem 2009, 284, (44), 30288-97.

93. Akkerman, J. W. N., From low-density lipoprotein to platelet activation. Int J Biochem Cell Biol 2008, 40, (11), 2374-8.

94. Morii, T.; Ohno, Y.; Kato, N.; Hirose, H.; Kawabe, H.; Hirao, K.; Eguchi, T.; Maruyama, T.; Hayashi, M.; Saito, I.; Yazaki, Y.; Saruta, T., CD36 single nucleotide polymorphism is associated with variation in low-density lipoprotein-cholesterol in young Japanese men. Biomarkers 2009, 14, (4), 207-12.

95. Calvo, D.; Gomez-Coronado, D.; Suarez, Y.; Lasuncion, M. A.; Vega, M. A., Human CD36 is a high affinity receptor for the native lipoproteins HDL, LDL, and VLDL. J Lipid Res 1998, 39, (4), 777-88.

96. Marleau, S.; Harb, D.; Bujold, K.; Avallone, R.; Iken, K.; Wang, Y.; Demers, A.; Sirois, M. G.; Febbraio, M.; Silverstein, R. L.; Tremblay, A.; Ong, H., EP 80317, a ligand of the CD36 scavenger receptor, protects apolipoprotein E-deficient mice from developing atherosclerotic lesions. Faseb J 2005, 19, (13), 1869-71.

97. Avallone, R.; Demers, A.; Rodrigue-Way, A.; Bujold, K.; Harb, D.; Anghel, S.; Wahli, W.; Marleau, S.; Ong, H.; Tremblay, A., A growth hormone-releasing peptide that binds scavenger receptor CD36 and ghrelin receptor up-regulates sterol transporters and cholesterol efflux in macrophages through a peroxisome proliferator-activated receptor gamma-dependent pathway. Mol Endocrinol 2006, 20, (12), 3165-78.

98. Patel, S. N.; Serghides, L.; Smith, T. G.; Febbraio, M.; Silverstein, R. L.; Kurtz, T. W.; Pravenec, M.; Kain, K. C., CD36 mediates the phagocytosis of Plasmodium falciparuminfected erythrocytes by rodent macrophages. J Infect Dis 2004, 189, (2), 204-13.

99. Coburn, C. T.; Knapp, F. F.; Febbraio, M.; Beets, A. L.; Silverstein, R. L.; Abumrad, N. A., Defective uptake and utilization of long chain fatty acids in muscle and adipose tissues of CD36 knockout mice. J Biol Chem 2000, 275, (42), 32523-9.

100. Koonen, D. P.; Glatz, J. F.; Bonen, A.; Luiken, J. J., Long-chain fatty acid uptake and FAT/ CD36 translocation in heart and skeletal muscle. Biochim Biophys Acta 2005, 1736, (3), 163-80.

101. Alexander Aguilera, A.; Hernandez Diaz, G.; Lara Barcelata, M.; Angulo Guerrero, 0.; Oliart Ros, R. M., Induction of CD36 expression elicited by fish oil PUFA in spontaneously hypertensive rats. J Nutr Biochem 2006, 17, (11), 760-5.

102. Glatz, J. F.; Luiken, J. J.; Bonen, A., Membrane fatty acid transporters as regulators of lipid metabolism: implications for metabolic disease. Physiol Rev 2010, 90, (1), 367-417. 
103. Pietsch, A.; Weber, C.; Goretzki, M.; Weber, P. C.; Lorenz, R. L., N-3 but not N-6 fatty acids reduce the expression of the combined adhesion and scavenger receptor CD36 in human monocytic cells. Cell Biochem Funct 1995, 13, (3), 211-6.

104. Zhu, W.; Smart, E. J., Myristic acid stimulates endothelial nitric-oxide synthase in a CD36and an AMP kinase-dependent manner. J Biol Chem 2005, 280, (33), 29543-50.

105. Coort, S. L.; Willems, J.; Coumans, W. A.; van der Vusse, G. J.; Bonen, A.; Glatz, J. F.; Luiken, J. J., Sulfo-N-succinimidyl esters of long chain fatty acids specifically inhibit fatty acid translocase (FAT/CD36)-mediated cellular fatty acid uptake. Mol Cell Biochem 2002, 239, (1-2), 213-9.

106. Isenberg, J. S.; Jia, Y.; Fukuyama, J.; Switzer, C. H.; Wink, D. A.; Roberts, D. D., Thrombospondin-1 inhibits nitric oxide signaling via CD36 by inhibiting myristic acid uptake. J Biol Chem 2007, 282, (21), 15404-15.

107. Coburn, C. T.; Hajri, T.; Ibrahimi, A.; Abumrad, N. A., Role of CD36 in membrane transport and utilization of long-chain fatty acids by different tissues. J Mol Neurosci 2001, 16, (2-3), 117-21.

108. Harmon, C. M.; Abumrad, N. A., Binding of sulfosuccinimidyl fatty acids to adipocyte membrane proteins: isolation and amino-terminal sequence of an 88-kD protein implicated in transport of long-chain fatty acids. J Membr Biol 1993, 133, (1), 43-9.

109. Drover, V. A.; Nguyen, D. V.; Bastie, C. C.; Darlington, Y. F.; Abumrad, N. A.; Pessin, J. E.; London, E.; Sahoo, D.; Phillips, M. C., CD36 mediates both cellular uptake of very long chain fatty acids and their intestinal absorption in mice. J Biol Chem 2008, 283, (19), 13108-15.

110. Laugerette, F.; Passilly-Degrace, P.; Patris, B.; Niot, I.; Febbraio, M.; Montmayeur, J. P.; Besnard, P., CD36 involvement in orosensory detection of dietary lipids, spontaneous fat preference, and digestive secretions. J Clin Invest 2005, 115, (11), 3177-84.

111. Gaillard, D.; Laugerette, F.; Darcel, N.; El-Yassimi, A.; Passilly-Degrace, P.; Hichami, A.; Khan, N. A.; Montmayeur, J. P.; Besnard, P., The gustatory pathway is involved in CD36mediated orosensory perception of long-chain fatty acids in the mouse. Faseb J 2008, 22, (5), 1458-68.

112. Ibrahimi, A.; Sfeir, Z.; Magharaie, H.; Amri, E. Z.; Grimaldi, P.; Abumrad, N. A., Expression of the CD36 homolog (FAT) in fibroblast cells: effects on fatty acid transport. Proc Natl Acad Sci USA 1996, 93, (7), 2646-51.

113. Nickerson, J. G.; Alkhateeb, H.; Benton, C. R.; Lally, J.; Nickerson, J.; Han, X. X.; Wilson, M. H.; Jain, S. S.; Snook, L. A.; Glatz, J. F.; Chabowski, A.; Luiken, J. J.; Bonen, A., Greater transport efficiencies of the membrane fatty acid transporters FAT/CD36 and FATP4 compared with FABPpm and FATPI and differential effects on fatty acid esterification and oxidation in rat skeletal muscle. J Biol Chem 2009, 284, (24), 16522-30.

114. Eyre, N. S.; Cleland, L. G.; Mayrhofer, G., FAT/CD36 expression alone is insufficient to enhance cellular uptake of oleate. Biochem Biophys Res Commun 2008, 370, (3), 404-9.

115. Eda, S.; Eda, K.; Prudhomme, J. G.; Sherman, I. W., Inhibitory activity of human lactoferrin and its peptide on chondroitin sulfate $A_{-}, C D_{36-}$, and thrombospondin-mediated cytoadherence of plasmodium falciparum-infected erythrocytes. Blood 1999, 94, (1), 32632.

116. Baruch, D. I.; Ma, X. C.; Pasloske, B.; Howard, R. J.; Miller, L. H., CD36 peptides that block cytoadherence define the CD36 binding region for Plasmodium falciparum-infected erythrocytes. Blood 1999, 94, (6), 2121-7.

117. Aitman, T. J.; Glazier, A. M.; Wallace, C. A.; Cooper, L. D.; Norsworthy, P. J.; Wahid, F. N.; Al-Majali, K. M.; Trembling, P. M.; Mann, C. J.; Shoulders, C. C.; Graf, D.; St Lezin, E.; Kurtz, T. W.; Kren, V.; Pravenec, M.; Ibrahimi, A.; Abumrad, N. A.; Stanton, L. W.; Scott, J., Identification of CD36 (Fat) as an insulin-resistance gene causing defective fatty acid and glucose metabolism in hypertensive rats. Nat Genet 1999, 21, (1), 76-83. 
118. Englyst, N. A.; Taube, J. M.; Aitman, T. J.; Baglin, T. P.; Byrne, C. D., A novel role for CD36 in VLDL-enhanced platelet activation. Diabetes 2003, 52, (5), 1248-55.

119. Pravenec, M.; Zidek, V.; Simakova, M.; Kren, V.; Krenova, D.; Horky, K.; Jachymova, M.; Mikova, B.; Kazdova, L.; Aitman, T. J.; Churchill, P. C.; Webb, R. C.; Hingarh, N. H.; Yang, Y.; Wang, J. M.; Lezin, E. M.; Kurtz, T. W., Genetics of CD36 and the clustering of multiple cardiovascular risk factors in spontaneous hypertension. J Clin Invest 1999, 103, (12), 1651-7.

120. Goudriaan, J. R.; Dahlmans, V. E.; Febbraio, M.; Teusink, B.; Romijn, J. A.; Havekes, L. M.; Voshol, P. J., Intestinal lipid absorption is not affected in CD36 deficient mice. Mol Cell Biochem 2002, 239, (1-2), 199-202.

121. Bonen, A.; Han, X. X.; Habets, D. D.; Febbraio, M.; Glatz, J. F.; Luiken, J. J., A null mutation in skeletal muscle FAT/CD36 reveals its essential role in insulin- and AICARstimulated fatty acid metabolism. Am J Physiol 2007, 292, (6), El740-9.

122. Febbraio, M.; Abumrad, N. A.; Hajjar, D. P.; Sharma, K.; Cheng, W.; Pearce, S. F.; Silverstein, R. L., A null mutation in murine CD36 reveals an important role in fatty acid and lipoprotein metabolism. J Biol Chem 1999, 274, (27), 19055-62.

123. Guy, E.; Kuchibhotla, S.; Silverstein, R.; Febbraio, M., Continued inhibition of atherosclerotic lesion development in long term western diet fed $\mathrm{CD} 36^{-/} / \mathrm{apo}^{-/}$mice. Atherosclerosis 2007, 192, (1), 123-30.

124. Lipsky, R. H.; Ikeda, H.; Medved, E. S., A dinucleotide repeat in the third intron of CD36. Hum Mol Genet 1994, 3, (1), 217.

125. Kashiwagi, H.; Tomiyama, Y.; Kosugi, S.; Shiraga, M.; Lipsky, R. H.; Nagao, N.; Kanakura, Y.; Kurata, Y.; Matsuzawa, Y., Family studies of type II CD36 deficient subjects: linkage of a CD36 allele to a platelet-specific mRNA expression defect(s) causing type II CD36 deficiency. Thromb Haemost 1995, 74, (2), 758-63.

126. Kashiwagi, H.; Tomiyama, Y.; Nozaki, S.; Kiyoi, T.; Tadokoro, S.; Matsumoto, K.; Honda, S.; Kosugi, S.; Kurata, Y.; Matsuzawa, Y., Analyses of genetic abnormalities in type I CD36 deficiency in Japan: identification and cell biological characterization of two novel mutations that cause CD36 deficiency in man. Hum Genet 2001, 108, (6), 459-66.

127. Hanawa, H.; Watanabe, K.; Nakamura, T.; Ogawa, Y.; Toba, K.; Fuse, I.; Kodama, M.; Kato, K.; Fuse, K.; Aizawa, Y., Identification of cryptic splice site, exon skipping, and novel point mutations in type I CD36 deficiency. J Med Genet 2002, 39, (4), 286-91.

128. Imai, M.; Tanaka, T.; Kintaka, T.; Ikemoto, T.; Shimizu, A.; Kitaura, Y., Genomic heterogeneity of type II CD36 deficiency. Clin Chim Acta 2002, 321, (1-2), 97-106.

129. Kashiwagi, H.; Tomiyama, Y.; Kosugi, S.; Shiraga, M.; Lipsky, R. H.; Kanayama, Y.; Kurata, Y.; Matsuzawa, Y., Identification of molecular defects in a subject with type I CD36 deficiency. Blood 1994, 83, (12), 3545-52.

130. Yamamoto, N.; Akamatsu, N.; Sakuraba, H.; Yamazaki, H.; Tanoue, K., Platelet glycoprotein IV (CD36) deficiency is associated with the absence (type I) or the presence (type II) of glycoprotein IV on monocytes. Blood 1994, 83, (2), 392-7.

131. Fukuchi, K.; Nozaki, S.; Yoshizumi, T.; Hasegawa, S.; Uehara, T.; Nakagawa, T.; Kobayashi, T.; Tomiyama, Y.; Yamashita, S.; Matsuzawa, Y.; Nishimura, T., Enhanced myocardial glucose use in patients with a deficiency in long-chain fatty acid transport (CD36 deficiency). J Nucl Med 1999, 40, (2), 239-43.

132. Hirano, K.; Kuwasako, T.; Nakagawa-Toyama, Y.; Janabi, M.; Yamashita, S.; Matsuzawa, Y., Pathophysiology of human genetic CD36 deficiency. Trends Cardiovasc Med 2003, 13, (4), 136-41.

133. Yamamoto, N.; Ikeda, H.; Tandon, N. N.; Herman, J.; Tomiyama, Y.; Mitani, T.; Sekiguchi, S.; Lipsky, R.; Kralisz, U.; Jamieson, G. A., A platelet membrane glycoprotein (GP) deficiency in healthy blood donors: Naka- platelets lack detectable GPIV (CD36). Blood 1990, 76, (9), 1698-703. 
134. Watanabe, K.; Ohta, Y.; Toba, K.; Ogawa, Y.; Hanawa, H.; Hirokawa, Y.; Kodama, M.; Tanabe, N.; Hirono, S.; Ohkura, Y.; Nakamura, Y.; Kato, K.; Aizawa, Y.; Fuse, I.; Miyajima, S.; Kusano, Y.; Nagamoto, T.; Hasegawa, G.; Naito, M., Myocardial CD36 expression and fatty acid accumulation in patients with type I and II CD36 deficiency. Ann Nucl Med 1998, $12,(5), 261-6$.

135. Teraguchi, M.; Ikemoto, Y.; Unishi, G.; Ohkohchi, H.; Kobayashi, Y., Influence of CD36 deficiency on heart disease in children. Circ J 2004, 68, (5), 435-8.

136. Yanai, H.; Chiba, H.; Morimoto, M.; Abe, K.; Fujiwara, H.; Fuda, H.; Hui, S. P.; Takahashi, Y.; Akita, H.; Jamieson, G. A.; Kobayashi, K.; Matsuno, K., Human CD36 deficiency is associated with elevation in low-density lipoprotein-cholesterol. Am J Med Genet 2000, 93 (4), 299-304.

137. Miyaoka, K.; Kuwasako, T.; Hirano, K.; Nozaki, S.; Yamashita, S.; Matsuzawa, Y., CD36 deficiency associated with insulin resistance. Lancet 2001, 357, (9257), 686-7.

138. Kamiya, M.; Nakagomi, A.; Tokita, Y.; Yasutake, M.; Kusama, Y.; Takayama, M.; Takano, T., Type I CD36 deficiency associated with metabolic syndrome and vasospastic angina: a case report. J Cardiol 2006, 48, (1), 41-4.

139. Chen, M.; Yang, Y.; Braunstein, E.; Georgeson, K. E.; Harmon, C. M., Gut expression and regulation of $F A T / C D 36$ : possible role in fatty acid transport in rat enterocytes. Am $\mathrm{J}$ Physiol 2001, 281, (5), E916-23.

140. Nassir, F.; Wilson, B.; Han, X.; Gross, R. W.; Abumrad, N. A., CD36 is important for fatty acid and cholesterol uptake by the proximal but not distal intestine. J Biol Chem 2007, 282, (27), 19493-501.

141. Drover, V. A.; Ajmal, M.; Nassir, F.; Davidson, N. 0.; Nauli, A. M.; Sahoo, D.; Tso, P.; Abumrad, N. A., CD36 deficiency impairs intestinal lipid secretion and clearance of chylomicrons from the blood. J Clin Invest 2005, 115, (5), 1290-7.

142. Bonen, A.; Tandon, N. N.; Glatz, J. F.; Luiken, J. J.; Heigenhauser, G. J., The fatty acid transporter FAT/CD36 is upregulated in subcutaneous and visceral adipose tissues in human obesity and type 2 diabetes. Int J Obes 2006, 30, (6), 877-83.

143. Koonen, D. P.; Jacobs, R. L.; Febbraio, M.; Young, M. E.; Soltys, C. L.; Ong, H.; Vance, D. E.; Dyck, J. R., Increased hepatic CD36 expression contributes to dyslipidemia associated with diet-induced obesity. Diabetes 2007, 56, (12), 2863-71.

144. Luiken, J. J.; Coort, S. L.; Koonen, D. P.; Bonen, A.; Glatz, J. F., Signalling components involved in contraction-inducible substrate uptake into cardiac myocytes. Proc Nutr Soc 2004, 63, (2), 251-8.

145. Hajri, T.; Han, X. X.; Bonen, A.; Abumrad, N. A., Defective fatty acid uptake modulates insulin responsiveness and metabolic responses to diet in CD36-null mice. $\mathrm{J}$ Clin Invest 2002, 109, (10), 1381-9.

146. Handberg, A.; Levin, K.; Hojlund, K.; Beck-Nielsen, H., Identification of the oxidized lowdensity lipoprotein scavenger receptor CD36 in plasma: a novel marker of insulin resistance. Circulation 2006, 114, (11), 1169-76.

147. Glintborg, D.; Hojlund, K.; Andersen, M.; Henriksen, J. E.; Beck-Nielsen, H.; Handberg, A., Soluble CD36 and risk markers of insulin resistance and atherosclerosis are elevated in polycystic ovary syndrome and significantly reduced during pioglitazone treatment. Diabetes Care 2008, 31, (2), 328-34.

148. Handberg, A.; Lopez-Bermejo, A.; Bassols, J.; Vendrell, J.; Ricart, W.; Fernandez-Real, J. M., Circulating soluble CD36 is associated with glucose metabolism and interleukin-6 in glucose-intolerant men. Diab Vasc Dis Res 2009, 6, (1), 15-20.

149. Handberg, A.; Norberg, M.; Stenlund, H.; Hallmans, G.; Attermann, J.; Eriksson, J. W., Soluble CD36 (sCD36) clusters with markers of insulin resistance, and high sCD36 is associated with increased type 2 diabetes risk. J Clin Endocrinol Metab 2010, 95, (4), $1939-46$ 
150. Jimenez-Dalmaroni, M. J.; Xiao, N.; Corper, A. L.; Verdino, P.; Ainge, G. D.; Larsen, D. S.; Painter, G. F.; Rudd, P. M.; Dwek, R. A.; Hoebe, K.; Beutler, B.; Wilson, I. A., Soluble CD36 ectodomain binds negatively charged diacylglycerol ligands and acts as a co-receptor for TLR2. Plos One 2009, 4, (10), e7411.

151. Podrez, E. A.; Poliakov, E.; Shen, Z.; Zhang, R.; Deng, Y.; Sun, M.; Finton, P. J.; Shan, L.; Febbraio, M.; Hajjar, D. P.; Silverstein, R. L.; Hoff, H. F.; Salomon, R. G.; Hazen, S. L., A novel family of atherogenic oxidized phospholipids promotes macrophage foam cell formation via the scavenger receptor CD36 and is enriched in atherosclerotic lesions. J Biol Chem 2002, 277, (41), 38517-23.

152. D’Archivio, M.; Scazzocchio, B.; Filesi, C.; Vari, R.; Maggiorella, M. T.; Sernicola, L.; Santangelo, C.; Giovannini, C.; Masella, R., Oxidized LDL up-regulates CD36 expression by the Nrf2 pathway in 3T3-L1 preadipocytes. FEBS Lett 2008, 582, (15), 2291-8.

153. Rahaman, S. 0.; Lennon, D. J.; Febbraio, M.; Podrez, E. A.; Hazen, S. L.; Silverstein, R. L., A CD36-dependent signaling cascade is necessary for macrophage foam cell formation. Cell Metab 2006, 4, (3), 211-21.

154. Katayama, I.; Hotokezaka, Y.; Matsuyama, T.; Sumi, T.; Nakamura, T., Ionizing radiation induces macrophage foam cell formation and aggregation through JNK-dependent activation of CD36 scavenger receptors. Int J Radiat Oncol Biol Phys 2008, 70, (3), 835-46.

155. Kennedy, D. J.; Kuchibhotla, S. D.; Guy, E.; Park, Y. M.; Nimako, G.; Vanegas, D.; Morton, R. E.; Febbraio, M., Dietary cholesterol plays a role in CD36-mediated atherogenesis in LDLR-knockout mice. Arterioscler Thromb Vasc Biol 2009, 29, (10), 1481-7.

156. Martin-Fuentes, P.; Civeira, F.; Recalde, D.; Garcia-Otin, A. L.; Jarauta, E.; Marzo, I.; Cenarro, A., Individual variation of scavenger receptor expression in human macrophages with oxidized low-density lipoprotein is associated with a differential inflammatory response. J Immunol 2007, 179, (5), 3242-8.

157. Silverstein, R. L., Inflammation, atherosclerosis, and arterial thrombosis: role of the scavenger receptor CD36. Cleve Clin J Med 2009, 76, S27-30.

158. Nagarajan, S., Anti-oxLDL IgG blocks oxLDL interaction with CD36, but promotes FcgammaR, CD32A-dependent inflammatory cell adhesion. Immunol Lett 2007, 108, (1), 52-61.

159. Harb, D.; Bujold, K.; Febbraio, M.; Sirois, M. G.; Ong, H.; Marleau, S., The role of the scavenger receptor $\mathrm{CD} 36$ in regulating mononuclear phagocyte trafficking to atherosclerotic lesions and vascular inflammation. Cardiovasc Res 2009, 83, (1), 42-51.

160. Cho, S.; Park, E. M.; Febbraio, M.; Anrather, J.; Park, L.; Racchumi, G.; Silverstein, R. L.; Iadecola, C., The class B scavenger receptor CD36 mediates free radical production and tissue injury in cerebral ischemia. J Neurosci 2005, 25, (10), 2504-12.

161. Cho, S.; Szeto, H. H.; Kim, E.; Kim, H.; Tolhurst, A. T.; Pinto, J. T., A novel cell-permeable antioxidant peptide, SS31, attenuates ischemic brain injury by down-regulating CD36. J Biol Chem 2007, 282, (7), 4634-42.

162. Kim, E.; Tolhurst, A. T.; Qin, L. Y.; Chen, X. Y.; Febbraio, M.; Cho, S., CD36/fatty acid translocase, an inflammatory mediator, is involved in hyperlipidemia-induced exacerbation in ischemic brain injury. J Neurosci 2008, 28, (18), 4661-70.

163. Bochkov, V. N.; Mechtcheriakova, D.; Lucerna, M.; Huber, J.; Malli, R.; Graier, W. F.; Hofer, E.; Binder, B. R.; Leitinger, N., Oxidized phospholipids stimulate tissue factor expression in human endothelial cells via activation of ERK/EGR-1 and $\mathrm{Ca}^{2+} /$ NFAT. Blood 2002, 99, (1), 199-206.

164. Barnwell, J. W.; Asch, A. S.; Nachman, R. L.; Yamaya, M.; Aikawa, M.; Ingravallo, P., A human 88-kD membrane glycoprotein (CD36) functions in vitro as a receptor for a cytoadherence ligand on Plasmodium falciparum-infected erythrocytes. J Clin Invest 1989, 84, (3), 765-72.

165. Cserti-Gazdewich, C. M.; Dzik, W. H.; Dorn, M. E.; Quagliaroli, R. O.; Xu, S.; Ssewanyana, 
I.; Nayyar, R.; Preffer, F. I., Quantitation of CD36 (platelet glycoprotein IV) expression on platelets and monocytes by flow cytometry: application to the study of Plasmodium falciparum malaria. Cytometry B Clin Cytom 2009, 76, (2), 127-34.

166. Isenberg, J. S.; Calzada, M. J.; Zhou, L.; Guo, N.; Lawler, J.; Wang, X. Q.; Frazier, W. A.; Roberts, D. D., Endogenous thrombospondin-1 is not necessary for proliferation but is permissive for vascular smooth muscle cell responses to platelet-derived growth factor. Matrix Biol 2005, 24, (2), 110-23.

167. Xu, X.; Pang, J.; Yin, H.; Li, M.; Hao, W.; Chen, C.; Cao, J. M., Hexarelin suppresses cardiac fibroblast proliferation and collagen synthesis in rat. Am J Physiol 2007, 293, (5), H2952-8.

168. Brinkmann, J. F.; Abumrad, N. A.; Ibrahimi, A.; van der Vusse, G. J.; Glatz, J. F., New insights into long-chain fatty acid uptake by heart muscle: a crucial role for fatty acid translocase/CD36. Biochem J 2002, 367, (Pt 3), 561-70.

169. Kontrova, K.; Zidkova, J.; Bartos, B.; Skop, V.; Sajdok, J.; Kazdova, L.; Mikulik, K.; Mlejnek, P.; Zidek, V.; Pravenec, M., CD36 regulates fatty acid composition and sensitivity to insulin in 3T3-LI adipocytes. Physiol Res 2007, 56, (4), 493-6.

170. Unno, Y.; Sakai, M.; Sakamoto, Y.; Kuniyasu, A.; Nagai, R.; Nakayama, H.; Horiuchi, S., Glycolaldehyde-modified bovine serum albumin downregulates leptin expression in mouse adipocytes via a CD36-mediated pathway. Ann N Y Acad Sci 2005, 1043, 696-701.

171. Unno, Y.; Sakai, M.; Sakamoto, Y.; Kuniyasu, A.; Nakayama, H.; Nagai, R.; Horiuchi, S., Advanced glycation end products-modified proteins and oxidized LDL mediate downregulation of leptin in mouse adipocytes via CD36. Biochem Biophys Res Commun 2004, 325, (1), 151-6.

172. Bokor, S.; Legry, V.; Meirhaeghe, A.; Ruiz, J. R.; Mauro, B.; Widhalm, K.; Manios, Y.; Amouyel, P.; Moreno, L. A.; Molnar, D.; Dallongeville, J., Single-nucleotide polymorphism of CD36 locus and obesity in European adolescents. Obesity (Silver Spring) 2009, 18, (7), 1398-403.

173. Wieclawska, B.; Rozalski, M.; Trojanowski, Z.; Watala, C., Modulators of intraplatelet calcium concentration affect the binding of thrombospondin to blood platelets in healthy donors and patients with type 2 diabetes mellitus. Eur J Haematol 2001, 66, (6), 396-403.

174. Huang, M. M.; Bolen, J. B.; Barnwell, J. W.; Shattil, S. J.; Brugge, J. S., Membrane glycoprotein IV (CD36) is physically associated with the Fyn, Lyn, and Yes protein-tyrosine kinases in human platelets. Proc Natl Acad Sci USA 1991, 88, (17), 7844-8.

175. Dorahy, D. J.; Lincz, L. F.; Meldrum, C. J.; Burns, G. F., Biochemical isolation of a membrane microdomain from resting platelets highly enriched in the plasma membrane glycoprotein CD36. Biochem J 1996, 319, 67-72.

176. Hirao, A.; Hamaguchi, I.; Suda, T.; Yamaguchi, N., Translocation of the Csk homologous kinase (Chk/Hyl) controls activity of CD36-anchored Lyn tyrosine kinase in thrombinstimulated platelets. Embo J 1997, 16, (9), 2342-51.

177. Hoebe, K.; Georgel, P.; Rutschmann, S.; Du, X.; Mudd, S.; Crozat, K.; Sovath, S.; Shamel, L.; Hartung, T.; Zahringer, U.; Beutler, B., CD36 is a sensor of diacylglycerides. Nature $2005,433,(7025), 523-7$. 



\section{CHAPTER 3}

\section{Signaling role of CD36 in platelet}

activation and thrombus formation on immobilized thrombospondin or oxidized LDL

Reyhan Nergiz-Unal, Moniek M.E. Lamers, Roger van Kruchten, Joost J. F.P. Luiken, Judith M.E.M. Cosemans, Jan F.C. Glatz, Marijke J.E. Kuijpers, Johan W.M. Heemskerk 


\title{
Signaling role of CD36 in platelet activation and thrombus formation on immobilized thrombospondin or oxidized LDL
}

\begin{abstract}
Platelets express high levels of glycoprotein CD36. Thrombospondin-1 (TSP1) and oxidized low density lipoprotein (oxLDL) are known ligands, yet the function of CD36 in platelet activation is still poorly understood. We assessed that TSPI and oxLDL caused limited activation of platelets in suspension. However, immobilized TSPI and OXLDL, but not LDL, provoked platelet adhesion and spreading with a major role of CD36. The spreading was accompanied by potent $\mathrm{Ca}^{2+}$ fluxes, and resulted in exposure of $\mathrm{P}$-selectin and phosphatidylserine, all in a CD36-dependent manner with additional contributions of $\alpha_{\mathrm{IIb}} \beta_{3}$ integrins and ADP receptor stimulation. Platelet adhesion and spreading on immobilized TSP1 and OxLDL via CD36 strongly relied on activation of Src family and Syk protein kinases. In whole blood perfusion, immobilization of TSPI or oxLDL with collagen enhanced the formation of thrombi at high-shear flow, with platelets expressing activated $\alpha_{\mathrm{IIb}} \beta_{31}$ P-selectin and phosphatidylserine, again in a CD36-dependent way. It is concluded that surface-bound TSPI and oxLDL activate platelets partly via CD36 through a Syk kinase-dependent $\mathrm{Ca}^{2+}$-signaling pathway, which enhances collagendependent thrombus formation under flow. This provides novel insight into the role of CD36 in hemostasis.
\end{abstract}




\section{Introduction}

The 80-90 kDa protein CD36, or glycoprotein (GP)IV, is a major platelet glycoprotein with 10,000-25,000 copies expressed on the plasma membrane surface and additional copies present in the $\alpha$-granules ${ }^{1,2}$. CD36 is a double membrane-spanning protein with two short $\mathrm{N}$ - and $\mathrm{C}$-terminal cytoplasmic domains and a large glycosylated extracellular domain with recognized binding sites for thrombospondin-1 (TSP1), oxidized lowdensity lipoproteins (oxLDL), oxidized forms of phospholipids and long-chain fatty acids $^{3,4}$. Most or all CD36 ligands are considered to bind at or near the CLESH-1

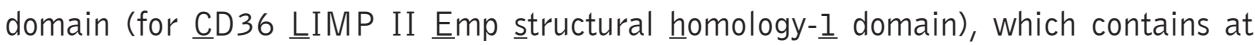
least two consensus glycosylation sites and is located next to the proline- and cysteinrich domain, determining the conformation of the large extracellular loop ${ }^{5}$.

In spite of its abundant presence, the function of platelet CD36 is still unclear. Earlier, CD36 was considered to be a collagen receptor ${ }^{6,7}$, but platelets from CD36-deficient patients have normal collagen-induced activation responses ${ }^{8-10}$. Peptide studies pointed to a role of CD36 in binding TSP1 to platelets and other cells ${ }^{11,12}$. This is considered to be relevant for platelet activation, since TSPI like CD36 is expressed in the $\alpha$-granules and hence may act as autocrine mediator ${ }^{13,14}$. On the other hand, TSPI recognizes in a $\mathrm{Ca}^{2+}$-dependent way other membrane proteins, including integrins, integrin-associated protein (CD47), and GPIb ${ }^{15-17}$. As a scavenging protein in macrophages, CD36 acts as receptor for $0 x L D L$ and oxidized phospholipids ${ }^{18,19}$. In platelets, an activating and signaling role of oxLDL-CD36 binding is reported, next to that of other scavenger receptors like SR-A ${ }^{20,21}$.

Binding of $0 x L D L$ to platelets and other cells triggers signal transduction, but the precise role herein of CD36 is still a matter of debate ${ }^{3,5}$. In platelets, oxLDL induces or enhances activation of Src family and Syk kinases, accompanied by $\mathrm{Ca}^{2+}$ entry, which events have been attributed to lysophosphatidate receptor activation ${ }^{22}$. In various cell types, interaction of oxLDL with CD36 activates members of the mitogen-activated protein kinase family (MAPK: Erk2, p38, JNK) 20,23. Also TSPI binding to platelets leads to signal transduction. For instance, thrombospondin peptides evoke in part integrin $\alpha_{\mathrm{IIb}} \beta_{3}$-independent signaling via Src kinases, LAT, Syk and phospholipase $\mathrm{C} \gamma 2^{24,25}$. Under shear conditions, TSP1-CD36 interaction can activate platelets via GPIb and hence complement von Willebrand factor-dependent platelet tethering ${ }^{17,26}$. Another report proposes that TSPI binding reverses platelet inhibition by nitric oxide ${ }^{27}$. Yet, TSPI may also act on platelets independently of CD36 ${ }^{28}$. In sum, while oxLDL and TSPI seem to activate platelets in different ways, there is a similarity in the triggering of protein tyrosine kinases, perhaps via CD36.

In the present paper, we investigated the alleged roles of TSPI and $0 x L D L$ as CD36 ligands. We describe that each can strongly activate platelets via CD36, when immobilized on a surface, thus triggering a classical mechanism of outside-in signal transduction by CD36-mediated adhesion. The activation involved both protein tyrosine kinases, $\mathrm{Ca}^{2+}$ fluxes and autocrine feed-forward loops relying on ADP receptors. 


\section{Materials and Methods}

\section{Materials}

Native LDL, freshly isolated from human plasma (Intracel, Frederick, MD, USA) was processed and used within 2 weeks. Human trimeric, platelet-derived TSP1, PP1, PP2, PP3, Src-family kinase (SFK) inhibitor I, and Syk inhibitors II and IV were from Merck (Darmstadt, G). Human fibrinogen, bovine serum albumin (BSA) and fucoidan from Fucus vesiculosus were from Sigma (St Louis, MO, USA); H-Phe-Pro-Arg chloromethyl ketone (PPACK) from Calbiochem (La Jolla, CA, USA). Low molecular weight heparin (fragmin) was from Pfızer. The $\mathrm{P}_{2 \mathrm{Y}_{12}}$ receptor antagonist, cangrelor (AR-C69931MX) was kindly provided by the Medicines Company (Parsippany, NJ, USA). Fibrillar Horm type I collagen was from Nycomed Pharma (Munich, G); annexin A5 labeled with fluorescein isothiocyanate (FITC) from PharmaTarget (Maastricht, the Netherlands). Human fibrinogen labeled with Oregon green (OG)488, annexin A5 labeled with Alexa Fluor (AF)647, pluronic F-127, dimethyl BAPTA and Fluo-4 acetoxymethyl esters came from Invitrogen (Leiden, the Netherlands). Anti-human CD36 mAb FA6-152, directed against the TSPI and oxLDL binding site, was from Santa Cruz Biotechnology (Santa Cruz, CA, USA); human IgGI isotype control from Genway Biotech (San Diego, Ca, USA). CD36 peptide $\mathrm{P}(93-110)$ and thrombin receptor-activating peptide SFLLRN were from Bachem (Bubendorf, Switzerland). FITC-labeled anti-CD62 mAb was from Immunotech (Marseille, France); FITC-PACl mAb from BD Biosciences (San Jose, CA, USA); anti-phosphotyrosine MAb 4G10 from Upstate (Billerica, MA, USA); rabbit polyclonal anti- $\alpha$-tubulin Ab from Abcam (Cambridge, UK); and HRP-conjugated IgG ECL Ab from GE Healthcare (Hoevelaken, the Netherlands). Other materials were from sources as described ${ }^{29}$.

\section{Blood collection and platelet preparation}

Donors gave full informed consent according to the Helsinki declaration, and had not taken medication for 2 weeks. Blood was collected into acid citrate dextrose $(85 \mathrm{mM}$ trisodium citrate, $67 \mathrm{mM}$ glucose, $42 \mathrm{mM}$ citric acid) to prepare platelet-rich plasma and washed platelets. For flow perfusion experiments, blood was collected into $40 \mu \mathrm{M}$ PPACK and $20 \mathrm{U} \mathrm{mL}^{-1}$ fragmin; additional $10 \mu \mathrm{M}$ PPACK was added after $1 \mathrm{~h}^{30}$. Washed platelets were resuspended in Hepes buffer pH 7.45 (10 mM Hepes, 136 mM $\mathrm{NaCl}, 2.7 \mathrm{mM} \mathrm{KCl}, 2 \mathrm{mM} \mathrm{MgCl}, 0.42 \mathrm{mM}$ glucose and $0.1 \% \mathrm{BSA}$ ) in the presence

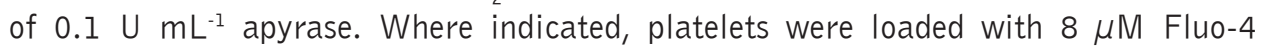
acetoxymethyl ester or $50 \mu \mathrm{M}$ dimethyl BAPTA acetoxymethyl ester in the presence of $0.4 \mathrm{mg} \mathrm{mL}^{-1}$ pluronic F-12731.

\section{LDL oxidation}

Native LDL ( $1.0 \mathrm{~g} \mathrm{~mL}^{-1}$ ) was dialyzed against phosphate-buffered saline at $4{ }^{\circ} \mathrm{C}$, and oxidized under controlled conditions, as described elsewhere ${ }^{32}$. Briefly, LDL was treated with $25 \mu \mathrm{M} \mathrm{CuSO}_{4}$ at $37{ }^{\circ} \mathrm{C}$ during $8 \mathrm{~h}$, after which oxidation was stopped with $50 \mu \mathrm{M}$ EDTA. Preparations were immediately dialyzed against phosphate-buffered saline with 
$10 \mu \mathrm{M}$ EDTA $\left(4^{\circ} \mathrm{C}\right)$, and were checked for oxidation by $1 \%$ agarose gel electrophoresis. Used preparations had a relative electrophoretic mobility versus LDL of $\sim 3.5$ and were oxidized for about $90 \%$. Storage was for a maximum of 2 weeks under $\mathrm{N}_{2}$ at $4{ }^{\circ} \mathrm{C}$. Overoxidized preparations were not used. For specific experiments, native LDL was oxidized for 48-72 $\mathrm{h}$ with $5 \mu \mathrm{M} \mathrm{FeSO}$ at $4{ }^{\circ} \mathrm{C}$, and dialyzed as described ${ }^{33}$.

\section{Flow cytometry}

Washed platelets $\left(2 \times 10^{8} \mathrm{~mL}^{-1}\right)$ in Hepes buffer with $2 \mathrm{mM} \mathrm{CaCl}$ were activated with ADP or SFLLRN in the presence or absence of TSPI $\left(2.5 \mu \mathrm{g} \mathrm{mL}^{-1}\right)$ or oxLDL (250 $\mu \mathrm{g} \mathrm{mL} \mathrm{L}^{-1}$ ) without stirring. After $10 \mathrm{~min}$, activation of integrin $\alpha_{\mathrm{IIb}} \beta_{3}$ and $\alpha$-granule secretion was detected with OG488-fibrinogen (150 $\mathrm{g} \mathrm{mL}^{-1}$ ), and FITC-labeled antiCD62 mAb (1:50), respectively. Fluorescence was measured with a FACScan flow cytometer counting a minimum 10,000 events ${ }^{29}$.

\section{Platelet aggregation and adhesion}

Aggregation of platelets in plasma was determined by light transmission aggregometry ${ }^{34}$. For static adhesion assays, 96-well plates were $1 \mathrm{~h}$ coated with human fibrinogen, TSP 1 , or oxLDL (100 $\mu \mathrm{g} \mathrm{mL}^{-1}$ each), and then blocked with $1 \%$ BSA. Platelets $\left(1.5 \times 10^{8} \mathrm{~mL}^{-}\right.$ ${ }^{1}$ ) in Hepes buffer containing $2 \mathrm{mM} \mathrm{CaCl}_{2}$ were pretreated with indicated inhibitors for $10 \mathrm{~min}$, and allowed to adhere to coated wells for $45 \mathrm{~min}$. Non-adherent platelets were washed out, adherent platelets were solubilized with Triton X-100, and acid phosphatase activity was determined from the cleavage of $p$-nitrophenyl-phosphate at $405 \mathrm{~nm}$ using a microplate reader ${ }^{35}$. Adhered platelets per well were calculated by comparing with a platelet standard range.

\section{Spreading and activation responses of adhered platelets}

Glass coverslips were coated with fibrinogen, TSPI, LDL, or oxLDL $\left(100 \mu \mathrm{g} \mathrm{mL}^{-1}\right.$ each), and blocked with Hepes buffer containing 1\% BSA. The presence of coated proteins on coverslip surface was verified by immune-fluorescence microscopy. Blocked coverslips with BSA ( $1 \%$ ) were mounted in an open incubation chamber, and incubated with platelets $\left(1.5 \times 10^{8} \mathrm{~mL}^{-1}\right)$ in Hepes buffer containing $2 \mathrm{mM} \mathrm{CaCl}_{2}$ and inhibitors as indicated. Spreading of individual adhered platelets was monitored by real time capturing of microscopic brightfield contrast images ${ }^{36}$. Surface expression of activation markers on adhered platelets, i.e. P-selectin (FITC-anti-CD62 mAb), phosphatidylserine (AF647-annexin A5) and activated $\alpha_{\mathrm{II}} \beta_{3}$ integrin (FITC-PACl mAb) ${ }^{29}$, was measured by two-color confocal microscopy and differential interference contrast, using a Leica TCS SP5 multiphoton system (Rijswijk, the Netherlands). Images were analyzed with the software package Metamorph (MDS Analytical Technologies).

For measurement of single-cell $\mathrm{Ca}^{2+}$ responses during adhesion, coated coverslips were incubated with Fluo-4-loaded platelets $\left(5 \times 10^{7} \mathrm{~mL}^{-1}\right)$ in Hepes buffer with $2 \mathrm{mM}$ $\mathrm{CaCl}_{2}$. Fluorescence changes of adhering platelets were recorded in real-time at $5 \mathrm{~Hz}$ using a sensitive EM-CCD camera system, controlled by Visitech software (Sunderland, $(U K)^{34}$. Single cell traces of nanomolar $\mathrm{Ca}^{2+}$ concentrations were obtained by off-line 
analysis of selected regions-of-interest, representing one adhered platelet, and pseudoratio calibration ${ }^{37}$.

\section{Thrombus formation under flow}

Glass coverslips remained uncoated or were coated with fibrillar type I collagen, TSPI, LDL oxLDL, or combinations of these (all applied at $100 \mu \mathrm{g} \mathrm{mL}^{-1}$ ). For co-coatings, collagen was applied first ${ }^{30}$, and after fibrillation, TSP1, oxLDL or LDL was postcoated. The presence of TSPI or (ox) LDL in (co)coatings was confirmed by immunofluorescence microscopy. Coverslips were blocked with $1 \%$ BSA, and mounted into a transparent parallel-plate flow chamber (depth $50 \mu \mathrm{m}$, width $3 \mathrm{~mm}$ ) for whole blood flow experiments. PPACK/fragmin-anticoagulated blood was perfused at a shear rate of $1000 \mathrm{~s}^{-1}$, and microscopic brightfield and fluorescence images of thrombus formation were taken $^{36}$. Expression of activation markers on platelets in thrombi was analyzed with probes as described above and the Leica TCS SP5 multiphoton system.

\section{Gel electrophoresis and western blotting}

Tyrosine phosphorylation was measured by western blot analysis of platelet lysates. Surface-adhered platelets (BSA-free media) were lysed with ice-cold NP-40-based lysis buffer $\mathrm{pH} 7.45$ in the presence of protease and phosphatase inhibitors ${ }^{38}$. Protein in lysates was quantified with a BioRad DC protein kit. Samples with pre-established equal protein amounts were separated on 10\% SDS-PAGE gels, and transferred to blotting membranes by semi-dry transfer. Membranes were immunoblotted with $4 \mathrm{G} 10$ anti-phosphotyrosine mAb ( $1 \mu \mathrm{g} \mathrm{mL}^{-1}$ ) and secondary HRP-coupled sheep anti-mouse Ab (1:5000), using an ECL system ${ }^{29}$. Duplicate blots were stained with Ab against $\alpha$-tubulin ( $1 \mu \mathrm{g} \mathrm{mL}^{-1}$ ) as sample loading control. Analysis of antibody staining was by densitometry ${ }^{38}$.

\section{Statistical analysis}

Significance of differences was determined with a parametric t test or a non-parametric Mann-Whitney $U$ test, as required, using the statistical package for social sciences (SPSS 15.0 (SPSS, Chicago, IL, USA).

\section{Results}

\section{Role of CD36 in stable adhesion and spreading of platelets on immobilized TSP1 or OxLDL}

To elucidate the role of CD36 in platelet activation, suspensions of platelets were stimulated with of its two alleged ligands, TSPI and oxLDL. A commercial TSPI preparation was used isolated from human platelets, and oxLDL was freshly made from LDL by controlled oxidation ${ }^{32}$. Using flow cytometry, it was established that TSPl $\left(2.5 \mu \mathrm{g} \mathrm{mL} \mathrm{m}^{-1}\right)$ did not significantly influence ADP- or SFLLRN-induced integrin $\alpha_{\mathrm{IIb}} \beta_{3}$ activation or $\alpha$-granule secretion, measured as fibrinogen binding and $\mathrm{P}$-selectin expression, respectively (Figure 3.1A,B). On the other hand, oxLDL $(250 \mu \mathrm{g} \mathrm{mL}$ 
A
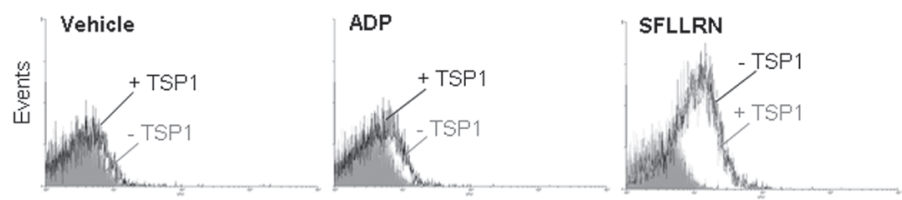

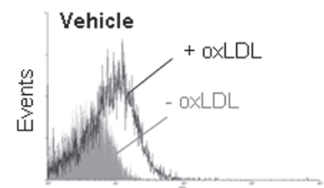

OG-fibrinogen (FL1)
ADP

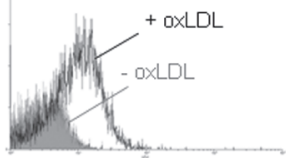

OG-fibrinogen (FL1)
SFLLRN

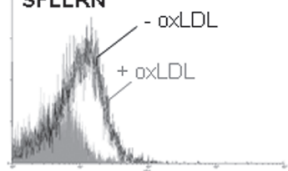

OG-fibrinogen (FL1)

\section{B}

TSP1
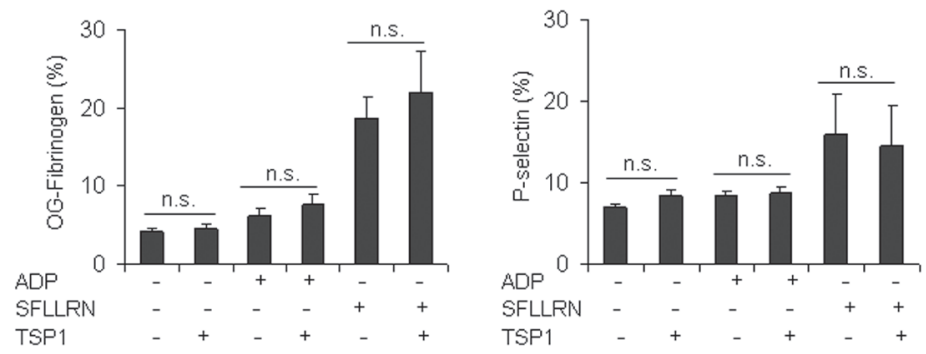

C

oxLDL
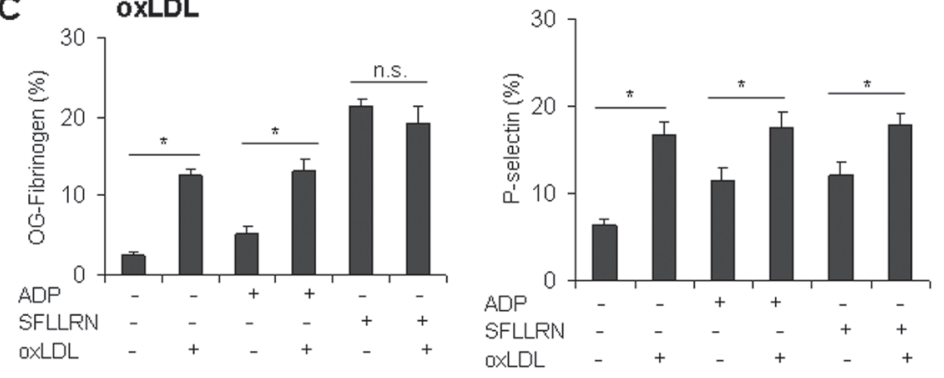

- Figure 3.1. Limited platelet activation by soluble oxLDL but not TSP1. Washed platelets were stimulated with low doses of ADP $(5 \mu \mathrm{M})$ or SFLLRN $(5 \mu \mathrm{M})$ in the presence or absence of TSP1 $\left(2.5 \mu \mathrm{g} \mathrm{mL}^{-1}\right)$ or oxLDL $(250 \mu \mathrm{g} \mathrm{mL}-1)$. After $10 \mathrm{~min}$, activation of $\alpha_{\mathrm{IIb}} \beta_{3}\left(\mathrm{OG} 488\right.$-fibrinogen, $\left.150 \mu \mathrm{g} \mathrm{mL}^{-1}\right)$ and expression of P-selectin (FITC-anti-CD62 mAb, 1:50) were assessed by flow cytometry. (A) Representative histograms of OG488-fibrinogen fluorescence after platelet stimulation. (B) Quantitative effect of TSP1 addition on $\alpha_{\mathrm{IIL}} \beta_{3}$ activation and P-selectin expression. (C) Quantitative effect of oxLDL on activation markers. Data are percentages of positive platelets. Means \pm S.E.M. $(n=3-6) ; * P<0.05 v s$. vehicle control.

1) moderately stimulated integrin activation and secretion, but did not enhance the activating effects of ADP and SFLLRN (Figure 3.1B,C). The blocking anti-CD36 mAb FA6-152 antagonized the effects caused by oxLDL (not shown, but see below). Together, these results confirmed the mild activating effect of oxidation-modified LDL on platelets in suspension via CD36 20,39 . 
Both TSPI and oxLDL deposit in the matrix of the (damaged) vessel wall ${ }^{13,40,41}$. Considering that surface-bound fibrinogen can activate platelets via outside-in $\alpha_{\text {IIb }} \beta_{3}$ signaling ${ }^{1}$, we evaluated whether also immobilized TSPI and 0 XDL can trigger such signaling via CD36. In a well-plate assay, it appeared that the coating of wells with fibrinogen, TSPI or oxLDL, but not native LDL, resulted in high stable platelet adhesion (Figure 3.2). The involvement of CD36 was demonstrated with two inhibitors used at maximally effective concentrations: the blocking FA6-152 mAb, directed against the TSPI and oxLDL binding site on CD36 ${ }^{42}$; and the CD36-derived peptide P(93-110), corresponding to theTSPI binding site and competing with CD36-TSP1 interaction ${ }^{11}$. Control measurements showed that neither FA6-152 mAb nor P(93-110) peptide affected platelet adhesion to fibrinogen (Figure 3.2A). However, both inhibitors substantially reduced adhesion to $T S P 1$, while only FA6-152 mAb interfered with adhesion to oxLDL, confirming the specificity of $\mathrm{P}(93-110)$ for TSPI binding. With both immobilized TSPI
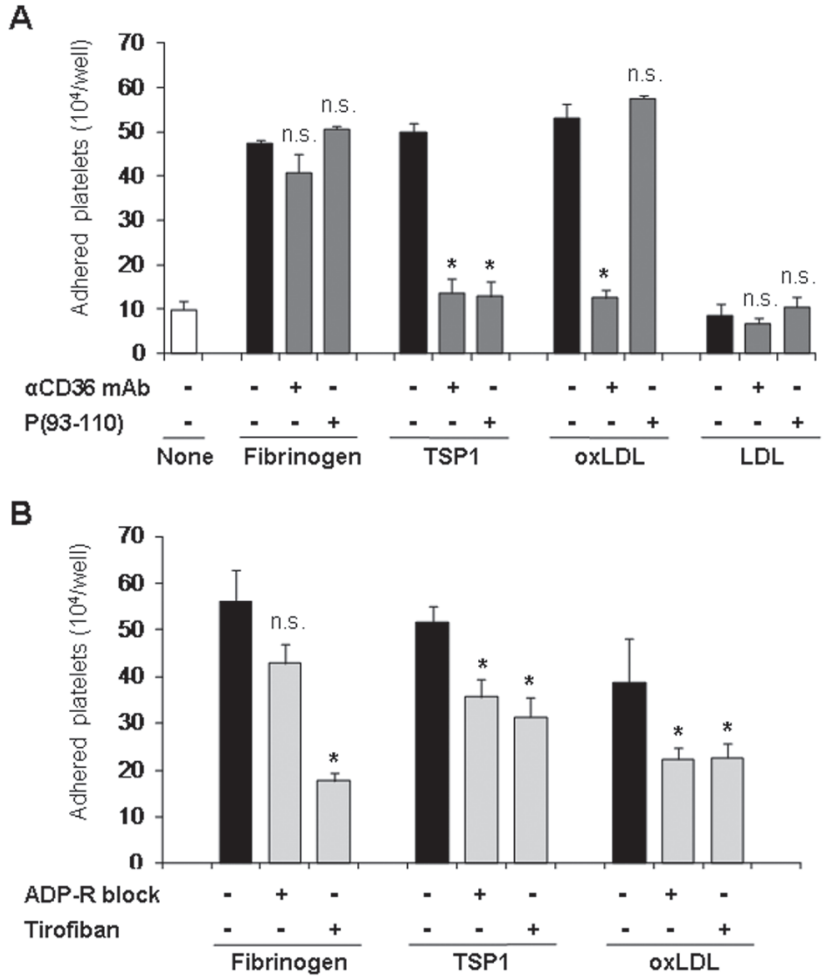

Figure 3.2. Roles of CD36 and ADP receptors in platelet adhesion to various immobilized ligands. Washed platelets were treated as indicated, and allowed to adhere to immobilized fibrinogen, TSP1, oxLDL or LDL in wells for $45 \mathrm{~min}$. After rinse to remove non-adherent platelets, remaining cells were lysed to measure acid phosphatase (relative absorbance at $405 \mathrm{~nm}$ ). Stably adhered platelets per well were determined from a platelet standard range. (A) Effect of platelet treatment with with vehicle buffer, FA6152 anti-CD36 mAb $\left(2 \mu \mathrm{g} \mathrm{mL}^{-1}\right)$ or CD36 peptide $\mathrm{P}(93-110)\left(50 \mu \mathrm{g} \mathrm{mL}^{-1}\right)$. (B) Effect of platelet treatment with ADP receptor blockers (10 $\mu \mathrm{M}$ cangrelor, $100 \mu \mathrm{M}$ MRS 2179) and/or tirofiban $\left(2 \mu \mathrm{g} \mathrm{mL}^{-1}\right)$. Means \pm S.E.M. (n=3), n.s., not significant, $* P<0.05$ vs. vehicle control. 
A Fibrinogen
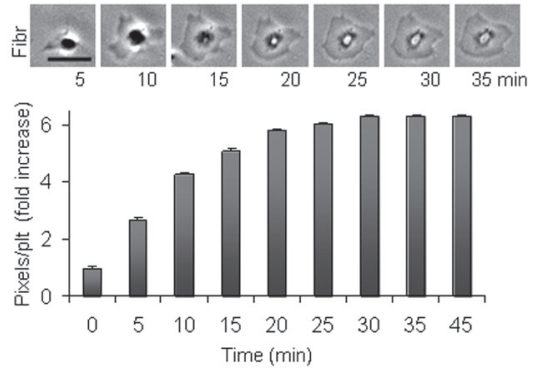

C oxLDL
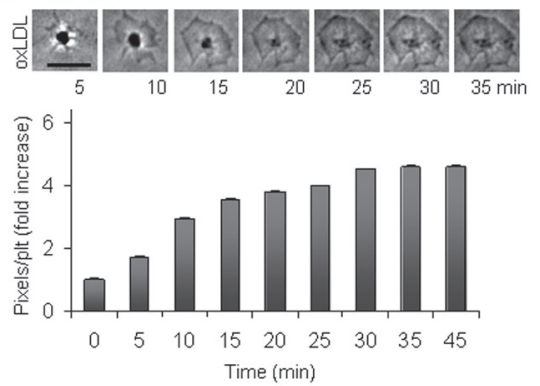

B TSP1
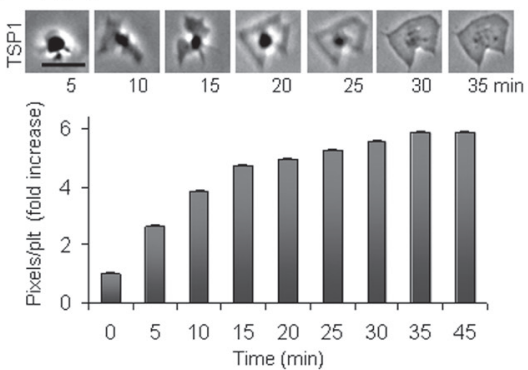

D LDL
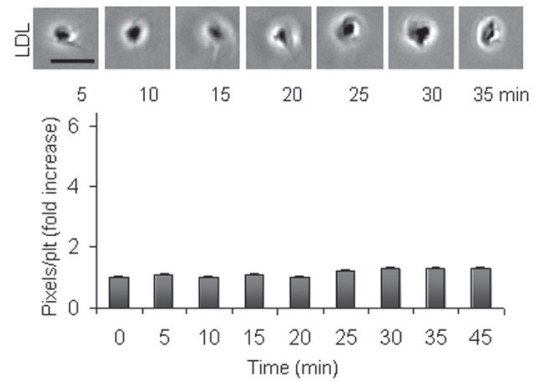

- Figure 3.3. Spreading of platelets on immobilized fibrinogen, TSP1 and oxLDL, but not on LDL, Washed platelets were allowed to adhere to surfaces coated with fibrinogen (A), TSP1 (B), oxLDL (C) or LDL (D) during $45 \mathrm{~min}$. Shown are microscopic phase contrast images from representative, single adhered platelets, captured at indicated time intervals (bars, $10 \mu \mathrm{m}$ ). Graphs give increased in surface area covered per platelet in time, expressed as fold increase in pixels. Means \pm S.E.M. ( $n=4-6$ experiments, 10 platelets/ experiment).

and $0 x L D L$, the adhesion was partly reduced by blocking of the platelet $P_{2} Y_{1}$ and $P 2 Y_{12}$ receptors (with MRS 2179 and AR-C69931MX, respectively) or by blocking of $\alpha_{\text {IIb }} \beta_{3}$ with tirofiban (Figure 3.2B). Tirofiban did not increase the effect of anti-CD36 mAb (not shown, but see below).

Time-lapse video microscopy was applied to monitor the morphological changes of platelets stably adhering to coated surfaces. In agreement with published data ${ }^{43,44}$, platelets on fibrinogen formed filopods and lamellipods, causing a $>6$ fold increase in surface area coverage completing in $45 \mathrm{~min}$ (Figure 3.3A). Strikingly, also platelets stably adhered to immobilized TSPI and oxLDL actively produced filopods and lamellipods (Figure 3.3B,C). In contrast platelet interaction with immobilized native $L D L$, as a control surface, did not result in stable adhesion nor provoked changes in morphology (Figure 3.3D).

The CD36 inhibitors, FA6-152 mAb and P(93-110) peptide, suppressed the extent of spreading of platelets on TSPI by $\sim 50 \%$, but only the antibody reduced the spreading on oxLDL by $70 \%$ (Figure 3.4A,B). Isotype control IgGl $\left(2 \mu \mathrm{g} \mathrm{mL}^{-1}\right)$ did not interfere with platelet spreading on TSPI or OxLDL (not shown). Spreading on fibrinogen was reduced by the FA6-152 mAb with $<10 \%$. Similarly as for fibrinogen-adhered platelets ${ }^{45}$, blocking of the $P 2 Y_{1}$ and $P 2 Y_{12}$ receptors resulted in diminished spreading 
A
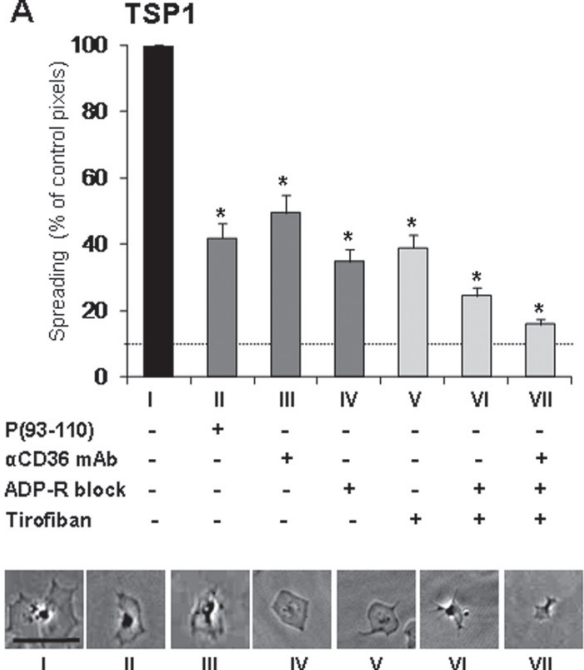

B
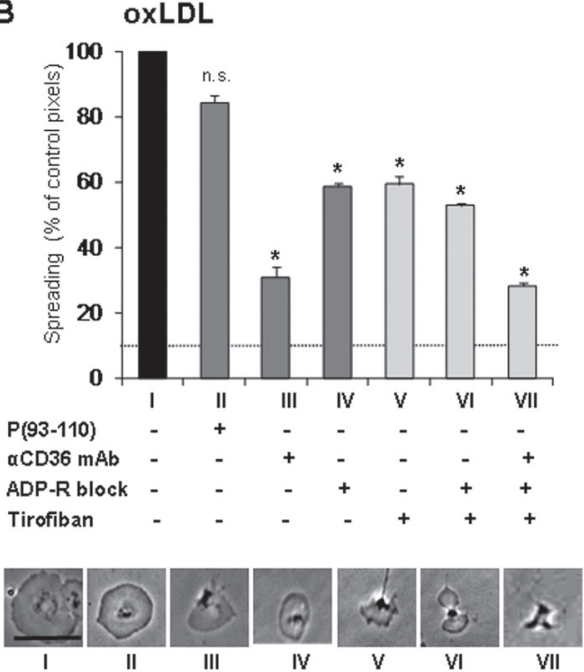

Figure 3.4. Roles of CD36 and ADP receptors in platelet spreading on immobilized TSP1 or oxLDL. Washed platelets were incubated with vehicle buffer, $\mathrm{P}(93-110)$ peptide $\left(50 \mu \mathrm{g} \mathrm{mL}^{-1}\right)$, FA6-152 anti-CD36 $\mathrm{mAb}\left(2 \mu \mathrm{g} \mathrm{mL}^{-1}\right)$, ADP receptor blockers (10 $\mu \mathrm{M}$ cangrelor and $100 \mu \mathrm{M}$ MRS 2179) or tirofiban (2 $\mu \mathrm{g}$ $\mathrm{mL}^{-1}$ ), as indicated. Microscopic images were recorded after $45 \mathrm{~min}$ of platelet adhesion to immobilized TSP1 (A) or oxLDL (B). Images are given from one representative adhered platelet per condition (bars, $10 \mu \mathrm{m})$. Graphs show inhibitor effects on platelet spreading, expressed as percentage of pixels at control conditions. Horizontal lines represent average pixel number of non-spread platelets. Means \pm S.E.M. $(n=6-$ $8) ; * P<0.05 v s$. vehicle control.

of platelets on TSPI or oxLDL (Figure 3.4A,B). Blocking of $\alpha_{\mathrm{IIb}} \beta_{3}$ with tirofiban was equally effective. Combined application of FA6-152 mAb, ADP receptors antagonists and tirofiban nearly completely eliminated spreading on TSPI, but not on oxLDL. Interestingly, post-addition of anti-CD36 mAb, but not of isotype control IgGl, after 10 minutes of spreading resulted in halt of spreading or even in detachment of partially spread platelets from the surface (not shown). This explained the major reduction by the FA6-152 mAb in the assay of platelet adhesion (Figure 3.2A).

The potential involvement of SR-A as OXLDL receptor was investigated using the SR-A antagonist fucoidan ${ }^{20}$. By itself fucoidan $\left(50 \mu \mathrm{g} \mathrm{mL}^{-1}\right)$ was inactive on platelet spreading. However, in combination with FA6-152 mAb, it reduced the size of platelets on $0 x L D L$ with $28 \pm 2 \%$ (mean \pm S.E.M., $n=3$ ) to that of resting, non-adhered platelets. Together, these data point to a marked, activating role of CD36 ligand binding, enhanced by autocrine ADP and $\alpha_{I I b} \beta_{3}$ activation, to trigger the cytoskeletal rearrangements required for pseudopod and filopod formation of platelets on immobilized TSPI and oxLDL. The contribution of $\alpha_{\mathrm{IIb}} \beta_{3}$ is in agreement with evidence for a functional association of CD36 with $\alpha_{\mathrm{IIb}} \beta_{3}$ and the tetraspannin CD9 in platelet membranes ${ }^{46}$.

\section{Role of CD36 in platelet activation on TSP1 or oxLDL surfaces}

Subsequent studies were carried out to determine the intracellular signaling during CD36-dependent adhesion and spreading of platelets. Real-time measurement of $\mathrm{Ca}^{2+}$ 
A
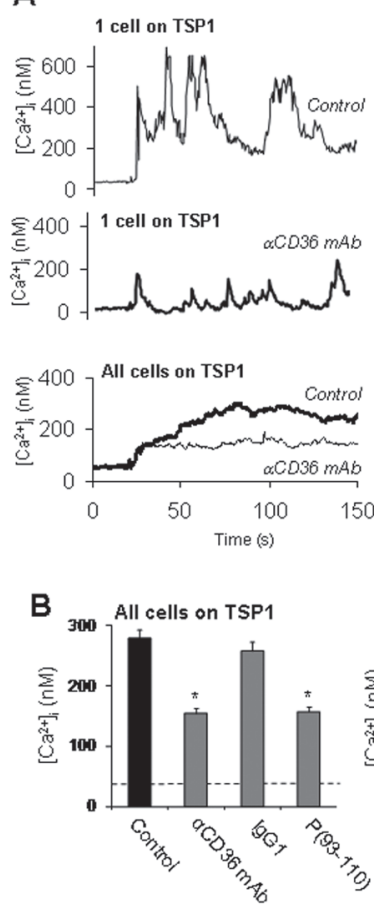

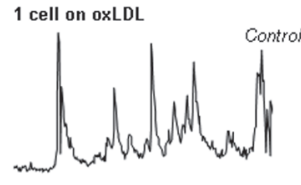

1 cell on oxLDL

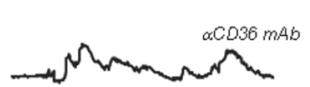

All cells on oxLDL
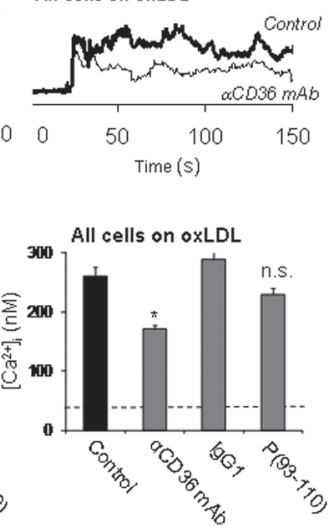
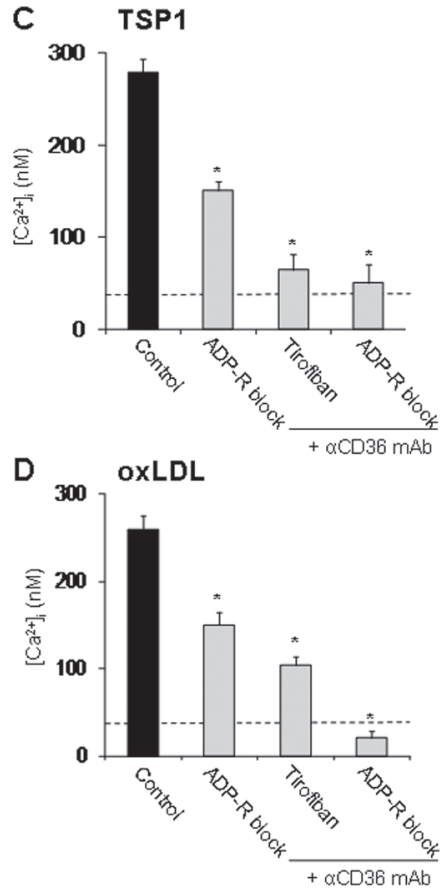

- Figure 3.5. Roles of CD36 and ADP receptors in $\mathrm{Ca}^{2+}$ responses of platelets adhered to TSP1 or oxLDL. (A, B) Fluo-4-loaded platelets were 10 min treated with vehicle buffer, FA6-152 anti-CD36 mAb $(2 \mu \mathrm{g}$ $\left.\mathrm{mL}^{-1}\right)$, IgG1 isotype control $\left(2 \mu \mathrm{g} \mathrm{mL}^{-1}\right)$ or $\mathrm{P}(93-110) \mathrm{CD} 36$ peptide $\left(50 \mu \mathrm{g} \mathrm{mL}^{-1}\right)$. Changes in Fluo-4 recorded during platelet adhesion to immobilized TSP1 (left) or oxLDL (right). (A) Traces of $\mathrm{Ca}^{2+}$ rises of representative, single platelets and averaged overlays from $>50$ platelets per condition ( $T=0$, stable adhesion). (B) Mean $\mathrm{Ca}^{2+}$ rise during interval of 60-120 s after initial rise; platelets were treated as indicated. (C, D) Mean $\mathrm{Ca}^{2+}$ rises during interval of 60-120 s after initial rise; platelets were treated with vehicle, ADP receptor blockers, tirofiban and/or anti-CD36 mAb (see Figure 3.2). Horizontal lines give basal levels of $\left[\mathrm{Ca}^{2+}\right]_{\mathrm{i}}$. Data are means \pm S.E.M. $(n=50-55) ;{ }^{*} P<0.05 v s$. vehicle control.

responses of single, Fluo-4-loaded platelets showed high-amplitude, repetitive spiking rises in cytosolic $\left[\mathrm{Ca}^{2+}\right]_{\mathrm{i}}$, which only started after several minutes of stable adhesion of the cells on either TSPlor oxLDL (Figure 3.5A). The $\mathrm{Ca}^{2+}$ spikes were decreased in amplitude, but not abolished with anti-CD36 FA6-152 mAb. In contrast, with P(93110) peptide present, only the $\mathrm{Ca}^{2+}$ responses of TSPl-adhered platelets were reduced, such in agreement with the peptide's expected effect. Recording of fluorescence images at low frequency of $0.25 \mathrm{~Hz}$ during longer time periods $(30 \mathrm{~min}$ ) indicated that in the majority of cells the $\mathrm{Ca}^{2+}$ rises persisted during the whole period of spreading. Other control studies with LDL oxidized for $72 \mathrm{~h}$ with $\mathrm{FeSO}_{4}^{33}$ provoked similar long-term rises in $\mathrm{Ca}^{2+}$ (data not shown).

Quantitative analysis of the rises in $\mathrm{Ca}^{2+}$ indicated that blockade of CD36 (FA6-152 $m A b)$ caused a $40-50 \%$ reduction in mean $\mathrm{Ca}^{2+}$ signal after stable platelet adhesion to TSPI or oxLDL surfaces (Figure 3.5B). Control IgGI was completely ineffective. On both surfaces, blockage of ADP receptors resulted in a reduction of the mean $\mathrm{Ca}^{2+}$ 
rise, which was partial in the absence but complete in the presence of FA6-152 mAb (Figure 3.5C,D). Tirofiban alone suppressed the $\mathrm{Ca}^{2+}$ rises with $\sim 40 \%$. Combination of tirofiban with FA6-152 mAb nearly completed blocked the $\mathrm{Ca}^{2+}$ rises of platelets on TSP1 (Figure 3.5C), but not on oxLDL (Figure 3.5D). Hence, the $\mathrm{Ca}^{2+}$ signal appears to be dependent partly from CD36 and partly from ADP receptor activation, with both processes operating simultaneously.

Using a confocal microscopic system with differential interference contrast optics, activation-dependent surface characteristics were determined of the adhered platelets. After spreading, the platelets were labeled with AF647-annexin A5 to probe phosphatidylserine exposure, and with FITC-anti-CD62 mAb to detect P-selectin exposure, both of which are $\mathrm{Ca}^{2+}$-dependent responses. Quantitative analysis of overlay images showed that the majority (81\%) of the platelets adhered on TSP1 had P-selectin expressed, whereas a smaller fraction (17\%) exposed phosphatidylserine (Figure 3.6A). Staining with FITC-PACl mAb indicated that most TSP1-adhered platelets had activated $\alpha_{\mathrm{IIb}} \beta_{3}$ integrins (74\%). Typically, staining with PACl mAb was concentrated in a circular

\section{A TSP1}
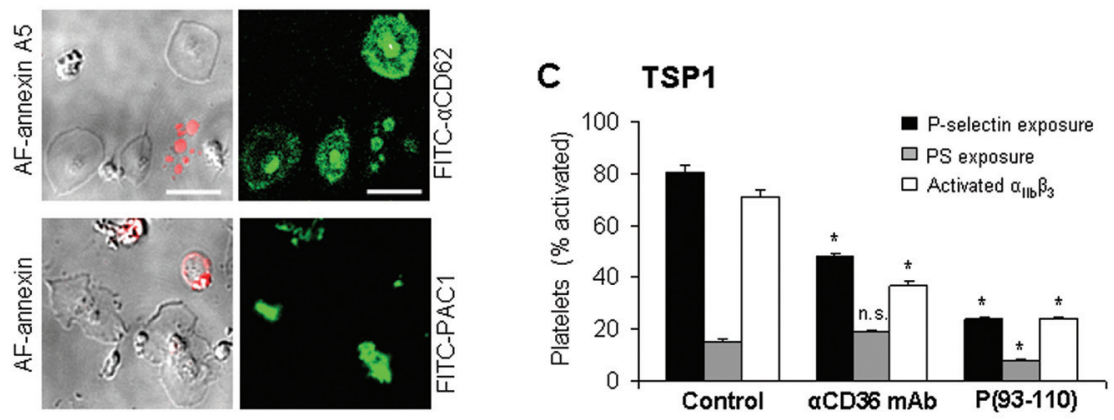

\section{B oxLDL}
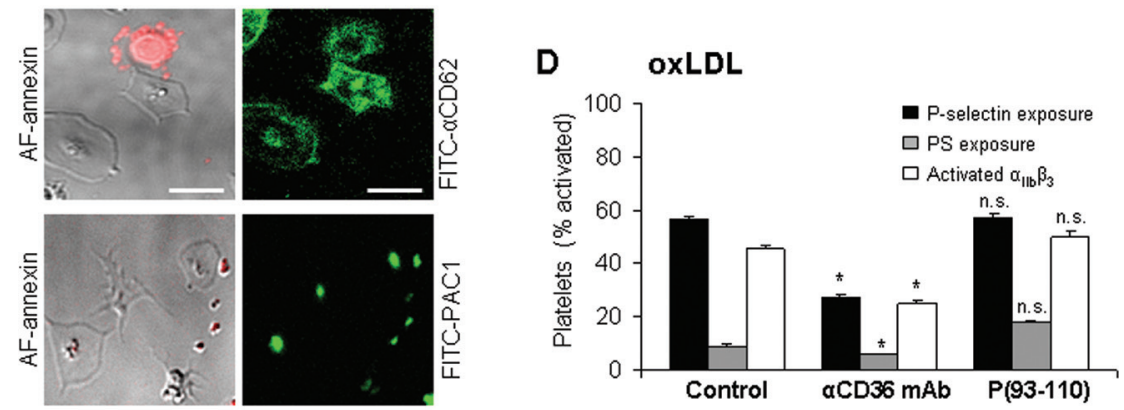

Figure 3.6. Role of CD36 in activation of platelets adhered to TSP1 or oxLDL. Washed platelets, pretreated with vehicle, anti-CD36 mAb FA6-152 $\left(2 \mu \mathrm{g} \mathrm{mL}^{-1}\right)$, or P(93-110) peptide $\left(50 \mu \mathrm{g} \mathrm{mL}^{-1}\right)$, adhered to immobilized TSP1 or oxLDL for $45 \mathrm{~min}$. Platelets on coverslips were stained for P-selectin (FITC antiCD62P mAb, green) or integrin activation (FITC-PAC1, green) in combination with AF647-annexin A5 (red). Confocal images of green and red fluorescence, as overlays with differential interference contrast images (bars, $10 \mu \mathrm{m}$ ). (A, B), Representative images of platelets adhered to TSP1 or oxLDL. (C, D) Fractions of adhered platelets exposing P-selectin, active $\alpha_{\mathrm{II}} \beta_{3}$ integrins and phosphatidylserine following adhesion to TSP1 or oxLDL. Means \pm S.E.M. $(n=3-4) ; * P<0.05 v s$. vehicle control. 
region at the platelet core. The staining for P-selectin and activated $\alpha_{\mathrm{II}} \beta_{3}$, and to a lesser extent for phosphatidylserine, was reduced by CD36 blockage with either FA6-152 mAb or $\mathrm{P}(93-110)$ (Figure 3.6C). During spreading on oxLDL, slightly lower percentages of platelets expressed the activation markers (Figure 3.6B,D). In this case only the FA6$152 \mathrm{mAb}$ was inhibitory. The combination of FA6-152 mAb and ADP receptor blockers further reduced the fractions of adhered platelets binding FITC-PACl to $10 \%$ (TSP1) or $8 \%$ (oxLDL). These results thus support the concept that CD36-mediated adhesion to TSPI or oxLDL evokes $\mathrm{Ca}^{2+}$-dependent secretion, which in combination with ADP receptor activation leads to integrin activation and platelet spreading.

Integrin $\alpha_{\mathrm{IIb}} \beta_{3}$-induced signaling in fibrinogen-adhered platelets is known to be mediated by activation of S rc-family and Syk protein tyrosine kinase ${ }^{1,44}$. We investigated a possible role of these kinases in the spreading and activation of platelets adhered to TSP1 or oxLDL. Platelet pretreatment with Src-family kinase inhibitors (PP1, PP2, SKF inhibitor I) or Syk inhibitors II or IV, but not with the control substance PP3, greatly reduced the adhesion to either surface (Figure 3.7A, B). With the two chosen inhibitors, PPI and Syk inhibitor II, but not with PP3, spreading of the remaining adhered platelets was diminished with $>40 \%$ on TSPI and with $>60 \%$ on oxLDL (Figure 3.7C,D). Interestingly, the effect of Syk inhibitor II was not increased with anti-CD36 mAb.

To verify a role of CD36 and $\alpha_{\text {IIb }} \beta_{3}$ in tyrosine kinase activation of the TSPI- and oxLDL-adhered platelets, tyrosine phosphorylation was evaluated. Western blots from platelet lysates, probed with anti-phosphotyrosine mAb 4G10, showed the appearance of multiple tyrosine-phosphorylated proteins (Figure 3.7E). The phosphorylation markedly reduced upon blocking of CD36 (FA6-152 mAb) or $\alpha_{\mathrm{IIb}} \beta_{3}$ (tirofiban) interactions, as well as in the presence of Syk inhibitor II. These results were confirmed by measuring the $\mathrm{Ca}^{2+}$ rises in Fluo-4-loaded, adhered platelets. While CD36 blockage suppressed $45 \pm 4 \%$ and $39 \pm 3 \%$ of the $\mathrm{Ca}^{2+}$ rise of platelets on TSPI and $0 \times L D L$, respectively, the combined presence of FA6-152 (2 $\left.\mathrm{g} \mathrm{mL}^{-1}\right)$ plus Syk inhibitor II ( $\left.1 \mu \mathrm{M}\right)$ suppressed this response with $91 \pm 4 \%$ and $79 \pm 6 \%$ (mean values \pm S.E.M., $n>10$ ). On the other hand, tirofiban suppressed $\sim 40 \%$ of the $\mathrm{Ca}^{2+}$ rise, but in combination with Syk inhibitor II this was $87 \pm 4 \%$ and $79 \pm 6 \%$, respectively. Furthermore, pretreatment of platelets with the intracellular $\mathrm{Ca}^{2+}$ chelating agent, dimethyl BAPTA strongly reduced the spreading on TSP1 (oxLDL) surface from $90 \pm 3 \%(76 \pm 4 \%)$ to $<10 \%(n=4$, $P<.05)$. Taken together, these results thus point to a role of both adhesive receptors, CD36 and $\alpha_{\mathrm{II}} \beta_{3}$ in tyrosine kinase activation, likely via stimulated Syk kinase, and $\mathrm{Ca}^{2+}$ signaling and spreading of platelets on TSPI and OxLDL.

\section{Role of CD36 in collagen-dependent thrombus formation in combination with TSP1 or oxLDL}

Immobilized collagen is an active surface provoking thrombus formation at high shear flow conditions ${ }^{29,31}$. We investigated whether immobilized TSPI and oxLDL could contribute to this process. Surfaces were prepared containing these proteins, while also collagencontaining surfaces were post-coated with TSP1, oxLDL or LDL. Whole blood was perfused 

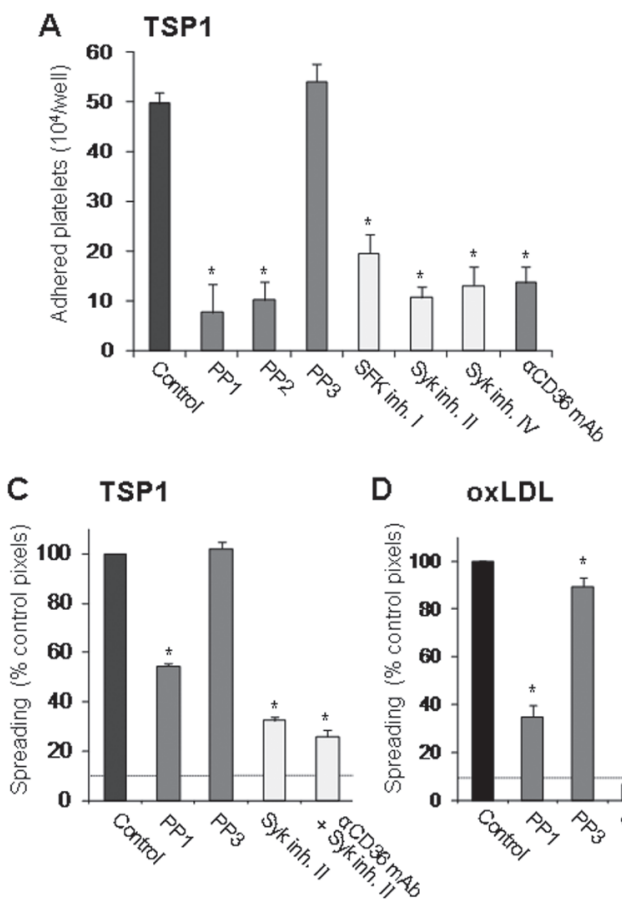

oxLDL

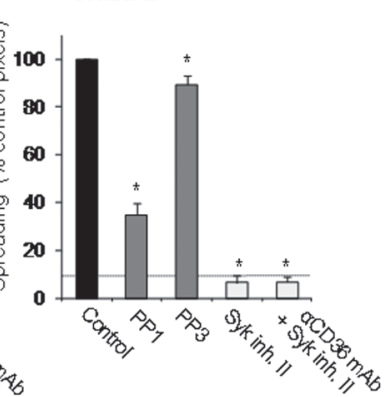

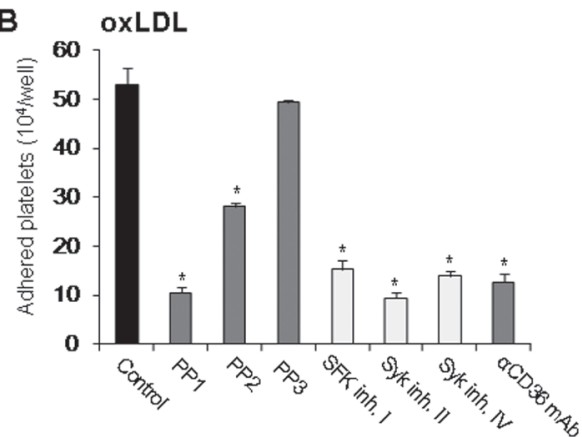

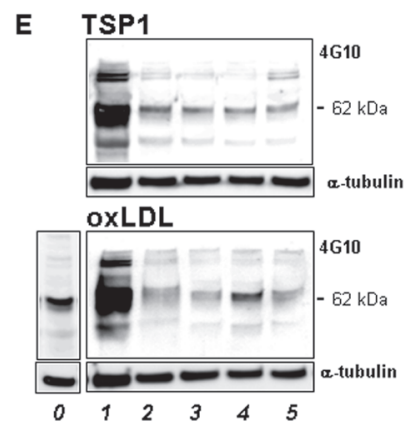

Figure 3.7. Roles of protein tyrosine kinases in platelet adhesion and activation to immobilized TSP1 or oxLDL. Washed platelets were incubated for $10 \mathrm{~min}$ with vehicle, PP1 $(20 \mu \mathrm{M})$, PP2 $(40 \mu \mathrm{M})$, PP3 (40 $\mu \mathrm{M})$, SFK inhibitor I $(10 \mu \mathrm{M})$, Syk inhibitor II $(1 \mu \mathrm{M})$, Syk inhibitor IV $(10 \mu \mathrm{M})$ or FA6-152 anti-CD36 $\mathrm{mAb}\left(2 \mu \mathrm{g} \mathrm{mL}^{-1}\right)$, as indicated. Stable adhesion and spreading were determined after $45 \mathrm{~min}$, as in Figs. 1 and 3, respectively. $(A, B)$ Inhibitor effects on stable adhesion to TSP1 or oxLDL. (C,D) Inhibitor effects on platelet spreading. (E) Inhibitor effects on tyrosine phosphorylation of adhered platelets. Platelets (BSAfree media) were collected after $45 \mathrm{~min}$ of adhesion, lysed, and subjected to gel electrophoresis. Shown are western blots representative for 3 independent experiments, after staining for phospho-tyrosine (4G10 $\mathrm{mAb}$ ) or for $\alpha$-tubulin (lane loading controls). Lanes represent the following incubation conditions: 0 , suspended resting platelets; $1-5$, adhered platelets: 1 , control; 2, tirofiban $\left(2 \mu \mathrm{g} \mathrm{mL}^{-1}\right) ; 3$, Syk inhibitor II; 4, tirofiban + Syk inhibitor II; 5, FA6-152 mAb.

through parallel-plate flow chambers with these surfaces at an intermediate shear rate of $1000 \mathrm{~s}^{-1}$. While a TSPI surface supported adhesion of only single platelets, TSPI in combination with collagen markedly increased the deposition of platelets and the formation of large-sized aggregates (Figure 3.8A,B). Immobilized LDL (as control) or oxLDL alone were unable to form aggregates (Figure 3.8B). When combined with collagen, also oxLDL (but not LDL) significantly increased platelet deposition and aggregate formation. Importantly, the enhanced thrombus formation with co-coated TSPI or ox LDL was annulled in the presence of anti-CD36 mAb (Figure 3.8C). Confocal microscopy was performed to determine the activation state of the platelets. Analysis of confocal fluorescence images showed increased staining for P-selectin, exposed phosphatidylserine and $\alpha_{\mathrm{II}} \beta_{3}$ activation of the thrombi that were formed on collagen/TSPI or collagen/oxLDL (Figure 3.9). Hence, in the presence of collagen, immobilized TSPI and oxLDL, also increased thrombus growth and platelet activation under flow conditions. 
A
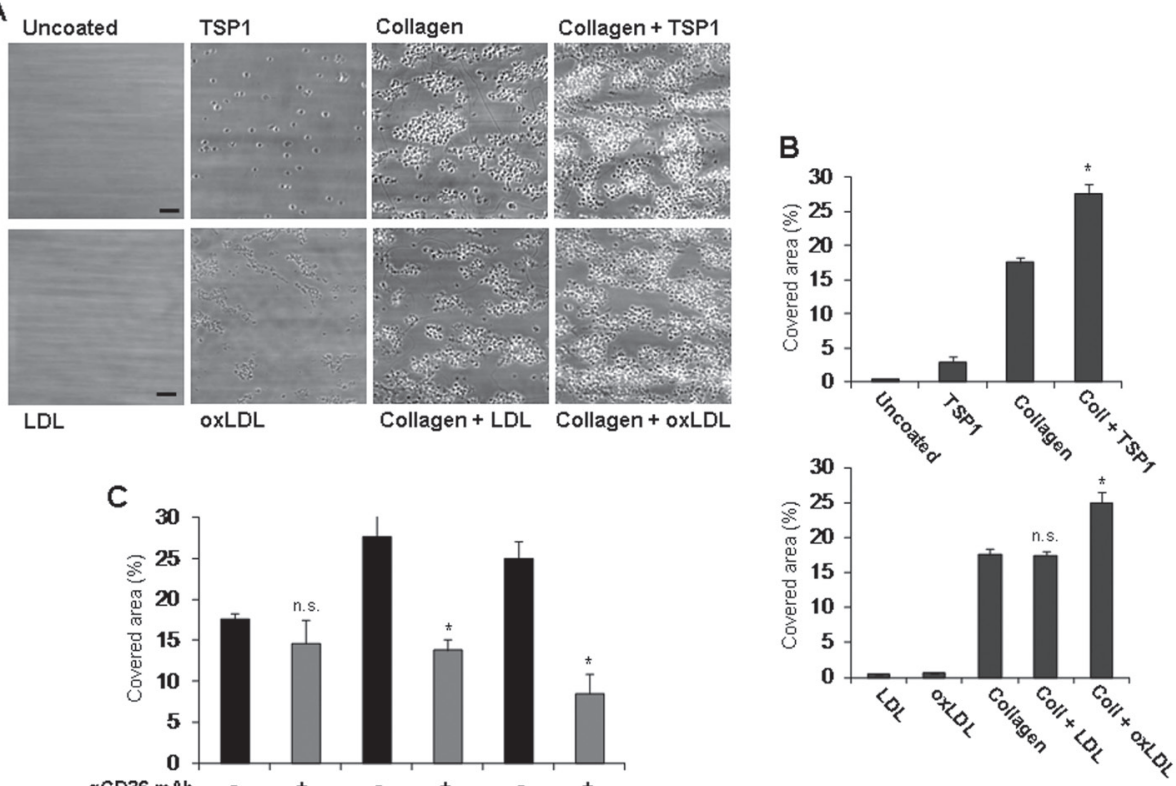

- Figure 3.8. Potentiation of collagen-induced thrombus formation by co-immobilized TSP1 and oxLDL. PPACK/fragmin-anticoagulated blood, incubated with vehicle or FA6-152 anti-CD36 mAb (4 $\left.\mu \mathrm{g} \mathrm{mL}^{-1}\right)$, was flowed during $4 \mathrm{~min}$ at a shear rate of $1000 \mathrm{~s}^{-1}$ over various coated surfaces. Coating was with TSP1, collagen, LDL, oxLDL or combinations of proteins, as indicated. All surfaces were blocked with BSA after coating. (A) Representative phase contrast images after 4 min of flow (bars, $10 \mu \mathrm{m}$ ). (B) Surface area coverage with thrombi. (C) Effect of anti-CD36 mAb on thrombus formation. Means \pm S.E.M. $(n=4-6)$; $* P<0.05$ vs. vehicle control.

\section{Discussion}

The present study provides novel evidence that surface-immobilized TSPI and oxLDL are strong platelet-stimulating agents. This is a relevant finding, since both TSPI and oxLDL can accumulate in the healthy and atherosclerotic vessel walls and, hence, contribute to the thrombogenic response upon vascular endothelial dysfunction ${ }^{13,40,47}$. Similarly to fibrinogen surfaces ${ }^{44}$, we find that immobilized TSPI and oxLDL trigger outside-in signaling events in platelets, which seem to be regulated for a major part through CD36. Common signaling mechanisms of platelets in contact with TSPI or oxLDL - inhibitable by blockage of CD36 or tyrosine kinases -, are spreading, pronounced $\mathrm{Ca}^{2+}$ rises, integrin $\alpha_{\mathrm{II}} \beta_{3}$ activation, subsequent signaling, granule secretion to produce autocrine mediators, and limited phosphatidylserine exposure. Importantly, we also find that both immobilized TSPI and oxLDL enhance the thrombus-forming potency of collagen surfaces under flow conditions. Jointly, these results reveal a so far unknown way of outside-in signaling by surface-bound TSPI and oxLDL and a novel mechanism of CD36 signaling in activation of the adhered platelets.

Other authors also report a small activating effect of $0 x L D L$ on platelets in suspension stimulated with ADP and SFLLRN ${ }^{21-23}$, which is in agreement with the present data. In 


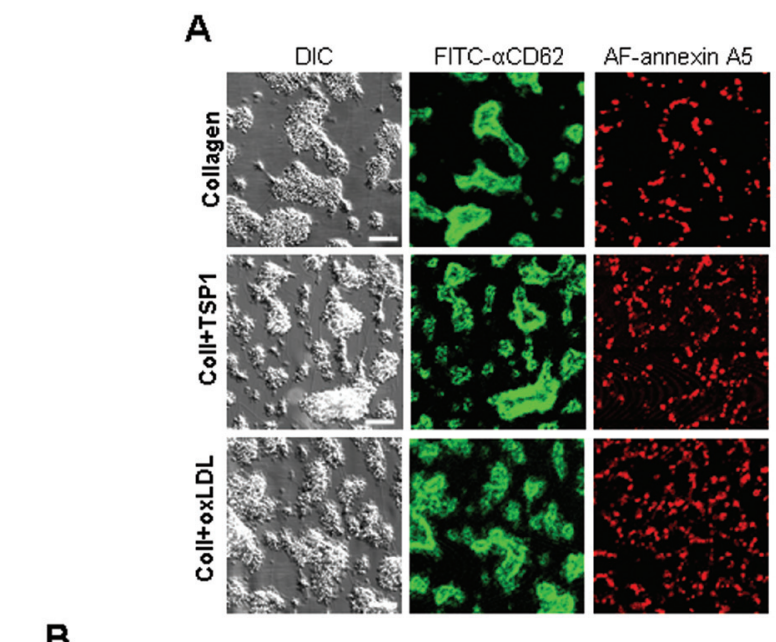

B
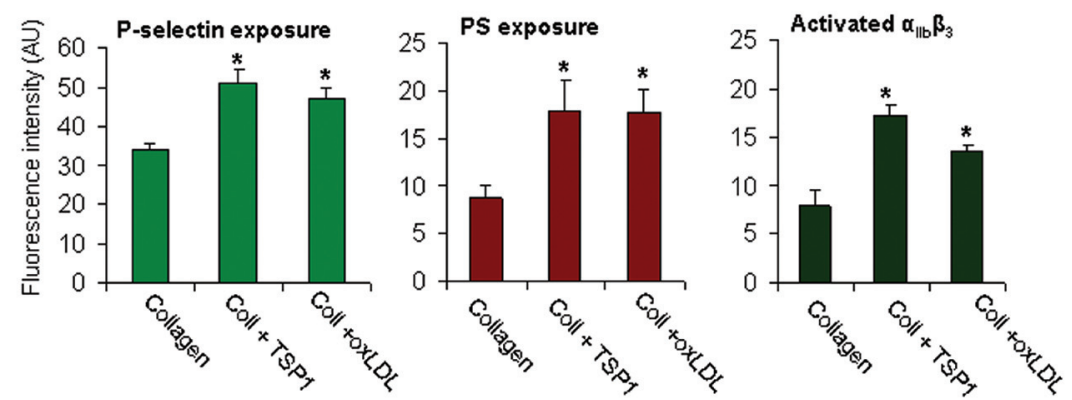

Figure 3.9. Co-immobilized TSP1 and oxLDL increase platelet activation state in thrombus formation. PPACK/fragmin-anticoagulated blood was flowed during $4 \mathrm{~min}$ at shear rate of $1000 \mathrm{~s}^{-1}$ indicated coated surfaces: collagen alone or collagen combined with TSP1 or oxLDL. (A) Overlays of confocal DIC and fluorescence images of thrombi (bars, $10 \mu \mathrm{m}$ ) after staining for P-selectin (FITC anti-CD62P mAb, green) and phosphatidylserine (PS) exposure (AF647-annexin A5, red). Other surfaces were stained for activated $\alpha_{\mathrm{II}} \beta_{3}$ (FITC-PAC1 Ab). (B) Quantification of integrated fluorescence intensity from thrombi on various surfaces. Means \pm S.E.M. $(n=3-4) ;{ }^{*} P<0.05$ compared to vehicle control.

addition, LDL oxidized under controlled conditions was found to activate the signaling pathway of p38 mitogen-activated protein kinase in part via CD3620. Reports on TSP1induced activation of platelets in suspension are mostly limited to the use of C-terminal TSPI peptides, triggering platelet aggregation via Fc receptor $\gamma$-chain phosphorylation, protein tyrosine kinases and autocrine dependent events ${ }^{24,25}$. In our hands, the full TSPI protein did not evoke platelet aggregation up to a dose of $2.5 \mu \mathrm{g} \mathrm{mL}^{-1}$. Strikingly, when immobilized both oxLDL and TSPI appear to be much more potent in activating platelets than as soluble agonists. This is suggestive either for a conformation change of the immobilized proteins, e.g. in a similar way to that of surface-bound fibrinogen ${ }^{43}$, or perhaps for a receptor (CD36?) cross-linking effect such as reported for collagen-related peptide ${ }^{48}$. Other papers have also shown that platelets under shear can deposit on TSP1, partly via CD36, but this was ascribed to GPIb- or von Willebrand factor-dependent adhesion ${ }^{17,40}$. 
The present data show a major role of CD36 in spreading and $\mathrm{Ca}^{2+}$ fluxes of platelets on TSPI or $0 x L D L$, such in junction with signaling via autocrine stimulation of ADP receptors and via $\alpha_{\mathrm{II}} \beta_{3}$ activation. With TSPI, the platelet responses were markedly suppressed by the CD36 peptide $P(93-110)$, representing the TSP binding site, and by the blocking mAb FA6-152. However, with oxLDL only the FA6-152 mAb was effective. This is in good agreement with the non-identical (but adjacent) ligand binding sites for TSPI and oxLDL on CD363,5. Importantly, ADP receptor inhibitors and integrin blockers were both active in reducing platelet activation on both surfaces. Involvement of integrin activation, likely in cross-talk with ADP-mediated events ${ }^{49}$, can be explained by the reported linkage of $\mathrm{CD} 36$ with $\mathrm{CD} 9$ and $\alpha_{\mathrm{IIb}} \beta_{3}$ in the platelet membrane ${ }^{46}$. A cross-over effect from CD36 to integrin signaling may explain why immobilized TSPI (this paper) and TSPI peptides ${ }^{24,25}$ seem to trigger similar Src-family and Syk kinase signaling events as those arising from $\alpha_{\text {IIb }} \beta_{3}$ outside-in signaling of platelets on fibrinogen ${ }^{1,44,50}$. A similar mechanism of CD36 signaling in interaction with other membrane receptors may also occur in other cells ${ }^{3}$.

Our studies shed new light on the early reports of CD36 as a platelet collagen receptor, which was corroborated by the reduced platelet-collagen interaction with antiCD36 antibodies and in patients with CD36 deficiencies ${ }^{7,51}$. We find that co-coating of TSPI or oxLDL enhances collagen-dependent thrombus formation and the expression of platelet activation markers via CD36. This implies that platelet interaction under flow with these surface occurs via multiple adhesive receptors, such as was demonstrated in earlier studies of platelets on collagen ${ }^{36}$. Hence, also under other conditions where (platelet-derived) TSPI or (plasma-derived) oxLDL is expected to bind to collagen, CD36 may play a role in platelet adhesion and activation. Immobilization may also explain the reported role of oxLDL in murine thrombus formation ${ }^{21}$.

In summary, we propose a model for platelet activation by immobilized TSPI or oxLDL via CD36-dependent outside-in signaling to protein tyrosine kinases, in particular Syk, resulting in $\mathrm{Ca}^{2+}$ fluxes and downstream platelet responses (Figure 3.10). This pathway appears to be enforced by integrin activation, autocrine ADPmediated activation, and ensuing signaling events. Under conditions of deposited TSPI

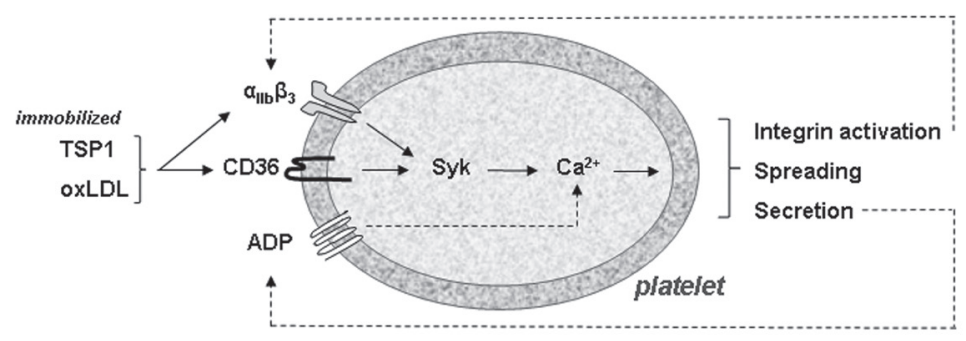

Figure 3.10. Proposed role of CD36 in TSP1- and oxLDL-dependent activation and spreading of platelets. Immobilized TSP1 and oxLDL evoke via CD36 and integrin $\alpha_{\mathrm{IIb}} \beta_{3}$, activation pathways involving Syk kinase and $\mathrm{Ca}^{2+}$ signaling, which lead to $\alpha_{\mathrm{II}} \beta_{3}$ activation, spreading of platelets and secretion. Autocrine produced ADP and outside-in signaling promote these responses (dotted lines). See also text. 
and oxLDL, this $\mathrm{CD} 36$ route enhances collagen-dependent thrombus formation. These results thereby demonstrate a novel role of $\mathrm{CD} 36$ in the activation of adhered platelets.

\section{Acknowledgements}

We acknowledge support from the Hacettepe University (Ankara, Turkey) to R.N.U, and from CARIM for confocal equipment. 


\section{References}

1. Shattil SJ, Brugge JS. Protein tyrosine phosphorylation and the adhesive functions of platelets. Curr Opin Cell Biol. 1991;3:869-879.

2. Berger G, Caen JP, Berndt MC, Cramer EM. Ultrastructural demonstration of CD36 in the alpha-granule membrane of human platelets and megakaryocytes. Blood. 1993;82:30343044.

3. Silverstein RL, Febbraio M. CD36, a scavenger receptor involved in immunity, metabolism, angiogenesis, and behavior. Sci Signal. 2009;2:re3.

4. Glatz JF, Luiken JJ, Bonen A. Membrane fatty acid transporters as regulators of lipid metabolism: implications for metabolic disease. Physiol Rev. 2010;90:367-417.

5. Nergiz-Unal R, Rademakers T, Cosemans JM, Heemskerk JW. CD36 as a multiple-ligand signaling receptor in atherothrombosis. Cardiovasc Hematol Agents Med Chem. 2011;9:4255.

6. Tandon NN, Kralisz U, Jamieson GA. Identification of glycoprotein IV (CD36) as a primary receptor for platelet-collagen adhesion. J Biol Chem. 1989;264:7576-7583.

7. Diaz-Ricart M, Tandon NN, Carretero M, Ordinas A, Bastida E, Jamieson GA. Platelets lacking functional CD36 (glycoprotein IV) show reduced adhesion to collagen in flowing whole blood. Blood. 1993;82:491-496.

8. Yamamoto N, Akamatsu N, Yamazaki H, Tanoue K. Normal aggregations of glycoprotein IV (CD36)-deficient platelets from seven healthy Japanese donors. Br J Haematol. 1992;81:8692.

9. Daniel JL, Dangelmaier C, Strouse R, Smith JB. Collagen induces normal signal transduction in platelets deficient in CD36 (platelet glycoprotein IV). Thromb Haemost. 1994;71:353356.

10. Kehrel B, Wierwille S, Clemetson KJ, Anders O, Steiner M, Knight CG, Farndale RW, Okuma M, Barnes MJ. Glycoprotein VI is a major collagen receptor for platelet activation: it recognizes the platelet-activating quaternary structure of collagen, whereas CD36, glycoprotein IIb/IIIa, and von Willebrand factor do not. Blood. 1998;91:491-499.

11. Leung LL, Li WX, McGregor JL, Albrecht G, Howard RJ. CD36 peptides enhance or inhibit CD36-thrombospondin binding. A two-step process of ligand-receptor interaction. J Biol Chem. 1992;267:18244-18250.

12. Frieda $S$, Pearce $A$, Wu J, Silverstein RL. Recombinant GST/CD36 fusion proteins define a thrombospondin binding domain. Evidence for a single calcium-dependent binding site on CD36. J Biol Chem. 1995;270:2981-2986.

13. Bornstein P. Thrombospondins as matricellular modulators of cell function. J Clin Invest. 2001;107:929-934.

14. Bonnefoy A, Hantgan R, Legrand C, Frojmovic MM. A model of platelet aggregation involving multiple interactions of thrombospondin-1, fibrinogen, and GPIIbIIIa receptor. J Biol Chem. 2001;276:5605-5612.

15. Agbanyo FR, Sixma JJ, de Groot PG, Languino LR, Plow EF. Thrombospondin-platelet interactions. Role of divalent cations, wall shear rate, and platelet membrane glycoproteins. J Clin Invest. 1993;92:288-296.

16. Chung J, Wang XQ, Lindberg FP, Frazier WA. Thrombospondin-1 acts via IAP/CD47 to synergize with collagen in $\alpha 2 \beta 1$-mediated platelet activation. Blood. 1999;94:642-648.

17. Jurk K, Clemetson KJ, de Groot PG, Brodde MF, Steiner M, Savion N, Varon D, Sixma $\mathrm{JJ}$, van Aken $\mathrm{H}$, Kehrel BE. Thrombospondin-1 mediates platelet adhesion at high shear via glycoprotein Ib (GPIb): an alternative/backup mechanism to von Willebrand factor. Faseb J. 2003;17:1490-1492.

18. Podrez EA, Febbraio M, Sheibani N, Schmitt D, Silverstein RL, Hajjar DP, Cohen PA, Frazier WA, Hoff HF, Hazen SL. Macrophage scavenger receptor CD36 is the major receptor for $L D L$ modified by monocyte-generated reactive nitrogen species. J Clin Invest. 2000;105:1095-1108. 
19. Febbraio M, Silverstein RL. CD36: implications in cardiovascular disease. Int J Biochem Cell Biol. 2007;39:2012-2030.

20. Korporaal SJ, van Eck M, Adelmeijer J, IJsseldijk M, Out R, Lisman T, Lenting PJ, van Berkel TJ, Akkerman JW. Platelet activation by oxidized low density lipoprotein is mediated by CD36 and scavenger receptor-A. Arterioscler Thromb Vasc Biol. 2007;27:2476-2483.

21. Podrez EA, Byzova TV, Febbraio M, Salomon RG, Ma Y, Valiyaveettil M, Poliakov E, Sun M, Finton PJ, Curtis BR, Chen J, Zhang R, Silverstein RL, Hazen SL. Platelet CD36 links hyperlipidemia, oxidant stress and a prothrombotic phenotype. Nat Med. 2007;13:10861095.

22. Maschberger P, Bauer M, Baumann-Siemons J, Zangl KJ, Negrescu EV, Reininger AJ, Siess W. Mildly oxidized low density lipoprotein rapidly stimulates via activation of the lysophosphatidic acid receptor Src family and Syk tyrosine kinases and $\mathrm{Ca}^{2+}$ influx in human platelets. J Biol Chem. 2000;275:19159-19166.

23. Chen K, Febbraio M, Li W, Silverstein RL. A specific CD36-dependent signaling pathway is required for platelet activation by oxidized low-density lipoprotein. Circ Res. 2008;102:15121519.

24. Trumel C, Plantavid M, Lévy-Toledano S, Ragab A, Caen JP, Aguado E, Malissen B, Payrastre B. Platelet aggregation induced by the C-terminal peptide of thrombospondin-1 requires the docking protein LAT but is largely independent of $\alpha \operatorname{IIb} \beta 3$. J Thromb Haemost. 2003;1:320-329.

25. Tulasne D, Judd BA, Johansen M, Asazuma N, Best D, Brown EJ, Kahn M, Koretzky GA, Watson SP. C-terminal peptide of thrombospondin-1 induces platelet aggregation through the Fc receptor $\gamma$-chain-associated signaling pathway and by agglutination. Blood. 2001;98:3346-3352.

26. Bonnefoy A, Hoylaerts MF. Thrombospondin-1 in von Willebrand factor function. Curr Drug Targets. 2008;9:822-832.

27. Isenberg JS, Romeo MJ, Yu C, Yu CK, Nghiem K, Monsale J, Rick ME, Wink DA, Frazier WA, Roberts DD. Thrombospondin-1 stimulates platelet aggregation by blocking the antithrombotic activity of nitric oxide/cGMP signaling. Blood. 2008;111:613-623.

28. Saumet A, de Jesus N, Legrand C, Dubernard V. Association of thrombospondin-1 with the actin cytoskeleton of human thrombin-activated platelets through an $\alpha \mathrm{IIb} \beta 3$ - or CD36independent mechanism. Biochem J. 2002;363:473-482.

29. Munnix IC, Kuijpers MJ, Auger J M, Thomassen CM, Panizzi P, van Zandvoort MA, Rosing J, Bock PE, Watson SP, Heemskerk JW. Segregation of platelet aggregatory and procoagulant microdomains in thrombus formation. Regulation by transient integrin activation. Arterioscler Thromb Vasc Biol. 2007;27:2484-2490.

30. Munnix IC, Strehl A, Kuijpers MJ, Auger J M, van der Meijden PE, van Zandvoort MA, oude Egbrink M, Nieswandt B, Heemskerk JW. The glycoprotein VI-phospholipase C $\gamma 2$ signaling pathway controls thrombus formation induced by collagen and tissue factor in vitro and in vivo. Arterioscler Thromb Vasc Biol. 2005;25:2673-2678.

31. Auger JM, Kuijpers MJ, Senis YA, Watson SP, Heemskerk JW. Adhesion of human and mouse platelets to collagen under shear: a unifying model. Faseb J. 2005;19:825-827.

32. Groeneweg M, Kanters $E$, Vergouwe MN, Duerink H, Kraal G, Hofker MH, de Winther MP. Lipopolysaccharide-induced gene expression in murine macrophages is enhanced by prior exposure to oxLDL. J Lipid Res. 2006;47:2259-2267.

33. Korporaal SJA, Gorter G, van Rijn HJM, Akkerman JWN. The effect of oxidation on the plateletactivating properties of low density lipoprotein. Arterioscler Thromb Vasc Biol. 2005;25:867-872.

34. Gilio K, Munnix IC, Mangin P, Cosemans JM, Feijge MA, van der Meijden PE, Olieslagers S, Chrzanowska-Wodnicka MB, Lillian R, Schoenwaelder S, Koyasu S, Sage S0, Jackson SP, Heemskerk JW. Non-redundant roles of phosphoinositide 3-kinase isoforms alpha and 
beta in glycoprotein VI-induced platelet signaling and thrombus formation. J Biol Chem. 2009;284:33750-33762.

35. Bellavite P, Andrioli G, Guzzo P, Arigliano P, Chirumbolo S, Manzato F, Santonastaso C. A colorimetric method for the measurement of platelet adhesion in microtiter plates. Anal Biochem. 1994;216:444-450.

36. Siljander PR, Munnix IC, Smethurst $P$, Deckmyn H, Lindhout T, Ouwehand WH, Farndale RW, Heemskerk JW. Platelet receptor interplay regulates collagen-induced thrombus formation in flowing human blood. Blood. 2004;103:1333-1341.

37. Heemskerk JW, Willems GM, Rook MB, Sage SO. Ragged spiking of free calcium in ADPstimulated human platelets: regulation of puff-like calcium signals in vitro and ex vivo. $J$ Physiol. 2001;535:625-635.

38. Cosemans JM, van Kruchten R, Olieslagers S, Schurgers LJ, Verheyen FK, Munnix IC, Waltenberger J, Angelillo-Scherrer A, Hoylaerts MF, Carmeliet P, Heemskerk JW. Potentiating roles for Gas6 and Tyor, AxI and Mer (TAM) receptors in human and murine platelet activation and thrombus stabilization. J Thromb Haemost. 2010;8:1797-1808.

39. Podrez EA, Poliakov E, Shen Z, Zhang R, Deng Y, Sun M, Finton PJ, Shan L, Gugiu B, Fox PL, Hoff HF, Salomon RG, Hazen SL. Identification of a novel family of oxidized phospholipids that serve as ligands for the macrophage scavenger receptor CD36. J Biol Chem. 2002;277:38503-38516.

40. Bonnefoy A, Daenens K, Feys HB, De Vos R, Vandervoort P, Vermylen J, Lawler J, Hoylaerts MF. Thrombospondin-1 controls vascular platelet recruitment and thrombus adherence in mice by protecting (sub)endothelial VWF from cleavage by ADAMTS13. Blood. 2006;107:955-964.

41. Davignon J, Ganz P. Role of endothelial dysfunction in atherosclerosis. Circulation. 2004; 109:III27-32.

42. Mosig S, Rennett K, Krause S, Kzhyshkowska J, Kerstin Neunübel K, Heller R, Funke H. Different functions of monocyte subsets in familial hypercholesterolemia: potential function of $\mathrm{CD}_{14}{ }^{+} \mathrm{CDI}^{+}$monocytes in detoxification of oxidized LDL. Faseb J. 2009;23.

43. Shattil SJ, Haimovich B, Cunningham M, Lipfert L, Parsons JT, Ginsberg MH, Brugge JS. Tyrosine phosphorylation of ppl25FAK in platelets requires coordinated signaling through integrin and agonist receptors. J Biol Chem. 1994;269:14738-14745.

44. Clark EA, Shattil SJ, Ginsberg MH, Bolen J, Brugge JS. Regulation of the protein tyrosine kinase pp72syk by platelet agonists and the integrin $\alpha I$ Ib $\beta 3$. J Biol Chem. 1994;269:2885928864.

45. Haimovich B, Kaneshiki N, Ji P. Protein kinase $C$ regulates tyrosine phosphorylation of pp125FAK in platelets adherent to fibrinogen. Blood. 1996;87:152-161.

46. Miao WM, Vasile E, Lane WS, Lawler J. CD36 associates with CD9 and integrins on human blood platelets. Blood. 2001;97:1689-1696.

47. Uchida Y, Uchida Y, Kameda N. Visualization of lipid components in human coronary plaques using color fluorescence angioscopy. Circ J. 2010:in press.

48. Farndale RW, Sixma JJ, Barnes MJ, de Groot PG. The role of collagen in thrombosis and haemostasis. J Thromb Haemost. 2004;2:561-573.

49. Nesbitt WS, Giuliano S, Kulkarni S, Dopheide SM, Harper IS, Jackson SP. Intercellular calcium communication regulates platelet aggregation and thrombus growth. J Cell Biol. 2003;160:1151-1161.

50. Watson SP, Auger JM, McCarty 0JT, Pearce AC. GPVI and integrin $\alpha \operatorname{IIb} \beta 3$ signaling in platelets. J Thromb Haemost. 2005;3:1752-1762.

51. Matsuno K, Diaz-Ricart M, Montgomery RR, Aster RH, Jamieson GA, Tandon N N. Inhibition of platelet adhesion to collagen by monoclonal anti-CD36 antibodies. Br J Haematol. 1996;92:960-967. 


\section{CHAPTER 4}

\section{Subtle roles of platelet CD36 and}

thrombospondin-1 in murine thrombus formation on collagen

Reyhan Nergiz-Unal, Marijke J.E. Kuijpers, Irene Vroegrijk, Roger van Kruchten, Suzanne J.A. Korporaal, Maria Febbraio, Marc F. Hoylaerts, Marc Tjwa,

Peter J. Voshol, Judith M.E.M. Cosemans, Johan W.M. Heemskerk 


\title{
Subtle roles of platelet CD36 and thrombospondin-1 in murine thrombus formation on collagen
}

\begin{abstract}
Platelets abundantly express glycoprotein CD36. Activated platelets release the CD36 ligand thrombospondin-1 (TSP1) from their $\alpha$-granules. We hypothesized that the interaction of CD36 with TSPI contributes to platelet activation and thrombus formation. Flow cytometry with murine platelets deficient in CD36 indicated unchanged ADP- and collagen-receptor induced integrin $\alpha_{\mathrm{IIb}} \beta_{3}$ activation, $\alpha$-granule secretion and phosphatidylserine exposure. Static adhesion to immobilized TSP1 was diminished in the CD36-deficient platelets. Thrombus formation was studied ex vivo by flowing whole blood from CD36- or TSP1-deficient mice over various surfaces. On a collagen surface, thrombus formation was unchanged in either case in comparison to wildtype blood, but the thrombi from both types of knockout mice tegrated more rapidly than wildtype thrombi upon perfusion with rinsing medium. Post-coating of the collagen with supernatant from wildtype, but not of TSP1-deficient platelets, resulted in increased thrombus formation and increased appearance of platelet activation markers, only with blood from wildtype mice but not with blood from CD36-deficient mice. Together, these results point to a subtle role of murine CD36 and platelet-derived TSPI in: (i) collagendependent thrombus formation, and (ii) thrombus stabilization under flow. Hence, platelet CD36 binding to TSP1 is another of the multiple receptor-ligand interactions required for the maintenance of a stable thrombus.
\end{abstract}




\section{Introduction}

The glycoprotein CD36 is a major integral membrane protein on the platelet surface with 10,000-25,000 copies expressed per cell1,2. While spanning the plasma membrane twice, CD36 has a large extracellular domain with several glycosylation sites, and contains short $\mathrm{N}$ - and $\mathrm{C}$-terminal cytoplasmic domains. The extracellular domain is capable to bind oxidized forms of low density lipoprotein (oxLDL) and phospholipids, long-chain fatty acids as well as thrombospondin-1 (TSP1) ${ }^{3-5}$. TSPI is present in the $\alpha$-granules of platelets and in storage granules of other cells like fibroblasts, endothelial cells and smooth muscle cells, from which it can be secreted and accumulate in the vessel wall ${ }^{6-8}$. Functional studies with these cells indicate that CD36 can act as a receptor for TSP19-

13. This may point to an autocrine effect of secreted TSP1, although there is no evidence yet supporting this idea.In spite of its high expression level, the function of CD36 on platelets is still unclear. Earlier, CD36 was considered to be a collagen receptor ${ }^{14,15}$, but platelets from CD36-deficient patients appeared to display normal collagen-induced responses ${ }^{16-18}$. Recent papers point to a property of CD36 as oxLDL receptor, e.g. under conditions promoting atherogenesis ${ }^{19,20}$, while peptide studies suggest that CD36 acts as platelet-activating receptor for $\mathrm{TSP}^{21,22}$.

In Chapter 3, we have shown that CD36 evokes outside-in signaling responses of human platelets adhered to surface-immobilized oxLDL or TSP1. In the present chapter, we aimed to determine whether the interaction of CD36 with TSPI also contributes to thrombus formation using blood from mice deficient in either CD36 or TSP1.

\section{Materials and Methods}

\section{Materials}

Human platelet-derived TSPI and H-Phe-Pro-Arg chloromethyl ketone (PPACK) were obtained from Calbiochem (La Jolla CA, USA). Fibrinogen from mouse plasma, bovine serum albumin (BSA), ADP and thrombin were from Sigma-Aldrich (St. Luis M0, USA). Low molecular weight heparin (fragmin) was from Pfızer (Capelle a/d IJssel, The Netherlands). Glycoprotein VI agonist, convulxin, was purified to homogeneity from the crude venom of Crotalus durissus terrificus (Latoxan, Valence, France) ${ }^{23}$. Fibrillar Horm type I collagen was from Nycomed Pharma (Munich, Germany). Annexin A5 (detecting surface-exposed phosphatidylserine) labeled with fluorescein isothiocyanate (FITC) was from PharmaTarget (Maastricht, the Netherlands); annexin A5 labeled with Alexa fluor (AF)647 from Molecular Probes (Eugene OR, USA). FITC-labeled antiCD62 mAb (detecting surface exposure of granular P-selectin) was from Immunotech (Marseille, France); PE-labeled anti-mouse CD62 J0N/A mAb (detecting the activated conformation of integrin $\alpha_{\mathrm{IIb}} \beta_{3}$ ) from Emfret Analytics (Würzburg, Germany); antimurine TSPI mAb from Abcam (Cambridge, UK). Other materials were from sources as described before ${ }^{24}$.

\section{Animals}

Experiments were approved by the local Animal Experimental Committees. Mice homozygously deficient in $\operatorname{CD} 36\left(\mathrm{Cd}_{3} 6^{--}\right)$were generated as described, and crossed 
back $>6$ times to a C57BI/6 genetic background ${ }^{25}$. Mice deficient in TSPI (Tsp1 ${ }^{-/}$) also of $\mathrm{C} 57 \mathrm{Bl} / 6$ background were kindly provided by Dr. Jack Lawler (Harvard Medical School, Boston MA, USA) ${ }^{26}$. In blood from all mouse strains, platelet and erythrocyte counts were in the normal range. Wildtype and corresponding knockout mice were of the same breeding program.

\section{Blood collection and platelet preparation}

Murine blood was obtained by retro-orbital puncture under general anesthesia. For flow studies, blood was collected into $40 \mu \mathrm{M} \mathrm{PPACK}, 5 \mathrm{U} / \mathrm{ml}$ heparin and $40 \mathrm{U} / \mathrm{ml}$ fragmin. For platelet preparation, blood was collected into $129 \mathrm{mM}$ citrate, $1 \mathrm{U} / \mathrm{ml}$ heparin and $5 \mathrm{mM}$ glucose. Washed platelets from wildtype or knockout mice were resuspended in modified Tyrode's Hepes buffer (5 mM Hepes, $136 \mathrm{mM} \mathrm{NaCl}, 2.7 \mathrm{mM} \mathrm{KCl}, 0.42 \mathrm{mM}$ $\mathrm{NaH}_{2} \mathrm{PO}_{4}, 2 \mathrm{mM} \mathrm{MgCl}{ }_{2}, 0.1 \%$ glucose and 0.1\% BSA, pH 7.45) ${ }^{24}$. Cells were counted with a Coulter counter. Aliquots of suspended Tsp $1^{+/+}$or $\operatorname{Tsp~}^{1 /-}$ platelets $\left(1 \times 10^{9} / \mathrm{ml}\right)$ were activated with thrombin (20 nM) for $10 \mathrm{~min}$, after which PPACK (200 nM) was added to inactivate thrombin. Supernatants from activated platelets were then prepared by centrifuging for $1 \mathrm{~min}$ at $2650 \mathrm{~g}$, and were stored frozen until use.

\section{Flow cytometry}

Washed platelets $\left(1 \times 10^{8} / \mathrm{ml}\right)$ in Tyrode's Hepes buffer $\mathrm{pH} 7.45$ with $2 \mathrm{mM} \mathrm{CaCl}$ were activated with ADP (0.5-5 $\mu \mathrm{M})$ or convulxin (20-50 $\mathrm{ng} / \mathrm{ml})$ without stirring. After 10 min, activation of integrin $\alpha_{\text {IIb }} \beta_{3}$, $\alpha$-granule secretion, and phosphatidylserine exposure was detected with PE-labeled JON/A mAb $(150 \mu \mathrm{g} / \mathrm{ml})$, FITC-labeled anti-CD62 $\mathrm{mAb}(1: 40)$ and FITC-labeled annexin A5 (1 $\mu \mathrm{g} / \mathrm{ml})$, respectively ${ }^{27}$. Fluorescence was measured with an Accuri C6 flow cytometer (Ann Arbor MI, USA).

\section{Platelet adhesion and activation}

Round glass coverslips were coated with purified TSPI $(3 \mu \mathrm{l}, 100 \mu \mathrm{g} / \mathrm{ml})$ or platelet supernatant ( $3 \mu \mathrm{l}$ per coverslip), and blocked with Tyrode's Hepes buffer containing $1 \%$ BSA. Coverslips in an open chamber were incubated with platelets $\left(1.5 \times 10^{8} / \mathrm{ml}\right)$ in Tyrode's Hepes buffer containing $2 \mathrm{mM} \mathrm{CaCl}_{2}$. Filopod formation of individual adhered platelets was monitored in real time by capturing microscopic bright field contrast images $^{28}$. Exposure of phosphatidylserine (AF647-annexin A5) of adhered platelets ${ }^{27}$ was measured by fluorescence microscopy ${ }^{24,27}$. Images were analyzed with the software package MetaMorph (Molecular Devices, Sunnyvale CA, USA).

\section{Thrombus formation under flow}

Rectangular coverslips were coated with fibrillar type I collagen $(3 \mu \mathrm{l}, 50 \mu \mathrm{g} / \mathrm{ml})$, as described $^{28}$. Where indicated, coated coverslips were post-incubated with supernatant from activated platelets $(3 \mu \mathrm{l})$. After blocking with Tyrode's Hepes buffer containing $1 \%$ BSA, coverslips were mounted into a transparent parallel-plate flow chamber (depth 50 $\mu \mathrm{m}$, width $3 \mathrm{~mm}$ ) for flow experiments. PPACK/heparin-anticoagulated mouse blood was perfused for 4 min at a shear rate of $1000 \mathrm{~s}^{-1}$, after which microscopic bright field and fluorescence images of thrombi ere immediately taken as described ${ }^{28}$. Where indicated, 
thrombi were post-perfused with Tyrode's Hepes buffer ( $\mathrm{pH}$ 7.45) containing $2 \mathrm{mM}$ $\mathrm{CaCl}_{2}, 2 \mathrm{mM} \mathrm{MgCl}$ and $1 \mathrm{U} / \mathrm{ml}$ heparin for 6 min to determine thrombus stability ${ }^{29}$.

Surface expression of activation markers on adhered platelets was measured after 5 min staining under stasis by confocal microscopy, i.e. activation of $\alpha_{\mathrm{IIb}} \beta_{3}$ integrin by staining with PE-JON/A mAb, and expression of phosphatidylserine using AF647annexin $A 5^{27}$. Non-confocal images were recorded with an EVOS inverted digital fluorescence microscope ( $A M G$, Bothell WA, USA). Brightfield contrast images were analyzed for surface area coverage, thrombus size and area distribution of individual segmented features ${ }^{28}$, and fluorescence images were analyzed for integrated fluorescence intensity, using Metamorph software.

\section{Statistical analysis}

Significance of differences was determined with a parametric $t$ test or a non-parametric Mann-Whitney $U$ test, as required; size distribution of platelet aggregates was evaluated by $\chi^{2}$ analysis using the statistical package for social sciences (SPSS version 17, Chicago IL, USA).

\section{Results}

\section{Murine platelet CD36 as thrombospondin receptor}

Using flow cytometry, activation properties were compared of washed platelets from $\mathrm{Cd} 36^{-/}$mice and corresponding wildtype, $\mathrm{Cd} 36^{+/+}$mice. As indicated in Figure 4.1, deficiency in CD36 did not lead to a significant reduction in integrin $\alpha_{\mathrm{IIb}} \beta_{3}$ activation (measured with JON/A mAb), when platelets were stimulated with low or high doses

A

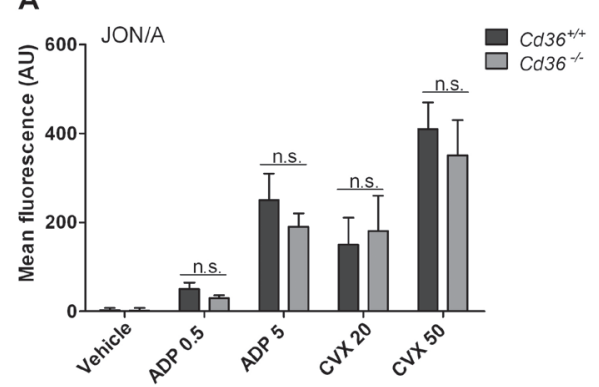

- Figure 4.1. No contribution of murine CD36 in activation of suspended platelets. Washed platelets from $\mathrm{Cd} 36^{+/+}$or $\mathrm{Cd} 36^{-/}$mice were stimulated with ADP $(0.5-5 \mu \mathrm{M})$ or convulxin $(20-50 \mathrm{ng} / \mathrm{ml})$ during $10 \mathrm{~min}$. Platelet activation parameters were determined with flow cytometry. (A) Activation of $\alpha_{\mathrm{II}} \beta_{3}$ was detected with PElabeled JON/A mAb, $(B)$ expression of P-selectin was detected with FITC-anti-CD62 mAb, and $(C)$ exposure of phosphatidylserine was detected with FITC-annexin A5. Data are means \pm S.E.M. $(n=4-$ 5); n.s., not significant.
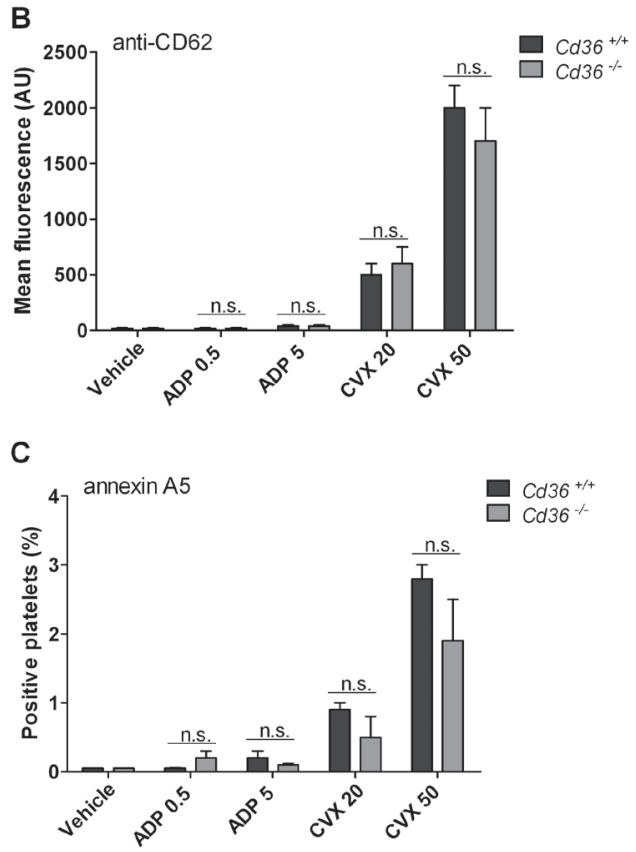
of the purinergic receptor agonist, ADP, or the glycoprotein VI agonist, convulxin. Similarly, CD36 deficiency did not affect $\alpha$-granule secretion (measured with FITCanti-P-selectin $m A b$ ) or phosphatidylserine exposure (measured with AF-annexin A5), induced by these agonists. This compares well to results from others showing that ADPor thrombin-induced fibrinogen binding and P-selectin expression were not significantly altered in platelets from CD36-deficient mice ${ }^{19,30}$.

Given the presence of TSPI in the matrix of the vessel wall6,31,32, we explored whether immobilized TSPI may cause adhesion and activation of mouse platelets via CD36. Static adhesion assays were performed using coverslips coated with purified TSPI (human) or with supernatant derived from activated wildtype platelets. Staining of such coverslips with anti-TSPI mAb demonstrated in both cases the presence of TSPI on the surface (data not shown). Markedly, coating with either purified TSPI or platelet supernatant resulted in a lower adhesion of $\mathrm{Cd}_{3} 6^{--}$platelets than of corresponding $\mathrm{Cd} 36^{+/+}$platelets (Figure 4.2A,B). Post-labeling with FITC-annexin A5 furthermore indicated that the lower adhesion of $\mathrm{Cd}_{3} 6^{--}$platelets was accompanied by a similar reduction of phosphatidylserine-exposing platelets (Figure $4.2 C, D$ ). In agreement with

A

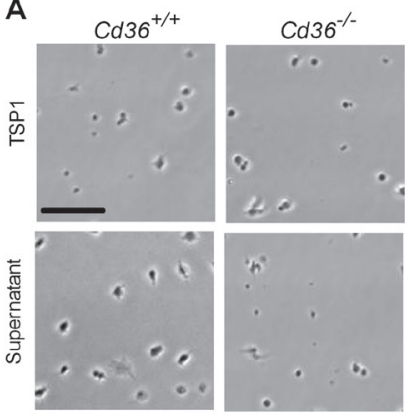

C
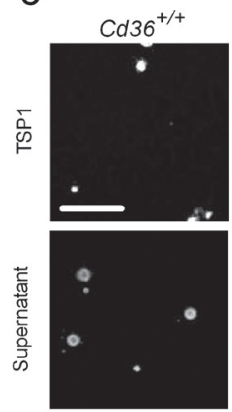

$\operatorname{cd} 36^{-/-}$

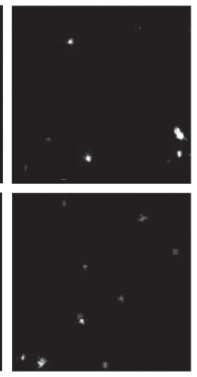

B

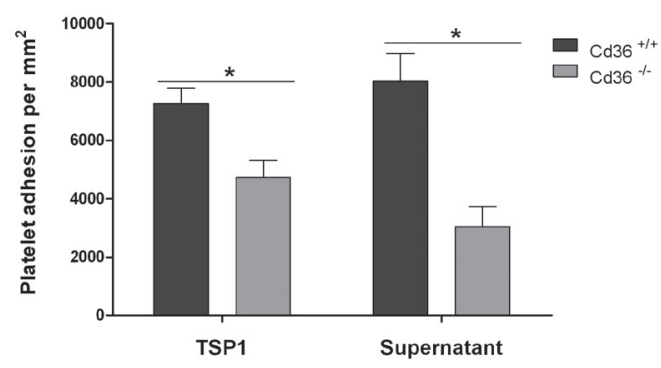

D

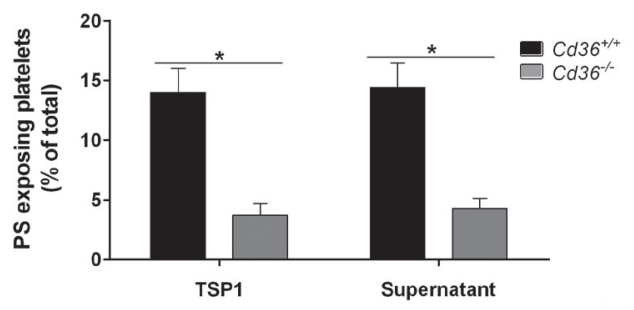

Figure 4.2. Function of murine CD36 in static platelet adhesion and activation on surfaces coated with TSP1 or platelet supernatant. Washed platelets from $\mathrm{Cd} 36^{+/+}$or $\mathrm{Cd} 36^{-1-}$ mice $\left(1.5 \times 10^{8 /}\right.$ $\mathrm{ml}$ ) were allowed to adhere to surfaces coated with TSP1 or supernatant from activated platelets. After 45 min, microscopic images were taken, and adhered cells were stained with FITC-annexin A5. $(A, C)$ Representative images from adhered platelets (bars, $25 \mu \mathrm{m}$ ). Quantification of $(B)$ number of adhered platelets per $\mathrm{mm}^{2}$, and $(D)$ fractions of adhered platelets exposing phosphatidylserine (PS). Means \pm S.E.M. $(n=3-4) ;{ }^{*} p<0.05 v s . C d 36^{+/+}$control. 
these data, others have shown that the interaction of human platelets with TSPI can be suppressed with anti-CD36 $\mathrm{mAbs}^{10,33}$.

\section{Subtle roles of murine CD36 and TSP1 in collagen-dependent thrombus formation}

Considering that the interaction of CD36 with immobilized TSPI promotes platelet activation, we studied whether TSP1 may contribute to thrombus formation via CD36 under flow conditions. Therefore, PPACK-anticoagulated blood from Tsp $1^{-1}$ mice or corresponding $\mathrm{Tsp}^{+/+}$mice was perfused over a collagen surface at high-shear flow, following common procedures ${ }^{27,34}$. Microscopic images of the platelets deposited on collagen after 4 min of flow did not reveal clear differences between the Tsp $1^{1-}$ and Tsp $1^{+/+}$blood (Figure 4.3A). This was confirmed by analysis of the surface area covered by the adhered platelets (Figure 4.3B). Confocal microscopic images, taken after staining with fluorescently labeled JON/A mAb showed a comparable extent of $\alpha_{\mathrm{IIb}} \beta_{3}$ activation, but images after staining with labeled annexin A5 demonstrated significantly less phosphatidylserine exposure in thrombi formed with $\mathrm{Tsp}^{1 \%}$ blood in comparison to wildtype blood. Knowing that phosphatidylserine expression in this flow test is a measure of collagen-induced platelet activation via glycoprotein $V I^{28,35}$, this pointed to reduced glycoprotein VI responsiveness of the Tsp $1^{-1-}$ platelets, which interestingly was apparent as lower phosphatidylserine exposure but not as reduced platelet aggregation.
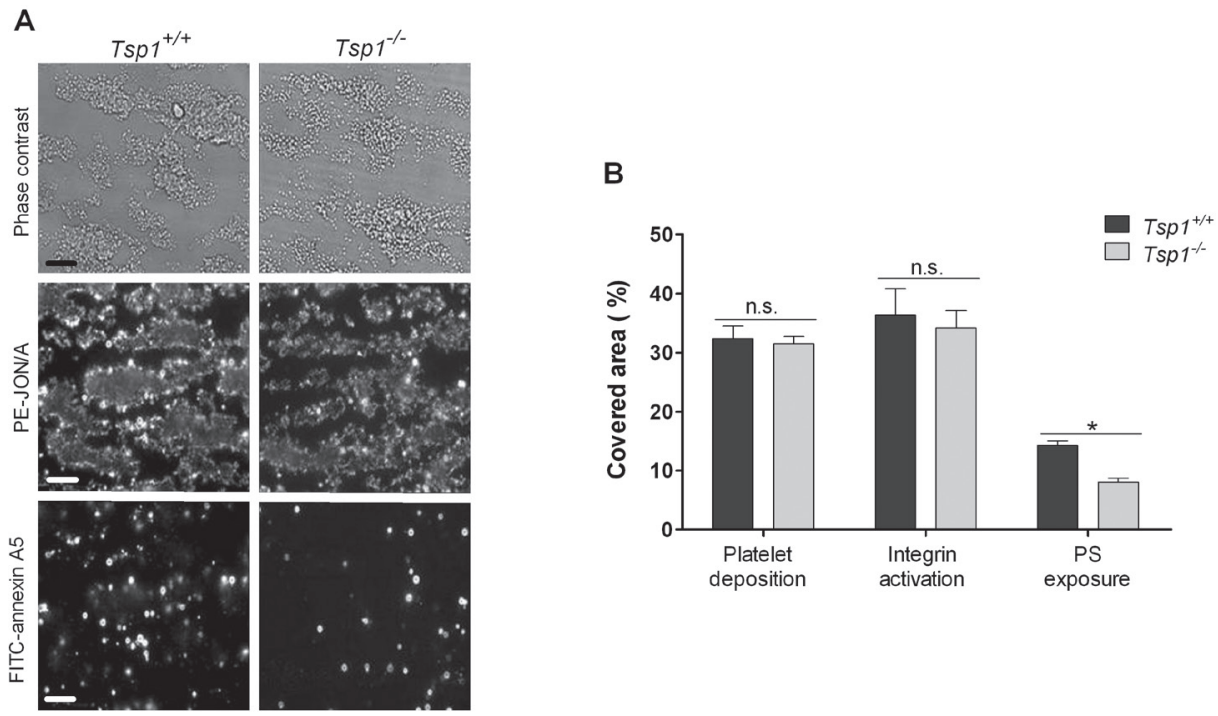

Figure 4.3. Limited role of murine TSP1 in thrombus formation on collagen. PPACK-anticoagulated blood from $T s p 1^{+/+}$or $T s p 1^{-/}$mice was flowed during 4 min over type I collagen at a shear rate of 1000 $\mathrm{s}^{-1}$. Images were recorded with an EVOS microscope. Thrombi were post-stained with PE-JON/A mAb and FITC-annexin A5, as indicated. (A) Representative phase contrast and fluorescence images after flow (bars, $25 \mu \mathrm{m}$ ). (B) Quantification of surface area coverage of all platelets (platelet deposition), JON/Alabeled platelets (integrin activation) and annexin A5-labeled platelets (PS exposure). Means \pm S.E.M. $(n=3-4) ;{ }^{*} p<0.05$ vs. Tsp $1^{+/+}$control. 
Similar flow experiments were performed with PPACK-anticoagulated blood from $\mathrm{Cd} 36^{-}$mice. The blood was flowed over surfaces containing only collagen, or collagen that was post-treated with supernatant from activated platelets. When using supernatant from activated $T s p 1^{+/+}$platelets, this resulted in deposition of TSPI on the collagen, as could be demonstrated by staining with anti-TSPI mAb (not shown). Collagen surfaces were also treated with supernatant from activated Tsp $1^{-1-}$ platelets. Control experiments indicated that surface treatment with supernatant alone did not result in platelet adhesion with blood from either $\mathrm{Cd} 36^{+/+}$or $\mathrm{Cd} 36^{-/}$mice (Figure $4.4 \mathrm{~A}, \mathrm{~B}$ ). However, with collagen, post-treatment with supernatant from $T s p 1^{+/+}$platelets but not from $\mathrm{Tsp}^{1-}$ platelets resulted in increased thrombus formation, in comparison to collagen alone. Morphometric analysis of images further indicated that the mean aggregate size was also larger, when blood from $\mathrm{Cd} 36^{+/+}$mice was flowed (Figure 4.4C,D). However, with CD36-deficient blood, no such increase in platelet deposition or thrombus size was observed.

Knowing that paracrine agonists such as ADP, thromboxane, and Gas6 contribute not only to platelet aggregate formation but also to stabilization of the thrombi29,36, we investigated the stability of aggregates formed byCd36- or Tsp $1^{-1}$ blood. Upon post-

A

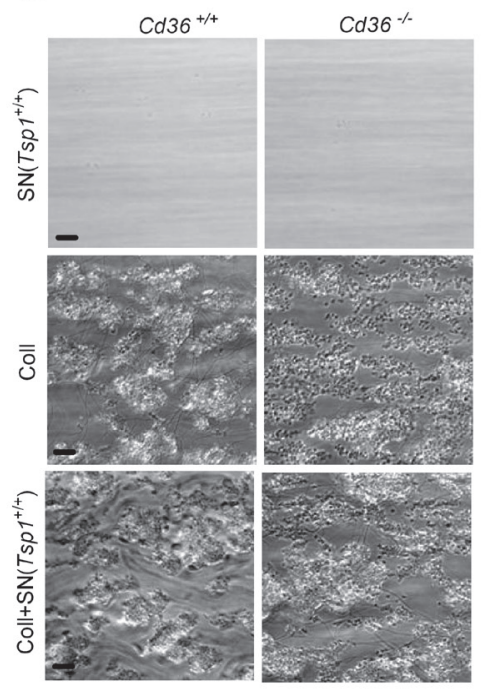

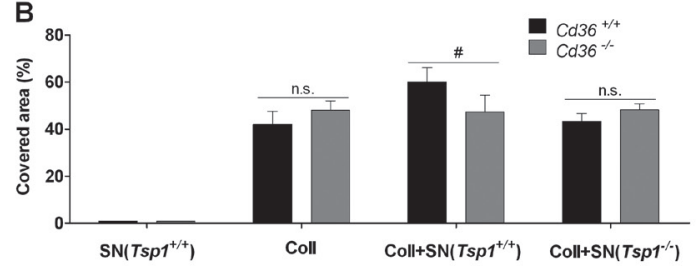

C

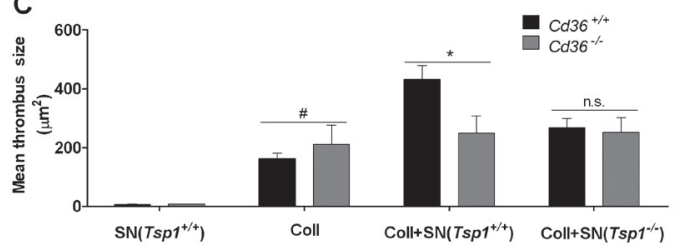

D

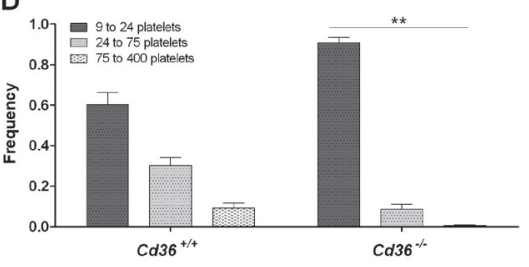

Figure 4.4. Contribution of murine CD36 in thrombus formation on collagen. Surfaces were coated with type I collagen (coll) and/or post-coated with supernatant $(\mathrm{SN})$ from activated $T s p 1^{+/+}$or $T_{s p} 1^{-/}$platelets, as indicated. PPACK-anticoagulated blood from $\mathrm{Cd} 36^{+/+}$or $\mathrm{Cd} 36^{--}$mice was flowed during $4 \mathrm{~min}$ at $1000 \mathrm{~s}^{-1}$, after which formed thrombi were analyzed. (A) Representative phase contrast images after $4 \mathrm{~min}$ of flow (bars, $25 \mu \mathrm{m}$ ). Quantification of $(B)$ platelet surface area coverage, and $(C)$ mean thrombus size. $(D)$ Morphometric analysis of thrombi consisting of 9-24, 24-75 or 75-400 platelets; indicated is frequency distribution. Means \pm S.E.M. $(n=5-6) .{ }^{*} p<0.05,{ }^{\#} p<0.1 v s . C d 36^{+++}$control; ${ }^{* *} p<0.05$ $\left(\chi^{2} v s\right.$. control). 
perfusion with rinsing buffer, the thrombi of both the CD36-deficient and the TSP1deficient platelets appeared to disintegrate shortly after rinse, such in contrast to the thrombi of corresponding wildtype platelets which remained stable for a longer period (Figure 4.5). This suggested that interaction of CD36 with TSPI helps to maintain the formation of a stable thrombus under flow.

\section{$>$ Figure 4.5. Roles of CD36} and TSP1 in thrombus stabilization on collagen. Blood from $\mathrm{Cd}_{36} 6^{-1}$, Tsp $1^{-/-}$or wildtype control mice was flowed over collagen during $4 \mathrm{~min}$ at $1000 \mathrm{~s}^{-1}$. The formed thrombi were then post-perfused for another 6 min with rinsing buffer (Tyrode's Hepes buffer, $2 \mathrm{mM} \mathrm{CaCl}_{2}, 2 \mathrm{mM} \mathrm{MgCl}_{2}, 1$ $\mathrm{U} / \mathrm{ml}$ heparin). Phase-contrast images were taken during the post-perfusion at indicated times. Representative data for 3 experiments.
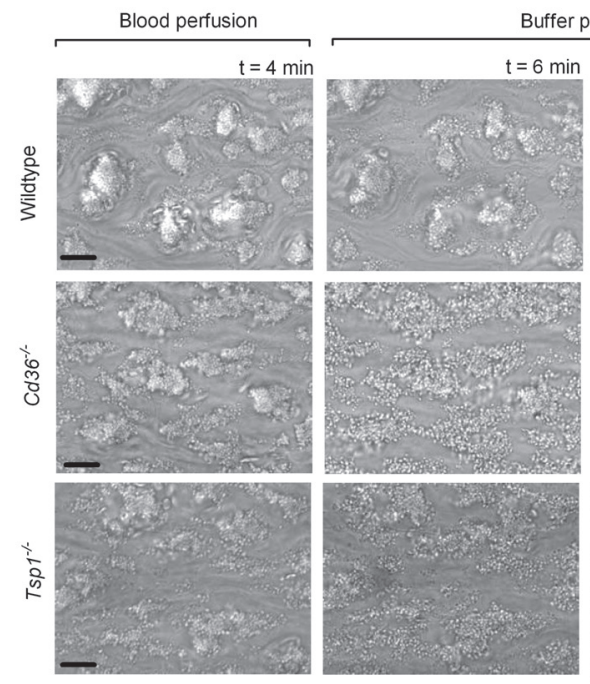

Buffer perfusion
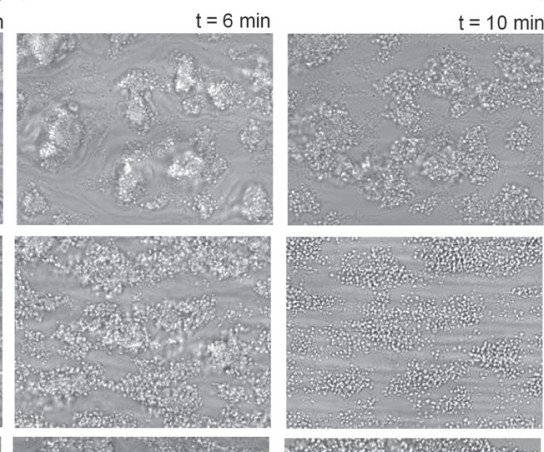
experiments.

In different experiments, thrombi were stained with fluorescently labeled JON/A $\mathrm{mAb}$ and annexin A5 immediately after perfusion, to determine $\alpha_{\mathrm{II}} \beta_{3}$ activation and phosphatidylserine exposure, respectively. Confocal fluorescence microscopy demonstrated a comparable extent of $\alpha_{\mathrm{II}} \beta_{3}$ activation (Figure 4.6A,B) and phosphatidylserine exposure (Figure 4.6C,D) of $\mathrm{Cd}_{3} 6^{+/+}$and $\mathrm{Cd} 36^{-/}$thrombi formed on collagen alone. However, on collagen surfaces post-treated with supernatant from $\mathrm{Tsp}^{+/+}$platelets, but not from Tsp $1^{-/-}$platelets, $\mathrm{Cd} 36^{+/+}$thrombi were higher in either staining than $\mathrm{Cd}_{3} 6^{--}$thrombi. Together, this points to a platelet-activating effect of immobilized TSP1 via CD36, in the presence of collagen, contributing to thrombus growth and stability.

\section{Discussion}

The present study with murine platelets provides novel evidence that surface-immobilized TSPI can act as a platelet-stimulating agent, such in agreement with earlier established data with human platelets (Chapter 3 ). This is considered to be a relevant finding, since TSPI is present in blood plasma and it can be secreted by various cells of the cardiovascular system, such as platelets, endothelial cells and smooth muscle cells, with as a consequence accumulation in the healthy and atherosclerotic vessel wall ${ }^{9,37-40}$. Since TSPI is present in the $\alpha$-granules of platelets ${ }^{6,7}$, this may point to an autocrine effect of released $\mathrm{TSP1}$, i.e. by depositing on collagen or on the surface of a developing thrombus and thus enforcing the thrombus-forming process. In agreement with the present results, 
A
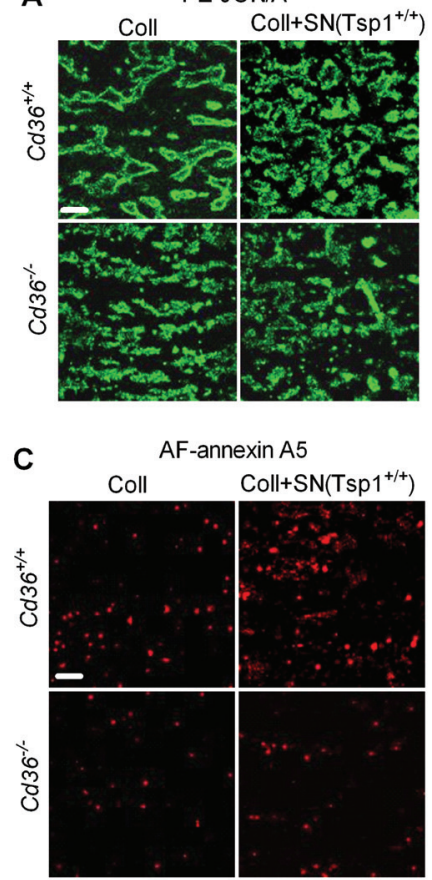

B

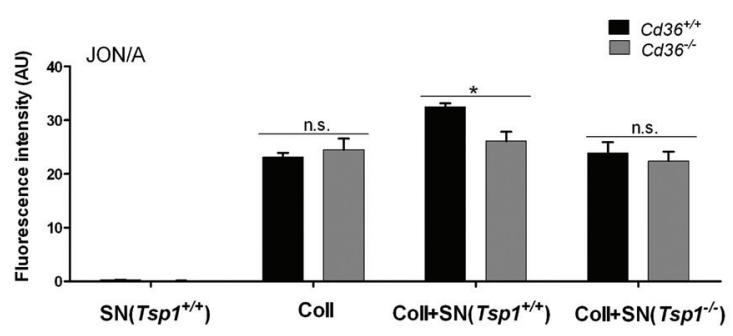

D

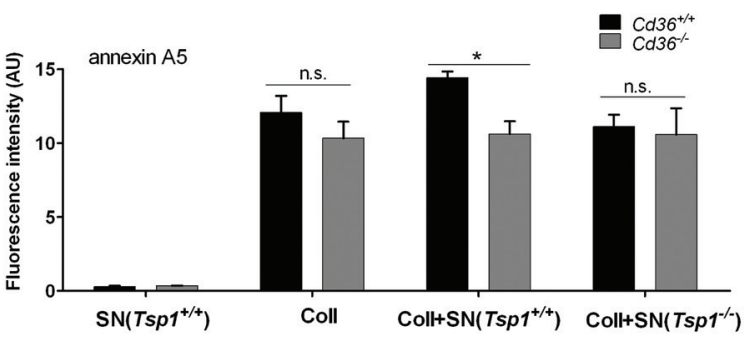

Figure 4.6. Enhanced thrombus formation by CD36-expresing platelets on collagen post-coated with platelet supernatant. PPACK-anticoagulated blood from $\mathrm{Cd}_{3} 6^{+++}$or $\mathrm{Cd} 36^{--}$mice was flowed during $4 \mathrm{~min}$ at $1000 \mathrm{~s}^{-1}$ over a surface coated with collagen (coll) and/or supernatant (SN) from activated Tsp $1^{+/+}$ or $T s p 1^{-/}$platelets. $(A, B)$ Representative fluorescence images (bars, $\left.25 \mu \mathrm{m}\right)$ of thrombi after flow and staining for activated $\alpha_{\mathrm{IIb}} \beta_{3}$ (PE-JON/A mAb) and phosphatidylserine exposure (AF647-annexin A5). $(B, D)$ Quantification of fluorescence coverage by stained thrombi. Means \pm S.E.M. $(n=6-7) ; * p<0.05 v s$. Cd $36^{+++}$control.

others have observed that platelet recruitment on a damaged vessel in vivo is retarded in TSP1-deficient mice in comparison to wildtype mice ${ }^{31}$. Furthermore, it has been reported that CD36 along with GPIb is implicated in the adhesion of pre-activated platelets to TSP1 under arterial shear conditions ${ }^{10}$.

In earlier work from our group, it was shown that continuous inside-out signaling via ADP/ADP receptors and Gas6/Gas6 receptors is required for perpetuated $\alpha_{\text {IIb }} \beta_{3}$ activation and maintenance of platelet-platelet interaction in an aggregate, and thereby for continued stabilization of a thrombus 292010 A267. The present findings extend this to the contribution of another autocrine axis in the thrombus stabilization, namely the interaction of CD36 with platelet-derived TSP1.

The results of this chapter also shed new light on early reports considering CD36 as a platelet collagen receptor ${ }^{15,41}$. We indeed find that the presence of TSPI enhances collagen-dependent thrombus formation and increases the expression of platelet activation markers via CD36. Hence, in experiments where (platelet-derived) TSPI can bind to collagen, there likely is a supportive role of CD36 in platelet adhesion. Furthermore, in the presence of deposited TSP1, CD36 appears to enhance collagen- 
dependent thrombus formation. Taken together, our results point to subtle roles of murine CD36 and platelet-derived TSP1 in: (i) collagen-dependent thrombus formation, and (ii) thrombus stabilization under flow. Hence, platelet CD36 binding to TSPI can be considered another of the multiple receptor-ligand interactions required for the maintenance of a stable thrombus.

\section{Acknowledgements}

We acknowledge grant support from Hacettepe University (Ankara, Turkey) to R.N.U. and from Landsteiner Foundation for Blood Transfusion Research (LSBR 0912F) to S.J.A.K. 


\section{References}

1. Berger G, Caen JP, Berndt MC, Cramer EM. Ultrastructural demonstration of CD36 in the alpha-granule membrane of human platelets and megakaryocytes. Blood. 1993;82:30343044.

2. Ghosh A, Murugesan G, Chen K, Zhang L, Wang Q, Febbraio M, Anselmo RM, Marchant K, Barnard J, Silverstein RL. Platelet CD36 surface expression levels affect functional responses to oxidized LDL and are associated with inheritance of specific genetic polymorphisms. Blood. 2011; in press.

3. Nergiz-Unal R, Rademakers T, Cosemans JM, Heemskerk JW. CD36 as a multiple-ligand signaling receptor in atherothrombosis. Cardiovasc Hematol Agents Med Chem. 2011;9:4255.

4. Silverstein RL, Febbraio M. CD36, a scavenger receptor involved in immunity, metabolism, angiogenesis, and behavior. Sci Signal. 2009;2:re3.

5. Glatz JF, Luiken JJ, Bonen A. Membrane fatty acid transporters as regulators of lipid metabolism: implications for metabolic disease. Physiol Rev. 2010;90:367-417.

6. Bornstein P. Thrombospondins as matricellular modulators of cell function. J Clin Invest. 2001;107:929-934.

7. Bonnefoy A, Hantgan R, Legrand C, Frojmovic MM. A model of platelet aggregation involving multiple interactions of thrombospondin-1, fibrinogen, and GPIIbIIIa receptor. J Biol Chem. 2001;276:5605-5612.

8. Tan K, Lawler J. The interaction of Thrombospondins with extracellular matrix proteins. J Cell Commun Signal. 2009;3:177-187.

9. Esemuede N, Lee T, Pierre-Paul D, Sumpio BE, Gahtan V. The role of thrombospondin-1 in human disease. J Surg Res. 2004;122:135-142.

10. Jurk K, Clemetson KJ, de Groot PG, Brodde MF, Steiner M, Savion N, Varon D, Sixma JJ, Van Aken H, Kehrel BE. Thrombospondin-1 mediates platelet adhesion at high shear via glycoprotein Ib (GPIb): an alternative/backup mechanism to von Willebrand factor. Faseb J. 2003;17:1490-1492.

11. Aiken ML, Ginsberg MH, Byers-Ward V, Plow EF. Effects of OKM5, a monoclonal antibody to glycoprotein IV, on platelet aggregation and thrombospondin surface expression. Blood. 1990;76:2501-2509.

12. Stomski FC, Gani JS, Bates RC, Burns GF. Adhesion to thrombospondin by human embryonic fibroblasts is mediated by multiple receptors and includes a role for glycoprotein 88 (CD36). Exp Cell Res. 1992;198:85-92.

13. Isenberg JS, Wink DA, Roberts DD. Thrombospondin-1 antagonizes nitric oxide-stimulated vascular smooth muscle cell responses. Cardiovasc Res. 2006;71:785-793.

14. Tandon NN, Kralisz U, Jamieson GA. Identification of glycoprotein IV (CD36) as a primary receptor for platelet-collagen adhesion. J Biol Chem. 1989;264:7576-7583.

15. Diaz-Ricart M, Tandon NN, Carretero M, Ordinas A, Bastida E, Jamieson GA. Platelets lacking functional CD36 (glycoprotein IV) show reduced adhesion to collagen in flowing whole blood. Blood. 1993;82:491-496.

16. Yamamoto N, Akamatsu N, Yamazaki H, Tanoue K. Normal aggregations of glycoprotein IV (CD36)-deficient platelets from seven healthy Japanese donors. Br J Haematol. 1992;81:8692.

17. Daniel JL, Dangelmaier C, Strouse R, Smith JB. Collagen induces normal signal transduction in platelets deficient in CD36 (platelet glycoprotein IV). Thromb Haemost. 1994;71:353356.

18. Kehrel B, Wierwille S, Clemetson KJ, Anders 0, Steiner M, Knight CG, Farndale RW, Okuma M, Barnes MJ. Glycoprotein VI is a major collagen receptor for platelet activation: it recognizes the platelet-activating quaternary structure of collagen, whereas CD36, glycoprotein IIb/IIIa, and von Willebrand factor do not. Blood. 1998;91:491-499. 
19. Podrez EA, Byzova TV, Febbraio M, Salomon RG, Ma Y, Valiyaveettil M, Poliakov E, Sun M, Finton PJ, Curtis BR, Chen J, Zhang R, Silverstein RL, Hazen SL. Platelet CD36 links hyperlipidemia, oxidant stress and a prothrombotic phenotype. Nat Med. 2007;13:10861095.

20. Korporaal SJ, van Eck M, Adelmeijer J, IJsseldijk M, Out R, Lisman T, Lenting PJ, van Berkel TJ, Akkerman JW. Platelet activation by oxidized low density lipoprotein is mediated by CD36 and scavenger receptor-A. Arterioscler Thromb Vasc Biol. 2007;27:2476-2483.

21. Leung LL, Li WX, McGregor JL, Albrecht G, Howard RJ. CD36 peptides enhance or inhibit CD36-thrombospondin binding. A two-step process of ligand-receptor interaction. J Biol Chem. 1992;267:18244-18250.

22. Frieda S, Pearce A, Wu J, Silverstein RL. Recombinant GST/CD36 fusion proteins define a thrombospondin binding domain. Evidence for a single calcium-dependent binding site on CD36. J Biol Chem. 1995;270:2981-2986.

23. Siljander $P$, Farndale RW, Feijge MA, Comfurius $P$, Kos $S$, Bevers EM, Heemskerk JW. Platelet adhesion enhances the glycoprotein VI-dependent procoagulant response: involvement of p38 MAP kinase and calpain. Arterioscler Thromb Vasc Biol. 2001;21:618-627.

24. Gilio K, Harper MT, Cosemans JM, Konopatskaya 0, Munnix IC, Prinzen L, Leitges M, Liu Q, Molkentin JD, Heemskerk JW, Poole AW. Functional divergence of platelet protein kinase $C$ (PKC) isoforms in thrombus formation on collagen. J Biol Chem. 2010;285:23410-23419.

25. Febbraio M, Abumrad NA, Hajjar DP, Sharma K, Cheng W, Pearce SF, Silverstein RL. A null mutation in murine CD36 reveals an important role in fatty acid and lipoprotein metabolism. J Biol Chem. 1999;274:19055-19062.

26. Lawler J, Sunday M, Thibert V, Duquette M, George EL, Rayburn H, Hynes RO. Thrombospondin- 1 is required for normal murine pulmonary homeostasis and its absence causes pneumonia. J Clin Invest. 1998;101:982-992.

27. Munnix IC, Kuijpers MJ, Auger J M, Thomassen CM, Panizzi P, van Zandvoort MA, Rosing J, Bock PE, Watson SP, Heemskerk JW. Segregation of platelet aggregatory and procoagulant microdomains in thrombus formation. Regulation by transient integrin activation. Arterioscler Thromb Vasc Biol. 2007;27:2484-2490.

28. Siljander PR, Munnix IC, Smethurst PA, Deckmyn H, Lindhout T, Ouwehand WH, Farndale RW, Heemskerk JW. Platelet receptor interplay regulates collagen-induced thrombus formation in flowing human blood. Blood. 2004;103:1333-1341.

29. Cosemans JM, Munnix IC, Wetzker R, Heller R, Jackson SP, Heemskerk JW. Continuous signaling via phosphoinositide 3-kinase isoforms $\beta$ and $\gamma$ is required for platelet ADP receptor function in dynamic thrombus stabilization. Blood. 2006;108:3045-3052.

30. Brodde MF, Korporaal SJ, Herminghaus G, Fobker M, Van Berkel TJ, Tietge UJ, Robenek H, Van Eck M, Kehrel BE, Nofer JR. Native high-density lipoproteins inhibit platelet activation via scavenger receptor BI Role of negatively charged phospholipids. Atherosclerosis. 2011;215:374-382.

31. Bonnefoy A, Daenens K, Feys HB, De Vos R, Vandervoort P, Vermylen J, Lawler J, Hoylaerts MF. Thrombospondin-1 controls vascular platelet recruitment and thrombus adherence in mice by protecting (sub)endothelial VWF from cleavage by ADAMTS13. Blood. 2006;107:955-964.

32. Davignon J, Ganz P. Role of endothelial dysfunction in atherosclerosis. Circulation. 2004;109:III27-32.

33. Lagadec $P$, Dejoux 0 , Ticchioni M, Cottrez F, Johansen M, B rown EJ, Bernard A. Involvement of a CD47-dependent pathway in platelet adhesion on inflamed vascular endothelium under flow. Blood. 2003;101:4836-4843.

34. Auger JM, Kuijpers MJ, Senis YA, Watson SP, Heemskerk JW. Adhesion of human and mouse platelets to collagen under shear: a unifying model. Faseb J. 2005;19:825-827.

35. Kuijpers MJE, Schulte V, Bergmeier W, Lindhout T, Brakebusch C, Offermanns S, Fässler 
R, Heemskerk JWM, Nieswandt B. Complementary roles of glycoprotein VI and $\alpha 2 \beta 1$ integrin in collagen-induced thrombus formation in flowing whole blood ex vivo. Faseb $\mathrm{J}$. 2003;17:685-687.

36. Cosemans JMEM, van Kruchten $R$, Olieslagers $S$, Schurgers LJ, Verheyen FK, Munnix ICA, Waltenberger J, Angelillo-Scherrer A, Hoylaerts MF, Carmeliet P, Heemskerk JWM. Potentiating roles for Gas6 and Tyor, AxI and Mer (TAM) receptors in human and murine platelet activation and thrombus stabilization. J Thromb Haemost. 2010;8:1797-1808.

37. Moura R, Tjwa M, Vandervoort P, Van Kerckhoven S, Holvoet P, Hoylaerts MF. Thrombospondin- 1 deficiency accelerates atherosclerotic plaque maturation in $A p o E^{-1}$ mice. Circ Res. 2008;103:1181-1189.

38. Wight TN, Raugi GJ, Mumby SM, Bornstein P. Light microscopic immunolocation of thrombospondin in human tissues. J Histochem Cytochem. 1985;33:295-302.

39. Bonnefoy A, Hoylaerts MF. Thrombospondin- 1 in von Willebrand factor function. Curr Drug Targets. 2008;9:822-832.

40. Uchida Y, Uchida Y, Kameda N. Visualization of lipid components in human coronary plaques using color fluorescence angioscopy. Circ J. 2010;74:2181-2186.

41. Matsuno K, Diaz-Ricart M, Montgomery RR, Aster RH, Jamieson GA, Tandon N N. Inhibition of platelet adhesion to collagen by monoclonal anti-CD36 antibodies. $\mathrm{Br} \mathrm{J}$ Haematol. 1996;92:960-967. 



\section{CHAPTER 5}

\section{Complementary roles of platelets and}

coagulation in thrombus formation on plaques

\section{acutely ruptured by targeted ultrasound treatment: a novel intravital model}

Marijke J.E. Kuijpers, Karen Gilio, Sietse Reitsma, Reyhan Nergiz-Unal, Lenneke

Prinzen, Sylvia Heeneman, Esther Lutgens, Marc A.M.J. van Zandvoort, Bernhard Nieswandt, Mirjam G.A. oude Egbrink, Johan W.M Heemskerk

J Thromb Haemost 2009; 7:152-61.

Reprinted with permission 


\title{
Complementary roles of platelets and coagulation in thrombus formation on plaques acutely ruptured by targeted ultrasound treatment: a novel intravital model
}

\begin{abstract}
Atherothrombosis is a major cause of cardiovascular events. However, animal models to study this process are scarce. We describe a first murine model of acute thrombus formation upon plaque rupture to study atherothrombosis by intravital fluorescence microscopy. Localized rupture of an atherosclerotic plaque in a carotid artery from Apoe $^{-/}$mice was induced in vivo using ultrasound. Rupture of the plaque and formation of localized thrombi was verified by two-photon laser scanning microscopy (TPLSM) in isolated arteries, and by immunohistochemistry. The thrombotic reaction was quantified by intravital fluorescence microscopy. Inspection of the ultrasound-treated plaques by histochemistry and TPLSM demonstrated local damage, collagen exposure, luminal thrombus formation as well as intra-plaque intrusion of erythrocytes and fibrin. Ultrasound treatment of healthy carotid arteries resulted in endothelial damage and limited platelet adhesion. Real-time intravital fluorescence microscopy demonstrated rapid platelet deposition on plaques and formation of a single thrombus that remained subocclusive. The thrombotic process was antagonized by thrombin inhibition, or by blocking of collagen or ADP receptor pathways. Multiple thrombi were formed in $70 \%$ of mice lacking CD40L. Targeted rupture of murine plaques results in collagen exposure and non-occlusive thrombus formation. The thrombotic process relies on platelet activation as well as on thrombin generation and coagulation, and is sensitive to established and novel antithrombotic medication. This model provides new possibilities to study atherothrombosis in vivo.
\end{abstract}




\section{Introduction}

Atherothrombosis is a life-threatening disease, which is caused by thrombus formation at the surface of ruptured or eroded atherosclerotic plaques in coronary or carotid arteries. Subsequently, a combination of acute and chronic events such as myocardial infarction or stroke can occur ${ }^{1,2}$. As the rupture of a vulnerable plaque is an unpredictable event, the ensuing process of thrombus formation is difficult to monitor in man.

In recent years, several murine thrombosis models have been developed to study thrombus formation in microvessels of the mesentery, but also in larger vessels such as the carotid artery ${ }^{3-6}$. In this work, intravital microscopic imaging has become a highly valuable tool to identify the dynamics of the thrombotic process. In general, it has been shown that arterial thrombosis is triggered and driven by activation of both platelets and the coagulation system, although the relative contribution of either may depend on the vessel type and the method of vascular damage. However, in all these models, healthy blood vessels were damaged rather than diseased, atherosclerotic vessels. Research into atherothrombosis thus lacks a suitable animal model of acute plaque rupture.

Upon feeding with high fat diet, Apoe ${ }^{-/-}$mice progressively develop atherosclerotic lesions in the aortic arch and the carotid arteries. Since spontaneous rupture of these lesions is very rare ${ }^{7}$, various methods have been explored to provoke this event. These include manual squeezing of the plaque-containing aorta between forceps; ${ }^{8}$; ligation of the carotid artery and cuff placement ${ }^{9}$; collar placement around the carotid artery followed by adenovirus p53 transfection ${ }^{10}$; generation of double knock-outs like Apoe ${ }^{-/-} \mathrm{NpC1}^{-1-}$ mice $^{11}$; and photochemical thrombus induction with rose Bengal ${ }^{5}$. However, these methodologies mostly led to incomplete or non-acute rupture of plaques or to nonpredicted localization of the thrombotic process.

Using intravital microscopy, earlier used to study thrombus formation in healthy murine carotid arteries ${ }^{12,13}$, we aimed to develop a model for plaque rupture-evoked thrombus formation in the same vessel type. We report that targeted ultrasound treatment of a plaque shoulder in carotid arteries of Apoe ${ }^{-/}$mice acutely produces a non-occlusive thrombus, the formation of which relies on both platelet activation and thrombin generation.

\section{Materials and Methods}

\section{Animals}

Apoe ${ }^{-/}$mice on C57Bl/6 background of either sex (4 weeks old) were obtained from Charles River (Maastricht, The Netherlands). Mice with the same background deficient in both Apoe and CD40L were obtained as described ${ }^{14}$. Experiments were approved by the local animal care and use committee.

\section{Materials}

Carboxyfluorescein diacetate succinimidyl ester (CFSE) and Syto4l were from Molecular Probes (Leiden, NL). Biotinylated CNA35 was conjugated with quantum dot (QD)585-streptavidine as described ${ }^{15}$. Hirudin was from Pharmion (Cambridge, 
UK), cangrelor from the Medicines Company (Parsippany, NJ), TGX221 from Baker (Melbourne, AUS). Anti-GPVI antibody JAQ1 was obtained as described ${ }^{16}$. Sources of other materials are given elsewhere ${ }^{13}$.

\section{Plaque rupture and measurement of acute thrombus formation}

Apoe $^{-/}$mice were fed a Western-type diet with $0.15 \%$ cholesterol for $18-20$ weeks. One or more plaques of a length of 0.5-1.0 mm were then present often in both carotid arteries (diameter 500-550 $\mu \mathrm{m}$ ) near the bifurcation. Animals were anesthetized by subcutaneous injection of ketamine and xylazine $(0.1 \mathrm{mg} / \mathrm{g}$ and $0.02 \mathrm{mg} / \mathrm{g}$ body weight); body temperature was held at $37^{\circ} \mathrm{C}$. Carotid arteries were carefully dissected free from surrounding tissue, and the animal was injected intravenously with CFSElabeled platelets ${ }^{17}$, obtained from a donor mouse with the same genetic background. Mice were subsequently injected with vehicle solution, anti-coagulant or anti-platelet drug, as indicated.

Using intravital fluorescence microscopy, a plaque was selected in one of the carotid arteries near the bifurcation under brightfield illumination. The tip ( $0.5 \mathrm{~mm}$ diameter) of a titanium ultrasound probe was placed at the shoulder region of a plaque. Rupture was induced by ultrasound application during $10 \mathrm{sec}$ at $6 \mathrm{kHz}$ using a VibraCell VCX130 processor (Sonics, Newtown, CT). Thrombus formation was recorded as fast as possible by capturing of 12-bit fluorescence images at $33 \mathrm{~Hz}$ during at least $10 \mathrm{~min}$, using a back-thinned electron multiplier C9100-12 EM-CCD camera (Hamamatsu, Japan) at fixed gain settings. Where indicated, effects of ultrasound treatment on carotid blood flow were monitored with a Doppler flow probe $(0.5 \mathrm{~mm} \mathrm{~V}$ series, Transonic Systems TS420, Ithaca, NY).

Time-series of images were analyzed using Wasabi (Hamamatsu) software. Per region of interest (ROI) representing the site of thrombus formation, total pixel intensity was calculated and corrected for background. To quantify thrombus size after specific time intervals, fluorescence images were processed using ImagePro software (Media Cybernetics, Silverspring, MD). Within the image of a carotid artery, two similar ROIs were defined, representing the thrombus area and an adjacent area representing the background. Subsequently, a threshold level was set by eliminating all pixels with intensity lower than $\mathbf{9 9 . 0 \%}$ of the pixels of the background ROI. Intensities (gray levels) of all pixels in the thrombus ROI were then integrated. No image processing was applied. Masks are shown in 10-color level.

\section{Isolation of mouse plasma and platelets}

Anesthetized mice were bled for isolation of platelet-rich plasma (PRP) for measurements of tissue factor-induced thrombin generation ${ }^{18}$, and of aggregation and P-selectin expression following platelet stimulation ${ }^{3}$.

\section{Two-Photon Laser Scanning Microscopy (TPLSM)}

After in vivo treatment, carotid arteries containing the bifurcation were isolated, and mounted into a perfusion chamber at $60 \mathrm{~mm} \mathrm{Hg}$ fluid pressure, as described ${ }^{15}$. Vessels 
were perfused with QD585-labeled CNA35 (50 nM) to detect luminally exposed collagen, and counter-stained with the nuclear probe Syto4l $(2.5 \mu \mathrm{M})$. Mounted vessels were scanned near the plaque-lumen interface (500 lines/sec, 3x Kalman averaging) at 50\% pulse-laser intensity (800 nm excitation, $100 \mathrm{fs}$ pulse-width). Two-photon fluorescence was recorded at 450-470 nm (blue), 500-550 nm (green) and 560-600 nm (red), using a Biorad $2100 \mathrm{MP}$ system (Zeiss, Hemel Hempstead, UK) ${ }^{13,15}$.

\section{Histology}

Carotid arteries including bifurcations were fixed and embedded into paraffin. Sections were stained with hematoxylin and eosin ${ }^{19}$, or Carstair's stain ${ }^{20}$.

\section{Statistical analysis}

Groups were compared with the non-parametric Mann-Whitney $U$ test (one-tailed). A p-value below 0.05 was considered significant; a p-value below 0.1 was considered as borderline significant. Data are presented as means \pm SEM.

\section{Results and Discussion}

\section{Targeted ultrasound treatment of a carotid plaque results in local collagen exposure and thrombus formation}

Apoe $^{-/}$mice were fed with a cholesterol-enriched diet for 18-20 weeks to achieve formation of one or more plaques around the bifurcation mostly in both carotid arteries (Figure 5.1A). After dissection from surrounding tissue these plaques are detected as a white mass by brightfield light transmission microscopy (Figure 5.1B-D). We studied the susceptibility of these plaques to rupture by local ultrasound treatment. Injection of CFSE-labeled Apoe- platelets and fluorescence microscopy enabled visualization of thrombus formation. After testing various ultrasound systems at different settings, most reproducible results were obtained with a VibraCell VCX130 sonicator system. This sonicator was equipped with a miniaturized ultrasound probe $(0.5 \mathrm{~mm}$-wide titanium tip) for local application of energy. Guided by the microscope, the titanium tip was placed at the downstream shoulder region of a suitable plaque (length 0.5-1.0 mm) of the left or right carotid artery (Figure 5.1B,E). After $10 \mathrm{sec}$ of ultrasound application (frequency of $6 \mathrm{kHz}$ ), platelets immediately adhered, after which a thrombus was formed in $95 \%$ of the cases (see below). However, the treatment did not change blood flow in the artery (Figure 5.1F). As estimated from the site of platelet adhesion, a circular area was damaged of $\sim 300 \mu \mathrm{m}$ in diameter.

Brightfield intravital observations of the outside of the vessel showed that the overall appearance of the plaque remained similar, thus demonstrating that the treatment had not resulted in removal of the plaque. In contrast, histological analysis of paraffin-embedded sections revealed clear morphologic changes inside the vessel, at the region where the ultrasound probe was applied. Whereas untreated control plaques had a smooth cap covered with endothelial cells (Figure 5.2A), plaques exposed to the ultrasound treatment had a frayed appearance and part of the core content was 
A

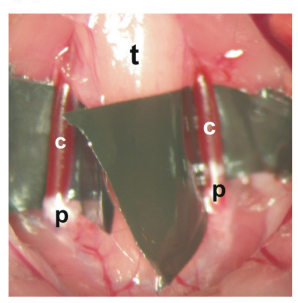

D

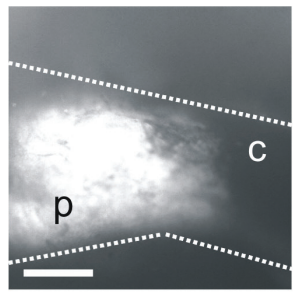

B

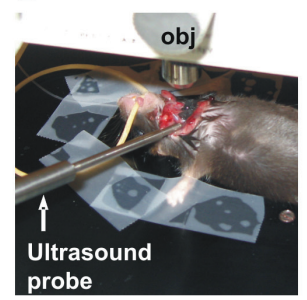

E

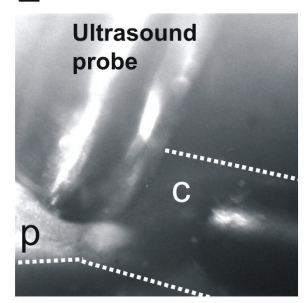

C

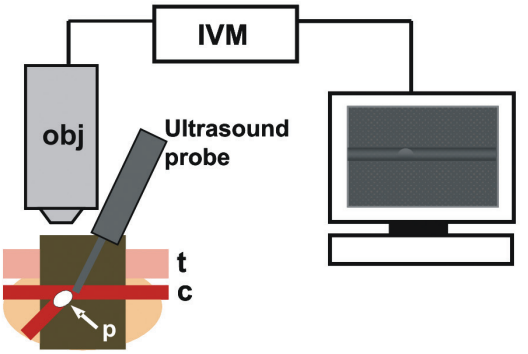

$\mathrm{F}$

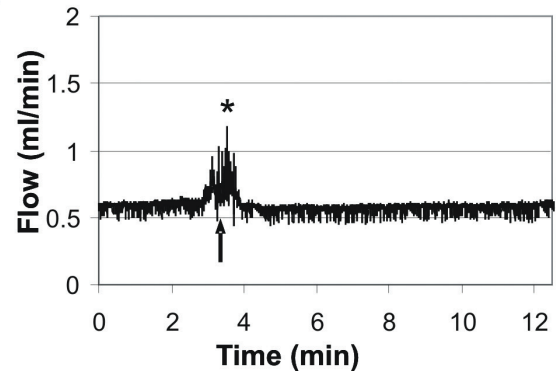

- Figure 5.1. Method of ultrasound treatment of atherosclerotic plaque in carotid artery. An artery from an $\mathrm{Apoe}^{-/}$mouse was dissected free from surrounding tissue (A) and observed by an intravital microscope system (IVM, B). Panels C gives a schematic representation: Indicated are carotid artery (c), objective (obj), plaque (p) and trachea (t). (D) Brightfield microscopic image of a $0.5 \mathrm{~mm}$ plaque near the artery bifurcation (bar, $250 \mu \mathrm{m}$ ). (E) Tip of titanium probe placed at the plaque shoulder. (F) Unchanged blood flow in carotid artery after ultrasound rupture of plaque (arrow), as measured with a Doppler flow probe ( $\mathrm{n}=3$ mice). *Peak is due to effect of ultrasound on the Doppler signal.

exposed to the vessel lumen (Figure 5.2B). On top and in between the disturbed plaque tissue, loose thrombi were present consisting of platelets and erythrocytes. Carstair's stain detected exposure of collagen and formation of fibrin networks (Figure 5.2C). No structural changes were seen in the tunica media and adventitia.

In control experiments, the same ultrasound treatment was applied to the healthy carotid arteries from wildtype mice. This resulted in damage but not in complete removal of the endothelial cells. Injection of CFSE-labeled autologous platelets showed adhesion of mostly single platelets and microaggregates at the treatment side (Figure 5.3).

Besides structural cap injury, a key marker of plaque rupture is intrusion of erythrocytes into the plaque core region ${ }^{21,22}$. To demonstrate this, we analyzed serial paraffin sections of a representative plaque-containing vessel, starting downstream and ending at $400 \mu \mathrm{m}$ upstream of the treatment site. This indeed showed intra-plaque accumulation of erythrocytes and fibrin starting at the ruptured site and continuing into sections of the upstream region (Figure 5.2D,E). Carotid vessels were also checked for the presence of intraplaque hemorrhages and neovessels, but these were not detected. Given the fact that spontaneous plaque rupture is very rare in mouse carotid plaques ${ }^{7}$, these results thus provide additional evidence that the ultrasound treatment indeed leads to rupture of the plaque. 
- Figure 5.2. Rupture of carotid plaque and presence of intra-plaque erythrocytes after ultrasound treatment. Stained sections from representative carotid arteries from Apoe $^{-/}$mice with hematoxylin/eosin (left panels) or with Carstair's stain (right panels), which colors collagen in blue and fibrin in bright red. (A) Sections of untreated plaque at the shoulder (bar, $150 \mu \mathrm{m}$ ). (B) Sections of an ultrasound-treated plaque, ruptured at the shoulder region, with loose thrombus (thr) (bar, $150 \mu \mathrm{m}$ ). (C) Higher magnification images of B (bar $10 \mu \mathrm{m}$ ). Dotted line indicates site of thrombus formed on plaque tissue; thrombus stains positively for erythrocytes (e), fibrin (f, brightly red) and platelets (plt). Note the nearby localization of thrombus and collagen (c, blue). (D) Sections of the same plaque, taken at $450 \mu \mathrm{m}$ upstream of the ruptured site. Arrows point to erythrocytes present underneath the plaque. (E) Higher magnification of adjacent section (bar, 10 $\mu \mathrm{m})$, marking intra-plaque erythrocytes (e) and fibrin (f).
A

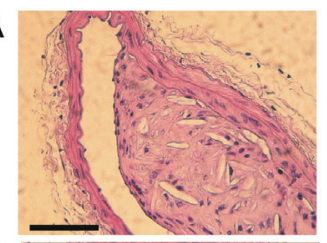

B

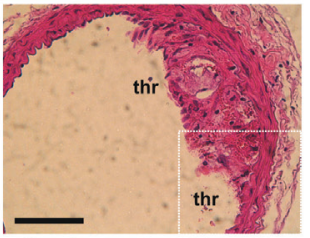

C
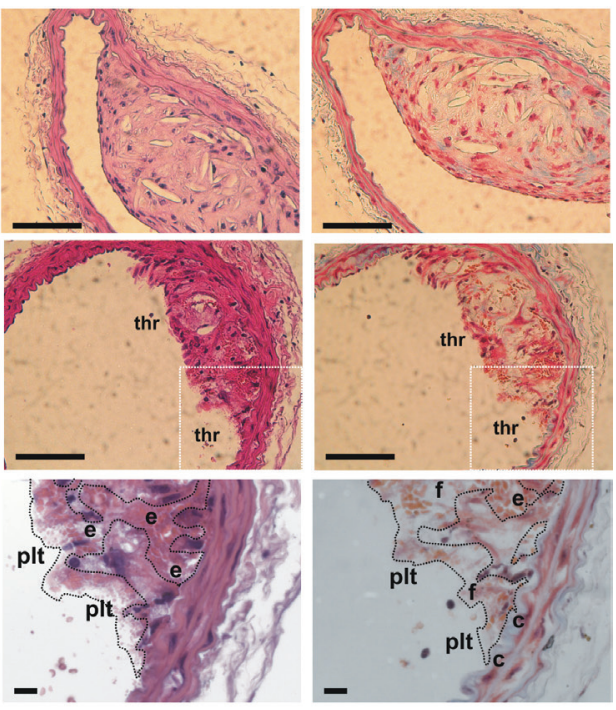

$\mathrm{D}$

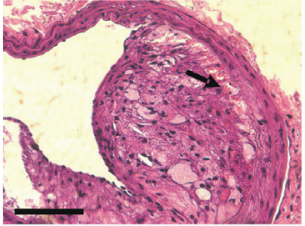

E

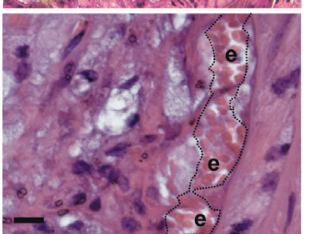

Haematoxylin/eosin
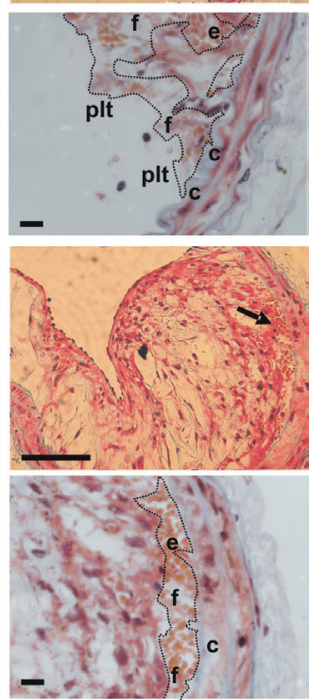

Carstair

The presence of fibrin indicated that coagulation had been activated upon plaque rupture. Earlier in vitro studies with isolated atherosclerotic plaque material demonstrated a role of plaque-derived tissue factor in the triggering of coagulation ${ }^{23,24}$. To verify a role of tissue factor, we determined tissue factor activity in plaque tissue obtained from apoe ${ }^{-1-}$ mice as described previously ${ }^{23}$. We observed 10 pM active tissue factor per mg of protein, indicating that substantial amounts of tissue factor are present within the plaques.

To further characterize the extent of vascular damage, intact carotid arteries were scanned by two-photon laser scanning microscopy (TPLSM), a technique which allows imaging of the morphological details of vessel wall and plaque shoulder (Figure 5.4A). Mice were injected with CFSE-labeled platelets, and plaques in the carotid arteries were treated or not by ultrasound. Intact arteries were then carefully isolated, mounted without fixation into a flow chamber, and slowly perfused with QD585-CNA35, a labeled Staphylococcus aureus protein that specifically binds to exposed collagen ${ }^{15}$. Optical cross-sections of ultrasound-treated vessels showed bright staining of collagen 


\begin{abstract}
Figure 5.3. Ultrasound treatment of healthy carotid artery results in limited platelet adhesion. Carotid arteries from wildtype mice were treated with ultrasound. Tissue sections were prepared and stained with hematoxylin/eosin. (A) Section of an ultrasound-treated artery. Representative images are given of low (bar, $150 \mu \mathrm{m}$ ) and high magnification (bar, $10 \mu \mathrm{m}$ ), arrows indicate nuclei of endothelial cells, arrowheads indicate platelets. (B) Corresponding section of untreated artery; low and high magnification images as above.
\end{abstract}
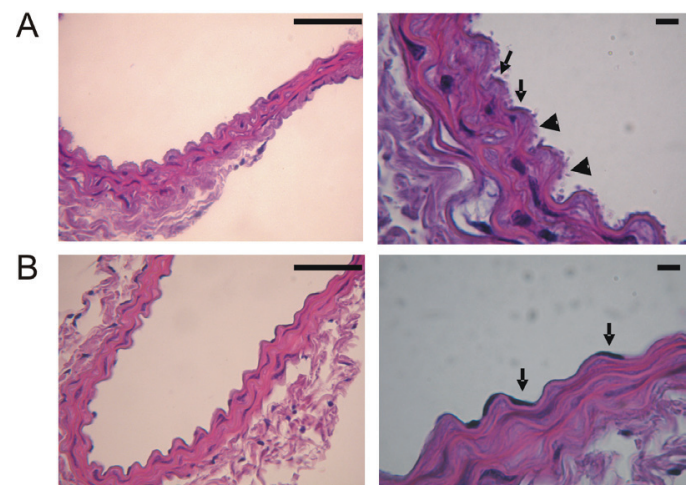

and fluorescent platelets at the plaque shoulder region near the lumen (Figure 5.4B). Post-staining of cellular nuclei with Syto 41 revealed aligned strings of smooth muscle cells in the vessel wall, whereas endothelial cells had mostly disappeared (Figure 5.4C). In contrast, in untreated control arteries, the endothelial cells of the plaque shoulder region still formed an intact monolayer, while hardly any collagen or platelet staining was visible (Figure 5.4D). Three-dimensional image reconstructions illustrate the large exposed collagen sheet in the ultrasound-treated vessel (Figure 5.4E,F). Together, these results indicate that the targeted use of ultrasound provoked local plaque damage, exposure of collagen, and assembly of a thrombus with platelets, fibrin and erythrocytes.

\title{
Targeted ultrasound treatment results in acute formation of subocclusive thrombi
}

Thrombus formation in damaged carotid arteries can be monitored in a sensitive way by intravital microscopic detection of CFSE-labeled platelets ${ }^{12}$. We used this method to quantify the thrombus-forming process following ultrasound plaque treatment. Mice were injected with CFSE-labeled Apoe ${ }^{-/}$platelets, at an extent that $9 \pm 2 \%$ of the circulating platelets were fluorescently labeled. At baseline fluorescent platelets flowed through the carotid artery, and incidentally adhered at the plaque region (Figure 5.5A). This confirms the earlier observation that murine platelets can stick to plaques and thereby contribute to atherosclerosis development ${ }^{25}$.

In the large majority of atherosclerotic arteries (14/15), targeted application of ultrasound $(6 \mathrm{kHz}$ for $10 \mathrm{sec}$ ) at the plaque shoulder resulted in local formation of a single fluorescent thrombus (Figure 5.5A). Only in one case, the ultrasound treatment led to formation of one larger thrombus with adjacent smaller thrombi. At lower ultrasound energy levels, no thrombi were formed (not shown). The maximal thrombus size was reached after a variable time of 30 to $60 \mathrm{sec}$, after which the thrombi declined (Figure 5.5B). As a consequence of this variation in growth, calculated integrated fluorescence intensities after 30 and $60 \mathrm{~s}$ were somewhat variable, i.e. $2192 \pm 870$ and $2078 \pm 780\left(\times 10^{3}\right.$, mean $\left.\pm S E M, n=8\right)$. In the declining phase, only few single platelets and - very rarely - platelet aggregates left the thrombus. Also fluorescence bleaching was relatively low $(<2 \% / \mathrm{min})$, suggesting that the declining phase had a different 

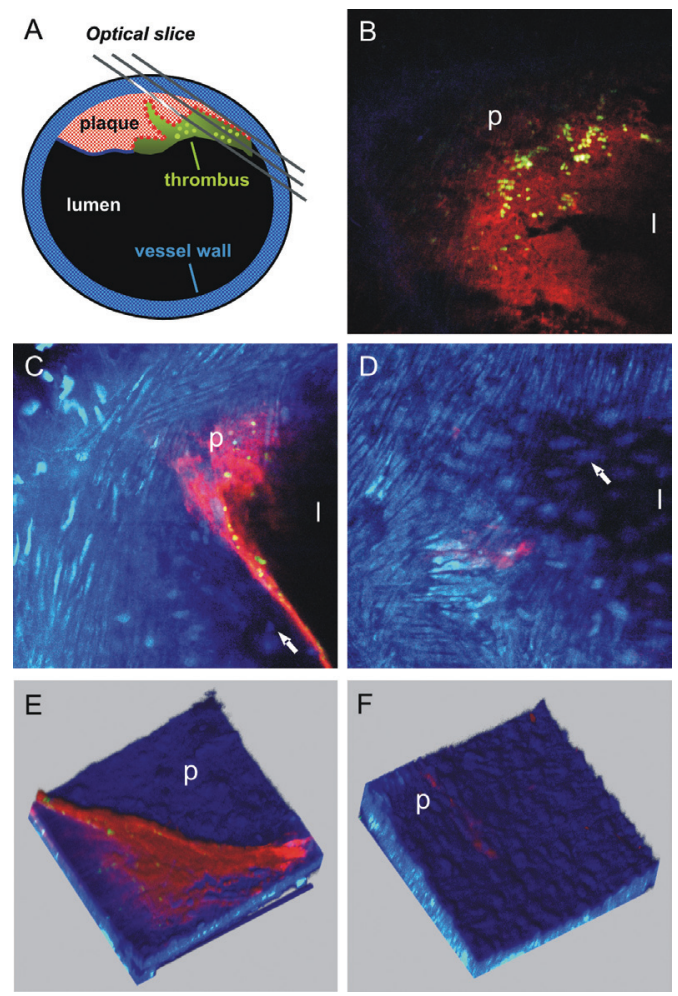

Figure 5.4. Platelet deposition and collagen exposure after plaque rupture by ultrasound treatment, as demonstrated by two-photon laser scanning microscopy. Ultrasound-treated and control carotid arteries were isolated from Apoe $^{-t}$ mice, mounted in a perfusion chamber and scanned with TPLSM for monitoring fluorescence at deep penetration. CFSE-labeled platelets (green) were injected prior to plaque rupture; no fixation was applied. (A) Schematic representation of optical sections through plaquecontaining artery. (B) Image of cross-section close to plaque shoulder of an ultrasound-treated vessel, postperfused with collagen-binding QD585-CNA35 (red). Note the aggregated CFSE-labeled platelets (green) close to the site of collagen staining (red). (C, D) Cross-sections through plaque (p) shoulder and lumen (l) of an ultrasound-treated vessel and a control vessel, post-perfused with QD585-CNA35 and nuclear stain Syto41 (blue). (C) Treated vessel: ultrasound treatment provoked exposure of a collagen network (red) with attached platelets (green) in the shoulder adjacent to the vessel lumen (black). Note normal alignment of smooth muscle nuclei (blue) and incidental endothelial nucleus (arrow). (D) Control vessel: undamaged vessel wall with weak staining for collagen (red) and monolayer of endothelial nuclei (blue, arrow) near the vessel lumen (black). Image sizes, $150 \times 150 \mu \mathrm{m}$. (E, F) Three-dimensional overview of stained ultrasoundtreated $(179 \times 179 \times 84 \mu \mathrm{m})$ and control $(179 \times 179 \times 55 \mu \mathrm{m})$ vessels from the luminal side. Note the locations of plaque (p) shoulder, and the marked exposed collagen network (red) in the treated vessel.

cause, e.g. contraction of platelets and fibrin. Analysis of images from multiple vessels learned that the secondary size reduction was a general phenomenon and extended to a period of 10 min (Figure 5.5C). Remarkably, thrombi never occluded the vessel. Also a second and third ultrasound treatment of the same plaque shoulder did not result in full occlusion. This biphasic pattern of thrombus formation resembles the pattern earlier described for laser-induced thrombus formation in murine arterioles, where platelet 


\section{A Control}
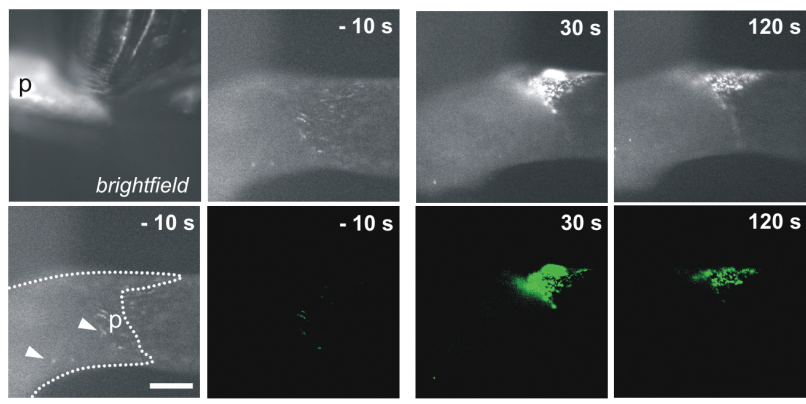

B
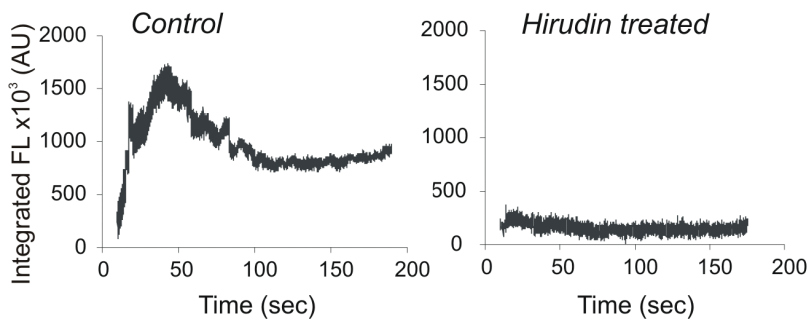

\section{Hirudin treated}
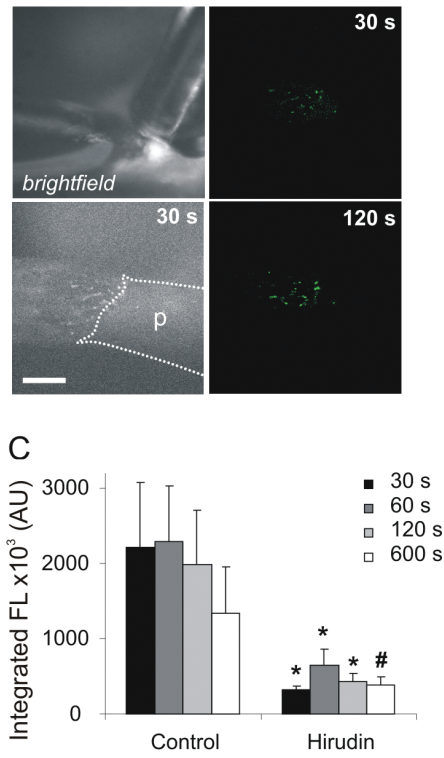

Figure 5.5. Rapid formation of sub-occlusive thrombi upon plaque rupture. Mice were untreated (control) or injected with hirudin $\left(5 \mathrm{mg} \mathrm{kg}^{-1}, 10 \mathrm{~min}\right.$ ). (A) Brightfield images of titanium tip at plaque shoulder (upper left), and fluorescence images before and at 30-120 sec after ultrasound treatment. Dotted areas indicate location of plaque (p); arrows indicate blood flow direction (bar, $250 \mu \mathrm{m}$ ). Green images are background-subtracted masks, showing CFSE-labeled platelets trapped in the thrombus. (B) Timecourses of fluorescence intensity above background of the same thrombi formed by ultrasound treatment. (C) Quantification of thrombus size. Data are integrated fluorescence intensities for multiple vessels after $30,60,120$ and $600 \mathrm{sec}$ (mean \pm SEM, $n=5-8$ mice). ${ }^{*} P<0.05$ and ${ }^{\#} P<0.10$ compared to control (MannWhitney).

loss was associated with increased cAMP levels ${ }^{26}$. Altogether, our results show that, in the carotid arteries of Apoe ${ }^{-/}$mice, thrombus formation induced by plaque rupture is an acute, well-regulated and partly transient process, which by itself does not lead to vascular occlusion.

\section{Platelet and thrombin inhibitors affect thrombus formation on ruptured plaques}

Various laser- and $\mathrm{FeCl}_{3}$-induced models of thrombus formation demonstrate that thrombus formation relies on the combined activation of platelets and the coagulation system ${ }^{4,6,20,27}$. Also in vitro studies, using isolated atherosclerotic plaques, point to a combined prothrombotic effect of platelet- and coagulation-stimulating factor ${ }^{23,24}$. It was therefore of interest to use inhibitors of both processes in the present plaque rupture model.

To study the role of thrombin, Apoe ${ }^{-/}$mice were injected intravenously with a highaffinity thrombin inhibitor, hirudin $\left(5 \mathrm{mg} \mathrm{kg}^{-1}\right)$. This resulted in complete eradication of thrombin generation in mouse plasma ex vivo (Figure 5.6A). In vivo, hirudin injection strongly suppressed the formation of thrombi following plaque rupture. Only small 
platelet aggregates assembled in the first minutes (Figure 5.5A,B). These aggregates did not grow in size over a time period of $10 \mathrm{~min}$ (Figure $5.5 \mathrm{C}$ ) or even $30 \mathrm{~min}$ (not shown). This pointed to a potent contribution of the coagulant system.

In other mouse models, the platelet collagen receptor GPVI and its co-receptor FcR $\gamma$-chain have been shown to play a key role in arterial thrombosis ${ }^{3,12}$. A suitable tool to study involvement of this pathway is by injection of the anti-GPVI mAb, JAQI $(100 \mu \mathrm{g})$. This results in mild and transient thrombocytopenia (maximal platelet drop of $30 \%$ ), but also in complete abolition of the platelet responses to collagen and other GPVI-activating agonists like convulxin ${ }^{3}$. This was confirmed in the present study, i.e. platelets from mice injected with JAQ1 were unable to expose P-selectin in response to convulxin (Figure 5.6B). In vivo experiments indicated that JAQ1 injection significantly impaired the thrombus formation evoked by plaque ultrasound treatment (Figure 5.7A,B). Fluorescence recordings after treatment showed normal numbers of circulating labeled platelets but greatly reduced adhesion, pointing to a diminished platelet interaction with exposed collagen.

Other Apoe ${ }^{-/}$mice were pre-injected with agents interfering with the ADP/P2Y signaling pathway, which is crucial for stable platelet aggregation ${ }^{28,29}$. Platelet $\mathrm{P}_{2} \mathrm{Y}_{12}$ receptors were blocked by continuous infusion with the specific inhibitor

- Figure 5.6. Efficacy of in vivo treatment with anticoagulant or anti-platelet agents. Anesthetized mice were injected intravenously with vehicle solution or indicated antagonist, as described for Figs. 4-5. PRP was isolated to verify treatment effects ex vivo. Data are representative for $\geq 2$ animals. (A) Thrombin generation induced by tissue factor (1 $\mathrm{pM})$ in the presence of $20 \mu \mathrm{M}$ ADP. Cangrelor $(1 \mu \mathrm{M})$ was added in vitro to measure residual $\mathrm{P} 2 \mathrm{Y}_{12}$ activity, where indicated (+cangr, dotted lines). (B) P-selectin expression on platelets, following 5 min activation with GPVI agonist convulxin $\left(10 \mathrm{ng} \mathrm{mL}^{-1}\right)$. Bars give percentages of positive cells, as determined by flow cytometry (mean \pm SEM, $n=4$ mice, $* P<0.05$ compared to vehicle). (C) Platelet aggregation induced by $5 \mu \mathrm{g} \mathrm{mL}^{-1}$ collagen or 20 $\mu \mathrm{M}$ ADP. Curves represent changes in optical transmission.
A
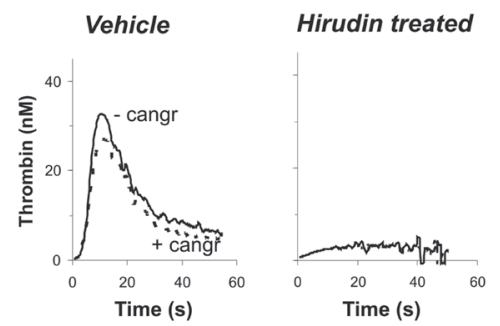

P2Y12 treated

B

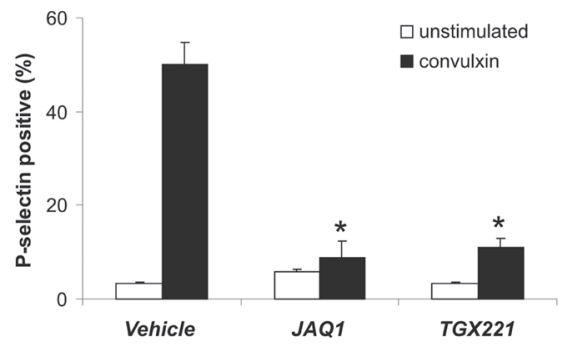

C

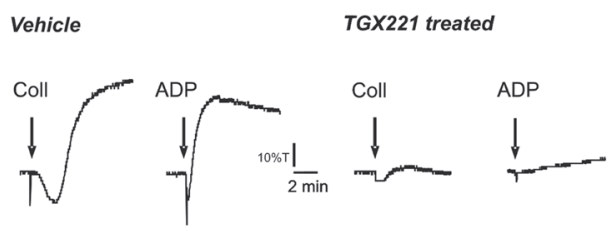


cangrelor ${ }^{30}$. Alternatively, TGX221 was injected as a single dose to block activity of phosphoinositide 3-kinase $\beta$, i.e. a key signaling enzyme downstream of $P 2 Y_{12}$ and GPVI. Control experiments showed that $P 2 Y_{12}$ receptor treatment abolished all ADPdependent stimulation of thrombin generation in mouse PRP (Figure 5.6A), which is a unique $P 2 Y_{12}$-mediated effect ${ }^{18}$. Other controls indicated that injection of TGX221 affected collagen- and ADP-evoked platelet aggregation as well as GPVI-dependent P-selectin exposure (Figure 5.6B,C). In vivo, both cangrelor and TGX221 reduced the thrombus formation caused by ultrasound treatment, while TGX221 provoked incidental embolization (Figure 5.7A,B). Together, these findings point to a contribution of both collagen and ADP receptor pathways to the thrombotic process induced by plaque ultrasound treatment.

Both thrombin and collagen have been reported to contribute to the progression of atherosclerotic lesions in Apoe ${ }^{-/}$mice. For instance, either thrombin inhibition with melagatran ${ }^{31}$ or deficiency in GPVI/FcR $\gamma^{32}$ can result in diminished lesion progression. These changes have been explained by anti-inflammatory effects of thrombin inhibition or of FcR $\gamma$ deletion, respectively. However, since local platelet activation can contribute to lesion progression and since activated platelets abundantly secrete pro-inflammatory mediators ${ }^{25,33}$, the present results suggest that thrombin and collagen are involved in platelet interactions with a damaged or ruptured plaque, e.g. by stimulating the formation of transient, non-occlusive thrombi.

\section{Subocclusive thrombus formation on carotid plaques in another genetic mouse model}

The effect of ultrasound treatment was also studied in mice with a different plaque phenotype. Mice lacking Apoe and CD40 L on platelets and leukocytes develop plaques with a reduced lipid and increased collagen content ${ }^{14}$. In addition, platelets from $\mathrm{CD}_{40 \mathrm{~L}^{-1-}}$ mice form thrombi with reduced stability ${ }^{29}$. Provoking plaque rupture in the carotid arteries of $\mathrm{Apoe}^{-/-} / \mathrm{CD} \mathrm{OL} \mathrm{L}^{-/-}$mice resulted in the formation of mostly two or more adjacent thrombi (5/7), which had a tendency to embolization (3/7) (Figure 5.7A,C). Histological analysis confirmed the presence of multiple thrombi at one damaged plaque (Figure 5.7C). Image analysis further showed that the $\mathrm{CD}_{40 \mathrm{~L}^{-1}}$ thrombi were similar in size as control thrombi. After 30,60 and $120 \mathrm{~s}$ of rupture, integrated fluorescence intensities of thrombi were $1267 \pm 371,824 \pm 261$ and $594 \pm 207 \times 10^{3}$, respectively (mean \pm SEM, $n=7$ ). Together, this indicates that the absence of CD $40 \mathrm{~L}$ increases the probability of multiple plaque rupture (possibly due to the increased collagen content), while it destabilizes platelet-platelet interactions in the thrombi.

\section{Concluding Remarks}

In this paper, we present a first validated animal model of acute plaque rupture, which allows studying the ensuing process of thrombus formation in real time. Rupture is induced by ultrasound treatment of the shoulder region of a murine carotid plaque. This results in local platelet adhesion and formation of a thrombus which remarkably remains subocclusive. The present atherothrombosis model thereby contrasts to other murine arterial thrombosis models, where larger parts of the vessel are damaged, e.g. by 


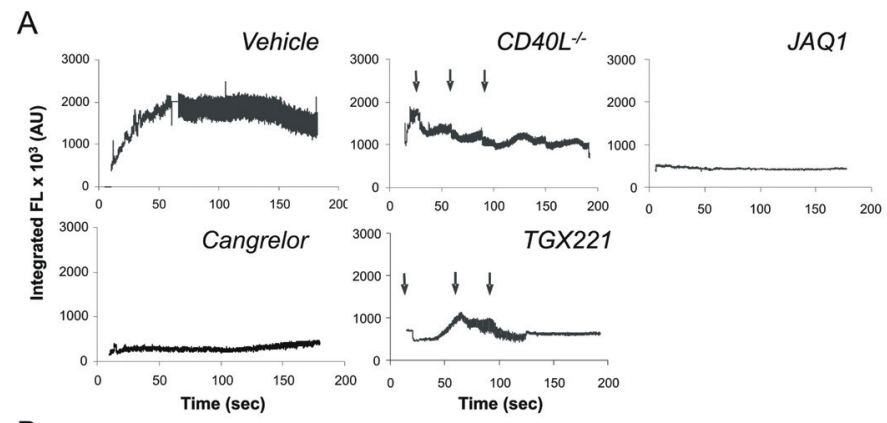

B

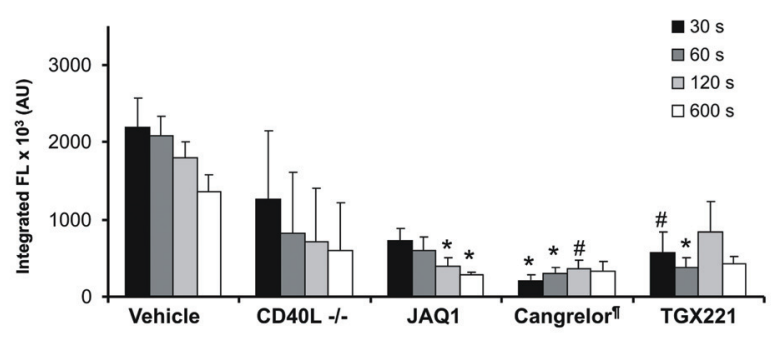

C $\quad \mathrm{CD}^{2} \mathrm{OL}$
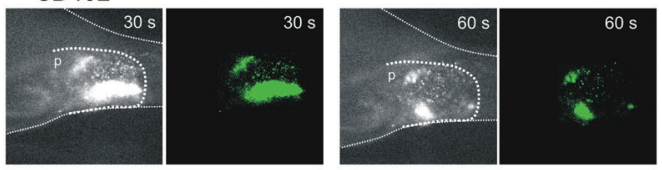

Ruptured site

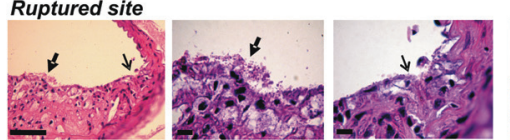

Non-ruptured site

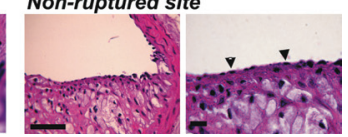

- Figure 5.7. Platelet inhibition affects thrombus formation caused by plaque rupture. $A p o e^{-/}$mice were injected intravenously with a single dose of vehicle solution (saline, $100 \mu 1$ ), JAQ1 mAb (4 mg kg${ }^{-1}$ ), TGX221 (5 mg kg$\left.{ }^{-1}\right)$, or were continuously infused with cangrelor (45 $\left.\mu \mathrm{g} \mathrm{kg}^{-1} / 15 \mathrm{~min}\right)$. After 10-15 min, a plaque was ruptured at the shoulder region by ultrasound treatment. (A) Representative time traces of thrombus formation in treated Apoe ${ }^{-/}$or Apoe $e^{-1 / C D} 40 \mathrm{~L}^{-/}$mice, shown as fluorescence intensity above background. (B) Quantification of thrombus size (integrated fluorescence intensities after 30-600 sec). Mean \pm SEM ( $n=5-8$ mice), ${ }^{I} n=3$ mice, ${ }^{*} P<0.05$ and ${ }^{\#} P<0.10$ compared to control (Mann-Whitney). (C) Ultrasound treatment of plaque in a $A p o e^{-/ /} / C D 4 O L^{-1-}$ mouse, resulting in formation of two adjacent thrombi with embolization. Top images: Fluorescence images and background-subtracted masks. Bottom images: Hematoxylin/eosin stained tissue sections at the site of ultrasound treatment (left three) and untreated upstream site (right two). Note the presence of two ruptured sites, one with a thrombus attached (thick arrow) and one with a remaining layer of platelets (thin arrow). Representative lower (bar $150 \mu \mathrm{m}$ ) and higher (bar $10 \mu \mathrm{m}$ ) magnification images are given; arrowheads indicate endothelial cells.

treatment with rose Bengal or $\mathrm{FeCl}_{3}$, or where the blood flow is temporarily interrupted, e.g. by ligation. In such cases thrombus formation generally leads to occlusion ${ }^{5}$. Differences of the current model in comparison to other models particularly are: the restricted area of plaque damage evoked by the small ultrasound tip; the limited extent of exposure of thrombogenic substances at the ruptured site; and/or the local high blood 
flow causing rapid dilution of soluble agonists. Nevertheless, all evidence indicates that both exposed collagen and tissue factor contribute to the thrombus formation, and this is the result of a multi-factorial process, involving platelet collagen and ADP receptors as well as thrombin and fibrin generation. The present results thus suggest that, at least in part, similar mechanisms play a role in thrombus formation on a ruptured plaque and on a damaged, non-diseased vessel wall. On the other hand, atherosclerotic plaques contain many components and cells with a thrombogenic potential e.g., oxidized LDL lysophosphatidic acid, macrophages) that are absent in healthy vessels. This plaque rupture model now presents the opportunity to study the importance of these components under conditions of in vivo thrombus formation.

The processes of plaque development and arterial thrombus formation are fundamentally different between man and mouse, if only because of the much smaller size of the murine vessels and hence of the lesions and thrombi formed in these vessels. The miniscule plaques in Apoe ${ }^{-/}$murine arteries have thin fibrous caps, are more extensively exposed to the blood stream and, when injured, can accommodate only small thrombi ${ }^{22}$. It is also clear that mouse plaques are notoriously resistant to rupture ${ }^{34}$. Also spontaneous formation of large luminal thrombi is only rarely observed in murine vessels; this is only reported under specific conditions, e.g. in Apoe ${ }^{-/-} \mathrm{Npc1}^{-1-}$ double knockouts ${ }^{11}$. The relative stability of mouse plaques is also apparent from the present experiments, where a high energy input ( $6 \mathrm{kHz}$ during $10 \mathrm{~s}$ ) was required to provoke rupture.

Autopsy studies suggest that rupture of human plaques in the majority of cases results in formation of relatively small thrombi rather than in large occlusive thrombi. Often, multiple ruptures are required for a symptomatic thrombotic event ${ }^{35,36}$. Reports have shown that in man only $11 \%$ of first plaque rupture results in coronary death (socalled virgin rupture $)^{37}$. This indicates that non-occlusive thrombus formation, as in the present model, is a relevant condition for the human situation, perhaps even more than the enormous occlusive thrombi that are formed in healthy vessels in other experimental models. In summary, we have developed a new model of acute plaque rupture, which allows real-time measurement of the atherothrombotic process in mice. Plaque ultrasound treatment results in endothelial denudation, collagen exposure and luminal thrombus formation, accompanied by intra-plaque intrusion of erythrocytes and fibrin formation. The thrombi are sub-occlusive and are sensitive to inhibition of thrombin and platelet ADP and collagen receptors. This model may be useful for unraveling the mechanisms of in vivo thrombus formation by plaque components and for evaluation of anti-thrombotic treatments.

\section{Acknowledgements}

We acknowledge dr. H. Spronk for tissue factor activity measurements. This study was supported by the Netherlands Heart Foundation (2005B079) and the Netherlands Organization for Scientific Research (902-16-276). 


\section{References}

1. Ruggeri ZM. Platelets in atherothrombosis. Nat Med. 2002;8:1227-1234.

2. Virmani R, Burke AP, Farb A, Kolodgie FD. Pathology of the vulnerable plaque. Am J Coll Cardiol. 2006;47:C13-C18.

3. Nieswandt B, Schulte V, Bergmeier W, Mokhtari-Nejad R, Rackebrandt K, Cazenave JP, OhImann $\mathrm{P}$, Gachet C, Zirngibl H. Long-term antithrombotic protection by in vivo depletion of platelet glycoprotein VI in mice. J Exp Med. 2001;193:459-469.

4. Falati S, Gross P, Merrill-Skoloff G, Furie BC, Furie B. Real-time in vivo imaging of platelets, tissue factor and fibrin during arterial thrombus formation in the mouse. Nat Med. 2002;8:1175-1181.

5. Westrick RJ, Winn ME, Eitzman DT. Murine models of vascular thrombosis. Arterioscler Thromb Vasc Biol. 2007;27:2079-2093.

6. Kuijpers MJE, Munnix ICA, Cosemans JMEM, van Vlijmen BJ, Reutelingsperger CPM, oude Egbrink MGA, Heemskerk JWM. Key role of platelet procoagulant activity in tissue factorand collagen-dependent thrombus formation in arterioles and venules in vivo. Differential sensitivity to thrombin inhibition. Microcirculation. 2008;15:269-282.

7. Johnson $\mathrm{JL}$, Jackson CL. Atherosclerotic plaque rupture in the apolipoprotein $\mathrm{E}$ knockout mouse. Atherosclerosis. 2001;154:399-406.

8. Reddick RL, Zhang SH, Maeda N. Aortic atherosclerotic plaque injury in apolipoprotein $\mathrm{E}$ deficient mice. Atherosclerosis. 1998;140:297-305.

9. Sasaki T, Kuzuya M, Nakamura K, Cheng XW, Shibata T, Sato K, Iguchi A. A simple method of plaque rupture induction in apolipoprotein E-deficient mice. Arterioscler Thromb VascBiol. 2006;26:1304-1309.

10. Von der Thusen JH, van Vlijmen BJ, Hoeben RC, Kockx M M, Havekes LM, van Berkel TJ, Biessen EA. Induction of atherosclerotic plaque rupture in apolipoprotein E-/- mice after adenovirus-mediated transfer of p53. Circulation. 2002;105:2064-2070.

11. Welch CL, Sun Y, Arey BJ, Lemaitre V, Sharma N, Ishibashi M, Sayers S, Li R, Gorelik A, Pleskac N, Collins-Fletcher K, Yasuda Y, Bromme D, D'Armiento J M, Ogletree M L, Tall AR. Spontaneous atherothrombosis and medial degradation in $\mathrm{Apoe}^{-1-} \mathrm{Npc}^{-1-}$ mice. Circulation. 2007;116:2444-2452.

12. Massberg S, Gawaz M, Gruner S, Schulte V, Konrad I, Zohlnhofer D, Heinzmann U, Nieswandt B. A crucial role of glycoprotein VI for platelet recruitment to the injured arterial wall in vivo. J Exp Med. 2003;197:41-49.

13. Munnix ICA, Kuijpers MJE, Auger JM, Thomassen CMLGD, Panizzi P, van Zandvoort MAMJ, Rosing J, Bock PE, Watson SP, Heemskerk JWM. Segregation of platelet aggregatory and procoagulant microdomains in thrombus formation. Regulation by transient integrin activation. Arterioscler Thromb Vasc Biol. 2007;27:2484-2490.

14. Lutgens E, Cleutjens KB, Heeneman S, Koteliansky VE, Burkly LC, Daemen MJ. Both early and delayed anti-CD40 L antibody treatment induces a stable plaque phenotype. Proc Natl Acad Sci U S A. 2000;97:7464-7469.

15. Megens RT, Oude Egbrink MGA, Cleutjens JP, Kuijpers MJE, Schiffers PH, Merkx M, Slaaf DW, van Zandvoort MAM. Imaging collagen in intact viable healthy and atherosclerotic arteries using fluorescently labeled CNA35 and two-photon laser scanning microscopy. Mol Imaging. 2007;6:247-260.

16. Nieswandt B, Bergmeier W, Schulte V, Rackebrandt K, Gessner JE, Zirngibl H. Expression and function of the mouse collagen receptor glycoprotein VI is strictly dependent on its association with the FcR $\gamma$ chain. J Biol Chem. 2000;275:23998-234002.

17. Kuijpers MJE, Pozgajova M, Cosemans JMEM, Munnix ICA, Eckes E, Nieswandt B, Heemskerk JWM. Role of murine integrin $\alpha 2 \beta 1$ in thrombus stabilization and embolization: contribution of thromboxane $A_{2}$. Thromb Haemost. 2007;98:1072-1080.

18. Van der Meijden PEM, Schoenwaelder SM, Feijge MAH, Cosemans JME, Munnix IC, 
A., Wetzker R, Heller R, Jackson SP, Heemskerk JWM. Dual $P 2 Y_{12}$ receptor signaling in thrombin-stimulated platelets - involvement of phosphoinositide 3-kinase $\beta$ but not $\gamma$ isoform in $\mathrm{Ca}^{2+}$ mobilization and procoagulant activity. FEBS J. 2008;275:371-385.

19. Lutgens $E$, van Suylen RJ, Faber BC, Gijbels MJ, Eurlings PM, Bijnens AP, Cleutjens KB, Heeneman S, Daemen MJAP. Atherosclerotic plaque rupture: local of systemic process. Arterioscler Thromb Vasc Biol. 2003;23:2123-2130.

20. Mangin $P$, Yap CL, Nonne C, Sturgeon SA, Goncalves I, Yuan Y, Schoenwaelder S M, Wright CE, Lanza F, Jackson SP. Thrombin overcomes the thrombosis defect associated with platelet GPVI/FcR $\gamma$ receptor deficiency. Blood. 2006; 107:4346-4353.

21. Johnson J, Carson K, Williams H, Karanam S, Newby A, Angelini G, George S, Jackson C. Plaque rupture after short periods of fat feeding in the apolipoprotein E-knockout mouse: model characterization and effects of pravastatin treatment. Circulation. 2005;111:14221430.

22. Jackson $C L$, Bennett $M R$, Biessen EA, Johnson JL, Krams R. Assessment of unstable atherosclerosis in mice. Arterioscler Thromb Vasc Biol. 2007;27:714-720.

23. Cosemans JMEM, Kuijpers MJE, Lecut C, Loubele ST, Heeneman S, Jandrot-Perrus M, Heemskerk JWM. Contribution of platelet glycoprotein VI to the thrombogenic effect of collagens in fibrous atherosclerotic lesions. Atherosclerosis. 2005;181:19-27.

24. Penz S, Reininger AJ, Brandl R, Goyal P, Rabie T, Bernlochner I, Rother E, Goetz C, Engelmann B, Smethurst PA, Ouwehand WH, Farndale R, Nieswandt B, Siess W. Human atheromatous plaques stimulate thrombus formation by activating platelet glycoprotein VI. FASEB J. 2005;19:898-909.

25. Gawaz M, Langer $H$, May AE. Platelets in inflammation and atherogenesis. J Clin Invest. 2005;115:3378-3384.

26. Sim DS, Merrill-Skoloff G, Furie BC, Furie B, Flaumenhaft R. Initial accumulation of platelets during arterial thrombus formation in vivo is inhibited by elevation of basal CAMP levels. Blood. 2004;103:2127-2134.

27. Munnix ICA, Strehl A, Kuijpers MJE, Auger JM, van der Meijden PEJ, van Zandvoort MAM, Oude Egbrink MGA, Nieswandt B, Heemskerk JWM. The glycoprotein VI-phospholipase C $\gamma 2$ signaling pathway controls collagen- and tissue factor-induced thrombus formation in vitro and in vivo. Atheroscl Thromb Vasc Biol. 2005;25:2673-2678.

28. Jackson SP, Schoenwaelder SM, Goncalves I, Nesbitt WS, Yap CL, Wright CE, Kenche V, Anderson KE, Dopheide SM, Yuan Y, Sturgeon SA, Prabaharan PE, Thompson PE, Smith GD, Shepherd PR, Daniele N, Kulkarni S, Abbott B, Saylik D, Jones C, Lu L, Giuliano S, Hughan SC, Angus JA, Robertson AD, Salem HH. PI 3-kinase pl10ß: a new target for antithrombotic therapy. Nat Med. 2005;11:507-514.

29. André $P$, Delaney SM, LaRocca $T$, Vincent $D$, DeGuzman $F$, Jurek M, Koller B, Phillips DR, Conley PB. P2Y ${ }_{12}$ regulates platelet adhesion/activation, thrombus growth, and thrombus stability in injured arteries. J Clin Invest. 2003;112:398-406.

30. Van Gestel MA, Heemskerk JWM, Slaaf DW, Heijnen VVT, Reneman RS, oude Egbrink $M G A$. In vivo blockade of platelet $A D P$ receptor $P 2 Y_{12}$ reduces embolus and thrombus formation but not thrombus stability. Arterioscler Thromb Vasc Biol. 2003;23:518-523.

31. Bea F, Kreuzer J, Preusch M, Schaab S, Isermann B, Rosenfeld ME, Katus H, Blessing E. Melagatran reduces advanced atherosclerotic lesion size and may promote plaque stability in apolipoprotein E-deficient mice. Arterioscler Thromb Vasc Biol. 2006;26:2787-2792.

32. Hernandez-Vargas P, Ortiz-Munoz G, Lopez-Franco O, Suzuki Y, Gallego-Delgado J, Sanjuan G, Lazaro A, Lopez-Parra V, Ortega L, Egido J, Gomez-Guerrero C. Fcgamma receptor deficiency confers protection against atherosclerosis in apolipoprotein $E$ knockout mice. Circ Res. 2006;99:1188-1196.

33. Massberg S, Brand K, Gruner S, Page S, Muller E, Muller I, Bergmeier W, Richter T, Lorenz M, Konrad I, Nieswandt B, Gawaz M. A critical role of platelet adhesion in the initiation of atherosclerotic lesion formation. J Exp Med. 2002;196:887-896. 
34. Williams $H$, Johnson JL, Carson KG, Jackson CL. Characteristics of intact and ruptured atherosclerotic plaques in brachiocephalic arteries of apolipoprotein $E$ knockout mice. Arterioscler Thromb Vasc Biol. 2002;22:788-792.

35. Virmani R, Kolodgie FD, Burke AP, Farb A, Schwartz SM. Lessons from sudden coronary death: a comprehensive morphological classification scheme for atherosclerotic lesions. Arterioscler Thromb Vasc Biol. 2000;20:1262-1275.

36. Schwartz SM, Galis ZS, Rosenfeld ME, Falk E. Plaque rupture in humans and mice. Arterioscler Thromb Vasc Biol. 2007;27:705-713.

37. Burke AP, Kolodgie FD, Farb A, Weber DK, Malcom GT, Smialek J, Virmani R. Healed plaque ruptures and sudden coronary death: evidence that subclinical rupture has a role in plaque progression. Circulation. 2001;103:934-940. 


\section{CHAPTER 6}

Stabilizing role of platelet $\mathrm{P} \mathrm{Y}_{12}$ receptors in shear-dependent thrombus formation on ruptured plaques

Reyhan Nergiz-Unal, Judith M.E.M. Cosemans, Marion A.H. Feijge,

Paola E.J. van der Meijden, Robert F. Storey, J.J.J. (Hans) van Giezen, Mirjam G.A. oude Egbrink, Johan W.M. Heemskerk, Marijke J.E. Kuijpers

PLoS One 2010: 12; 5: e10130.

Reprinted with permission 


\title{
Stabilizing role of platelet $\mathrm{P}_{2} \mathrm{Y}_{12}$ receptors in shear-dependent thrombus formation on ruptured plaques
}

\begin{abstract}
In most models of experimental thrombosis, healthy blood vessels are damaged. This results in the formation of a platelet thrombus that is stabilized by ADP signaling via P2Y receptors. However, such models do not predict involvement of $P 2 Y_{12}$ in the clinically relevant situation of thrombosis upon rupture of atherosclerotic plaques. We investigated the role of $\mathrm{P}_{2} \mathrm{Y}_{12}$ in thrombus formation on (collagen-containing) atherosclerotic plaques in vitro and in vivo, by using a novel mouse model of atherothrombosis. Plaques in the carotid arteries from Apoe ${ }^{-/}$mice were acutely ruptured by ultrasound treatment, and the thrombotic process was monitored via intravital fluorescence microscopy. Thrombus formation in vitro was assessed in mouse and human blood perfused over collagen or plaque material under variable conditions of shear rate and coagulation. Effects of two reversible $\mathrm{P}_{2 \mathrm{Y}_{12}}$ blockers, ticagrelor (AZD6140) and cangrelor (AR-C69931MX), were investigated. Acute plaque rupture by ultrasound treatment provoked rapid formation of non-occlusive thrombi, which were smaller in size and unstable in the presence of $\mathrm{P}_{2} \mathrm{Y}_{12}$ blockers. In vitro, when mouse or human blood was perfused over collagen or atherosclerotic plaque material, blockage or deficiency of $P 2 Y_{12}$ reduced the thrombi and increased embolization events. These $P 2 Y_{12}$ effects were present at shear rates $>500 \mathrm{~s}^{-1}$, and they persisted in the presence of coagulation. $\mathrm{P} 2 \mathrm{Y}_{12}$-dependent thrombus stabilization was accompanied by increased fibrin(ogen) binding. Platelet P2Y receptors play a crucial role in the stabilization of thrombi formed on atherosclerotic plaques. This $\mathrm{P} 2 \mathrm{Y}_{12}$ function is restricted to high shear flow conditions, and is preserved in the presence of coagulation.
\end{abstract}




\section{Introduction}

Rupture of an atherosclerotic plaque and occlusive arterial thrombus formation is the major cause of acute cardiovascular incidents and deaths in the Western countries ${ }^{1}$. The development of a thrombus is a complex and dynamic process, involving platelet aggregation, generation of thrombin and formation of a network of fibrin, to strengthen the platelet aggregate and stabilize the thrombus ${ }^{2,3}$. In vivo mouse models of experimental thrombosis have indicated a major role of platelet receptors in the process of thrombus formation and stabilization ${ }^{4}$. However, the studies have been carried out by damaging healthy mouse arteries in an artificial way, e.g. by laser-induced tissue ablation, free radical-generating agents or mechanical disruption. Thrombus formation in diseased, atherosclerotic arteries following plaque rupture has hardly been investigated.

Ruptured atherosclerotic plaques expose several platelet-adhesive and -activating components, such as collagen types I and III, von Willebrand factor (VWF), lysophosphatidic acid, thrombospondin, fibronectin, vitronectin, fibrin/fibrinogen and oxidized low density lipoprotein ${ }^{5-10}$. In addition, plaques contain tissue factor which, upon de-encryption, activates the extrinsic coagulation system ${ }^{5}$, while the intrinsic system of factor XII activation is triggered via collagen ${ }^{11}$. To which extent each of these plaque components contribute to thrombus formation is unclear, though the platelet-activating roles of VWF and collagen are well-described ${ }^{1}$. Collagen-bound VWF mediates the initial tethering and transient adhesion of platelets via glycoprotein (GP)Ib-V-IX. Stable platelet adhesion to VWF is achieved via integrin $\alpha_{\mathrm{IIb}} \beta_{3}$ and adhesion to collagen via the platelet receptors, GPVI and integrin $\alpha_{2} \beta_{1}{ }^{2,12,13}$. Recent in vitro studies suggest that these receptors also mediate platelet adhesion to collagen in damaged plaques ${ }^{5,6}$. Subsequent activation responses of adhered platelets include mobilization of cytosolic $\mathrm{Ca}^{2+}$, secretion of autocoids like ADP, activation of integrin $\alpha_{\mathrm{IIb}} \beta_{3}$ (fibrinogen receptor) and formation of pseudopods, all of which events help to recruit circulating platelets into a thrombus ${ }^{2,14}$. Part of the activated platelets become procoagulant by $\mathrm{Ca}^{2+}$-dependent exposure of phosphatidylserine on their surface, which is required for local thrombin generation ${ }^{15}$.

The autocrine agent ADP activates platelets via two receptors, $\mathrm{P}_{2} \mathrm{Y}_{1}$ and $\mathrm{P} 2 \mathrm{Y}_{12} ;$ the first of which mediates shape change and initiates platelet aggregation, while the latter is required for complete aggregation ${ }^{16}$. The importance of $P_{2} Y_{12}$ was revealed by the observation that the damage of arteries in $\mathrm{P}_{2} \mathrm{Y}_{12}$-deficient mice resulted in markedly delayed and unstable thrombus formation ${ }^{17}$. Mechanistically, we and others have shown that continuous signaling via $\mathrm{P}_{2} \mathrm{Y}_{12}$ is required to prevent platelet disaggregation and to maintain $\alpha_{I I b} \beta_{3}$ in its active conformation ${ }^{18,19}$. The $P 2 Y_{12}$ receptor also has a role in platelet procoagulant activity by potentiating tissue factor-induced thrombin generation via sustained $\mathrm{Ca}^{2+}$ mobilization ${ }^{20,21}$.

In the present paper, we used a recently developed mouse model of thrombus formation on acutely ruptured plaques to study the role of $\mathrm{P}_{2} \mathrm{Y}_{12}$ receptors in atherothrombosis. We investigated effects of the reversible $\mathrm{P}_{2} \mathrm{Y}_{12}$ antagonists, ticagrelor and cangrelor, not only using this in vivo model, but also in perfusion studies of whole ( $\mathrm{P}_{2} \mathrm{Y}_{12}$-deficient) mouse or human blood perfused over collagen-containing plaque material. The results 
point to a $\mathrm{P} 2 \mathrm{Y}_{12}$-dependent stabilization of thrombus formation at high shear, that is maintained under conditions of coagulation. This observation may have important implications for antithrombotic treatment in patients.

\section{Materials and Methods}

\section{Materials}

Fibrillar Horm collagen (type I) was purchased from Nycomed Pharma (Munich, Germany). Native fibrillar type I collagen was prepared from bovine tendon with minimal protease treatment, as described ${ }^{22}$. Fibrinogen labeled with Oregon Green (OG) 488 was from Invitrogen (Carlsbad, CA, USA). Carboxyfluorescein diacetate succinimidyl ester (CFSE) was from Molecular Probes (Leiden, the Netherlands). Rat-anti-mouse CD62 labeled with FITC (Wug.E9) and rat-anti-mouse GPIIbIIIa (JON/A) labeled with PE were from Emfret Analytics (Würzburg, Germany). Cangrelor (AR-C69931MX) and ticagrelor (AZD6140) were kindly provided by AstraZeneca (Mölndahl, Sweden). Ketamine and xylazine were from Eurovet (Bladel, the Netherlands). Sources of other materials are described elsewhere ${ }^{23}$.

\section{Animals}

Wild type C57BL/6 mice (12 weeks old) and Apoe ${ }^{-/}$mice on C57BL/6 background (4 weeks old) were obtained from Charles River (Maastricht, The Netherlands). The Apoe $^{-1-}$ mice were fed a Western-type diet with $0.15 \%$ cholesterol for $18-20$ weeks, i.e. until plaques had developed in the carotid arteries near the bifurcation. Mice homozygously deficient in $\mathrm{P}_{2} \mathrm{Y}_{12}$ receptors ${ }^{24}$ and corresponding wild types (C57BL/6 background) were bred and housed, as described previously ${ }^{25}$. Animal experiments were approved by the research ethics committees of the universities of Maastricht (The Netherlands) and Sheffield (UK).

\section{In vivo plaque rupture and measurement of thrombus formation}

Acute rupture of plaques in the carotid arteries was provoked by targeted ultrasound treatment, as described before ${ }^{26}$. Briefly, Apoe ${ }^{-/}$mice fed with cholesterol-containing diet were anesthetized by subcutaneous injection of ketamine and xylazine $0.1 \mathrm{mg} / \mathrm{g}$ and $0.02 \mathrm{mg} / \mathrm{g}$ body weight, respectively). The carotid arteries were carefully dissected free from surrounding tissue, and the anesthetized animals were injected intravenously with $10 \%$ CFSE-labeled platelets, which were obtained from a donor mouse of the same genotype. The mice were then injected with vehicle solution, ticagrelor or cangrelor, as described below. Body temperature was held at $37^{\circ} \mathrm{C}$ during all procedures.

Using brightfield illumination and intravital microscopy, a plaque was selected in one of the carotid arteries near the bifurcation. The tip $(0.5 \mathrm{~mm}$ diameter $)$ of a titanium ultrasound probe was then placed at the plaque shoulder region. Rupture of the plaque was induced by ultrasound application during $10 \mathrm{~s}$ at $6 \mathrm{kHz}$, using a VibraCell VCX130 processor (Sonics, Newtown, CT, USA). Thrombus formation was recorded in real time by capturing 12-bit fluorescence images at $33 \mathrm{~Hz}$ during at least $10 \mathrm{~min}$, using a back- 
thinned electron multiplier C9100-12 EM-CCD camera (Hamamatsu, Japan) at fixed gain settings. Local rupture of the plaques was verified by two-photon laser scanning microscopy and histological staining of sections of the carotid arteries ${ }^{26}$.

Time-series of fluorescence images were analyzed using Wasabi (Hamamatsu) software. Per region of interest (ROI), corresponding to the site of thrombus formation, total pixel intensity was calculated and corrected for background intensity. To quantify thrombus size, digital images taken at specific time points were processed using ImagePro software (Media Cybernetics, Silverspring, MD, USA). Within the carotid artery, two similar ROIs were defined, one representing the thrombus area and an adjacent ROI representing the background. A threshold level was set by eliminating all pixels with intensity lower than $99.0 \%$ of the pixels of the background ROI. Intensities (gray levels) of all pixels in the thrombus ROI were then integrated. No image processing was applied.

\section{In vivo administration of $\mathrm{P}_{2} \mathrm{Y}_{12}$ antagonist and blood collection}

Anesthetized mice were injected intravenously with vehicle solution (5\% mannitol in saline), ticagrelor (AZD6140) or cangrelor (AR-C69931MX). Ticagrelor was infused at a dose of $420 \mu \mathrm{g} / \mathrm{kg}$ for $1 \mathrm{~min}$, followed by $60 \mu \mathrm{g} / \mathrm{kg} / \mathrm{min}$ for $15 \mathrm{~min}$; cangrelor was infused at $3 \mu \mathrm{g} / \mathrm{kg} / \mathrm{min}$ for $15 \mathrm{~min}$, and infusions were continued during the experiment. Mice for control experiments were bled retro-orbitally under anesthetics after 15 min of infusion of vehicle solution, ticagrelor or cangrelor. Mouse blood was collected into $40 \mu \mathrm{M}$ PPACK and $5 \mathrm{U} / \mathrm{ml}$ heparin or trisodium citrate, as indicated ${ }^{13}$. Platelet-rich plasma (PRP) was isolated and used for platelet activation analysis. Human blood taken by venipuncture, was collected into $40 \mu \mathrm{M}$ PPACK or $12.9 \mathrm{mM}$ trisodium citrate, as indicated.

Flow-cytometric evaluation of platelets with active $\alpha_{\text {IIb }} \beta_{3}$ or P-selectin exposure was performed by activation with ADP $(40 \mu \mathrm{M})$ or convulxin $(100 \mathrm{ng} / \mathrm{ml})$ in $20 \mathrm{x}$ diluted whole mouse blood, followed by labeling with JON/A mAb or anti-CD62 mAb, respectively. Detection of fluorescence was with a FACScan flow cytometer, equipped with an argon laser (Becton-Dickinson, Franklin Lakes, NJ). The percentage of positive cells was analyzed using WinMDI 2.8 software (http://facs.scripps.edu).

\section{Whole blood perfusion experiments}

Human and mouse blood samples were perfused through a parallel-plate transparent flow chamber containing a coverslip, coated with either plaque material or collagen, as described $^{5}$. PPACK-anticoagulated blood was used for perfusion experiments without coagulation, respectively; ADP $(10 \mu \mathrm{M})$ was co-perfused, as indicated ${ }^{18}$. Coagulation was introduced by co-perfusion of human or mouse citrate-anticoagulated blood with 0.1 volume of $\mathrm{CaCl}_{2}(75 \mathrm{mM}), \mathrm{MgCl}_{2}(37.5 \mathrm{mM})$ and tissue factor (20 pM) in Hepes buffer $\mathrm{pH} 7.45(\mathrm{NaCl} 110 \mathrm{mM}$, glucose $10 \mathrm{mM}$, Hepes $5 \mathrm{mM}, \mathrm{KCl} 2.7 \mathrm{mM}$ and $0.1 \%$ bovine serum albumin). Wall shear rate was $300-1000 \mathrm{~s}^{-1}$, as indicated. After blood perfusion, thrombi on coverslips were rinsed with Hepes buffer supplemented with $2 \mathrm{mM} \mathrm{CaCl}_{2}, 2$ $\mathrm{mM} \mathrm{MgCl}$ and heparin $(1 \mathrm{U} / \mathrm{ml})$. Recording of real-time videos and capturing of phase- 
contrast images was with a non-confocal microscopic system ${ }^{13}$. Videos were analyzed offline for embolizing events (single or clustered platelets) per aggregate ${ }^{18}$. Randomly captured images were analyzed for surface area coverage, area distribution of individual segmented features or integrated fluorescence intensity with Image-Pro (ImagePro, Silver Spring MD, USA) or Metamorph software (MDS Analytical Technologies, Downingtown, PA, USA $)^{27}$. In specific experiments, OG488-fibrinogen $(25 \mu \mathrm{g} / \mathrm{ml})$ was added to human or ( $\mathrm{P}_{2} \mathrm{Y}_{12}$-deficient) mouse blood and, after perfusion over collagen or plaque material, fluorescence accumulation was detected by confocal laser scanning microscopy. Confocal images were recorded off-line with a BioRad 2100 multiphoton system at fixed settings of argon laser power, scanning rate and photomultiplier gain ${ }^{15}$.

\section{Coating of plaque material}

Human atherosclerotic plaques were collected at autopsy from a carotid artery and used in compliance with institutional guidelines (Department of Pathology, Maastricht University). Permission was obtained from the local Medical Ethics Committee. Murine atherosclerotic plaques were collected from the aortic arches of $6 \mathrm{Apoe}^{-/}$mice, fed with a Western-type diet with $0.15 \%$ cholesterol for $18-20$ weeks. After resection, atherosclerotic specimens were frozen into liquid nitrogen and stored at $-80{ }^{\circ} \mathrm{C}$. Thawed human and mouse atherosclerotic tissues were homogenized in phosphate-buffered saline. Plaque homogenates were pooled at $165 \mathrm{mg}$ wet tissue weight $/ \mathrm{ml}$, as described ${ }^{5}$. Coverslips were coated with plaque material at a density of $170 \mu \mathrm{g}$ wet weight $/ \mathrm{cm}^{2}$.

\section{Cone and plate(let) experiments}

An Impact-R cone and plate(let) analyzer (CPA, DiaMed, Cressier, Switzerland) was used to evaluate platelet adhesion and aggregation on a surface under defined flow conditions $^{28}$. Citrate-anticoagulated blood $(130 \mu \mathrm{l})$ was placed in a polystyrene well and subjected to a shear of 500-5000 s-1 for $2 \mathrm{~min}$. The platelet aggregates were washed and stained by May-Grünwald stain, according to the manufacturer's instructions (DiaMed). Platelet deposition was evaluated by an image analyzer system connected to the microscope, measuring the average size of the aggregates in $\mu \mathrm{m}^{2}$.

\section{Thrombin generation experiments}

Thrombin generation was measured in citrate-anticoagulated human or mouse PRP $\left(1 \times 10^{8}\right.$ platelets $\left./ \mathrm{ml}\right)$, as before ${ }^{29}$. Briefly, PRP was preincubated with inhibitors, and then treated with ADP $(20 \mu \mathrm{M})$ or vehicle for 10 min. Samples (4 volumes) were pipetted into a polystyrene 96-wells plate (Immulon 2HB, Dynex Technologies, Chantilly, VA, USA), already containing 1 volume of buffer $\mathrm{A}$ (20 mM Hepes, $140 \mathrm{mM} \mathrm{NaCl}$ and $0.5 \%$ bovine serum albumin) and tissue factor (6 pM). Coagulation was started by adding 1 volume of buffer B (2.5 mM Z-GGR-AMC, $20 \mathrm{mM}$ Hepes, $140 \mathrm{mM} \mathrm{NaCl}, 100 \mathrm{mM}$ $\mathrm{CaCl}_{2}$ and $6 \%$ bovine serum albumin). Samples were run at least in duplicate. Firstderivative curves of accumulation of fluorescence in human plasma were converted into nM thrombin using a human calibrator. 


\section{Statistical analysis}

Data are presented as means \pm SE. Groups were compared using the non-parametric Mann-Whitney $U$ test (one-tailed) using the statistical package for social sciences (SPSS 15.0, Chicago, IL, USA). Size distribution of platelet aggregates was evaluated by $\chi^{2}$ analysis ${ }^{27}$. A $p$-value below 0.05 was considered significant.

\section{Results}

\section{Inhibition of mouse $\mathbf{P}_{2} \mathbf{Y}_{12}$ receptors causes unstable thrombus formation after rupture of an atherosclerotic plaque}

To study the role of platelet $\mathrm{P} 2 \mathrm{Y}_{12}$ in atherothrombosis, we used a recently established mouse model of acute plaque rupture ${ }^{26}$. Mice deficient in ApoE were fed a cholesterolenriched diet for 18-20 weeks. Plaque-containing carotid arteries were dissected free from surrounding tissue, and CFSE-labeled Apoe ${ }^{-/}$platelets were injected to enable measurement of fluorescence by intravital microscopy. In control animals infused with vehicle solution, targeted treatment with an ultrasound probe resulted in acute rupture and subsequent non-occlusive thrombus formation (Figure 6.1A). As described, this thrombotic process relies on GPVI-induced platelet activation as well as on thrombin generation and coagulation ${ }^{26}$. Mice were infused with effective concentrations of one of the reversible $\mathrm{P} 2 \mathrm{Y}_{12}$ antagonists, ticagrelor or cangrelor. In blood samples taken from some of these mice, it was checked that the ticagrelor or cangrelor interventions abolished ADP- and collagen-induced platelet aggregation (data not shown). In other mice, the infusion of either $\mathrm{P}_{2} \mathrm{Y}_{12}$ antagonist greatly suppressed platelet accumulation induced by carotid plaque rupture, in that only loose thrombi appeared, which consisted of single-layered fluorescent platelets, in contrast to the compact bright fluorescent thrombi in vehicle-treated mice (Figure 6.1B). The reduced thrombus formation was also apparent from time-courses of integrated fluorescence intensity after plaque rupture (Figure 6.1C). Similarly as described ${ }^{26}$, in vehicle-treated mice, plaque rupture caused a biphasic pattern of rapid increase and slower decline in fluorescence accumulation. Only few single platelets were seen to leave the thrombus in the declining phase. Since fluorescence bleaching was relatively low, the declining phase had a different cause, likely contraction of the platelet-fibrin thrombus.

Off-line quantification of images showed that $\mathrm{P}_{2} \mathrm{Y}_{12}$ inhibition with either antagonist reduced the size of thrombi compared to the vehicle control (Figure 6.1D). Video analysis further revealed that the thrombi formed in the presence of $\mathrm{P}_{2} \mathrm{Y}_{12}$ inhibitor were relatively unstable. With ticagrelor or cangrelor present, 4-5 fold more emboli were shed from thrombi in comparison to control mice (Figure 6.1E). Together, these data pointed to a marked inhibiting effect of the reversible $P_{2} Y_{12}$ antagonists on in vivo thrombus formation following plaque rupture.

\section{Absence of functional $\mathrm{P}_{2} \mathrm{Y}_{12}$ receptors suppresses thrombus formation and thrombin generation, but increases disaggregation}

To study the mechanism by which $\mathrm{P} 2 \mathrm{Y}_{12}$ contributes to thrombus stabilization, we performed flow chamber experiments over native type I collagen with blood from Apoe ${ }^{-/}$ 
A

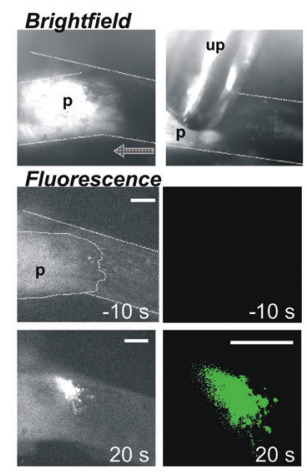

B
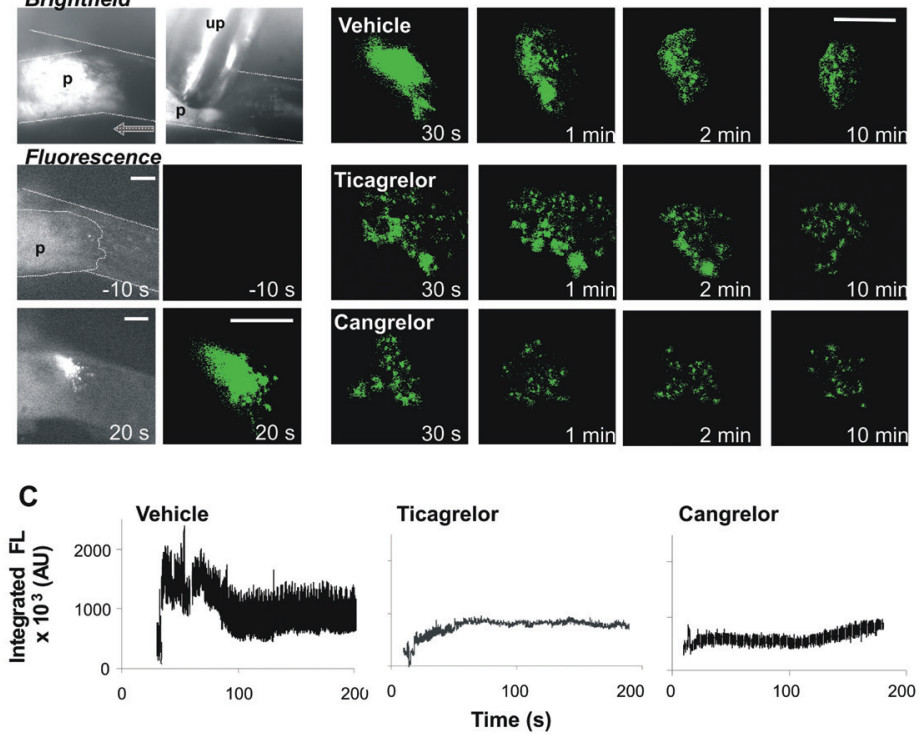

Cangrelor

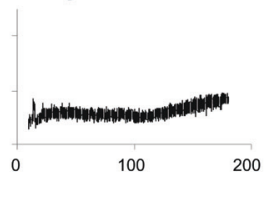

$E$

D

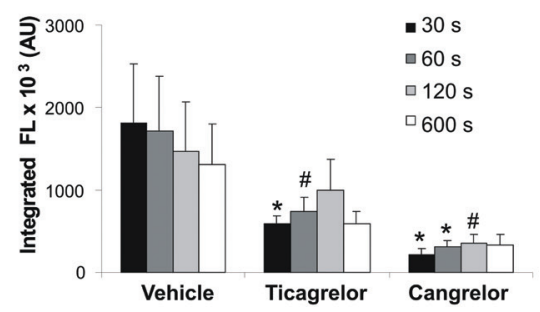

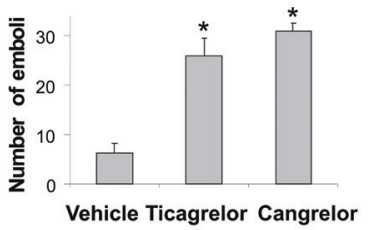

Figure 6.1. Inhibition of $\mathrm{P} 2 \mathrm{Y}_{12}$ receptors causes unstable thrombus formation on acutely ruptured plaques in mice. $A p o e^{-/-}$mice were infused with vehicle solution as a control. Other mice were infused with ticagrelor $(210 \mu \mathrm{g} / \mathrm{kg}$ for $1 \mathrm{~min}$, followed by $30 \mu \mathrm{g} / \mathrm{kg} / \mathrm{min}$ during the experiment). In the third group of mice, cangrelor was continuously infused at $3 \mu \mathrm{g} / \mathrm{kg} / \mathrm{min}$. Infusion of ticagrelor and cangrelor started at 15 min before ultrasound treatment. (A) Brightfield image of a carotid plaque (p) with ultrasound probe (up). Further, raw fluorescence images (left) and threshold masked images (right) of CFSE-labeled platelets before and after ultrasound treatment. Dotted area indicates location of carotid artery (bars, $100 \mu \mathrm{m}$ ). Time stamps point to images at baseline ( $-10 \mathrm{~s}$ ) or after plaque rupture $(20 \mathrm{~s})$. (B) Representative threshold masked images of thrombi on ruptured plaques of mice infused with vehicle, ticagrelor or cangrelor (bar, $100 \mu \mathrm{m}$ ). Note the microthrombi with $\mathrm{P}_{2} \mathrm{Y}_{12}$ antagonist formed within 1 min of ultrasound treatment. (C) Time-courses of integrated CFSE fluorescence intensity above background (arbitrary units, AU) of representative thrombi formed. (D) Quantification of thrombus size at various time points after ultrasound treatment. Data are integrated fluorescence intensities from threshold masked images. (E) Number of fluorescent emboli shed during 3 min after plaque rupture. Data are means \pm SE $(n=3-8),{ }^{*} p<0.05$ and ${ }^{"} p<0.1$ compared to vehicle.

mice which were infused with ticagrelor. Perfusion of blood from ticagrelor-treated mice resulted in diminished thrombus formation on collagen (Figure 6.2A). The treatment significantly reduced platelet deposition, while it increased the disaggregation events 


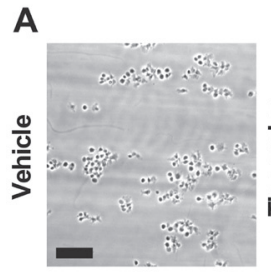

B

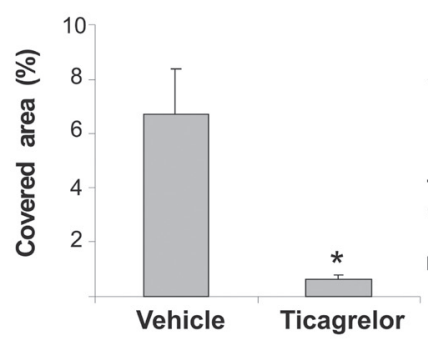

D

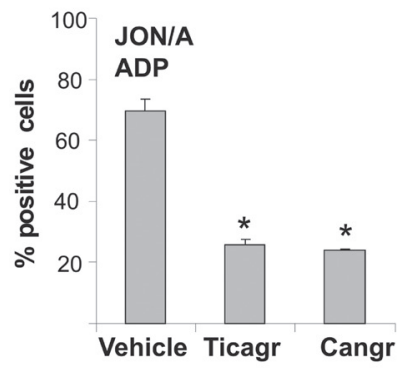

C
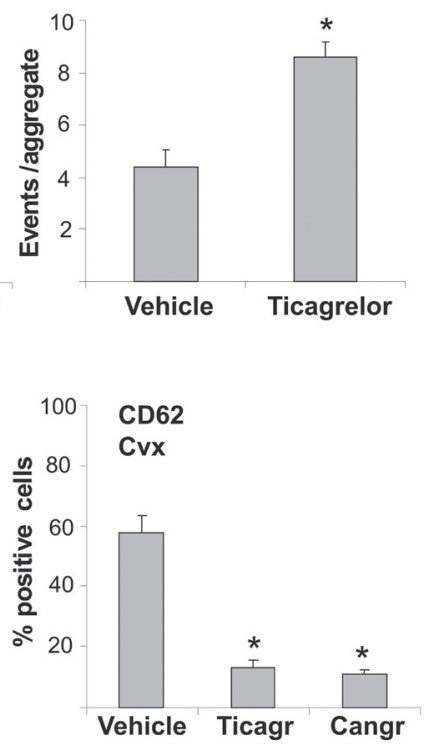

- Figure 6.2. Inhibition of murine $\mathrm{P}_{2} \mathrm{Y}_{12}$ receptors diminishes thrombus formation and provokes platelet disaggregation under flow. Apoe $e^{-1 /}$ mice were infused with vehicle solution, ticagrelor or cangrelor (see Figure 6.1). (A-C) PPACK/heparin anticoagulated blood from treated mice was perfused over native type I collagen at a shear rate of $1000 \mathrm{~s}^{-1}$ for $4 \mathrm{~min}$. (A) Representative phase-contrast images after $4 \mathrm{~min}$ perfusion (bar $=20 \mu \mathrm{m}$ ). (B) Quantitative effect of ticagrelor on surface area coverage by platelets. (C) Average number of disaggregation events measured from a preformed aggregate during flow. (D) Flowcytometric evaluation in whole blood of platelets with active $\alpha_{\mathrm{II}} \beta_{3}(\mathrm{JON} / \mathrm{A} \mathrm{mAb})$ by activation with ADP $(20 \mu \mathrm{M})$, and of platelets exposing P-selectin (anti-CD62 mAb) by activation with convulxin (Cvx, $10 \mathrm{ng} /$ $\mathrm{ml})$. Bars give percentages of positive platelets. Data are means $\pm \mathrm{SE}(n=3-4),{ }^{*} p<0.05$.

(Figure 6.2B, C). Flow cytometry using whole blood from mice infused with ticagrelor demonstrated near complete inhibition of $\alpha_{\text {IIb }} \beta_{3}$ activation in response to ADP and of $\mathrm{P}$-selectin expression in response to low convulxin (Figure 6.2D).

To confirm the role of $\mathrm{P}_{2} \mathrm{Y}_{12}$ in these platelet responses, experiments were performed with blood from $\mathrm{P} 2 \mathrm{Y}_{12}$-deficient mice. Perfusion of blood from these mice also resulted in diminished thrombus formation (Figure 6.3A), accompanied by increased disaggregation events (Figure 6.3B). Furthermore, flow cytometry using whole blood from $\mathrm{P}_{2} \mathrm{Y}_{12}{ }^{-}$ deficient mice demonstrated complete inhibition of $\alpha_{I I b} \beta_{3}$ activation in response to ADP 

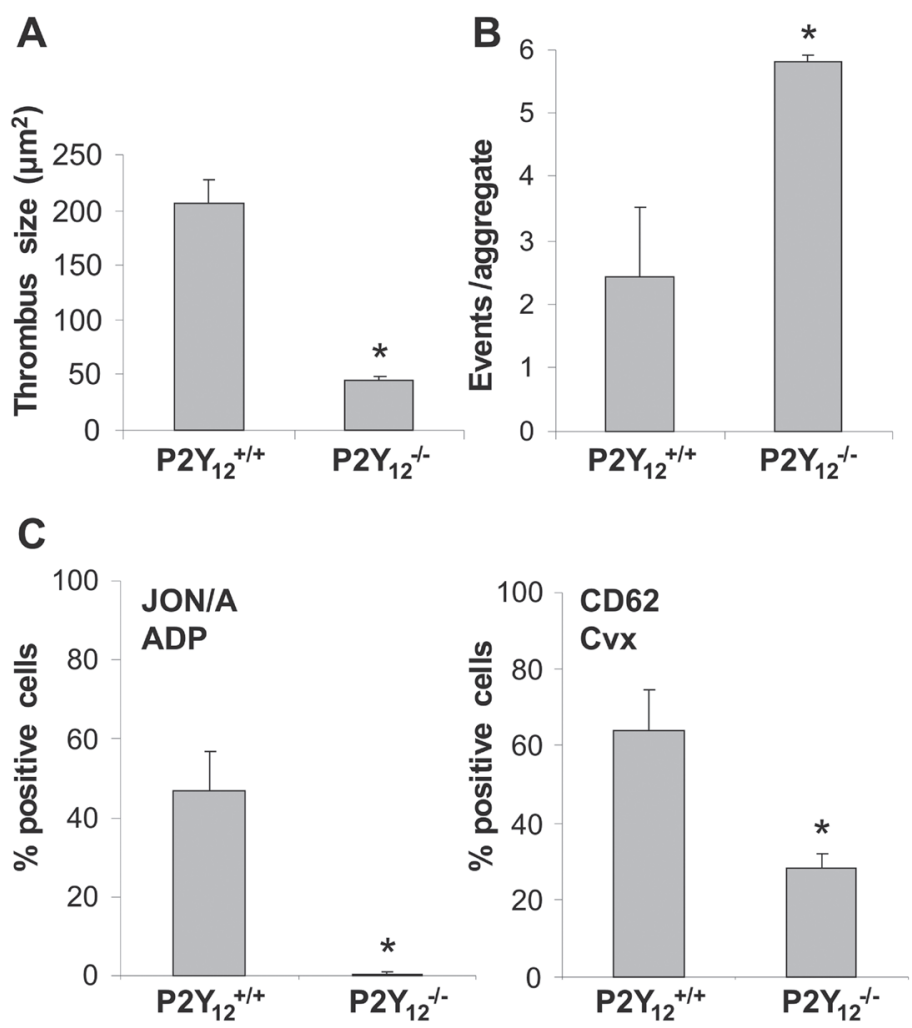

Figure 6.3. Deficiency in mouse $\mathrm{P} \mathrm{Y}_{12}$ receptors diminishes thrombus formation on collagen and provokes disaggregation under flow. Blood from $\mathrm{P} 2 \mathrm{Y}_{12}$ deficient $\left(\mathrm{P} 2 \mathrm{Y}_{12}{ }^{-l-}\right)$ or wild type $\left(\mathrm{P} 2 \mathrm{Y}_{12}{ }^{++}\right)$ mice was perfused over native type I collagen at $1000 \mathrm{~s}^{-1}$ for $4 \mathrm{~min}$ in the presence of $10 \mu \mathrm{M}$ ADP. (A) Quantitative effect of $\mathrm{P} 2 \mathrm{Y}_{12}$ deficiency on surface area coverage by platelets. (B) Average number of disaggregation events measured from a preformed aggregate during flow $(n=3)$. (C) Flow-cytometric evaluation of ADP-stimulated platelets with active $\alpha_{\mathrm{II}} \beta_{3}(\mathrm{JON} / \mathrm{A} \mathrm{mAb})$ and of convulxin-stimulated platelets exposing P-selectin (anti-CD62 mAb) in whole blood. Experiments were performed as in Figure 6.2. Data are means $\pm \operatorname{SE}(n=5-6),{ }^{*} p<0.05$.

and of P-selectin expression in response to low convulxin (Figure 6.3C). Ticagrelor was without further effect on these responses of $\mathrm{P}_{2} \mathrm{Y}_{12}$-deficient platelets (not shown).

Since enhancement of platelet-dependent thrombin generation is an established outcome of $P 2 Y_{12}$ signaling ${ }^{20}$, effects of $P 2 Y_{12}$ antagonism on thrombin generation were investigated in mouse and human PRP. Dose-response experiments demonstrated that $20 \mu \mathrm{M}$ ticagrelor or cangrelor were maximally effective (data not shown). At this concentration, either antagonist partly reduced the stimulating effect of ADP on thrombin peak levels in mouse and human PRP (Figure 6.4A,C). Since in particular the rate of thrombin generation is an important parameter in flow-dependent thrombus formation, we quantified the slope of the thrombin generation curves for effects of $P 2 Y_{12}$ inhibition. both ticagrelor and cangrelor markedly suppressed this slope in mouse and 
A

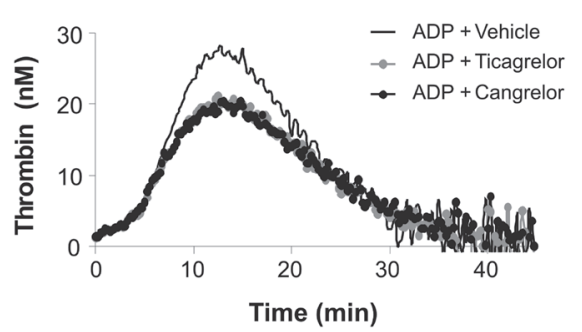

C

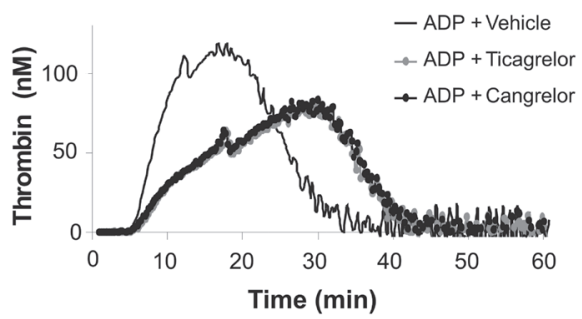

B

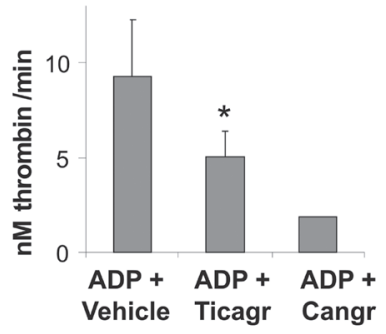

D

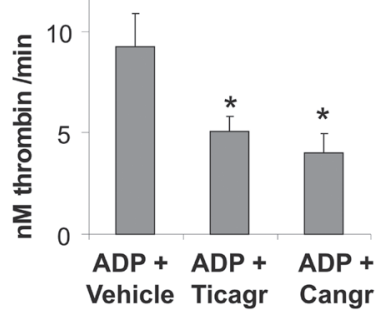

Figure 6.4. Procoagulant role of $\mathrm{P}_{2} \mathrm{Y}_{12}$ receptors in platelet-dependent thrombin generation. Mouse (A, B) or human (C, D) PRP was preincubated with vehicle, ticagrelor $(20 \mu \mathrm{M})$ or cangrelor (20 $\mu \mathrm{M})$, and stimulated with ADP $(20 \mu \mathrm{M})$. Thrombin generation was measured after triggering with tissue factor $(1 \mathrm{pM})$ and $\mathrm{CaCl}_{2}(16.7 \mathrm{mM})$. (A, C) Representative thrombin generation curves of PRP stimulated with ADP alone, or ADP in combination with $\mathrm{P}_{2} \mathrm{Y}_{12}$ inhibitor. (B, D) Quantitative effect of ticagrelor or cangrelor on ADP-stimulated rate of thrombin formation. Data are means $\pm \mathrm{SE}(n=3-6),{ }^{*} p<0.05$ compared to ADP + vehicle.

human PRP (Figure 6.4B,D). We reasoned that this contribution of $\mathrm{P}_{2} \mathrm{Y}_{12}$ may play a role in thrombus stabilization by increasing the availability of thrombin to activate platelets and form fibrin fibers.

\section{Inhibition of $\mathrm{P}^{2} \mathrm{Y}_{12}$ impairs thrombus formation and stabilization at high but not low shear rate}

The clinical efficacy of $\mathrm{P}_{2} \mathrm{Y}_{12}$ antagonists may depend on the local shear rate, which can vary considerably at arterial sites of vulnerable atherosclerotic plaques. To investigate this, human blood was perfused at low and high shear rate over a collagen-containing surface under physiological conditions allowing coagulation. Under control conditions in the absence of $\mathrm{P} 2 \mathrm{Y}_{12}$ inhibitors, stable thrombi containing platelets and fibrin were formed at shear rates of 300 to $1000 \mathrm{~s}^{-1}$ (Figure 6.5A). Fibrin fibers were most clearly visible between adjacent thrombi. In the presence of ticagrelor or cangrelor, much smaller thrombi were formed. Especially at $1000 \mathrm{~s}^{-1}$, fibrin fiber formation and the average thrombus size were drastically reduced with ticagrelor (Figure 6.5B). Analysis of the size distribution patterns on coverslip showed that ticagrelor suppressed the formation of larger thrombi (>400 platelets) only at this higher shear rate (Figure $6.5 \mathrm{C}$ ). Interestingly, this was accompanied by a twofold increase in disaggregation 
A

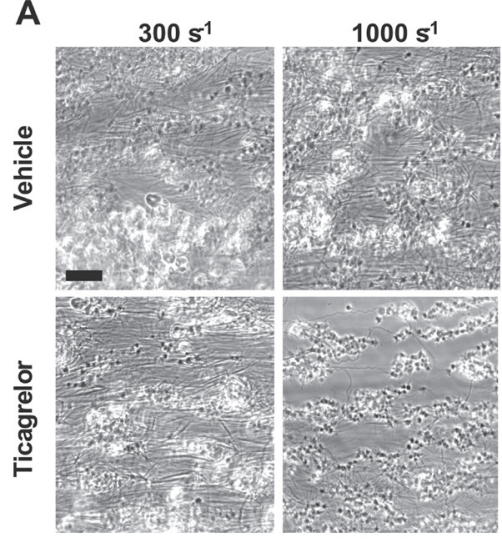

B

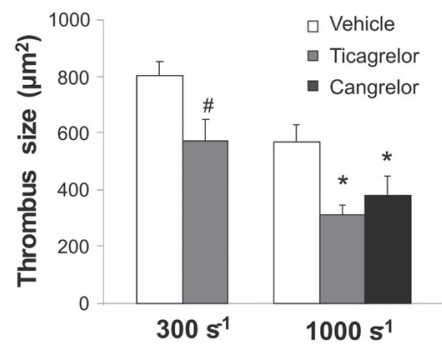

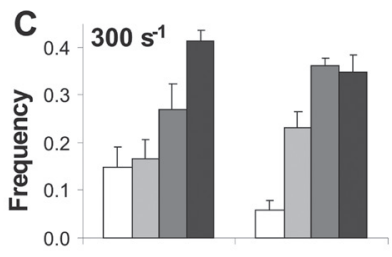

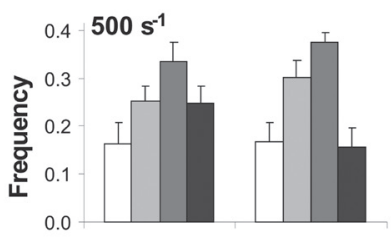

$0.4-1000 \mathrm{~s}^{-1}$
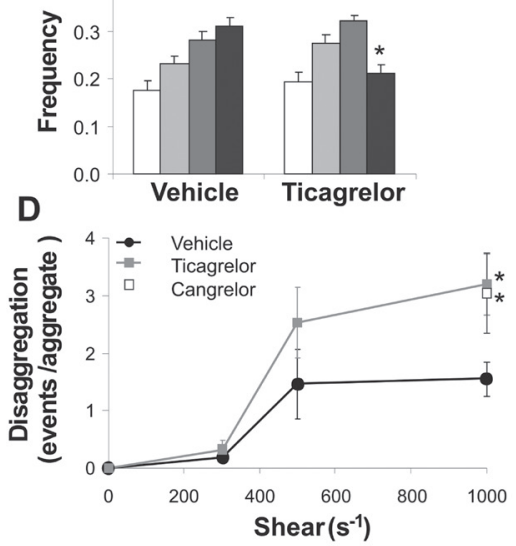

Figure 6.5. Inhibition of $\mathrm{P} 2 \mathrm{Y}_{12}$ receptors affects collagen-dependent thrombus formation at high but not low shear rate. Citrate-anticoagulated human blood, recalcified with $\mathrm{CaCl}_{2} / \mathrm{MgCl}_{2}$ in the presence of $2 \mathrm{pM}$ tissue factor, was perfused over Horm type I collagen at a shear rate of 300 or $1000 \mathrm{~s}^{-1}$. Blood samples were preincubated with vehicle, ticagrelor $(20 \mu \mathrm{M})$ or cangrelor $(10 \mu \mathrm{M})$, as indicated. (A) Representative phase-contrast images after 4 min of perfusion (bar $=20 \mu \mathrm{m}$ ). (B) Average size of thrombi formed in treated blood samples at different shear rates. (C) Frequency distribution of feature size on coverslips; estimated numbers of platelets per feature (aggregate) were: 9-24 (white), 24-75 (light gray), $75-400$ (dark gray) and $>400$ (black). (D) Number of disaggregation events from individual aggregates in the 4th minute of blood perfusion at 300 or $1000 \mathrm{~s}^{-1}$. Data are means $\pm \mathrm{SE}(n=3-9),{ }^{*} p<0.05$ compared to vehicle.

events, again only at $1000 \mathrm{~s}^{-1}$ (Figure 6.5D). Similar effects of $\mathrm{P} 2 \mathrm{Y}_{12}$ inhibition on thrombus stabilization at high shear were seen in flow studies without coagulation (not shown). Together, these experiments indicated that, under conditions of high shear and coagulation, $\mathrm{P}_{2} \mathrm{Y}_{12}$ antagonism suppressed the formation of stable, fibrin-containing thrombi.

To confirm the shear-dependent effect of $\mathrm{P}_{2} \mathrm{Y}_{12}$ inhibition, additional whole blood experiments were performed with a cone and plate(let) analyzer. This test evaluates platelet adhesion and aggregation to a surface under defined shear conditions ${ }^{28}$. At a low shear rate of $500 \mathrm{~s}^{-1}$, the size of the platelet aggregates was not influenced by ticagrelor 
or cangrelor (Figure 6.6A, B). However, at $5000 \mathrm{~s}^{-1}$, the larger size aggregates became greatly sensitive to $P 2 Y_{12}$ inhibition. This experiment hence supports the conclusion that $\mathrm{P} 2 \mathrm{Y}_{12}$ contributes to thrombus formation especially at high shear rate.

\section{Inhibition or deficiency of $\mathbf{P} 2 \mathrm{Y}_{12}$ suppresses thrombus formation on plaques under high shear flow}

To approach the clinical situation, plaque tissue was isolated from large atherosclerotic vessels obtained by autopsy. Cell-free homogenates were prepared from pools of four plaques ${ }^{5}$, and these were used as thrombogenic surface for flow chamber studies. Human blood, supplemented with 0G488-labeled fibrinogen, was perfused over the plaque homogenate, again under conditions of high shear and coagulation. This resulted in the assembly of large, fluorescent thrombi, which were interconnected by fluorescent fibrin fibers (Figure 6.7A). Preincubation of the blood with ticagrelor or cangrelor substantially

A

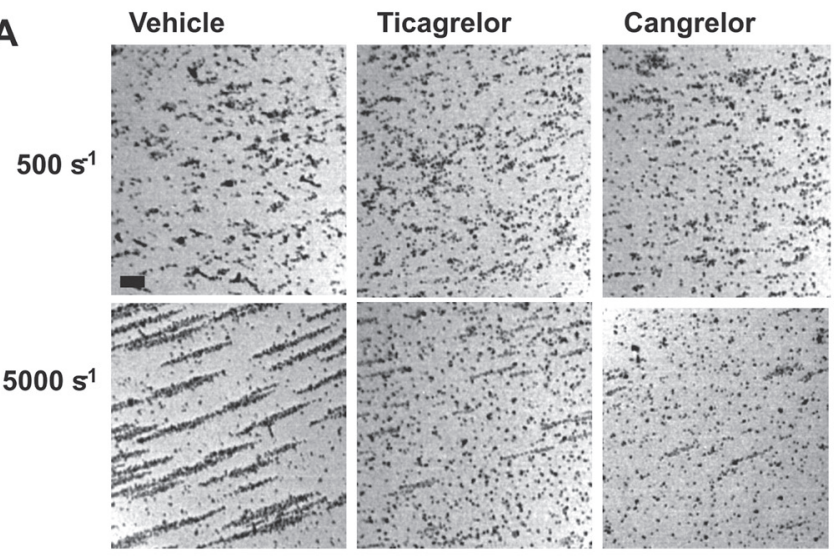

B

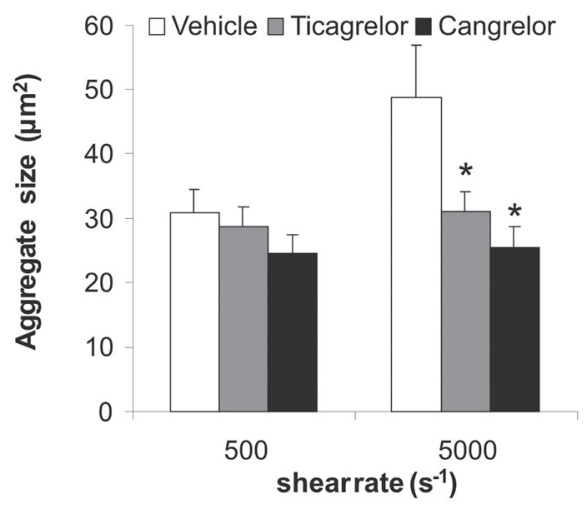

Figure 6.6. Inhibition of $\mathrm{P} 2 \mathrm{Y}_{12}$ receptors reduces aggregate size at high but not low shear in cone and plate(let) analyzer. Citrate-anticoagulated human blood was preincubated with vehicle, ticagrelor (20 $\mu \mathrm{M})$ or cangrelor $(10 \mu \mathrm{M})$ for $10 \mathrm{~min}$. Blood samples were subjected to a shear rate of 500 or $5000 \mathrm{~s}^{-1}$ for $2 \mathrm{~min}$ in a cone and plate(let) analyzer (CPA). (A) Representative images of platelet aggregates formed on the surface after $2 \mathrm{~min}$ (bar $=20 \mu \mathrm{m})$. (B) Average aggregate size in $\mu \mathrm{m}^{2}$. Data are means $\pm \mathrm{SE}(n=4-6)$, $*_{p}<0.05$ compared to vehicle. 

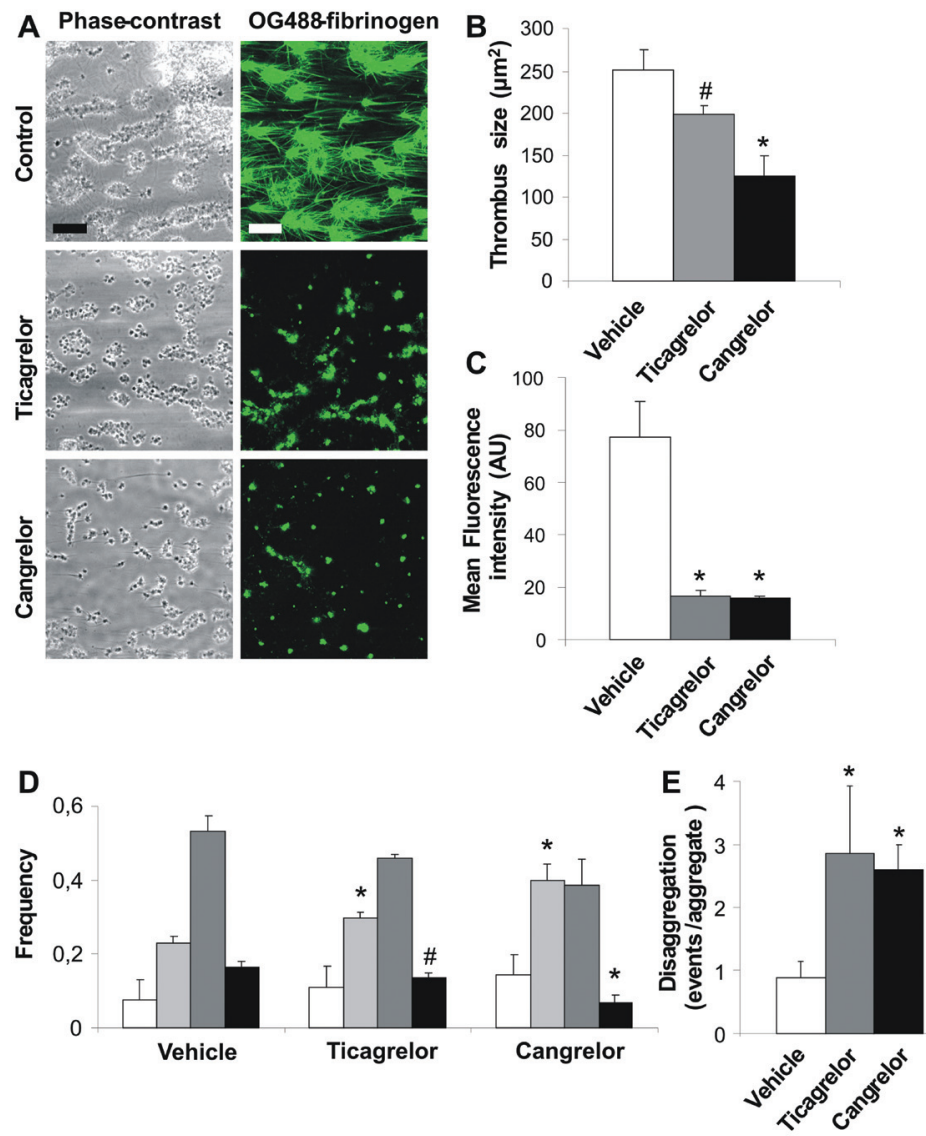

Figure 6.7. Inhibition of $\mathrm{P}_{2} \mathrm{Y}_{12}$ receptors affects plaque-induced thrombus formation at high shear rate. Citrate-anticoagulated human blood was supplemented with OG488-fibrinogen $(25 \mu \mathrm{g} / \mathrm{ml})$, recalcified with $\mathrm{CaCl}_{2} / \mathrm{MgCl}_{2}$ in the presence of $2 \mathrm{pM}$ tissue factor and perfused over homogenized human plaque material at $1000 \mathrm{~s}^{-1}$ for $8 \mathrm{~min}$. Blood was pre-incubated with ticagrelor $(20 \mu \mathrm{M})$ or cangrelor $(10$ $\mu \mathrm{M}$ ) as indicated. (A) Representative phase-contrast and fluorescence images (bar $=20 \mu \mathrm{m}$ ). (B) Average size of thrombi after perfusion. (C) Mean fluorescence intensity from fibrin(ogen)-binding platelets and thrombi. (D) Histograms of features on surface; the estimated numbers of platelets per feature were 9-24 (white), 24-75 (light gray), 75-400 (dark gray) and $>400$ (black). (E) Disaggregation events measured per platelet aggregate per min. Data are means $\pm \operatorname{SE}(n=3),{ }^{*} p<0.05,{ }^{*} p=0.06$ compared to vehicle.

reduced thrombus size as well as fibrin fiber formation (Figure 6.7B,C). That thrombus size was reduced with either $\mathrm{P}_{2} \mathrm{Y}_{12}$ antagonist was further confirmed by morphometric analysis of the platelet aggregates (Figure 6.7D). This was in agreement with analysis of the disaggregation events during blood flow, pointing to a marked destabilization of the thrombi formed in the presence of ticagrelor or cangrelor (Figure 6.7E).

To confirm these results based on pharmacological inhibition of $\mathrm{P}_{2} \mathrm{Y}_{12}$, flow experiments were performed using blood from $\mathrm{P}_{2} \mathrm{Y}_{12}$-deficient mice. Blood was perfused over homogenized plaque material, which was isolated from atherosclerotic aortic arches 


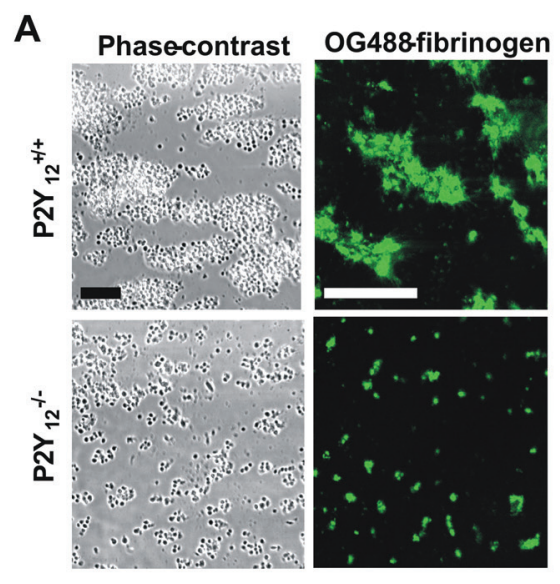

B

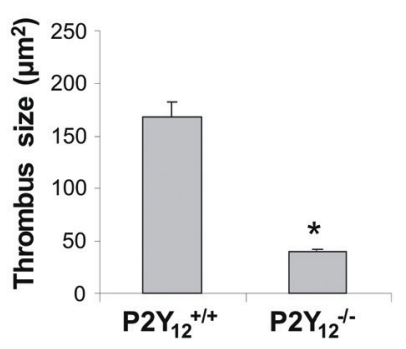

D
C

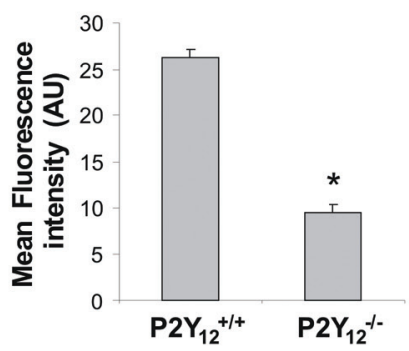

E
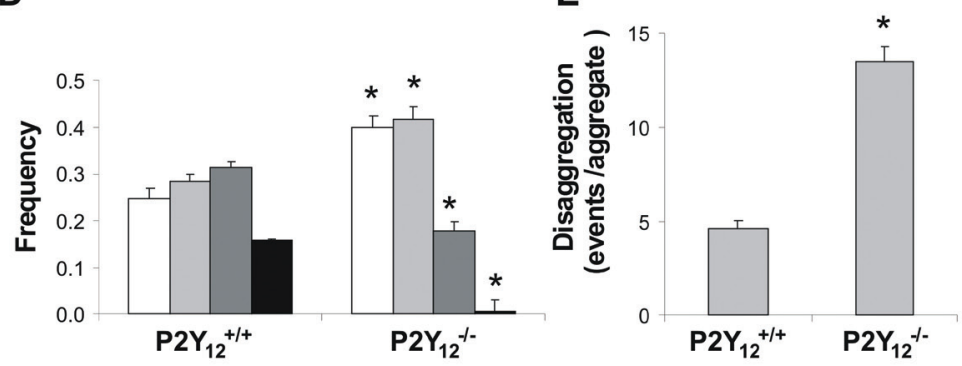

Figure 6.8. Deficiency of murine $\mathrm{P} 2 \mathrm{Y}_{12}$ receptors affects thrombus formation on plaque at high shear rate. Citrate-anticoagulated blood from $\mathrm{P} 2 \mathrm{Y}_{12}{ }^{-1-}$ and corresponding wild type $\left(\mathrm{P} 2 \mathrm{Y}_{12}{ }^{+/+}\right)$mice was supplemented with OG488-fibrinogen $(25 \mu \mathrm{g} / \mathrm{ml})$ and co-perfused with ADP $(10 \mu \mathrm{M})$ over homogenized murine plaque material at $1000 \mathrm{~s}^{-1}$ for $4 \mathrm{~min}$. (A) Representative phase-contrast and fluorescence images (bar $=20 \mu \mathrm{m}$ ). (B) Average size of thrombi after perfusion. (C) Average fluorescence intensity (arbitrary units) from fibrin(ogen)-binding platelets and thrombi. (D) Histograms of features on surface; estimated numbers of platelets per feature were 9-24 (white), 24-75 (light gray), 75-400 (dark gray) and >400 (black). (E) Disaggregation events measured per platelet aggregate per min. Data are means $\pm \operatorname{SE}(n=3)$, $* p<0.05$.

of cholesterol-fed Apoe ${ }^{-/}$mice. Perfusion of $\mathrm{P}_{2} \mathrm{Y}_{12}$-deficient blood over this material resulted in greatly reduced thrombus formation, leaving only a monolayer of platelets at the plaque surface (Figure 6.8A). Deficiency in $\mathrm{P}_{2} \mathrm{Y}_{12}$ also suppressed the deposition 
of OG488-fibrinogen. Image analysis pointed to a significant reduction in both overall thrombus size (Figure 6.8B) and label accumulation (Figure 6.8C). Morphometric analysis showed the formation of more smaller aggregates with $\mathrm{P} 2 \mathrm{Y}_{12}$-deficient blood (Figure 6.8D). These thrombi were instable, as appeared from analysis of the platelet disaggregation events during flow (Figure 6.8E).

Altogether these results indicate that $A D P$, via $P 2 Y_{12}$ stabilizes thrombi formed under flow on ruptured plaques in the mouse carotid artery in vivo, and on human and mouse plaque material in vitro. Furthermore, they show that the contribution of $P 2 Y_{12}$ to thrombus stability increases with shear rate and is maintained in the presence of coagulation.

\section{Discussion}

In the present paper, we used a novel in vivo mouse model of thrombus formation on acutely ruptured atherosclerotic plaques, to demonstrate a marked antithrombotic effect of two reversible blocking agents of the platelet $\mathrm{P}_{2} \mathrm{Y}_{12}$ receptors, i.e. ticagrelor and cangrelor. Both $\mathrm{P}_{2} \mathrm{Y}_{12}$ inhibitors destabilized thrombus formation by increasing the embolization of platelets, with as a result smaller sized thrombi. Our data extend earlier findings, using the same model of acute atherothrombosis, which indicated that thrombus formation is the result of a multi-factorial process involving: platelet interaction with collagen, exposure of tissue factor, generation of thrombin, and formation of fibrin fibers ${ }^{26}$. Recently, other authors have confirmed the importance of collagen and thrombin, using the same model of carotid plaque rupture by ultrasound ${ }^{30}$. Since these in vivo data pointed to collagen as a major thrombogenic component in the carotid plaque, we continued to study thrombus formation by in vitro perfusion studies with immobilized plaque material or native collagen as a surface. However, it should be noted that also other thrombogenic components have been identified in plaque material, including tissue factor, oxidized low density lipoproteins and lysophosphatidate ${ }^{8,10,31}$.

A key role of platelet $\mathrm{P}_{2} \mathrm{Y}_{12}$ receptors in thrombus stabilization was confirmed by in vitro flow studies using either mouse or human blood. Markedly, when coagulation was introduced, blockage or deficiency of $\mathrm{P}_{2} \mathrm{Y}_{12}$ suppressed the formation of larger sized platelet aggregates as well as the formation of fibrin fibers, in particular at high shear rate. Furthermore, inhibition or absence of $\mathrm{P}_{2} \mathrm{Y}_{12}$ destabilized the thrombi formed on immobilized collagens or plaque material. Also cone-and-plate(let) experiments, where platelets adhered to a surface, showed an enhancing effect of $\mathrm{P} 2 \mathrm{Y}_{12}$ on thrombus formation at high but not low shear rate.

In earlier work, we and others have shown that autocrine, platelet-derived ADP contributes to thrombus growth and stability on collagen-containing surfaces ${ }^{18,32,33}$. The present data confirm this and indicate that, in addition, the thrombus-stabilizing role of $P 2 Y_{12}$ is maintained in the presence of coagulation. Mechanistically, $P 2 Y_{12}$ can contribute to the formation of stable thrombi via two different processes: (i) continuous signaling to phosphoinositide 3-kinases $\beta$ and $\gamma$ with as a result sustained $\alpha_{\text {IIb }} \beta_{3}$ activation $^{18}$; (ii) enhancement of thrombin/fibrin generation due to increased Gi-mediated $\mathrm{Ca}^{2+}$ mobilization and platelet procoagulant activity 20,21,34. The observations that ticagrelor 
and cangrelor retards ADP-dependent thrombin generation and fibrin formation relates to the latter function. In conjunction with the present results, others have reported that $\mathrm{P}_{2} \mathrm{Y}_{12}$ is implicated in shear-induced platelet aggregation via activation of Syk kinase and phosphoinositide 3-kinase ${ }^{35}$. Interestingly, another study describes no effect of cangrelor of collagen-dependent thrombus formation ${ }^{36}$. However, this study focused short-term processes ( $<1.5 \mathrm{~min}$ ), during which thrombi are still in the growing phase and the contribution of adhesive receptors such as GP-Ib-V-IX is relatively high. Our time-dependent analysis however indicates that a role of $\mathrm{P}_{2} \mathrm{Y}_{12}$ becomes more prominent at later stages.

The $\mathrm{P}_{2} \mathrm{Y}_{12}$-directed prodrug clopidogrel is increasingly used to prevent secondary ischemic events in patients with myocardial infarction or stroke 37,38 . Recently, clinical studies performed with the new, irreversible $\mathrm{P}_{2} \mathrm{Y}_{12}$ inhibitor prasugrel $\mathrm{I}^{39,40}$ and the reversible $P 2 Y_{12}$ inhibitor ticagrelor $r^{41,42}$ have shown promising results for the treatment of acute coronary syndrome. Our findings suggest that the success of such anti-P2Y interventions relies on the selective abrogation of a platelet response - autocrine activation of $\mathrm{P}_{2} \mathrm{Y}_{12}$ - that is at least in part dependent on the local, high shear conditions.

In summary, we have shown that $A D P$, via $P 2 Y_{12}$ stabilizes thrombi on ruptured plaques both in vivo and on human plaque material in vitro. Furthermore, this $\mathrm{P}_{2} \mathrm{Y}_{12}$ dependency of thrombus stability is maintained in the presence of coagulation, but most pronounced at high shear flow conditions.

\section{Acknowledgments}

We thank dr. R. Megens and Laura Jackman for participation in experiments. We also thank Schering Plough Research Institute for providing the $\mathrm{P} 2 \mathrm{Y}_{12}$ deficient mice. 


\section{References}

1. Ruggeri ZM. Platelets in atherothrombosis. Nat Med. 2002;8:1227-1234.

2. Jackson SP. The growing complexity of platelet aggregation. Blood. 2007;109:5087-5095.

3. Munnix IC, Cosemans JM, Auger JM, Heemskerk JW. Platelet response heterogeneity in thrombus formation. Thromb Haemost. 2009;102:1149-1156.

4. Denis CV, Wagner DD. Platelet adhesion receptors and their ligands in mouse models of thrombosis. Arterioscler Thromb Vasc Biol. 2007;27:728-739.

5. Cosemans JM, Kuijpers MJ, Lecut C, Loubele ST, Heeneman S, Jandrot-Perrus M, Heemskerk JW. Contribution of platelet glycoprotein VI to the thrombogenic effect of collagens in fibrous atherosclerotic lesions. Atherosclerosis. 2005;181:19-27.

6. Penz S, Reininger AJ, Brandl R, Goyal P, Rabie T, Bernlochner I, Rother E, Goetz C, Engelmann B, Smethurst PA, Ouwehand WH, Farndale R, Nieswandt B, Siess W. Human atheromatous plaques stimulate thrombus formation by activating platelet glycoprotein VI. Faseb J. 2005;19:898-909.

7. De Meyer GR, Hoylaerts MF, Kockx MM, Yamamoto H, Herman AG, Bult H. Intimal deposition of functional von Willebrand factor in atherogenesis. Arterioscler Thromb Vasc Biol. 1999;19:2524-2534.

8. Rother E, Brandl R, Baker DL, Goyal P, Gebhard H, Tigyi G, Siess W. Subtype-selective antagonists of lysophosphatidic acid receptors inhibit platelet activation triggered by the lipid core of atherosclerotic plaques. Circulation. 2003;108:741-747.

9. Guyton JR, Klemp KF. Development of the lipid-rich core in human atherosclerosis. Arterioscler Thromb Vasc Biol. 1996;16:4-11.

10. Katsuda S, Kaji T. Atherosclerosis and extracellular matrix. J Atheroscler Thromb. 2003; 10:267-274.

11. van der Meijden PE, Munnix IC, Auger JM, Govers-Riemslag JW, Cosemans JM, Kuijpers MJ, Spronk HM, Watson SP, Renne T, Heemskerk JW. Dual role of collagen in factor XIIdependent thrombus formation. Blood. 2009;114:818-890.

12. Auger JM, Kuijpers MJ, Senis YA, Watson SP, Heemskerk JW. Adhesion of human and mouse platelets to collagen under shear: a unifying model. Faseb J. 2005;19:825-827.

13. Kuijpers MJ, Schulte V, Bergmeier W, Lindhout T, Brakebusch C, Offermanns S, Fassler R, Heemskerk JW, Nieswandt B. Complementary roles of glycoprotein VI and alpha2betal integrin in collagen-induced thrombus formation in flowing whole blood ex vivo. Faseb J. 2003; 17:685-687.

14. Cosemans JM, Iserbyt BF, Deckmyn H, Heemskerk JW. Multiple ways to switch platelet integrins on and off. J Thromb Haemost. 2008;6:1253-1261.

15. Munnix IC, Kuijpers MJ, Auger J, Thomassen CM, Panizzi P, van Zandvoort MA, Rosing J, Bock PE, Watson SP, Heemskerk JW. Segregation of platelet aggregatory and procoagulant microdomains in thrombus formation: regulation by transient integrin activation. Arterioscler Thromb Vasc Biol. 2007;27:2484-2490.

16. Gachet C. P2 receptors, platelet function and pharmacological implications. Thromb Haemost. 2008;99:466-472.

17. André P, Delaney SM, LaRocca T, Vincent D, DeGuzman F, Jurek M, Koller B, Phillips DR, Conley PB. P2Y12 regulates platelet adhesion/ activation, thrombus growth, and thrombus stability in injured arteries. J Clin Invest. 2003;112:398-406.

18. Cosemans JM, Munnix IC, Wetzker R, Heller R, Jackson SP, Heemskerk JW. Continuous signaling via $\mathrm{PI} 3 \mathrm{~K}$ isoforms beta and gamma is required for platelet ADP receptor function in dynamic thrombus stabilization. Blood. 2006;108:3045-3052.

19. Goto S, Tamura N, Ishida H, Ruggeri ZM. Dependence of platelet thrombus stability on sustained glycoprotein IIb/IIIa activation through adenosine $5^{\prime}$-diphosphate receptor stimulation and cyclic calcium signaling. J Am Coll Cardiol. 2006;47:155-162.

20. van der Meijden PE, Feijge MA, Giesen PL, Huijberts M, van Raak LP, Heemskerk JW. 
Platelet P2Y(12) receptors enhance signalling towards procoagulant activity and thrombin generation A study with healthy subjects and patients at thrombotic risk. Thromb Haemost. 2005;93:1128-1136.

21. Leon C, Ravanat C, Freund M, Cazenave JP, Gachet C. Differential involvement of the P2YI and $\mathrm{P} 2 \mathrm{Y} 12$ receptors in platelet procoagulant activity. Arterioscler Thromb Vasc Biol. 2003;23:1941-1947.

22. Siljander P, Lassila R. Studies of adhesion-dependent platelet activation: distinct roles for different participating receptors can be dissociated by proteolysis of collagen. Arterioscler Thromb Vasc Biol. 1999;19:3033-3043.

23. Munnix ICA, Strehl A, Kuijpers MJE, Auger JM, van der Meijden PEJ, van Zandvoort MAM, Oude Egbrink MGA, Nieswandt B, Heemskerk JWM. The glycoprotein VI-phospholipase C $\gamma 2$ signaling pathway controls collagen- and tissue factor-induced thrombus formation in vitro and in vivo. Atheroscl Thromb Vasc Biol. 2005;25:2673-2678.

24. Foster CJ, Prosser DM, Agans JM, Zhai Y, Smith MD, Lachowicz JE, Zhang FL, Gustafson E, Monsma FJ, Jr., Wiekowski MT, Abbondanzo SJ, Cook DN, Bayne ML, Lira SA, Chintala MS. Molecular identification and characterization of the platelet ADP receptor targeted by thienopyridine antithrombotic drugs. J Clin Invest. 2001;107:1591-1598.

25. Evans DJ, Jackman LE, Chamberlain J, Crosdale DJ, Judge HM, Jetha K, Norman KE, Francis SE, Storey RF. Platelet $\mathrm{P} 2 \mathrm{Y}(12)$ receptor influences the vessel wall response to arterial injury and thrombosis. Circulation. 2009;119:116-122.

26. Kuijpers MJE, Gilio K, Reitsma S, Nergiz-Unal R, Prinzen L, Heeneman S, Lutgens E, Zandvoort MAMJv, Nieswandt B, Egbrink MGAo, Heemskerk JWM. Complementary roles of platelets and coagulation in thrombus formation on plaques acutely ruptured by targeted ultrasound treatment: a novel intravital model. J Thromb Haemost. 2009;7:152-161.

27. Siljander PR, Munnix IC, Smethurst PA, Deckmyn H, Lindhout T, Ouwehand WH, Farndale RW, Heemskerk JW. Platelet receptor interplay regulates collagen-induced thrombus formation in flowing human blood. Blood. 2004;103:1333-1341.

28. Varon D, Savion N. Cone and Plate(let) Analyzer. In: Michelson AD, ed. Platelets. San Diego, USA: Academic Press; 2002:337-345.

29. Vanschoonbeek K, Feijge MA, Van Kampen RJ, Kenis H, Hemker HC, Giesen PL, Heemskerk JW. Initiating and potentiating role of platelets in tissue factor-induced thrombin generation in the presence of plasma: subject-dependent variation in thrombogram characteristics. J Thromb Haemost. 2004;2:476-484.

30. Hechler B, Eckly A, Magnenat S, Freund M, Cazenave JP, Lanza F, Gachet C. Localized arterial thrombosis on ruptured atherosclerotic plaques of ApoE-/- mice after vascular injury with ultrasound. J Thromb Haemost. 2009;7:Abstract OC-TH-033.

31. Haseruck N, Erl W, Pandey D, Tigyi G, Ohlmann P, Ravanat C, Gachet C, Siess W. The plaque lipid lysophosphatidic acid stimulates platelet activation and platelet-monocyte aggregate formation in whole blood: involvement of $\mathrm{P} 2 \mathrm{Y} 1$ and $\mathrm{P} 2 \mathrm{Y} 12$ receptors. Blood. 2004; 103:2585-2592.

32. Penz SM, Reininger AJ, Toth 0 , Deckmyn H, Brandl R, Siess W. Glycoprotein Ibalpha inhibition and ADP receptor antagonists, but not aspirin, reduce platelet thrombus formation in flowing blood exposed to atherosclerotic plaques. Thromb Haemost. 2007;97:435-443.

33. Remijn JA, Wu YP, Jeninga EH, Ijsseldijk MJW, van Willigen G, de Groot PG, Sixma JJ, Nurden AT, Nurden P. Role of ADP receptor P2Y(12) in platelet adhesion and thrombus formation in flowing blood. Arterioscler Thromb Vasc Biol. 2002;22:686-691.

34. van der Meijden PE, Schoenwaelder SM, Feijge MA, Cosemans JM, Munnix IC, Wetzker $\mathrm{R}$, Heller R, Jackson SP, Heemskerk JW. Dual P2Y 12 receptor signaling in thrombinstimulated platelets - involvement of phosphoinositide 3-kinase beta but not gamma isoform in Ca2+ mobilization and procoagulant activity. Febs J. 2008;275:371-385.

35. Resendiz JC, Feng S, Ji G, Francis KA, Berndt MC, Kroll MH. Purinergic P2Y12 receptor 
blockade inhibits shear-induced platelet phosphatidylinositol 3-kinase activation. Mol Pharmacol. 2003;63:639-645.

36. Turner NA, Moake JL, McIntire LV. Blockade of adenosine diphosphate receptors P2Y12 and $\mathrm{P} 2 \mathrm{Y} 1$ is required to inhibit platelet aggregation in whole blood under flow. Blood. 2001;98:3340-3345.

37. Fintel DJ. Antiplatelet therapy in cerebrovascular disease: implications of Management of Artherothrombosis with Clopidogrel in High-risk Patients and the Clopidogrel for High Artherothrombotic Risk and Ischemic Stabilization, Management, and Avoidance studies' results for cardiologists. Clin Cardiol. 2007;30:604-614.

38. Vande Griend JP, Saseen JJ. Combination antiplatelet agents for secondary prevention of ischemic stroke. Pharmacotherapy. 2008;28:1233-1242.

39. Wiviott SD, Braunwald E, McCabe CH, Montalescot G, Ruzyllo W, Gottlieb S, Neumann FJ, Ardissino D, De Servi S, Murphy SA, Riesmeyer J, Weerakkody G, Gibson CM, Antman EM. Prasugrel versus clopidogrel in patients with acute coronary syndromes. N Engl J Med. 2007;357:2001-2015.

40. Jakubowski JA, Winters KJ, Naganuma H, Wallentin L. Prasugrel: a novel thienopyridine antiplatelet agent. A review of preclinical and clinical studies and the mechanistic basis for its distinct antiplatelet profile. Cardiovasc Drug Rev. 2007;25:357-374.

41. van Giezen JJ, Nilsson L, Berntsson P, Wissing BM, Giordanetto F, Tomlinson W, Greasley PJ. Ticagrelor binds to the human $\mathrm{P} 2 \mathrm{Y}$ receptor independently from ADP but antagonizes ADP-induced receptor signaling and platelet aggregation. J Thromb Haemost. 2009.

42. Wallentin L, Becker RC, Budaj A, Cannon CP, Emanuelsson H, Held C, Horrow J, Husted S, James S, Katus H, Mahaffey KW, Scirica BM, Skene A, Steg PG, Storey RF, Harrington RA, Freij $A$, Thorsen $M$. Ticagrelor versus clopidogrel in patients with acute coronary syndromes. N Engl J Med. 2009;361:1045-1057. 



\section{CHAPTER 7}

\section{Effect of dietary walnut}

\section{on atherosclerosis and coagulant state in ApoE-deficient mice}

Reyhan Nergiz-Unal, Marijke J.E. Kuijpers, Sylvia Heeneman, Marion A.H. Feijge,

Erik A.L. Biessen, Guido R.M.M. Haenen, H.Tanju Besler, Judith M.E.M. Cosemans, Johan W.M Heemskerk 


\title{
Effect of dietary walnut on atherosclerosis and coagulant state in ApoE-deficient mice
}

\begin{abstract}
Consumption of $n-3$ polyunsaturated fatty acids (PUFA) and antioxidant polyphenols is considered to decline the risk of cardiovascular disease. To determine the mechanism behind this cardioprotective effect, we performed an intervention study with proatherogenic Apoe ${ }^{-/}$mice which were fed high-fat diets containing either walnuts (rich in n-3 PUFA and antioxidant polyphenols), walnut oil (with n-3 PUFA only), or grape seed extract (with polyphenols only). Feeding walnuts for 8 weeks lowered plasma levels of triglycerides, cholesterol and prothrombin. This was accompanied by a lower accumulation of lipids in the liver, while plasma antioxidant capacity was slightly increased. On the other hand, feeding mice with walnut oil or grape seed extract did not provoke such changes in comparison to the control diet. Markedly, feeding of walnuts caused a strong reduction in atherosclerotic plaque development in the aortic arches. This associated with reduced staining in the plaques for the marker protein CD36, a scavenger receptor expressed by macrophages. Platelet activation and thrombus formation under flow were not changed with any of the diets. Taken together, these results indicate that, in Apoe ${ }^{-/}$mice on high-fat diet, dietary walnut intake beneficially influences lipid metabolism and atherosclerotic plaque development, with no more than limited effects on platelet and coagulation function. The effects of walnut intake were not mimicked by the intake of walnut oil.
\end{abstract}




\section{Introduction}

In today's world most deaths are attributable to chronic diseases, in particular cardiovascular diseases leading to thrombosis ${ }^{1}$. Both blood platelets and the coagulation system contribute to the processes of thrombosis and atherosclerosis. Platelets rapidly adhere to the arterial vessel wall at sites of endothelial damage, and hence contribute the development of atherosclerotic lesions under conditions of elevated levels of plasma lipids and coagulation factors ${ }^{2,3}$. To delay the clinical manifestations of atherosclerosis and thrombosis, there is growing interest in 'healthy' diets, particularly those with polyunsaturated fatty acids (PUFA) and antioxidants.

Epidemiologic studies have shown strong associations between the intake of $n-3$ PUFA in fish oil and of antioxidant polyphenols with a diminished risk of cardiovascular disease ${ }^{4,5}$. Walnuts are rich in both antioxidant polyphenols (ellagic acid) and $n-3$ PUFA. Walnuts indeed contain the highest content of $\alpha$-linolenic acid among all edible plants ${ }^{6-8}$. Hence, there is clear evidence that the consumption of walnuts may promote cardiovascular health ${ }^{7,9}$. The mechanism of action however is unclear, since different papers disagree whether ${ }^{10}$ or not ${ }^{11}$ walnut intake lowers platelet activation and plasma lipid levels. Another rich source of antioxidant polyphenols is provided by grape seed ${ }^{12}$. In human and in animals, intake of grape seed ingredients has been reported to reduce atherosclerotic plaque development and platelet activation ${ }^{13-16}$.Taken together, this raises the question how walnut intake, by the combined presence of $n-3$ PUFA and antioxidant polyphenols, can affect the processes of atherosclerosis and thrombosis. In the present paper, this was investigated with proatherogenic Apoe ${ }^{-/}$mice, where we compared the dietary effects of whole walnuts containing n-3 PUFA and antioxidant polyphenols, and of walnut oil (with only n-3 PUFA) or of grape seed extract (with only antioxidant polyphenols).

\section{Materials and Methods}

\section{Materials}

Ketamine and xylazine were obtained from Eurovet (Bladel, the Netherlands). Bovine serum albumin (BSA), ADP and ellagic acid were from Sigma-Aldrich (St. Luis M0, USA). H-Phe-Pro-Arg chloromethyl ketone (PPACK) was from Calbiochem (La Jolla CA, USA). Murine PAR4 peptide (GYPGKF) was a gift from Dr. S. Kunapuli, Temple University (Philadelphia PA, USA). Low molecular weight heparin (fragmin) was from Pfizer (Capelle a/d IJssel, the Netherlands). Convulxin was purified to homogeneity from the crude venom of Crotalus durissus terrificus (Latoxan, Valence, France) ${ }^{17}$. Recombinant human tissue factor was from Dade Behring (Marburg, Germany). Fibrillar Horm type I collagen was from Nycomed Pharma (Munich, Germany); fluorescein isothiocyanate (FITC) labeled annexin A5 from PharmaTarget (Maastricht, the Netherlands). FITClabeled anti-CD62 mAb was from Immunotech (Marseille, France); phycoerythrin (PE)labeled anti-mouse JON/A mAb from Emfret Analytics (Würzburg, Germany); and antimouse CD36 mAb from Chemicon (Billerica MA, USA). Other materials were from sources as described before ${ }^{18,19}$. 


\section{Animals and diets}

Experiments were approved by the local Animal Experimental Committee. Pathogen free Apoe $^{-/}$male mice at $\mathrm{C} 57 \mathrm{Bl} / 6$ background were obtained from Charles River (Maastricht, the Netherlands). During the study, animals were kept individually in transparent macrolon cages at $20-22^{\circ} \mathrm{C}$ ( $12 \mathrm{~h}$ light/dark cycle; $60 \%$ relative humidity). The mice were allowed to drink water ad libitum and were provided daily with $5 \mathrm{~g}$ of indicated diets. Food intake was calculated daily by back weighting the uneaten feed; whole body weight was measured weekly.

During a first period of two weeks, 48 mice (aged 8 weeks) were fed a standard purified diet containing 4 weight\% fat from TestDiet (AIN-93M, Richmond IN, USA). Animals were then randomly divided into four groups, and fed during 8 weeks a diet containing 0.2 weight\% cholesterol and 20 weight\% (34 energy\%) fat (Table 7.1 ). In these high-fat diets, the standard diet was supplemented with either: (i) sunflower oil rich in n-6 PUFA (high-fat control or HFC group); (ii) walnut oil rich in n-3 PUFA (WO group); (iii) whole walnuts rich in $n-3$ PUFA and antioxidant polyphenols (WW group); or (iv) sunflower oil supplemented with grape seed extract rich in antioxidant polyphenols (GSE group). Animals from the WW group received daily $1.2 \mathrm{~g}$ walnuts (Juglans regia L.), while animals of the GSE group received daily $12 \mathrm{mg}$ grape seed extract. Other macronutrients, i.e. protein, carbohydrate, and fiber were kept equal in all groups on a weight\% base (Table 7.1). Walnuts and walnut oil, both from same batch of nuts, were obtained from Zade Edible Oil Refinery \& Cold Pressed Oil Plant

Table 7.1. Composition of four Western type diets used in this study.

\begin{tabular}{lcccc}
\hline & \multicolumn{3}{c}{ Type of diet } \\
\hline Diet constituent & $\begin{array}{c}\text { High fat control } \\
\text { (HFC) }\end{array}$ & $\begin{array}{c}\text { Walnut oil } \\
\text { (W0) }\end{array}$ & $\begin{array}{c}\text { Whole walnut } \\
\text { (WW) }\end{array}$ & $\begin{array}{c}\text { Grape seed } \\
\text { extract (GSE) }\end{array}$ \\
\hline Energy content (kJ/g) & 21.6 & 21.6 & 21.8 & 21.6 \\
Carbohydrates (energy\%) & 53 & 54 & 53 & 53 \\
Protein (energy\%) & 13 & 13 & 13 & 13 \\
Fat (energy\%) & 34 & 33 & 34 & 34 \\
SAFA (\% of total FA) & 12 & 11 & 11 & 12 \\
MUFA (\%) & 21 & 24 & 16 & 21 \\
$n-6$ PUFA (\%) & 66 & 55 & 59 & 66 \\
$n-3$ PUFA (\%) & 1.5 & 10 & 13 & 1.5 \\
Fiber (weight\%) & 6.0 & 6.0 & 6.5 & 6.0 \\
Cholesterol (weight\%) & 0.2 & 0.2 & 0.2 & 0.2 \\
Total TEAC (per $\mu$ mol Trolox) & 3240 & 3650 & 7030 & 14250 \\
water soluble TEAC (id.) & 1100 & 1410 & 5080 & 2710 \\
ethanol soluble TEAC (id.) & 2140 & 2240 & 1950 & 11540 \\
\hline
\end{tabular}

Abbreviations: SAFA, saturated fatty acids; MUFA, mono unsaturated fatty acids; TEAC, Trolox equivalent antioxidant capacity. 
(Konya, Turkey), as was the sunflower oil. Grape seed extract was from Polyphenolics (MegaNatural BP, Madera CA, USA). Diets were stored in aliquots at $-80^{\circ} \mathrm{C}$. Portions were daily thawed before administration.

\section{Collection of blood and tissues}

At the end of the dietary period, mice were deprived from food for $5 \mathrm{~h}$ to obtain sober profiles of blood lipids. Complete narcosis was induced by subcutaneous injection of 0.1 $\mathrm{mg} / \mathrm{g}$ body weight ketamine and $0.02 \mathrm{mg} / \mathrm{g}$ body weight xylazine. Blood was drawn under anesthesia from the retro-orbital plexus, and was collected into PPACK ( $40 \mu \mathrm{M}$, final concentration) plus heparin $(5 \mathrm{U} / \mathrm{ml})$ to study thrombus formation. Where indicated, blood was drawn from the vena cava into trisodium citrate $(12.9 \mathrm{mM})$ to prepare platelet free plasma. Bled animals were sacrificed by diaphragm puncture, immediately after which aortic arches and livers were dissected by a standard protocol ${ }^{19,20}$. Organs were isolated from adherent tissue, and rinsed with ice-cold saline to remove remaining blood. Main parts of the livers were snap-frozen in liquid nitrogen. Remaining liver lobes were fixed in $4 \%$ formaldehyde. Aortic arches including the main branch points (brachiocephalic trunk, left common carotid artery and left subclavian artery), were carefully removed from surrounding tissue, and fixed in $1 \%$ formaldehyde. Fixed tissues were embedded into paraffin and sectioned with a rotary microtome. Sections were processed as described elsewhere ${ }^{21}$.

\section{Flow cytometry}

Whole blood samples were diluted in Tyrode's Hepes buffer $(5 \mathrm{mM}$ Hepes, $136 \mathrm{mM}$ $\mathrm{NaCl}, 2.7 \mathrm{mM} \mathrm{KCl}, 0.42 \mathrm{mM} \mathrm{NaH}_{2} \mathrm{PO}_{4}, 2 \mathrm{mM} \mathrm{MgCl}, 0.1 \%$ glucose and $0.1 \% \mathrm{BSA}$, $\mathrm{pH}$ 7.45) supplemented with $2 \mathrm{mM} \mathrm{CaCl}$ and $20 \mathrm{U} / \mathrm{ml}$ fragmin. Aliquots were activated for 10 min with ADP $(40 \mu \mathrm{M})$, convulxin $(100 \mathrm{ng} / \mathrm{ml})$ or PAR4 peptide GYPGKF $(0.5$ $\mathrm{mM}$ ) without stirring. Activation of platelet integrin $\alpha_{\mathrm{II}} \beta_{3}$ and secretion of $\alpha$-granules was detected with PE-labeled JON/A mAb (1:20) and FITC-labeled anti-CD62 mAb (1:40), respectively ${ }^{18}$. Fluorescence was measured with a FACScan flow cytometer (Becton-Dickinson, Franklin Lakes, NJ, USA), counting a minimum 10,000 events in a predefined forward scatter region representing platelets. Data was analyzed by WinMDI 2.9 software (http://facs.scripps.edu) 22 .

\section{Thrombus formation under flow}

Glass coverslips, coated with fibrillar type I collagen, were blocked with Tyrode's Hepes buffer containing 1\% BSA, and mounted into a transparent parallel-plate flow chamber, as described ${ }^{23,24}$. PPACK/heparin-anticoagulated blood was perfused through the chamber at a shear rate of $1000 \mathrm{~s}^{-1}$. During the perfusion, high-resolution microscopic images were recorded in real time with a Visitech imaging system (Sunderland, UK) equipped with two parallel-placed intensified, charge-coupled device cameras for recording brightfield light and epifluorescence. A 40x oil-immersion objective was used with phase-contrast optics. After 4 min of perfusion, the flow chamber was perfused 
with Tyrode's Hepes buffer pH 7.45 supplemented with $1 \mathrm{U} / \mathrm{ml}$ heparin at the same shear rate for $2 \mathrm{~min}$. Exposure of phosphatidylserine was detected with FITC-labeled annexin A5 ( $1 \mu \mathrm{g} / \mathrm{ml})$. Phase-contrast and fluorescent images were taken from at least 10 microscopic fields, which were randomly chosen. Images were analyzed with MetaMorph software (Molecular Devices, Sunnyvale, CA, USA).

\section{Antioxidant capacity}

Diet samples were lyophilized, and extracted against sodium phosphate buffer (aqueous/ water soluble antioxidants) or ethanol (organic/ethanol soluble antioxidants). Plasma samples were not extracted. All samples were deproteinized by trichloro acetic acid, and Trolox equivalent antioxidant capacity (TEAC) was determined using an ABTS [2,2'-azinobis (3-ethylbenzthiazoline-6-sulfonic acid] decolorization assay. Reactions

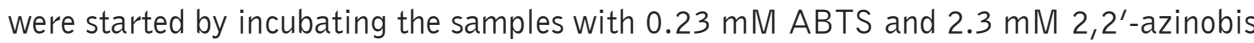
2-amidinopropane dihydrochloride in $100 \mathrm{mM}$ sodium phosphate buffer. Changes in absorbance in time were plotted and compared to a calibration curve. Slopes of the curves reflected antioxidant reducing capacity, which was expressed as $\mu$ mol Trolox equivalents, as described ${ }^{25}$.

\section{Coagulation parameters}

Thrombin generation was measured in citrated platelet-free plasma according to the automated thrombogram method, which was adapted for mouse plasma ${ }^{19,26}$. Briefly, $20 \mu \mathrm{l}$ plasma supplemented with $30 \mu \mathrm{M}$ procoagulant phospholipids was pipetted into wells of a micro-plate. Each well already contained $20 \mu \mathrm{l}$ recombinant tissue factor (18 pM) or $20 \mu$ lellagic acid (12 $\mu \mathrm{M})$ in Tyrode's Hepes buffer, pre-warmed to $37^{\circ} \mathrm{C}$. Coagulation was started by addition of $20 \mu \mathrm{l}$ fluorescent thrombin substrate (Z-GlyGly-Arg aminomethyl coumarin, $1.26 \mathrm{mM}$ ) and $\mathrm{CaCl}_{2}(24.6 \mathrm{mM})$. First-derivative curves of accumulation of fluorescence intensity in time were converted in to nanomolar thrombin concentrations by using a thrombin calibrator. Plasma levels of prothrombin and factor $V$ were measured with factor-deficient plasmas, as described ${ }^{19}$. Fibrinogen was determined according to the Claus method ${ }^{27}$.

\section{Measurement of lipids and cholesterol}

Lipids in diets were extracted with chloroform/methanol and trans-methylated, after which fatty acid profiles were analyzed by gas chromatography ${ }^{28}$. Plasma levels of total cholesterol (Cholesterol RTU, Biomerieux, France) and triglycerides (Triglyceride/ GB GPO-PAP, Roche Diagnostics, Switzerland) were measured with enzymatic color tests, following the manufacturers' instructions using an Absorbance Microplate Reader (EL808 Biotek, Winooski VT, USA) ${ }^{19}$. To measure lipid content in livers, $50 \mathrm{mg}$ of frozen liver tissue was added to $1.0 \mathrm{ml}$ of buffer $\mathrm{pH} 7.45$, consisting of $250 \mathrm{mM}$ sucrose, $2 \mathrm{mM}$ EDTA and $10 \mathrm{mM}$ Tris. Mixtures were homogenized by shaking for $30 \mathrm{~s}$ at 5000 rpm in a closed tube ${ }^{29}$. Triglycerides in the homogenates were measured, using the test described above, and normalized for protein content. Protein was measured with the BCA method according to the manufacturer's protocol (Pierce, Rockford IL, USA). 


\section{Histology and immunohistochemistry}

Paraffin-embedded livers and aortic arches with main branch points were cut into approximately 40 sections, each $4 \mu \mathrm{m}$ in thickness, following routine procedures ${ }^{20}$. Series of 20 sections, representing the central area with intact morphology of the complete arch, and serial sections of liver were used for histological analysis. Representative four sections ( $16 \mu \mathrm{m}$ apart) from each aortic arch and liver were stained with hematoxylin and eosin. Total plaque area in the aortic sections $(2 \times 4 \mathrm{~mm})$ was determined by averaging the identified atherosclerotic areas in each of the four sections. Immunohistochemistry to detect CD36 was performed on aortic sections by staining with anti-mouse CD36 mAb (1:100).

\section{Statistical analysis}

Results are expressed as mean \pm SEM. Data analysis, significance of differences was determined with a parametric $t$ test or a non-parametric Mann-Whitney $U$ test, as required, using Prism (GraphPad Software version 5.00 Inc., San Diego, CA, USA). Statistical significance was set at $p<0.05$.

\section{Results}

\section{Dietary effect on body weight}

Groups of 12 Apoe $^{-/}$mice were fed one of four types of high-fat diets (20 weight\% fat, 0.2 weight\% cholesterol), with compositions as shown in Table 7.1. The diet of the high-fat control (HFC) group consisted of sunflower oil, rich in $n-6$ PUFA; the walnut oil (WO) group received a diet containing 10\% n-3 PUFA; the whole walnut (WW) group received a diet rich in both n-3 PUFA and antioxidant polyphenols; and the grape seed extract (GSE) group received the sunflower oil plus polyphenols from grape seed. Extraction of the diets indicated that especially the level of water-soluble antioxidants was 5-fold increased in the whole walnut diet, while the level of ethanolsoluble antioxidants was 5 -fold increased in grape seed-containing diet, when compared to the high-fat control diet. During the 8-week dietary period, mice of the four groups similarly increased in body weight, starting from 23-24 $\mathrm{g}$ and reaching 36-38 g (Figure 7.1). In agreement with this, daily food intake did not differ between the four diet groups (data not shown).

\section{Dietary effect on platelet activation and thrombus formation}

Knowing that in vitro addition of antioxidant polyphenols can inhibit platelet function ${ }^{14,30}$, we investigated the effects of the diets (polyphenol-containing) on wholeblood platelet activation. Flow cytometry showed that neither $\alpha_{\mathrm{IIb}} \beta_{3}$ integrin activation (measured with JON/A mAb) nor $\alpha$-granule secretion (measured with anti-CD62 mAb) in response to $A D P$, convulxin or PAR4 peptide was changed in the WW, WO or GSE groups in comparison to the HFO group (Figure 7.2A,B). We then measured thrombus formation under flow as a physiological test of platelet activation, by perfusing PPACKanticoagulated blood over a collagen surface in a parallel-plate flow chamber at arterial 
Figure 7.1. Effect of different diets on body weight. Apoe $e^{-/}$mice were fed with one of the indicated Western-type diets during 8 weeks, giving 4 diet groups: high-fat control (HFC), walnut oil (WO), whole walnut (WW), and grape seed extract (GSE) group. Data shows increase in body weight during the dietary period. Means \pm S.E.M. $(n=12)$.

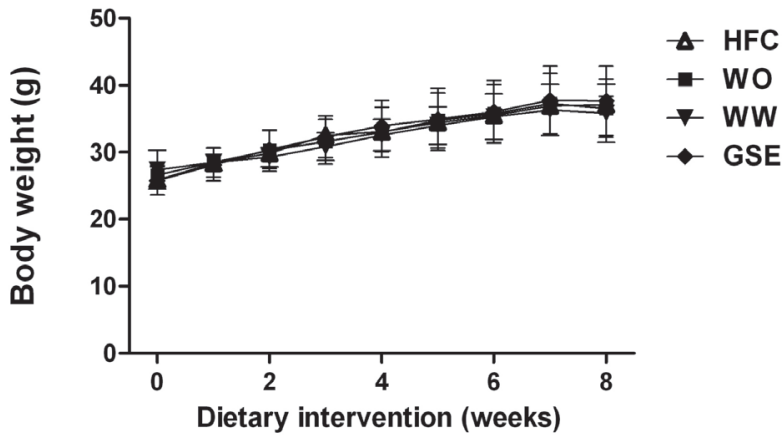

shear rate 22 . In this assay, platelets from all diet groups showed a similar buildup of aggregates on the collagen surface (Figure 7.2C,D). Post-staining with FITC-annexin A5 to probe phosphatidylserine-exposing platelets gave similar results for all diet groups.

A

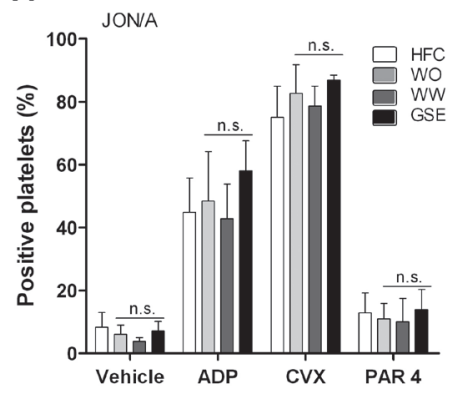

C

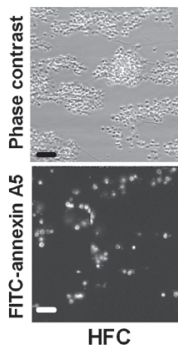

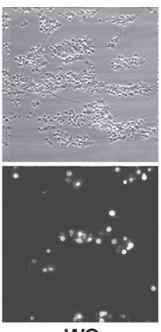

wo

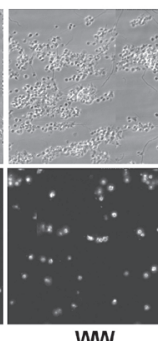

WW

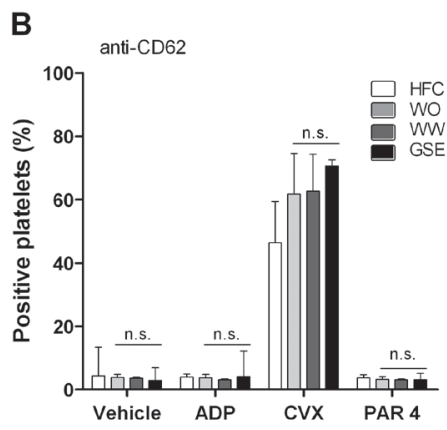

D

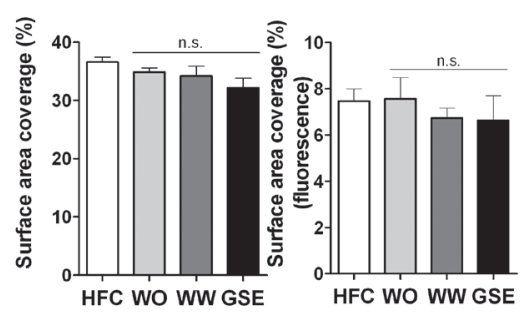

Figure 7.2. Effect of diets on platelet activation and thrombus formation. Blood from mice was used for analysis of platelet function and thrombus formation. (A, $B$ ) Platelets in diluted blood samples were stimulated with ADP $(40 \mu \mathrm{M})$, convulxin (CVX, $100 \mathrm{ng} / \mathrm{ml})$ or PAR4 peptide GYPGKF $(0.5 \mathrm{mM})$ for $10 \mathrm{~min}$. (A) Activation of $\alpha_{\mathrm{II}} \beta_{3}$ (PE-labeled JON/A mAb, $150 \mu \mathrm{g} / \mathrm{ml}$ ) and (B) expression of P-selectin (FITC-anti-CD62 mAb, 1:50) was assessed by flow cytometry. $(C, D$ ) PPACK-anticoagulated whole blood was flowed 4 min over a collagen surface. Thrombus formation was determined by microscopic analysis of all deposited platelets and of platelets staining with FITC-labeled annexin A5. (C) Representative phase contrast and fluorescence images (bars, $10 \mu \mathrm{m}$ ). (D) Surface area coverage of thrombi and of fluorescently labeled platelets exposing phosphatidylserine. Means \pm S.E.M. ( $n=4-6)$; n.s., not significant compared to HFC group. 


\section{Effect of walnut-rich diet on antioxidant capacity and prothrombin level}

Trolox equivalent antioxidant capacity (TEAC) was measured in plasma samples from sober animals. In contrast to the high intake of antioxidant polyphenols in the WW and GSE groups, TEAC was slightly increased only in plasmas from the WW group, when compared to the HFC group (Figure 7.3). This is in agreement with data from other authors, showing an increased TEAC in human plasma after walnut consumption ${ }^{31}$, and an unchanged TEAC in the plasma from hamsters receiving grape extract ${ }^{32}$.

Figure 7.3. Effect of diets on plasma antioxidant capacity. Plasmas from animals of the four diet groups were analyzed on Trolox equivalent antioxidant capacity (TEAC). Data is represented as $\mu \mathrm{mol}$ Trolox equivalents. Means \pm S.E.M. $(n=8-10) ; * p<0.05$ vs. HFC group.

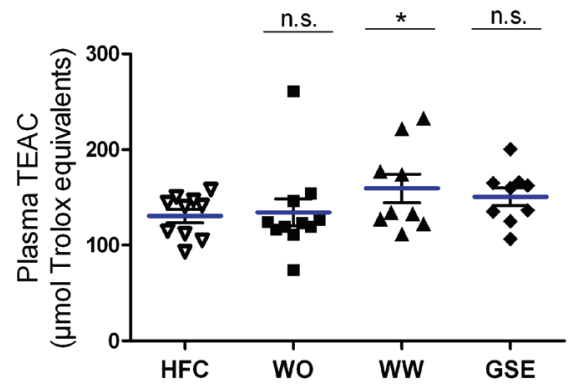

Considering that n-3 PUFA in dietary fish oil in human and in APOE2 knock-in mice diminish plasma coagulant activity along with lipid levels ${ }^{19,33}$, we measured these parameters also in the present study. Plasma levels of fibrinogen and factor $V$ were not different between the diet groups, but prothrombin was significantly reduced with $21 \%$ in the WW group in comparison to the HFC group (Figure 7.4A-C). For animals of all

A

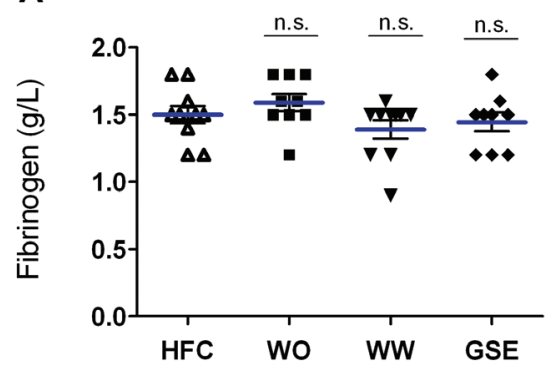

Figure 7.4. Effect of diets on plasma coagulation parameters. Plasma samples from animals of the four diet groups were analyzed for coagulation factors. Shown are levels of fibrinogen $(A)$, prothrombin $(B)$, and factor $\mathrm{V}(C)$. Means \pm S.E.M. $(n=8-10)$; n.s., not significant, ${ }^{*} p<0.05 v s$. HFC group.
B

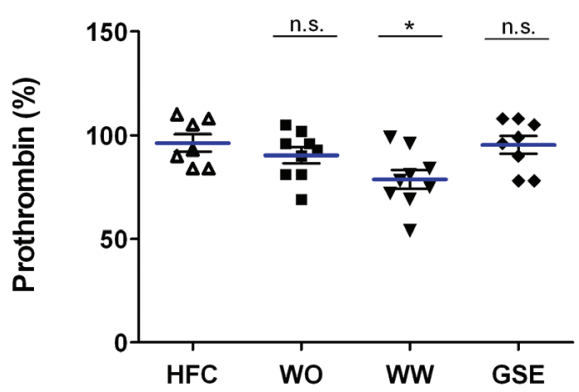

C

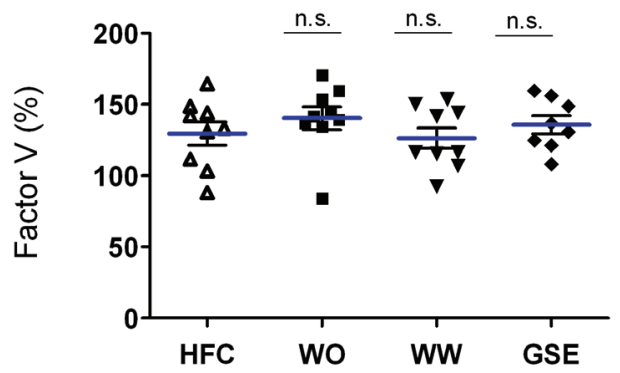


groups together, plasma levels of prothrombin and factor $V$ were closely correlated $(R=0.82, p=0.02)$. Thrombin generation was measured in plasma in response to tissue factor or ellagic acid, which stimulate the extrinsic or intrinsic coagulation pathway, respectively ${ }^{34}$. In tissue factor-triggered plasma samples, thrombin peak height - i.e. a measure of the maximal rate of thrombin generation - tended to be reduced in the WW group (Figure $7.5 \mathrm{~A}, \mathrm{~B}$ ). In plasma samples triggered with ellagic acid, the endogenous thrombin potential - reflecting the total thrombin-generating capacity - was $22 \%$ lower in the GSE group compared to the HFC group (Figure 7.5C,D).

Figure 7.5. Effect of diets on thrombin generation in plasma. Calibrated automated thrombin generation curves were generated using plasmas from the 4 diet groups . Shown are thrombin peak height and endogenous thrombin potential after plasma triggering with either tissue factor $(A, B)$ or ellagic acid $(C, D)$. Means \pm S.E.M. $(n=10-11) ;{ }^{*} p<0.1$, $* p<0.05$ vs. HFC group.
A

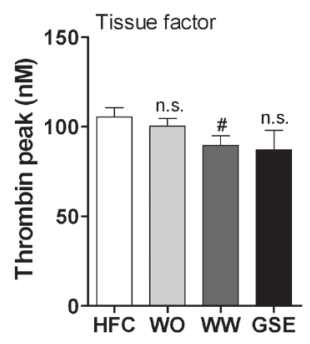

C

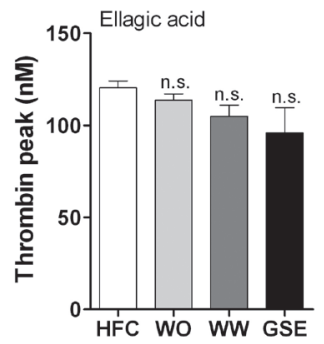

B

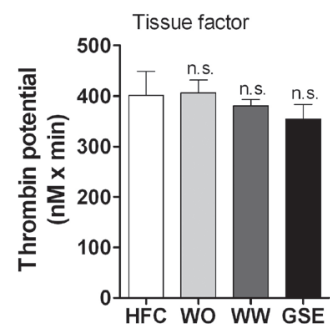

D

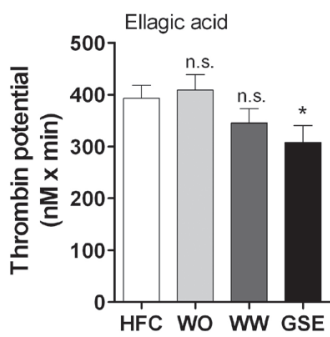

\section{Effect of walnut-rich diet on lipid levels}

The ability of the diets to affect lipid metabolism was explored by examination of fixed liver sections. These sections showed that lipid droplets were relatively small in livers of the only the WW group (Figure 7.6A). Assessment of triglyceride levels in livers pointed to a $30 \%$ reduction in the WW group when compared to the HFC group, whereas triglycerides in livers from the WO and GSE groups were not decreased (Figure 7.6B). Again, in the WW group, levels of triglycerides and total cholesterol in blood plasma were reduced with $36 \%$ and $23 \%$, respectively, in comparison to the HFC group (Figure 7.6C,D). In contrast, plasma triglycerides and total cholesterol levels in the WO and GSE groups were comparable to those of the control group.

\section{Effect of walnut-rich diet on atherosclerotic plaque development}

Aortic arches including main branch points were prepared and sectioned from all groups of mice to determine the development of atherosclerotic plaques in this area. 
A
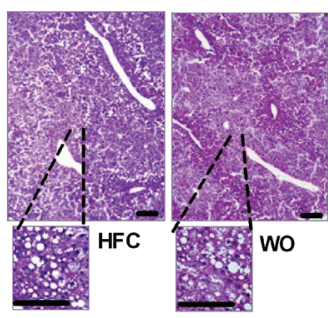

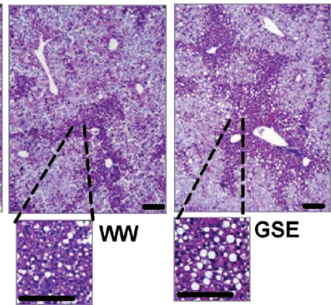

B

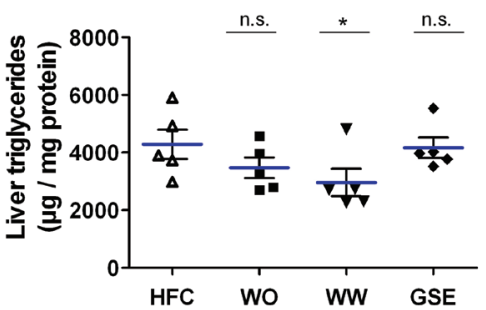

C

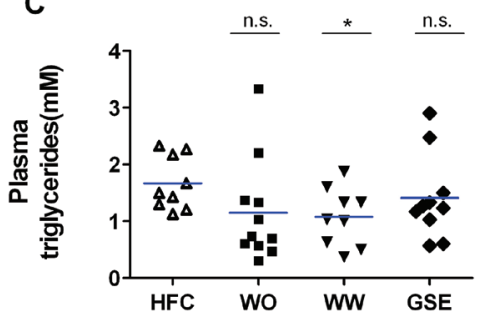

D

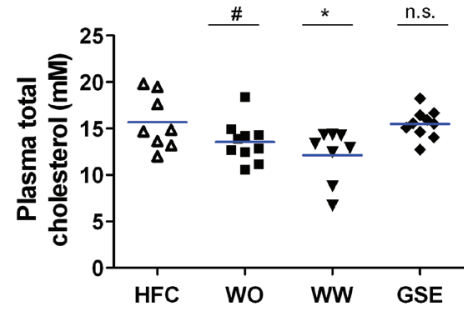

- Figure 7.6. Effect of diets on lipid profiles in liver and plasma. Triglyceride accumulation in liver, and plasma levels of total cholesterol and triglycerides were determined in mice of the 4 diet groups. (A) Representative paraffin sections of liver stained with hematoxylin-eosin (bars, $100 \mu \mathrm{m}$ ). Magnified images indicate fat droplets. $(B)$ Triglycerides levels in liver $(n=5)$. Levels of triglycerides $(C)$ and total cholesterol (D) in plasma $(n=9-11)$. Means \pm S.E.M. ; ${ }^{*} p<0.1,{ }^{*} p<0.05 v s$. HFC group.

Per aortic arch, four sections were analyzed for the determination of lesion size and for the expression of CD36, as a marker of atherosclerosis. Remarkably, there was a $55 \%$ reduction in atherosclerotic plaque area in the aortic arches from animals of the WW group, but not of the WO and GSE groups, compared to the HFC group (Figure 7.7A,B). Immunohistochemistry indicated high staining for CD36 in the plaque areas, where (CD36-expressing) macrophages are present. Staining of this scavenger receptor was about 50\% lower in the WW group compared to the HFC group (Figure 7.7C,D). In contrast, staining for CD36 was similar in aortic arches from the WO, GSE and HFC groups. Together, these data indicate that dietary supplementation with walnuts, but not with walnut oil or grape seed extract, suppresses the formation of atherosclerotic plaques and CD36 expression in the aortic region of $A p o e^{-/-}$mice.

\section{Discussion}

In this report, we investigated the effects of dietary walnuts on markers of atherothrombosis in Apoe ${ }^{-/-}$mice fed during 8 weeks with high-fat diet with cholesterol. The results show that intake of whole walnuts, but not of walnut oil, improves the lipid profiles in blood plasma and liver, and has moderate positive effects on coagulation and antioxidant capacity. These dietary effects are accompanied by a major reduction in atherosclerotic plaque formation and CD36 expression, but not by marked changes in platelet or coagulation activation. 
A

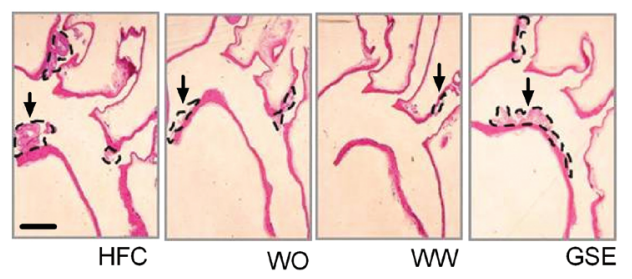

B

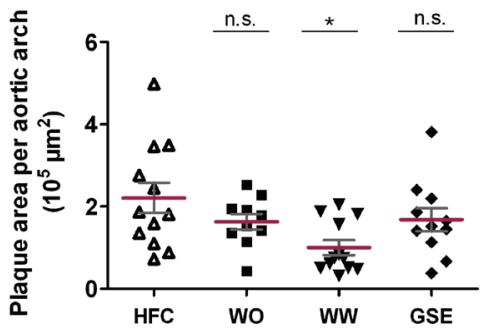

C
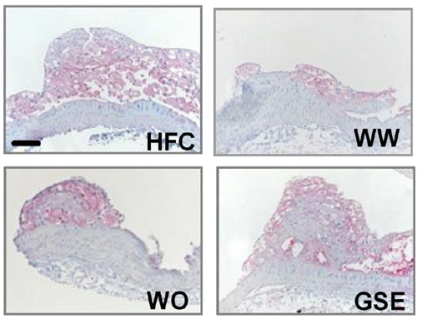

D

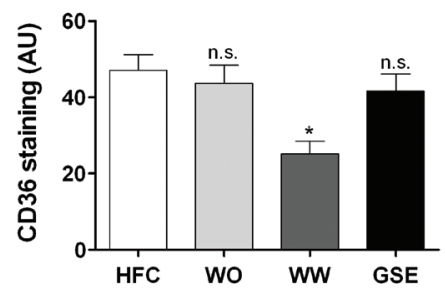

Figure 7.7. Effect of diets on atherosclerotic lesion development and CD36 expression. Progression of atherosclerotic plaques was analyzed in $A p o e^{-/}$mice of the 4 diet groups. (A) Representative sections of complete aortic arches showing plaque areas (arrows). Bars, $1 \mathrm{~mm}$. (B) Quantification of the extent of atherosclerosis. Data points represent one individual mouse (average of 4 sections per aorta). $(C)$ Representative sections of plaques stained for CD36 (bars, $150 \mu \mathrm{m}$ ). (D) Quantification of CD36 staining indicated as mean staining intensity (arbitrary units) of plaque areas. Means \pm S.E.M. $(n=10-12) ; * p<0.05$ vs. HFC group.

We were interested to determine the consequences of walnut intake, since these nuts contain antioxidant polyphenols and $n-3$ PUFA (mainly $\alpha$-linolenic acid), both of which are components considered to promote cardiovascular health. A surprising finding is that the intake of walnut oil (i.e. of $n-3$ PUFA alone) did not mimic the lipid-lowering and atheroprotective effects of the whole walnuts. This contrasts to the results of an earlier study with APOE2 knock-in mice, where the intake of fish oil resulted in clearly diminished lipid levels and decreased plasma coagulant activity ${ }^{19}$. However, the fish oil used in that study contained much higher levels of $n-3$ PUFA (59\%, eicosapentaenoic acid and docosahexaenoic acid) than the walnut oil ( $10 \%, \alpha$-linolenic acid) of the present experiments. Hence, it is conceivable that the limited amount of $n-3$ PUFA in walnut or walnut oil is insufficient to cause lipid-lowering and anticoagulant effects by itself.

In the present study, we found no more than limiting dietary effects on platelet and coagulation activities. Only after walnut intake, prothrombin in plasma was slightly lowered, while fibrinogen and factor $V$ levels remained unaltered. In agreement with this, human intervention studies have not shown effects of walnut intake on key coagulation parameters in subjects with metabolic syndrome ${ }^{35,36}$. Regarding platelets, one paper describes that walnut intake did not influence on human platelet activation ${ }^{11}$, whilst another study reports protective effects of grape seed extract on human platelets only after in vitro administration ${ }^{37}$. On the other hand, intravenously or orally administered 
grape seed extract has been reported to suppress in vivo thrombus formation in arteries ${ }^{15}$ and veins ${ }^{38}$ in animal experimental models.

The ability of walnuts, but not of walnut oil or grape seed, to diminish atherosclerotic plaque progression during the 8 weeks intervention period, is a novel finding. In apparent contrast, another study points to somewhat increased lipid levels and increased atherosclerosis in Apoe ${ }^{-/}$mice fed with walnut oil, but that study was statistically underpowered $^{39}$. On the other hand, in human it is reported that the regular intake of walnuts associates with a lowering of triglycerides ${ }^{40}$. Various kinds of in vitro effects of walnut extracts on cells have been reported, e.g. a reduced expression of cell adhesion molecules and a reduced formation of proinflammatory cytokines ${ }^{41-43}$. Unlike the present findings with mice, intake of grape seed extract was found to retard atherosclerosis in hyperlipidemic rabbits ${ }^{16}$ and hamsters ${ }^{32}$. This may point to inter-species differences in the absorption or metabolism of these dietary compounds.

Interestingly, we measured a reduced expression of CD36 in the plaque areas from mice fed with walnuts, which is supported by the results from others that CD36 is mainly localized in macrophages within atherosclerotic lesions ${ }^{44,45}$. There is also evidence that the CD36 receptor contributes to the atherosclerotic process, since in Apoe $e^{-/}$mice CD36 deficiency protects against plaque development ${ }^{46,47}$.

It is tentative to assume that the atheroprotective effect of walnuts is a consequence of the simultaneous presence of $\alpha$-linolenic acid and other substances, like the watersoluble antioxidant polyphenols. Support for this can be found in the literature, where it is suggested that antioxidants in walnuts are well bio-available, whereas those in grape seed are less easily absorbed by the gut ${ }^{48,49}$. Hence, the walnut-derived polyphenols ellagic acid monomers, ellagitannins and non-flavonoid compounds - may increase the antioxidant state of plasma to a larger extent than the proantocyanidins present in grape seed ${ }^{50-52}$.

Taken together, we report a beneficial effect of dietary walnut intake on plasma lipids and atherosclerotic plaque development in mice, with no more than limited effects on platelet and coagulation function. Mechanistically, the diet-dependent protection for atherosclerosis can be explained by less lipid uptake in the plaque area, perhaps in a way involving CD36. Whether antioxidant polyphenols are involved is still unclear. Although more studies are required, the emerging picture is that walnut intake beneficially influences atherosclerosis by components other than merely $n-3$ PUFA.

\section{Acknowledgements}

We acknowledge grant support from Hacettepe University (Ankara, Turkey). We thank S. Garcia Caraballo, Anique Janssen, Jack Cleutjens and Roger Bartholome for expert analytical assistance. 


\section{References}

1. World Health Organization. Cardiovascular diseases. Fact sheet No: 317. 2011: http://www. who.int/mediacentre/factsheets/fs317/en/index.html.

2. Davi G, Patrono C. Platelet activation and atherothrombosis. N Engl J Med. 2007;357:24822494.

3. Mackman N. Triggers, targets and treatments for thrombosis. Nature. 2008;451:914-918.

4. Banel DK, Hu FB. Effects of walnut consumption on blood lipids and other cardiovascular risk factors: a meta-analysis and systematic review. Am J Clin Nutr. 2009;90:56-63.

5. Vislocky LM, Fernandez ML. Biomedical effects of grape products. Nutr Rev. 2010;68:656670.

6. Feldman EB. The scientific evidence for a beneficial health relationship between walnuts and coronary heart disease. J Nutr. 2002;132:1062S-1101S.

7. Ros E, Mataix J. Fatty acid composition of nuts: implications for cardiovascular health. $\mathrm{Br}$ J Nutr. 2006;96:S29-35.

8. Crews C, Hough P, Godward J, Brereton P, Lees M, Guiet S, Winkelmann W. Study of the main constituents of some authentic walnut oils. J Agric Food Chem. 2005;53:4853-4860.

9. Chen CY, Blumberg JB. Phytochemical composition of nuts. Asia Pac J Clin Nutr. 2008;17 Suppl 1:329-332.

10. Canales A, Bastida S, Librelottto J, Nus M, Sanchez-Muniz FJ, Benedi J. Platelet aggregation, eicosanoid production and thrombogenic ratio in individuals at high cardiovascular risk consuming meat enriched in walnut paste. A crossover, placebo-controlled study. Br J Nutr. 2009;102:134-141.

11. Din JN, Aftab SM, Jubb AW, Carnegy FH, Lyall K, Sarma J, Newby DE, Flapan AD. Effect of moderate walnut consumption on lipid profile, arterial stiffness and platelet activation in humans. Eur J Clin Nutr. 2011;65:234-239.

12. Das DK, Sato M, Ray PS, Maulik G, Engelman RM, Bertelli AA, Bertelli A. Cardioprotection of red wine: role of polyphenolic antioxidants. Drugs Exp Clin Res. 1999;25:115-120.

13. Polagruto JA, Gross HB, Kamangar F, Kosuna K, Sun B, Fujii H, Keen CL, Hackman $\mathrm{RM}$. Platelet reactivity in male smokers following the acute consumption of a flavanol-rich grapeseed extract. J Med Food. 2007;10:725-730.

14. Olas B, Wachowicz B, Tomczak A, Erler J, Stochmal A, Oleszek W. Comparative anti-platelet and antioxidant properties of polyphenol-rich extracts from: berries of Aronia melanocarpa, seeds of grape and bark of Yucca schidigera in vitro. Platelets. 2008;19:70-77.

15. Sano T, Oda E, Yamashita T, Naemura A, Ijiri Y, Yamakoshi J, Yamamoto J. Anti-thrombotic effect of proanthocyanidin, a purified ingredient of grape seed. Thromb Res. 2005;115:115121.

16. Frederiksen H, Mortensen A, Schroder M, Frandsen H, Bysted A, Knuthsen P, Rasmussen SE. Effects of red grape skin and seed extract supplementation on atherosclerosis in Watanabe heritable hyperlipidemic rabbits. Mol Nutr Food Res. 2007;51:564-571.

17. Siljander P, Farndale RW, Feijge MAH, Comfurius P, Kos S, Bevers EM, Heemskerk JWM. Platelet adhesion enhances the glycoprotein VI-dependent procoagulant response: involvement of p38 MAP kinase and calpain. Arterioscler Thromb Vasc Biol. 2001;21:618627.

18. Gilio K, Harper MT, Cosemans JMEM, Konopatskaya 0, Munnix ICA, Prinzen L, Leitges M, Liu Q, Molkentin JD, Heemskerk JWM, Poole AW. Functional divergence of platelet protein kinase $C(P K C)$ isoforms in thrombus formation on collagen. J Biol Chem. 2010;285:2341023419

19. Vanschoonbeek K, Wouters K, van der Meijden PE, van Gorp PJ, Feijge MA, Herfs M, Schurgers LJ, Hofker MH, de Maat MP, Heemskerk JW. Anticoagulant effect of dietary fish oil in hyperlipidemia: a study of hepatic gene expression in APOE2 knock-in mice. Arterioscler Thromb Vasc Biol. 2008;28:2023-2029.

20. Lutgens E, Gorelik L, Daemen MJ, de Muinck ED, Grewal IS, Koteliansky VE, Flavell RA. 
Requirement for CD154 in the progression of atherosclerosis. Nat Med. 1999;5:1313-1316.

21. Lutgens E, Lievens D, Beckers L, Wijnands E, Soehnlein 0, Zernecke A, Seijkens T, Engel D, Cleutjens J, Keller AM, Naik SH, Boon L, Oufella HA, Mallat Z, Ahonen CL, Noelle RJ, de Winther MP, Daemen MJ, Biessen EA, Weber C. Deficient CD40-TRAF6 signaling in leukocytes prevents atherosclerosis by skewing the immune response toward an antiinflammatory profile. J Exp Med. 2010;207:391-404.

22. Munnix IC, Kuijpers MJ, Auger J M, Thomassen CM, Panizzi P, van Zandvoort MA, Rosing J, Bock PE, Watson SP, Heemskerk JW. Segregation of platelet aggregatory and procoagulant microdomains in thrombus formation. Regulation by transient integrin activation. Arterioscler Thromb Vasc Biol. 2007;27:2484-2490.

23. Kuijpers MJ, Schulte $V$, Bergmeier W, Lindhout $T$, Brakebusch $C$, Offermanns $S$, Fässler R, Heemskerk JW, Nieswandt B. Complementary roles of glycoprotein VI and $\alpha 2 \beta 1$ integrin in collagen-induced thrombus formation in flowing whole blood ex vivo. Faseb J. 2003;17:685687.

24. Siljander PR, Munnix IC, Smethurst $P$, Deckmyn $H$, Lindhout $T$, Ouwehand WH, Farndale RW, Heemskerk JW. Platelet receptor interplay regulates collagen-induced thrombus formation in flowing human blood. Blood. 2004;103:1333-1341.

25. Fischer MA, Gransier TJ, Beckers LM, Bekers 0, Bast A, Haenen GR. Determination of the antioxidant capacity in blood. Clin Chem Lab Med. 2005;43:735-740.

26. Tchaikovski SN, van Vlijmen BJ, Rosing J, Tans G. Development of a calibrated automated thrombography based thrombin generation test in mouse plasma. J Thromb Haemost. 2007;5:2079-2086.

27. Nieuwenhuys CMA, Béguin S, Offermans RFG, Emeis JJ, Hornstra G, Heemskerk JWM. Hypocoagulant and lipid-lowering effects of dietary n-3 polyunsaturated fatty acids with unchanged platelet activation in rat. Arterioscler Thromb Vasc Biol. 1998;18:1480-1489.

28. Nieuwenhuys CM, Hornstra G. The effects of purified eicosapentaenoic and docosahexaenoic acids on arterial thrombosis tendency and platelet function in rats. Biochim Biophys Acta. 1998;1390:313-322.

29. Shiri-Sverdlov R, Wouters K, van Gorp PJ, Gijbels MJ, Noel B, Buffat L, Staels B, Maeda $\mathrm{N}$, van Bilsen M, Hofker MH. Early diet-induced non-alcoholic steatohepatitis in APOE2 knock-in mice and its prevention by fibrates. J Hepatol. 2006;44:732-741.

30. Vitseva 0, Varghese S, Chakrabarti S, Folts JD, Freedman JE. Grape seed and skin extracts inhibit platelet function and release of reactive oxygen intermediates. $J$ Cardiovasc Pharmacol. 2005; 46:445-451.

31. Reiter RJ, Manchester LC, Tan DX. Melatonin in walnuts: influence on levels of melatonin and total antioxidant capacity of blood. Nutrition. 2005;21:920-924.

32. Auger C, Gerain P, Laurent-Bichon F, Portet K, Bornet A, Caporiccio B, Cros G, Teissedre $P L$, Rouanet JM. Phenolics from commercialized grape extracts prevent early atherosclerotic lesions in hamsters by mechanisms other than antioxidant effect. J Agric Food Chem. 2004;52:5297-5302.

33. Vanschoonbeek K, Feijge MA, Saris WH, de Maat MP, Heemskerk JW. Plasma triacylglycerol and coagulation factor concentrations predict the anticoagulant effect of dietary fish oil in overweight subjects. J Nutr. 2007;137:7-13.

34. Vanschoonbeek K, Feijge MA, Paquay M, Rosing J, Saris W, Kluft C, Giesen PL, de Maat MP, Heemskerk JW. Variable hypocoagulant effect of fish oil intake in humans: modulation of fibrinogen level and thrombin generation. Arterioscler Thromb Vasc Biol. 2004;24:17341740.

35. Pieters M, Oosthuizen W, Jerling JC, Loots DT, Mukuddem-Petersen J, Hanekom SM. Clustering of haemostatic variables and the effect of high cashew and walnut diets on these variables in metabolic syndrome patients. Blood Coagul Fibrinolysis. 2005;16:429-437.

36. Morgan JM, Horton K, Reese D, Carey C, Walker K, Capuzzi DM. Effects of walnut consumption as part of a low-fat, low-cholesterol diet on serum cardiovascular risk factors. Int J Vitam Nutr Res. 2002;72:341-347. 
37. Shanmuganayagam D, Beahm MR, Osman HE, Krueger CG, Reed JD, Folts JD. Grape seed and grape skin extracts elicit a greater antiplatelet effect when used in combination than when used individually in dogs and humans. J Nutr. 2002;132:3592-3598.

38. Zhang $Y$, Shi H, Wang W, Ke Z, Xu P, Zhong Z, Li X, Wang S. Antithrombotic effect of grape seed proanthocyanidins extract in a rat model of deep vein thrombosis. J Vasc Surg. 2011;53:743-753.

39. Iwamoto M, Kono M, Kawamoto D, Tomoyori $H$, Sato M, Imaizumi K. Differential effect of walnut oil and safflower oil on the serum cholesterol level and lesion area in the aortic root of apolipoprotein E-deficient mice. Biosci Biotechnol Biochem. 2002;66:141-146.

40. Zibaeenezhad MJ, Shamsnia SJ, Khorasani M. Walnut consumption in hyperlipidemic patients. Angiology. 2005;56:581-583.

41. Papoutsi Z, Kassi E, Chinou I, Halabalaki M, Skaltsounis LA, Moutsatsou P. Walnut extract (Juglans regia L.) and its component ellagic acid exhibit anti-inflammatory activity in human aorta endothelial cells and osteoblastic activity in the cell line KS483. Br J Nutr. 2008;99:715-722.

42. Bellido C, Lopez-Miranda J, Blanco-Colio LM, Perez-Martinez P, Muriana FJ, MartinVentura JL, Marin C, Gomez P, Fuentes F, Egido J, Perez-Jimenez F. Butter and walnuts, but not olive oil, elicit postprandial activation of nuclear transcription factor kappaB in peripheral blood mononuclear cells from healthy men. Am J Clin Nutr. 2004;80:1487-1491.

43. Jimenez-Gomez $Y$, Lopez-Miranda J, Blanco-Colio LM, Marin C, Perez-Martinez P, Ruano J, Paniagua JA, Rodriguez F, Egido J, Perez-Jimenez F. Olive oil and walnut breakfasts reduce the postprandial inflammatory response in mononuclear cells compared with a butter breakfast in healthy men. Atherosclerosis. 2009;204:e70-76.

44. Leonarduzzi G, Gargiulo S, Gamba P, Perrelli MG, Castellano I, Sapino A, Sottero B, Poli G. Molecular signaling operated by a diet-compatible mixture of oxysterols in up-regulating CD36 receptor in CD68 positive cells. Mol Nutr Food Res. 2010;54 Suppl 1:S31-41.

45. Handberg A, Skjelland M, Michelsen AE, Sagen EL, Krohg-Sorensen K, Russell D, Dahl A, Ueland T, Oie E, Aukrust P, Halvorsen B. Soluble CD36 in plasma is increased in patients with symptomatic atherosclerotic carotid plaques and is related to plaque instability. Stroke. 2008;39:3092-3095.

46. Febbraio M, Guy E, Silverstein RL. Stem cell transplantation reveals that absence of macrophage CD36 is protective against atherosclerosis. Arterioscler Thromb Vasc Biol. 2004; $24: 2333-2338$.

47. Kuchibhotla S, Vanegas D, Kennedy DJ, Guy E, Nimako G, Morton RE, Febbraio M. Absence of CD36 protects against atherosclerosis in ApoE knock-out mice with no additional protection provided by absence of scavenger receptor A I/II. Cardiovasc Res. 2008;78:185196.

48. Manach C, Williamson G, Morand C, Scalbert A, Remesy C. Bioavailability and bioefficacy of polyphenols in humans. I. Review of 97 bioavailability studies. Am J Clin Nutr. 2005;81:230S-242S.

49. Hwang IK, Kim DW, Park JH, Lim SS, Yoo KY, Kwon DY, Kim DW, Moon WK, Won MH. Effects of grape seed extract and its ethylacetate/ethanol fraction on blood glucose levels in a model of type 2 diabetes. Phytother Res. 2009;23:1182-1185.

50. Anderson KJ, Teuber SS, Gobeille A, Cremin P, Waterhouse AL, Steinberg FM. Walnut polyphenolics inhibit in vitro human plasma and LDL oxidation. J Nutr. 2001;131:28372842.

51. Fukuda $T$, Ito $H$, Yoshida T. Effect of the walnut polyphenol fraction on oxidative stress in type 2 diabetes mice. Biofactors. 2004;21:251-253.

52. Canales A, Benedi J, Nus M, Librelotto J, Sanchez-Montero JM, Sanchez-Muniz FJ. Effect of walnut-enriched restructured meat in the antioxidant status of overweight/obese senior subjects with at least one extra CHD-risk factor. J Am Coll Nutr. 2007;26:225-232. 



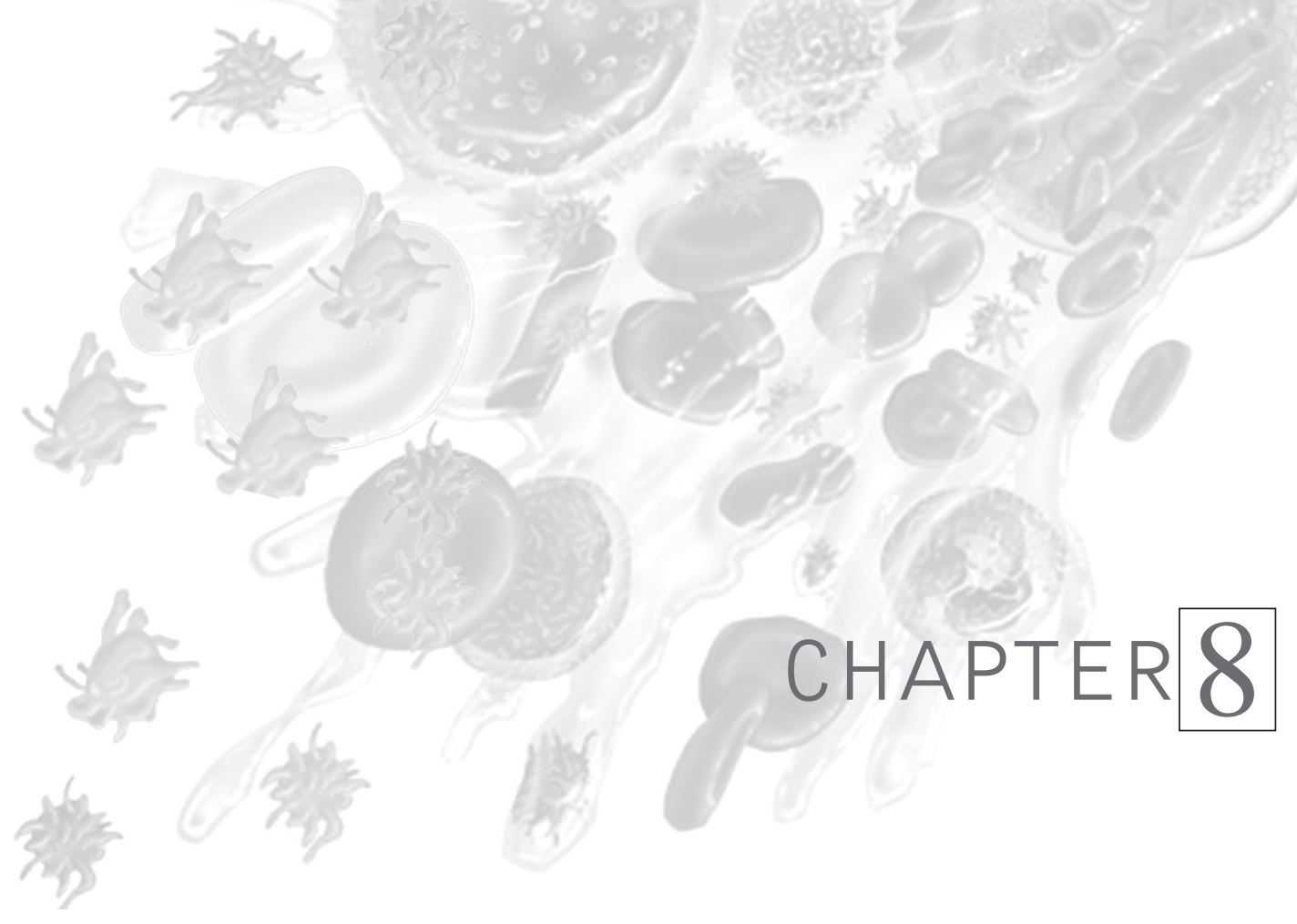

General Discussion

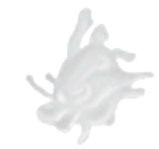




\section{New signaling function of platelet CD36}

Being identified as either a scavenger receptor on (macrophages), an adhesive receptor (platelets), or a fatty acid uptake receptor (cardiomyocytes), CD36 is supposed to interact with distinct sets of intracellular proteins ${ }^{1,2}$. In chapter 2 of this thesis it is described that this versatility in action mechanism of CD36 indeed results from its property to bind different ligands in various cell types. A complication of the research to the signaling pathways induced by CD36 is the fact that these ligands often bind to other cellular receptors as well. Given the well-defined signaling pathways in platelets, and taking into account the high CD36 copy number (10,000-25,000) on their surface, platelets seem to be suited by excellence to clarifying the mechanism used by CD36.

On platelets, CD36 is the predominant receptor for oxidized low density lipoprotein (oxLDL) and thrombospondin-1 (TSP1), which are present in the blood plasma and in the vascular wall, e.g. in atherosclerotic plaques (Figure 8.1). In chapter 3 (human

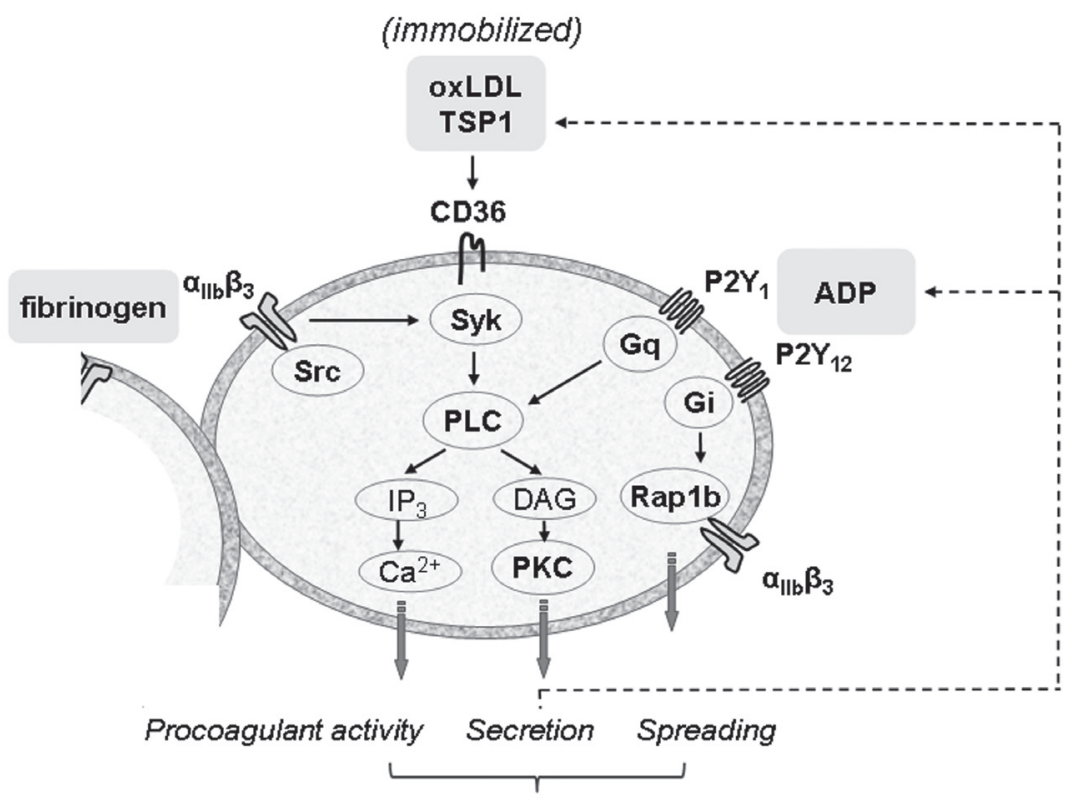

Thrombus formation and stabilization

Figure 8.1. Outside-in signaling scheme of platelet CD36 interacting with oxidized low density lipoprotein (oxLDL) or thrombospondin-1 (TSP1). Immobilized oxLDL and TSP1 appear to evoke a similar signal transduction pathway in platelets via CD36, which is enforced by integrin $\alpha_{\mathrm{II}} \beta_{3}$ and autocrine ADP signaling. Occupancy of CD36 results in activation of the key signaling protein tyrosine kinase in platelets, Syk. The result is phosphorylation and activation of phospholipase C (PLC) $\gamma$ isoforms, which forms inositol 1,4,5-trisphosphate $\left(\mathrm{IP}_{3}\right)$ and diacylglycerol (DAG). The $\mathrm{IP}_{3}$ releases $\mathrm{Ca}^{2+}$ from intracellular stores, while DAG activates protein kinase $\mathrm{C}$ (PKC) which contributes to $\alpha_{\mathrm{II}} \beta_{3}$ activation. Autocrine ADP stimulates the platelet $\mathrm{P} 2 \mathrm{Y}_{1}$ and $\mathrm{P} 2 \mathrm{Y}_{12}$ receptors, which couple to $\mathrm{Gq}$ and $\mathrm{Gi}$, respectively. Especially $\mathrm{Gi}$ stimulation establishes integrin $\alpha_{\mathrm{II}} \beta_{3}$ activation via Rap1b. Jointly, these CD36-induced signaling routes trigger platelet procoagulant activity, secretion and spreading, all of which responses are implicated in thrombus formation and thrombus stabilization. 
platelets) and chapter 4 (mouse platelets), it is established that CD36 interacts slowly but effectively with oxLDL and TSP1, particularly under conditions where these are immobilized at a surface. This work reveals a so far unknown mechanism of platelet activation by immobilized TSPI and oxLDL via CD36-dependent signaling, leading to activation of Src-family and Syk tyrosine kinases. This signaling route is enforced by feed-forward loops of integrin activation and autocrine ADP-mediated signaling events (Figure 8.1). Hence, similarly as has been established for fibrinogen surfaces many years $\mathrm{ago}^{3}$, immobilized TSPI and oxLDL appear to provoke outsidein signaling events in platelets mediated by CD36. Elucidated signaling responses sensitive to CD36 blocking or absence are the spreading of platelets, rises in intracellular $\mathrm{Ca}^{2+}$, activation of integrin $\alpha_{\mathrm{IIb}} \beta_{3}$, secretion of granules and expression of phosphatidylserine (PS).

Other papers have described CD36-dependent activation of various tyrosine/serine and threonine protein kinases in various cells. Evidence has been reported for the CD36dependent activation of the Src-family kinases, Fyn, Lyn and $\mathrm{Yes}^{4}$, and of the mitogenactivated protein kinases, Erk1/2, JNK and p38 $8^{5-7}$. An early paper using peptides derived from TSPI pointed to activation of platelet via FCR $\gamma$-chain, and CD36-dependent protein tyrosine kinases ${ }^{8}$. The present data show that CD36-dependent signaling is of particular importance in platelets adhered to immobilized TSPI or oxLDL.

\section{Modulating role of platelet CD36 in thrombus formation}

In chapters 3 and 4, it is also investigated whether the signaling induced by CD36 binding to TSPI or oxLDL contributes to collagen-dependent thrombus formation. Such a role of CD36 would shed new light on early studies using anti-CD36 antibodies and patients with CD36 deficiency, where the glycoprotein was considered to act as a receptor for collagen 9,10 . Since platelets are activated by collagen and then secrete $T S P 1$, which itself can bind to collagen ${ }^{11,12}$, these early data may be understood as that CD36 mediates platelet adhesion to collagen-bound TSP1 rather than to collagen itself.

We demonstrate that immobilized TSPI or oxLDL alone are not able to support thrombus formation under flow conditions, which is explained by the relatively slow activation of platelets in contact with these surfaces. However, co-coating of TSPI or oxLDL with collagen enhances the collagen-dependent platelet activation and thrombus formation via CD36 in both the human (chapter 3) and the mouse (chapter 4) systems. When combined with collagen, TSPI and OXLDL thus increase platelet deposition, aggregate formation, P-selectin expression, $\alpha_{\mathrm{IIb}} \beta_{3}$ activation and PS exposure under flow through co-activation via glycoprotein VI. Accordingly, platelet interaction with these combined surfaces under flow appears to occur via multiple adhesive and signaling receptors. In a similar way this was concluded earlier for platelets interacting with collagen/von Willebrand factor (vWF)13. Hence, under conditions where TSPI or oxLDL binds to collagen, CD36 may play an important role in platelet adhesion and activation, and thus in platelet aggregation (Figure 8.2). 


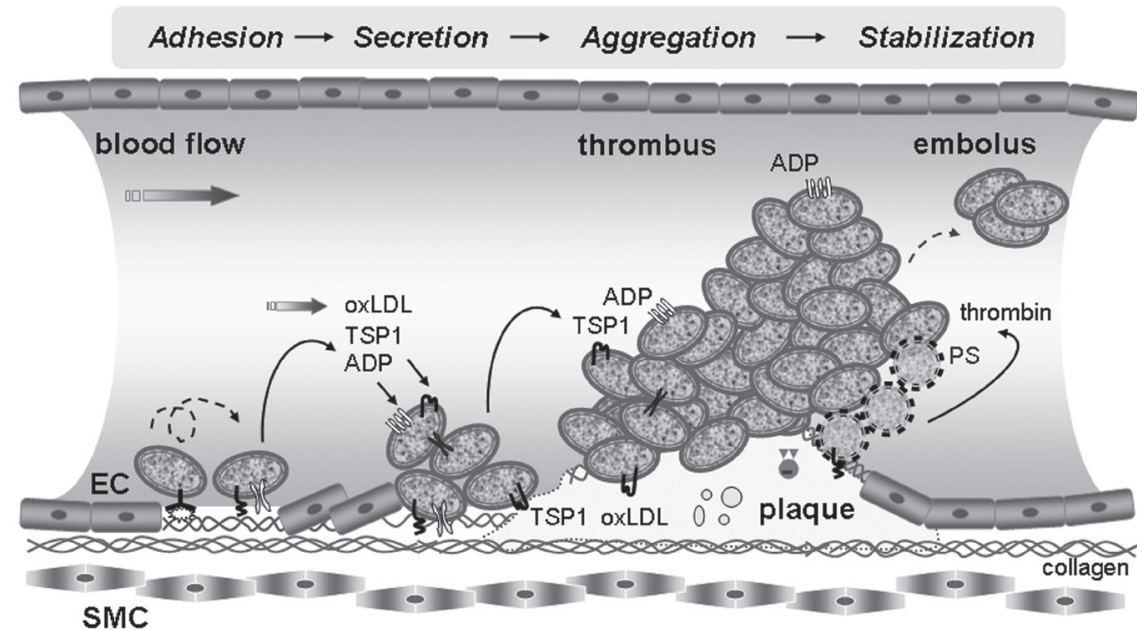

\begin{tabular}{|c|c|c|c|c|}
\hline GPIb-IX-V & $\int \beta \alpha_{2} \beta_{1}$ & $\mathrm{z}^{2} \mathrm{~m}$ WWF & $M \operatorname{CD} 36$ & || phosphatidylserine \\
\hline GPVI & $X \alpha_{\| l \mid} \beta_{3}$ & $10001 P 2 Y_{1112}$ & $5 \mathrm{TF}$ & \\
\hline
\end{tabular}

Figure 8.2. Proposed roles of CD36 and $\mathrm{P}^{2} \mathrm{Y}_{12}$ in collagen-dependent thrombus formation and stabilization. Vascular damage causes exposure of subendothelial extracellular matrix, containing collagen, thrombospondin-1 (TSP1) and oxidized LDL (oxLDL), to the flowing blood. Platelets rapidly adhere to the damaged surface via their receptors for von Willebrand factor (vWF) (GPIb-IX-V) and collagen (GPVI and integrin $\alpha_{2} \beta_{1}$ ). The adhesion and activation of platelets will be enforced through interaction of CD36 with immobilized TSP1 and oxLDL. Furthermore, activated platelets secrete their alpha and dense granules containing TSP1 and ADP, respectively. The former agent can stimulate CD36, while the latter stimulates $\mathrm{P} 2 \mathrm{Y}_{1}$ and $\mathrm{P} 2 \mathrm{Y}_{12}$, thus triggering the aggregate formation of platelets. In case of hyperlipidemia, soluble oxLDL may contribute herein as well. The resulting thrombus is stabilized, and thus prevented from embolisation, by ADP/P2 $\mathrm{Y}_{12}$-dependent persistent activation of integrin $\alpha_{\mathrm{IIb}} \beta_{3}$. This role of $\mathrm{P}_{2} \mathrm{Y}_{12}$ is still important in the presence of tissue factor-induced generation of thrombin and fibrin. Abbreviations: EC, endothelial cell; SMC, smooth muscle cell.

This multiligand interaction most likely is of physiological importance. Both TSPI and $0 \times L D L$, in addition to collagen, have been identified in damaged vessel walls and atherosclerotic plaques ${ }^{14-17}$. Furthermore, TSPI is present in the $\alpha$-granules of platelets ${ }^{18,19}$, and once released may be deposited on collagen or on the surface of a developing thrombus and then enforce the thrombus-forming process. Results from others support this idea. For instance, it was observed that platelet recruitment at the vessel wall is retarded in TSP1-deficient mice ${ }^{20}$. An other group claimed that CD36 is involved in the GPIb-dependent adhesion of platelets to TSPI under high-shear flow conditions $^{21}$, but these authors have not excluded a contribution of VWF. In conclusion, the emerging picture is that, upon endothelial denudation, collagen/vWF-dependent thrombus formation is enhanced by (platelet- or vessel wall-derived) TSPI as well as by (plasma- or plaque-derived) oxLDL via CD36. 


\section{Role of platelet P2Y $_{12}$ in thrombus stabilization: clinical relevance}

In chapter 5 the development of a new in vivo model of arterial thrombosis on acutely ruptured atherosclerotic plaques is described. It is demonstrated that targeted ultrasound treatment of a plaque in the carotid arteries of $A p o e^{-/}$mice acutely produces a nonocclusive thrombus due to both platelet activation and thrombin generation. This novel atherothrombosis model differs from earlier published models in several aspects: by the restricted area of plaque damage evoked by a small ultrasound tip; by the limited exposure of thrombogenic substances at the ruptured site; and by the persistent blood flow causing continuous dilution of thrombin and platelet-derived soluble agonists. Detailed analysis showed that the main triggers of the thrombotic process in this model were the exposure of collagen (causing GPVI-dependent platelet adhesion and activation) and tissue factor (triggering thrombin generation via the extrinsic pathway). Consequently, thrombus formation in this model is the result of a multifactorial process, involving platelet receptors for collagen and ADP as well as the generation of thrombin and fibrin (Figure 8.2).

The new mouse model of acute plaque rupture was used in chapter 6 to study the role of $\mathrm{P}_{2} \mathrm{Y}_{12}$ receptors in atherothrombosis. Mice were infused with irreversible or reversible $\mathrm{P}_{2} \mathrm{Y}_{12}$ antagonists, which terminated $A D P$-induced platelet aggregation. As a comparison, in ex vivo perfusion studies, murine or human blood was flowed over collagen-containing plaque material, also under conditions allowing coagulation. These in vivo and ex vivo inhibitor studies proved a key role of the platelet $\mathrm{P}_{2} \mathrm{Y}_{12}$ receptors in the stabilization of thrombi formed on a plaque. Markedly, this thrombus-stabilizing function of $\mathrm{P}_{2} \mathrm{Y}_{12}$ was observed at high shear flow conditions, and was maintained in the presence of coagulation. On the other hand, at low shear rate in the presence of coagulation, blocking of $\mathrm{P} 2 \mathrm{Y}_{12}$ did not influence formation of a fibrin containing thrombus. Reversible and irreversible $\mathrm{P}_{2} \mathrm{Y}_{12}$ inhibitors appeared to be similarly effective.

The results of chapter 6 extend the findings of earlier reports, in which we and others have shown that autocrine, platelet-derived ADP contributes to thrombus growth and stability on collagen-containing surfaces ${ }^{17,22}$. It was argued that, by binding to $P 2 Y_{12}$ ADP induces continuous signaling to phosphoinositide 3-kinases $\beta$ and $\gamma$ with as a result sustained $\alpha_{\text {IIb }} \beta_{3}$ activation and enhancement of coagulation due to Gi-mediated $\mathrm{Ca}^{2+}$ mobilization and platelet procoagulant activity ${ }^{22,23}$. Taken together, as represented in the scheme of Figure 8.2, we stipulate that the binding of autocrine ADP to P2Y prolongs the thrombotic process by stabilizing formed thrombi and by preventing shedding of platelet emboli.

In clinical manifestations, the prodrugs clopidogrel and prasugrel act as irreversible $\mathrm{P} 2 \mathrm{Y}_{12}$ receptor blockers, since they form active metabolites which cross-link to the receptor. Clopidogrel and prasugrel are increasingly being used for the secondary prevention of thrombotic events in patients with myocardial infarction ${ }^{24}$. Resistance to clopidogrel, which is mostly due to inefficient metabolism of the prodrug into the active metabolite, is a rather frequent condition that lowers the clinical efficacy ${ }^{25}$. Recent clinical trials point to promising results of the newly developed reversible $\mathrm{P} 2 \mathrm{Y}_{12}$ blocking agent ticagrelor, with less increase in bleeding and moderate incidence 
of stroke in comparison to clopidogrel ${ }^{26}$. In our flow studies with murine and human blood, both the irreversible and reversible $\mathrm{P}_{2} \mathrm{Y}_{12}$ antagonists performed equally well by preventing thrombus stabilization (chapter 6). In a recent paper similar flow chamber experiments were performed with blood from patients treated with aspirin plus irreversible $\mathrm{P}_{2} \mathrm{Y}_{12}$ antagonist. Comparable to our studies, thrombus buildup was reduced and disaggregation was increased after intake of the drugs ${ }^{27}$. Overall, this points to a $\mathrm{P}_{2} \mathrm{Y}_{12}$-dependent stabilization of thrombus formation at high shear rate, which is maintained under conditions of coagulation. This suggests that the success of anti-P2Y interventions may rely on the (arterial) shear conditions and the extent of coagulation. These findings are considered to be relevant for the antithrombotic treatment of patients with myocardial infarction.

\section{Walnut rich diet in the prevention of atherothrombosis}

Epidemiological and controlled clinical studies point to the importance of a wellbalanced diet for the prevention of cardiovascular disease ${ }^{28,29}$. There is a growing interest particularly in the alleged cardioprotective effect of dietary $n-3$ polyunsaturated fatty acids (PUFA) and antioxidant polyphenols. Yet, the mechanism by which these food components may prevent thrombotic disorders is still a matter of debate. In chapter 7 , it was determined how walnut supplementation can influence atherosclerosis and thrombosis in the same animal model as used before, namely Apoe ${ }^{-/}$mice being fed a high-fat cholesterol-rich diet. The effect of walnuts, containing both $n-3$ PUFA and antioxidant polyphenols, was compared to that of a diet with walnut oil consisting $n-3$ PUFA ( $\alpha$-linolenoate) from the same batch of nuts. Furthermore, a comparison was made with one of the richest sources of antioxidant polyphenols, e.g. grape seed extract. Atherosclerotic plaque development and thrombus formation were measured, as well as plasma lipids, platelet and coagulant activity, both of which being indicators of the hemostatic state of the animal.

As summarized in Table 8.1, feeding Apoe ${ }^{-/}$mice with walnuts lowered plasma cholesterol and triglyceride levels and reduced aortic plaque development. Interestingly, we found reduced expression of CD36 in the plaque-containing vessels in mice fed with walnut, which is in agreement with the results from others that CD36 is highly expressed by macrophages within the atherosclerotic lesions ${ }^{30-32}$. In contrast to the slight reduction in prothrombin levels, other parameters of coagulation and platelet activation were unchanged. Strikingly, feeding the same amount of walnut oil did not result in any significant changes. Furthermore, also the grape seed extract did not affect plaque progression or thrombosis-related parameters. This suggested that perhaps the combined intake of n-3 PUFA and antioxidant polyphenols is responsible for the lipidlowering and atheroprotective effects of walnuts. Since the polyphenols in grape seed are partly of a different class (ethanol soluble versus water soluble in walnut), it is still unclear whether specific types of polyphenols or the mere addition of polyphenols to $n-3$ PUFA is required for a lipid-lowering and atheroprotective action.

In earlier nutrition studies with APOE2 knock-in or Apoe-- mice, which were fed with fish oil containing high levels and different forms of $n$-3 PUFA (i.e. eicosapentaenoate 
Table 8.1. Comparison of $\boldsymbol{n - 3}$ PUFA-containing diets on parameters of atherosclerosis and thrombosis in mouse models. Data for whole walnut and walnut oil diet were obtained with male knockout $A p o e^{-/-}$mice receiving a high-fat diet with $\alpha$-linolenic acid as source of $n$-3 PUFA (chapter 7). Data for fish oil diet were obtained with male transgenic APOE2 knock-in or Apoe $e^{-/-}$mice receiving a high-fat diet with eicosapentaenoic and docosahexaenoic acid as source of $n-3$ PUFA ${ }^{33-35}$.

\begin{tabular}{lccc}
\hline & \multicolumn{3}{c}{ Diet type (\% of total fat) } \\
\cline { 2 - 4 } Parameter & walnut & walnut oil & fish oil \\
& $(13 \%$-3 PUFA $)$ & $(10 \%$-3 PUFA $)$ & $(>30 \% n-3$ PUFA) \\
\hline Plaque progression & $\downarrow$ & 0 & $\downarrow$ \\
Plasma/liver triglycerides & $\downarrow$ & 0 & $\downarrow$ \\
Plasma total cholesterol & $\downarrow$ & 0 & $\downarrow$ \\
Thrombus formation (ex vivo) & 0 & 0 & $?$ \\
Platelet activation & 0 & 0 & 0 \\
Prothrombin & $\downarrow$ & 0 & $\downarrow$ \\
Fibrinogen, factor $V$ & 0 & 0 & $\downarrow$ \\
Thrombin generation & 0 & 0 & $\downarrow$ \\
\hline
\end{tabular}

Symbols: $\downarrow$, decreased; 0, no effect; ?, unknown

and docosahexaenoate instead of $\alpha$-linolenoate), lowering in plasma lipids and plaque progression was accompanied by a clear anticoagulant effect (Table 8.1) 33-35. Assuming that the dietary effects in the two genotypes in terms of atherothrombosis are similar, likely explanations for the absence of lipid-lowering and anticoagulant activity upon walnut oil feeding are either the relatively low content of n-3 PUFA in this oil, or the different molecular species of $n-3$ PUFA in comparison to fish oil. Human nutritional studies indicate that regular walnut intake in specific patient groups associates with triglyceride lowering ${ }^{36}$, also without affecting global coagulation parameters ${ }^{37,38}$. One other paper describes that moderate walnut intake does not affect the activation of human platelets ${ }^{39}$.

Taken together, the present results suggest that walnut consumption in $A p o e^{-/-}$mice has an atheroprotective effect, which is not only caused by the presence of $n-3$ PUFA, but also by other factors such as polyphenols. Mechanistically, this protection is explained by decreased plasma levels of cholesterol and triglycerides, resulting in less lipid uptake in the atherosclerotic areas. Whether antioxidant polyphenols are involved in the plasma lipid regulation is unclear. This research obviously needs to be continued, but the emerging picture is that walnut consumption beneficially influences atherosclerosis by components other than merely n-3 PUFA, at least in this animal model.

\section{Concluding remarks}

The studies in this thesis shed a new light on the importance of two platelet receptors, i.e. $\mathrm{P}_{2} \mathrm{Y}_{12}$ and $\mathrm{CD} 36$, in thrombus formation under arterial flow conditions. Concerning $\mathrm{P}_{2} \mathrm{Y}_{12}$, remarkable progress has been made in recent years in the development of antagonists directed against this platelet receptor to treat arterial thrombosis. In this thesis, the mechanisms underlying the thromboprotective effect of $\mathrm{P}_{2} \mathrm{Y}_{12}$ inhibition are 
further revealed in mice in vivo and in human blood ex vivo. Also the role of CD36 was elucidated in studies with mouse and human platelets. From the concept of a most effective protection of atherothrombosis by a diet that improves the plasma lipid profile (first defense line), followed by antithrombotic medication (second defense line), CD36 appears to be at a key position. As a scavenger receptor, it contributes to the (oxidized) lipid-dependent progression of plaque formation, while as a signaling receptor on platelets it contributes to thrombus formation. It therefore is highly interesting to search for functional antagonists of this receptor. It is foreseen that this protein turns into a clinically relevant target in near future. 


\section{References}

1. Silverstein RL, Febbraio M. CD36, a scavenger receptor involved in immunity, metabolism, angiogenesis, and behavior. Sci Signal. 2010;2:re3.

2. Glatz JF, Luiken JJ, Bonen A. Membrane fatty acid transporters as regulators of lipid metabolism: implications for metabolic disease. Physiol Rev. 2010;90:367-417.

3. Clark EA, Shattil SJ, Ginsberg MH, Bolen J, Brugge JS. Regulation of the protein tyrosine kinase pp72syk by platelet agonists and the integrin $\alpha_{\mathrm{IIb}} \beta_{3}$. J Biol Chem. 1994;269:2885928864.

4. Huang MM, Bolen JB, Barnwell JW, Shattil SJ, Brugge JS. Membrane glycoprotein IV (CD36) is physically associated with the Fyn, Lyn, and Yes protein-tyrosine kinases in human platelets. Proc Natl Acad Sci USA. 1991;88:7844-7848.

5. Chen K, Febbraio M, Li W, Silverstein RL. A specific CD36-dependent signaling pathway is required for platelet activation by oxidized low-density lipoprotein. Circ Res. 2008;102:15121519.

6. Rahaman S0, Lennon DJ, Febbraio M, Podrez EA, Hazen SL, Silverstein RL. A CD36dependent signaling cascade is necessary for macrophage foam cell formation. Cell Metab. 2006;4:211-221.

7. Korporaal SJ, van Eck M, Adelmeijer J, IJsseldijk M, Out R, Lisman T, Lenting PJ, van Berkel TJ, Akkerman JW. Platelet activation by oxidized low density lipoprotein is mediated by CD36 and scavenger receptor-A. Arterioscler Thromb Vasc Biol. 2007;27:2476-2483.

8. Tulasne D, Judd BA, Johansen M, Asazuma N, Best D, Brown EJ, Kahn M, Koretzky GA, Watson SP. C-terminal peptide of thrombospondin-1 induces platelet aggregation through the Fc receptor $\gamma$-chain-associated signaling pathway and by agglutination. Blood. 2001;98:3346-3352.

9. Diaz-Ricart M, Tandon NN, Carretero M, Ordinas A, Bastida E, Jamieson GA. Platelets lacking functional CD36 (glycoprotein IV) show reduced adhesion to collagen in flowing whole blood. Blood. 1993;82:491-496.

10. Matsuno K, Diaz-Ricart M, Montgomery RR, Aster RH, Jamieson GA, Tandon N N. Inhibition of platelet adhesion to collagen by monoclonal anti-CD36 antibodies. $\mathrm{Br} \mathrm{J}$ Haematol. 1996;92:960-967.

11. Galvin NJ, Vance PM, Dixit VM, Fink B, Frazier WA. Interaction of human thrombospondin with types I-V collagen: direct binding and electron microscopy. J Cell Biol. 1987;104:14131422.

12. Cockburn CG, Barnes MJ. Characterization of thrombospondin binding to collagen (type I) fibres: role of collagen telopeptides. Matrix. 1991;11:168-176.

13. Siljander PR, Munnix IC, Smethurst PA, Deckmyn H, Lindhout T, Ouwehand WH, Farndale RW, Heemskerk JW. Platelet receptor interplay regulates collagen-induced thrombus formation in flowing human blood. Blood. 2004;103:1333-1341.

14. Uchida Y, Uchida Y, Kameda N. Visualization of lipid components in human coronary plaques using color fluorescence angioscopy. Circ J. 2010;74:2181-2186.

15. Cosemans JM, Kuijpers MJ, Lecut C, Loubele ST, Heeneman S, Jandrot-Perrus M, Heemskerk JW. Contribution of platelet glycoprotein VI to the thrombogenic effect of collagens in fibrous atherosclerotic lesions. Atherosclerosis. 2005;181:19-27.

16. Guyton JR, Klemp KF. Development of the lipid-rich core in human atherosclerosis. Arterioscler Thromb Vasc Biol. 1996;16:4-11.

17. Penz S, Reininger AJ, Brandl R, Goyal P, Rabie T, Bernlochner I, Rother E, Goetz C, Engelmann B, Smethurst PA, Ouwehand WH, Farndale R, Nieswandt B, Siess W. Human atheromatous plaques stimulate thrombus formation by activating platelet glycoprotein VI. Faseb J. 2005;19:898-909.

18. Bornstein P. Thrombospondins as matricellular modulators of cell function. J Clin Invest. 2001;107:929-934. 
19. Bonnefoy A, Hantgan R, Legrand C, Frojmovic MM. A model of platelet aggregation involving multiple interactions of thrombospondin-1, fibrinogen, and GPIIb/IIIa receptor. J Biol Chem. 2001;276:5605-5612.

20. Bonnefoy A, Daenens K, Feys HB, De Vos R, Vandervoort P, Vermylen J, Lawler J, Hoylaerts MF. Thrombospondin-1 controls vascular platelet recruitment and thrombus adherence in mice by protecting (sub)endothelial VWF from cleavage by ADAMTS13. Blood. 2006;107:955-964.

21. Jurk K, Clemetson KJ, de Groot PG, Brodde MF, Steiner M, Savion N, Varon D, Sixma JJ, Van Aken H, Kehrel BE. Thrombospondin-1 mediates platelet adhesion at high shear via glycoprotein Ib (GPIb): an alternative/backup mechanism to von Willebrand factor. Faseb J. 2003;17:1490-1492.

22. Cosemans JM, Munnix IC, Wetzker R, Heller R, Jackson SP, Heemskerk JW. Continuous signaling via phosphoinositide 3-kinase isoforms $\beta$ and $\gamma$ is required for platelet ADP receptor function in dynamic thrombus stabilization. Blood. 2006;108:3045-3052.

23. Van der Meijden PE, Feijge MA, Giesen PL, Huijberts M, van Raak EP, Heemskerk JW. Platelet $P 2 Y_{12}$ receptors enhance signalling towards procoagulant activity and thrombin generation: a study with healthy subjects and patients at thrombotic risk. Thromb Haemost. 2005;93:1128-1137.

24. Paikin JS, Eikelboom JW, Cairns JA, Hirsh J. New antithrombotic agents: insights from clinical trials. Nat Rev Cardiol. 2010;7:498-509.

25. Cattaneo M. Resistance to anti-platelet agents. Thromb Res. 2011;127:S61-63.

26. Steg $P G$, James $S$, Harrington RA, Ardissino D, Becker RC, Cannon CP, Emanuelsson $H$, Finkelstein A, Husted S, Katus H, Kilhamn J, Olofsson S, Storey RF, Weaver WD, Wallentin L. Ticagrelor versus clopidogrel in patients with ST-elevation acute coronary syndromes intended for reperfusion with primary percutaneous coronary intervention: a platelet inhibition and patient outcomes (PLATO) trial subgroup analysis. Circulation. 2011;122:2131-2141.

27. Mendolicchio GL, Zavalloni D, Bacci M, Corrada E, Marconi M, Lodigiani C, Presbitero $P$, Rota $L$, Ruggeri $Z M$. Variable effect of $P 2 Y_{12}$ inhibition on platelet thrombus volume in flowing blood. J Thromb Haemost. 2010;9:373-382.

28. Clifton PM. Effect of grape seed extract and quercetin on cardiovascular and endothelial parameters in high-risk subjects. J Biomed Biotechnol. 2004;2004:272-278.

29. Gebauer SK, Psota TL, Harris WS, Kris-Etherton PM. N-3 fatty acid dietary recommendations and food sources to achieve essentiality and cardiovascular benefits. Am J Clin Nutr. 2006;83:1526S-1535S.

30. Febbraio M, Guy E, Silverstein RL. Stem cell transplantation reveals that absence of macrophage CD36 is protective against atherosclerosis. Arterioscler Thromb Vasc Biol. 2004; 24:2333-2338.

31. Podrez EA, Febbraio M, Sheibani N, Schmitt D, Silverstein RL, Hajjar DP, Cohen PA, Frazier WA, Hoff HF, Hazen SL. Macrophage scavenger receptor CD36 is the major receptor for LDL modified by monocyte-generated reactive nitrogen species. J Clin Invest. 2000;105:1095-1108.

32. Handberg A, Skjelland M, Michelsen AE, Sagen EL, Krohg-Sorensen K, Russell D, Dahl A, Ueland $T$, Oie E, Aukrust P, Halvorsen B. Soluble CD36 in plasma is increased in patients with symptomatic atherosclerotic carotid plaques and is related to plaque instability. Stroke. 2008;39:3092-3095.

33. Vanschoonbeek K, Wouters K, van der Meijden PE, van Gorp PJ, Feijge MA, Herfs M, Schurgers LJ, Hofker MH, de Maat MP, Heemskerk JW. Anticoagulant effect of dietary fish oil in hyperlipidemia: a study of hepatic gene expression in APOE2 knock-in mice. Arterioscler Thromb Vasc Biol. 2008;28:2023-2029.

34. Wang HH, Hung TM, Wei J, Chiang AN. Fish oil increases antioxidant enzyme activities in macrophages and reduces atherosclerotic lesions in apoE-knockout mice. Cardiovasc Res. 2004;61:169-176. 
35. Casos K, Saiz MP, Ruiz-Sanz JI, Mitjavila MT. Atherosclerosis prevention by a fish oilrich diet in apo $\mathrm{E}(-/-)$ mice is associated with a reduction of endothelial adhesion molecules. Atherosclerosis. 2008;201:306-317.

36. Zibaeenezhad MJ, Shamsnia SJ, Khorasani M. Walnut consumption in hyperlipidemic patients. Angiology. 2005;56:581-583.

37. Pieters M, Oosthuizen W, Jerling JC, Loots DT, Mukuddem-Petersen J, Hanekom SM. Clustering of haemostatic variables and the effect of high cashew and walnut diets on these variables in metabolic syndrome patients. Blood Coagul Fibrinolysis. 2005;16:429-437.

38. Morgan JM, Horton K, Reese D, Carey C, Walker K, Capuzzi DM. Effects of walnut consumption as part of a low-fat, low-cholesterol diet on serum cardiovascular risk factors. Int J Vitam Nutr Res. 2002;72:341-347.

39. Din JN, Aftab SM, Jubb AW, Carnegy FH, Lyall K, Sarma J, Newby DE, Flapan AD. Effect of moderate walnut consumption on lipid profile, arterial stiffness and platelet activation in humans. Eur J Clin Nutr. 2011;65:234-239. 

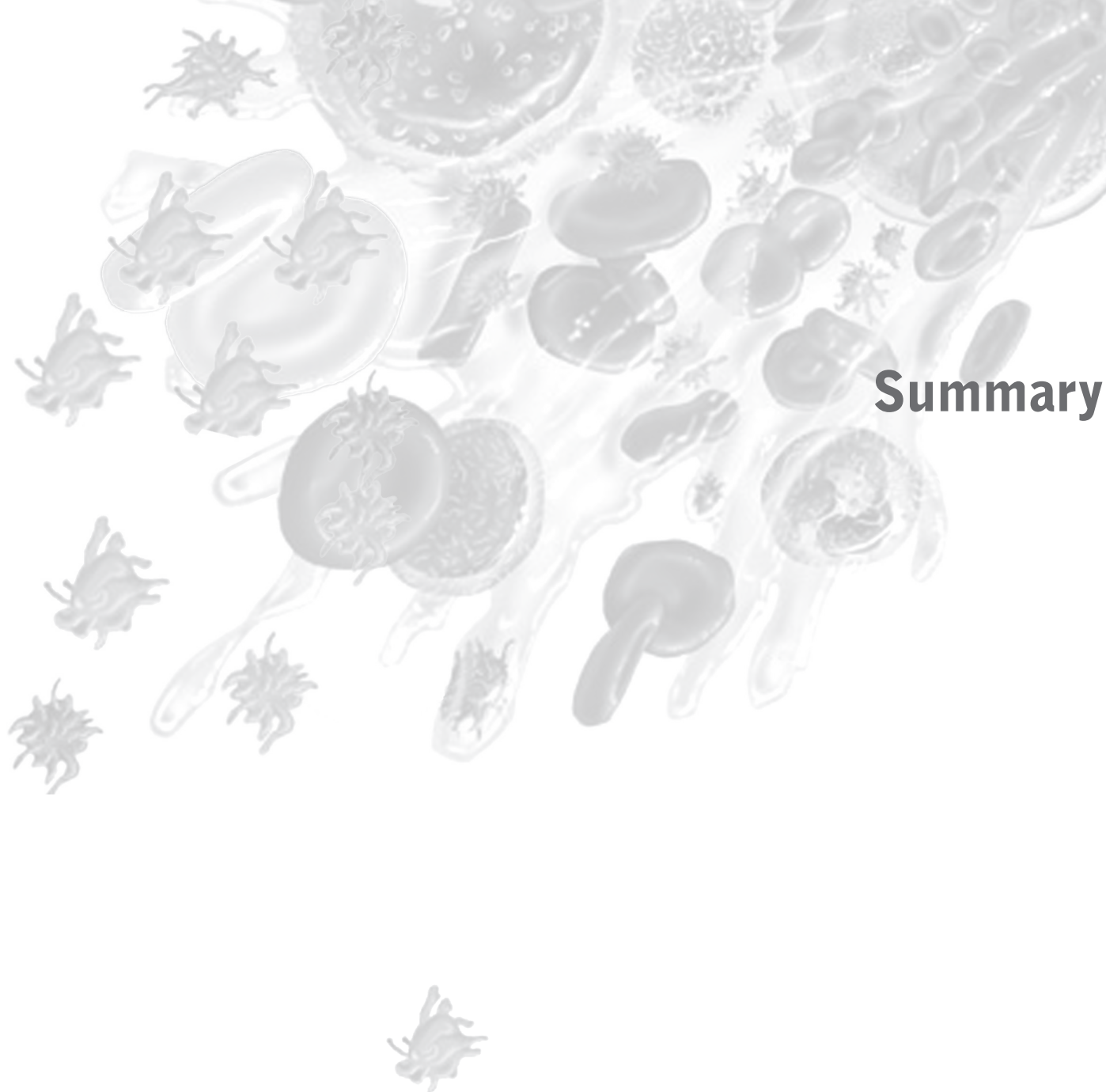

$\frac{16}{8}$ 


\section{Summary}

Platelets have an essential function in haemostasis, but also contribute to atherothrombosis. They rapidly adhere to the arterial vessel wall at sites of endothelial cell damage, and promote the development of chronic atherosclerotic lesions. Rupture or denudation of an atherosclerotic plaque causes massive platelet activation and the development of a local platelet-fibrin thrombus. In chapter 1 of this thesis relevant background information on platelet activation and thrombus formation is presented. Furthermore, the two platelet receptor proteins studied most extensively in this thesis, $\mathrm{CD} 36$ and $\mathrm{P}_{2} \mathrm{Y}_{12^{\prime}}$ are introduced. In the final part of this chapter the possible contribution of nutrition to atherosclerosis and arterial thrombosis is discussed.

The glycoprotein CD36, also known as glycoprotein IIIb/IV or FAT, is expressed on the surface of platelets, monocytes, endothelial cells, smooth muscle cells, and other cells of the cardiovascular system. In spite of its abundant presence, CD36 has been a mysterious protein with a poorly understood role for quite some time. How CD36 can affect cellular responses by interaction with a variety of ligands is reviewed in chapter 2, emphasizing on thrombospondin-1 (TSP1), oxidized low density lipoprotein (oxLDL) and fatty acids. Given the structure of CD36 with two transmembrane domains and short cytoplasmic tails, it is also considered how this receptor evokes intracellular signaling events. Starting from the structural analysis, a model is proposed where CD36 can trigger, via a limited number of signal transduction pathways, various types of processes in different cell types. This may explain the heterogeneous involvement of this protein in thrombosis, atherosclerosis and inflammation, or in glucose and lipid metabolism.

Although both TSPI and $0 \times 2 D L$ have been described in the literature as ligands of CD36, it is poorly understood how binding of these ligands contributes to platelet activation via CD36. This has been intensively investigated in the chapters 3 and $\mathbf{4}$. In suspension, TSPI and $0 x L D L$ are no more than weakly active on platelets. However, when immobilized at a surface they can strongly activate human platelets via CD36. As shown in chapter 3, platelet adhesion and spreading on immobilized TSPI or oxLDL, but not LDL, are accompanied by potent $\mathrm{Ca}^{2+}$ fluxes, exposure of $\mathrm{P}$-selectin and phosphatidylserine, all in a CD36-dependent manner. The CD36-dependent signaling pathway appears to rely on activation of Src family and Syk protein kinases, with additional contribution of platelet stimulation via $\alpha_{\mathrm{IIb}} \beta_{3}$ integrins and ADP receptors. Furthermore, surface-bound TSPI as well as ox LD L enhance collagen-dependent adhesion of platelets in whole blood under flow, and thereby stimulate thrombus formation. In chapter 4, this work has been extended by using mice deficient in either CD36 or TSP1. It is determined that the interaction of mouse CD36 with immobilized, platelet-derived TSPl enhances the thrombus-forming process under high-shear flow. Together, the data provide novel insight into the role of CD36 in haemostasis and thrombosis showing a subtle role of murine CD36 and platelet-derived TSP1 in collagen-dependent thrombus formation and stabilization.

While atherothrombosis is a major cause of fatal cardiovascular disease, animal models to study this process are scarce. In chapter 5, a novel murine model is described of acute thrombus formation upon plaque rupture, which has been used to study the 
mechanisms underlying atherothrombosis by intravital fluorescence microscopy. Localized rupture of an atherosclerotic plaque is induced in a carotid artery from an Apoe $^{-/}$mouse in vivo by targeted ultrasound treatment. As a consequence of the plaque rupture, collagen becomes exposed, which serves as the substratum of non-occlusive thrombus formation. Interventions to block platelet collagen receptors (glycoprotein VI) or thrombin generation demonstrate that this thrombotic process relies on both collagen-induced platelet activation and tissue factor-dependent coagulation. Furthermore, the formation of thrombi in this model appears to be sensitive to both established and novel antithrombotic medication. Subsequently, in chapter 6, this mouse model is used to study the role of $\mathrm{P}_{2} \mathrm{Y}_{12}$ receptors in atherothrombosis. In ApoEdeficient mice, the reversible $\mathrm{P}_{2} \mathrm{Y}_{12}$ antagonists, ticagrelor and cangrelor, both reduce thrombus formation evoked by plaque rupture. In addition, these inhibitors suppress the thrombus-forming process ex vivo in perfusion studies, where murine or human blood is flowed over collagen-containing plaque material. The results point to a $\mathrm{P}_{2} \mathrm{Y}_{12}$-dependent stabilization of thrombus formation at high shear flow, which is maintained under conditions of limited coagulation. This observation may have implications for current antithrombotic treatment.

There is growing interest in the possible cardioprotective effects of nutritional $n-3$ polyunsaturated fatty acids (PUFA) and antioxidant polyphenols. To evaluate this, in chapter 7 a dietary intervention study is described with proatherogenic ApoE-deficient mice held on a high-fat, cholesterol-containing diet including walnut or grape seed extract. The effects are compared of walnuts containing $n-3$ PUFA as well of antioxidant polyphenols, such in comparison to walnut oil (with only n-3 PUFA) and grape seed extract (with only antioxidant polyphenols). Feeding walnuts lowers plasma levels of triglycerides, cholesterol and prothrombin, and increases the antioxidant capacity of plasma. This is accompanied by a lower accumulation of lipids in the liver, and a marked reduction in development of CD36-expressing atherosclerotic plaques in the aortic arches. None of these changes are provoked by the high-fat diets with walnut oil or grape seed. Platelet activation, plasma thrombin generation, and whole-blood thrombus formation are not changed by any of the diets. Taken together, in the proatherogenic mice held on high-fat diet, the supplementation of walnuts leads to a reduced plasma lipid metabolism and a slower plaque progression, with no more than limited effects on platelet activation and coagulation. 

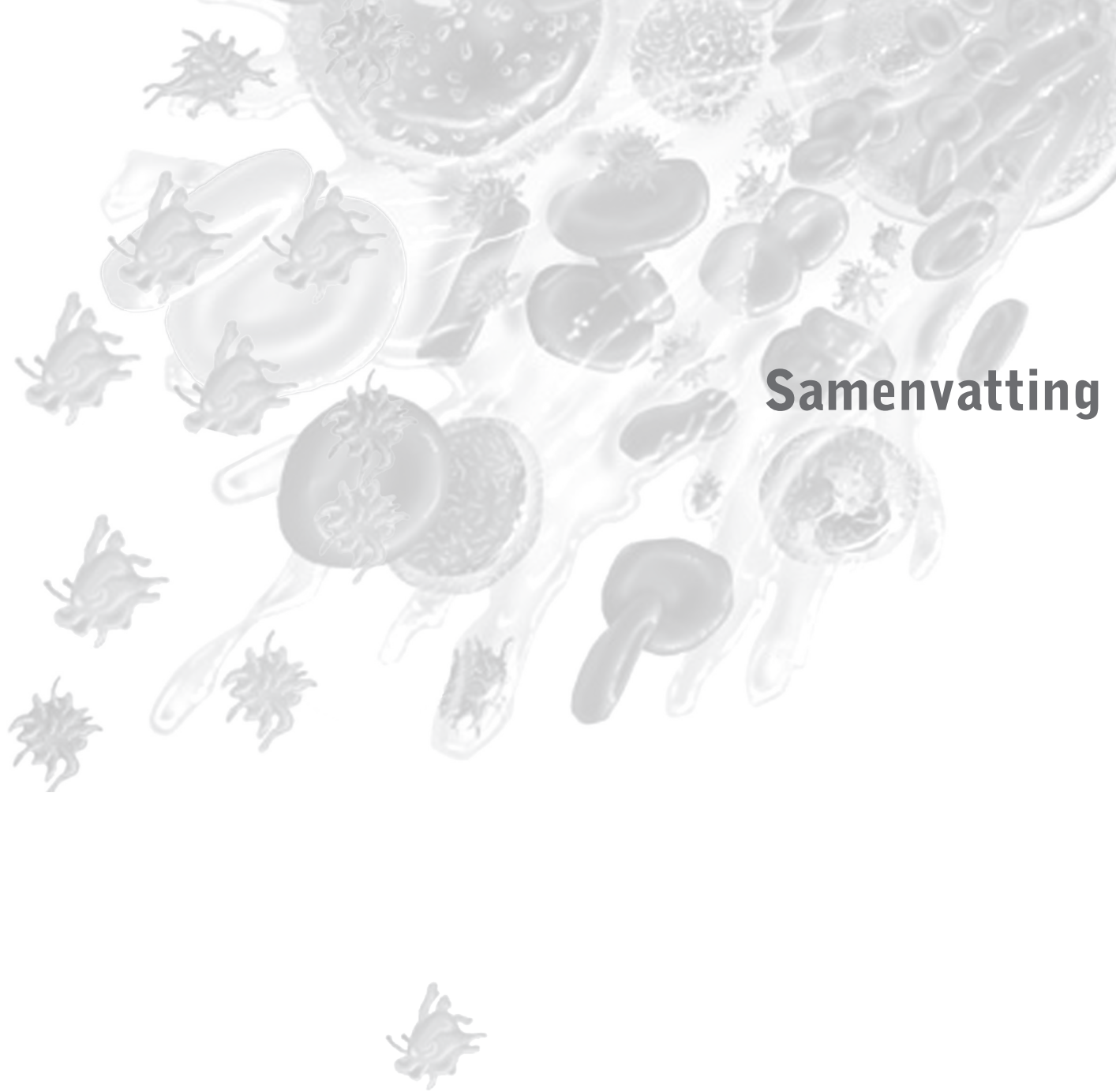

$\frac{16}{3}$ 


\section{Samenvatting}

Bloedplaatjes hebben een essentiële functie in de hemostase, maar spelen ook een rol in atherotrombose. Plaatjes hechten direct op plaatsen van de arteriële vaatwand waar de endotheellaag beschadigd is, en bevorderen dan de ontwikkeling van chronische atherosclerotische laesies. Het scheuren van een atherosclerotische plaque veroorzaakt massale plaatjesactivering en bewerkstelligt daarmee de vorming van een trombus bestaand uit plaatjes en fibrine. Hoofdstuk 1 van dit proefschrift geeft relevante achtergrondinformatie over de activering van plaatjes en het proces van trombusvorming. In het bijzonder worden de twee plaatjesreceptoren geïntroduceerd, die een centrale rol spelen in dit proefschrift, namelijk CD36 en $\mathrm{P}_{2} \mathrm{Y}_{12}$. In het laatste deel van dit hoofdstuk wordt de mogelijke bijdrage van voedingscomponenten aan atherosclerose en arteriële trombose besproken.

Het glycoproteïne CD36, ook wel bekend als glycoproteïne IIIb/IV-of FAT, komt tot expressie op het oppervlak van plaatjes, monocyten, endotheelcellen, gladde spiercellen en andere cellen van het cardiovasculaire systeem. Ondanks het grote aantal receptoren op het celoppervlak is CD36 een wat mysterieus eiwit, waarvan de functie lange tijd onduidelijk is gebleven. Hoe CD36 de activering van cellen kan beïnvloeden door de biding van verschillende soorten liganden is besproken in hoofdstuk $\mathbf{2}$. Hierbij is vooral ingegaan op de werking van de liganden trombospondine-1 (TSP1), geoxideerd lage-dichtheid lipoproteïne (oxLDL) en vrije vetzuren. Het eiwit CD36 heeft twee transmembraandomeinen met een korte cytoplasmatische staart. Gebaseerd op deze structuuranalyse is een model opgesteld, waarbij signalering via CD36 door niet meer dan een paar signaaltransductiewegen kan leiden tot verschillende soorten van reacties in verschillende celtypen. Dit model kan een verklaring bieden aan de heterogene rol van CD36 in trombose, atherosclerose en de glucose- of vetstofwisseling.

Alhoewel zowel TSPI en oxLDL in de literatuur beschreven worden als liganden van CD36, is het onduidelijk hoe deze liganden bijdragen aan de activering van plaatjes. Dit is nader onderzocht in de hoofdstukken 3 en 4. Wanneer TSPl en oxLDL in oplossing zijn, hebben ze een zwakke plaatjesactivering werking. Echter geïmmobiliseerd op een oppervlak blijken ze te fungeren ze als sterke plaatjesactivatoren (hoofdstuk 3). De hechting en spreiding van plaatjes op geïmmobiliseerd TSPl of oxLDL, maar niet op LDL, gaat gepaard met sterke calciumstromen in de cel, en met de oppervlakteexpressie van P-selectine en fosfatidylserine. Deze CD36-afhankelijke signaleringsroute wordt bewerkstelligd door de activering van proteïnekinasen van de Src en Syk families. Plaatjesactivering via $\alpha_{\mathrm{II}} \beta_{3}$ integrines en ADP-receptoren draagt hier ook nog aan bij. Daarnaast stimuleren geïmmobiliseerd TSPI en oxLDL de hechting van plaatjes aan collageen in volbloed bij de opbouw van een trombus onder stromingcondities. In hoofdstuk 4 is dit verder aangetoond met behulp van muizen die deficiënt zijn in CD36 of TSP1. Vastgesteld is dat de interactie van muizen CD36 met geïmmobiliseerd TSPl een stimulerend effect heeft op het proces van trombusvorming bij hoge stromingssnelheden. Samengevat geven deze resultaten nieuw inzicht in de rol van CD36 in de hemostase en de trombusvorming.

Atherotrombose, dat wil zeggen trombose na plaqueruptuur, is een belangrijke onderliggende oorzaak van hart-en vaatziekten. Echter diermodellen om dit proces 
van atherotrombose goed te bestuderen zijn schaars. In hoofdstuk $\mathbf{5}$ wordt een nieuw muismodel beschreven van de trombusvorming na het acuut opwekken van een plaqueruptuur. Dit model is gebruikt om de onderliggende mechanismen van atherotrombose te bestuderen met behulp van in vivo fluorescentiemicroscopie. Door een gerichte ultrageluidbehandeling wordt heel lokaal het scheuren van een atherosclerotische plaque opgewekt in een halsslagader van een muis met aanleg voor atherosclerose. Gevolg van deze ruptuur is dat het plaatjesactiverende collageen in de vaatwand wordt blootgesteld aan de bloedstroom. Met behulp van remmers van de plaatjes collageenreceptor glycoproteïne VI of van de vorming van trombine kon aangetoond worden, dat de trombusvorming in het bloedvat afhankelijk is van zowel collageen-geïnduceerde plaatjesactivering als van weefselfactor-afhankelijke bloedstolling. Bovendien blijkt de trombusvorming in dit model gevoelig voor bestaande en nieuwe antitrombotische medicatie.

In hoofdstuk 6 is ditzelfde muizenmodel gebruikt om de rol van de $P 2 Y_{12}$-receptoren op plaatjes in de atherotrombose te bestuderen. Door toediening van reversibele $\mathrm{P} 2 \mathrm{Y}_{12}$-remmers, namelijk ticagrelor of cangrelor, verminderde de trombusvorming na plaqueruptuur. Daarnaast onderdrukten deze remmers ook de trombusvorming in volbloedperfusieproeven, waarbij ofwel humaan bloed ofwel muizenbloed werd gestroomd over collageenbevattend plaquemateriaal. De resultaten wezen verder op een $\mathrm{P}_{2} \mathrm{Y}_{12}$-afhankelijke stabilisatie van de gevormde trombus met name bij hoge stromingssnelheden, zelfs in de aanwezigheid van een beperkte mate van bloedstolling. Deze bevindingen geven tesamen beter inzicht in de werkingsmechanismen van deze antitrombotische medicatie.

Momenteel is er een groeiende belangstelling voor de mogelijke beschermende effecten van n-3 meervoudig onverzadigde vetzuren (PUFA) en antioxidante polyfenolen voor het verkrijgen van hart- en vaatzieken. $0 \mathrm{~m}$ hierin meer inzicht te krijgen, is in hoofdstuk 7 een voedings interventiestudie uitgevoerd met proatherogene muizen. De muizen werden gevoed met een dieet met een hoog vet- en cholesterol-gehalte, dat werd aangevuld met walnoot(olie) of druivenpitextract. Vergeleken werden daarmee de voedingseffecten van walnoten (met $n-3$ vetzuren en antioxidante polyfenolen) en die van walnootolie (met alleen $n-3$ vetzuren) of van druivenpitextract (alleen antioxidante polyfenolen). Alleen de toevoeging van walnoten aan het vetrijke dieet verlaagde de plasmaspiegels van triglyceriden, cholesterol en protrombine, en verhoogde de antioxiderende capaciteit van het plasma. Dit ging verder gepaard met een lagere vetophoping in de lever, en een opmerkelijk sterke vermindering van CD36-positieve atherosclerotische plaques in de aortastreek. Geen van deze effecten was aanwezig bij de muizen die walnootolie of druivenpitextract kregen toegediend. De plaatjesactivering, de trombinegeneratie in plasma, en de trombusvorming in stromend bloed bleven onveranderd in elk van de drie dieetgroepen. Samengevat blijkt dus de toevoeging van walnoten aan een vetrijk dieet, althans in muizen, te leiden tot een verlaagd lipidmetabolisme in plasma en een vertraagde progressie van plaquevorming, terwijl effecten op de plaatjesactivering en bloedstolling nagenoeg afwezig zijn. 


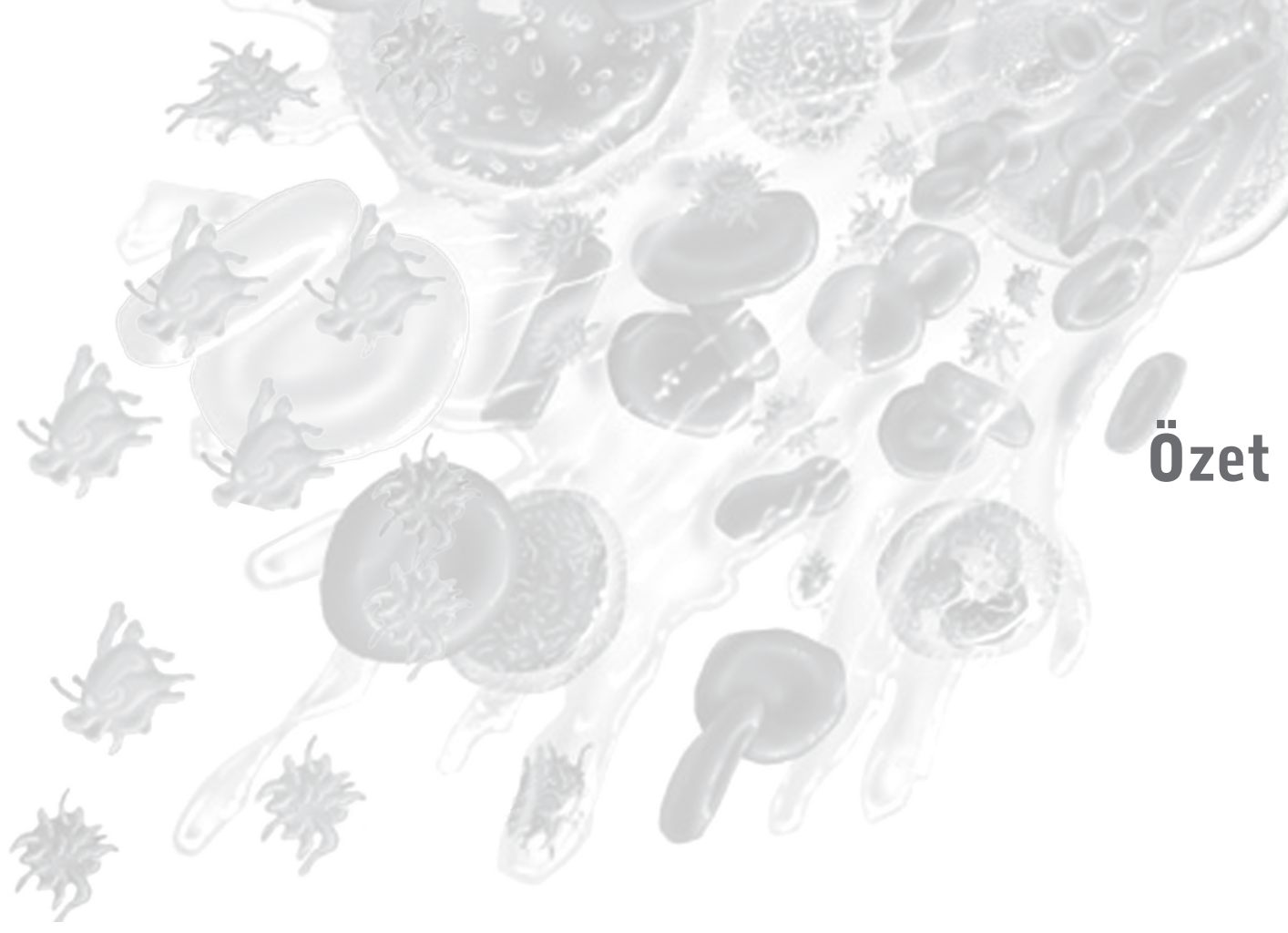

$\frac{\beta^{2}}{x_{3}^{2}}$

$\frac{16}{3}$ 


\section{Özet}

Hemostazda önemli bir işleve sahip olan trombositler, aynı zamanda aterotromboz gelişimine de katkıda bulunmaktadır. Bu hücreler, arter damar duvarının endotel hücre hasarı oluşan bölgelerine hızla yapışır ve kronik aterosklerotik lezyonların oluşumunda rol alır. Aterosklerotik plakların erozyona uğraması ya da yırtılması önemli oranda trombosit aktivasyonu ve trombosit fibrin ağı içeren trombüs oluşumuna neden olmaktadır. Trombosit aktivasyonu ve trombüs oluşumu ile ilgili genel bilgiler kısmi olarak 1. Bölüm'de ele alınmıştır. Daha sonraki bölümlerde genel olarak trombosit reseptörleri $\mathrm{CD} 36$ ve $\mathrm{P}_{2} \mathrm{Y}_{12}$ ile ilgili temel bilgilere yer verilmiştir. Son olarak beslenmenin ateroskleroz ve arteryel trombozdaki olası etkisi tartışılmıştır.

Glikoprotein IIIb/IV veya FAT olarak bilinen glikoprotein CD36; trombositler, monositler, endotel hücreleri, düz kas hücreleri ve diğer kardiyovasküler sistem hücrelerinde bulunmaktadır. CD36, hücrelerde yüksek miktarda bulunmasına rağmen fonksiyonu uzun bir süre tam olarak anlaşılamamıştır. CD36 ile ligand etkileşimlerinin hücresel yanıtı nasıl etkileyebileceği, trombospondin-1 (TSP1), okside düşük yoğunluklu lipoprotein (oxLDL) ve yağ asitleri üzerinde durularak 2. Bölüm'de değerlendirilmiştir. Ayrıca iki transmembran kısmı ve kısa sitoplazmik kuyruğu olan CD36'nın yapısı göz önüne alınarak reseptörün hücre içi sinyal yolaklarına olan etkisi irdelenmiştir. CD36'nın ayrıntılı bir moleküler yapı analizi yapılmış ve farklı hücrelerde sınırlı sayıda sinyal yolağı ile birçok süreci başlatmasını öngören bir model bu bölümde ileri sürülmüştür. Böylece bu proteinin tromboz, ateroskleroz, enflamasyon ya da glukoz ve lipid metabolizması ile olan ilişkisi değerlendirilmiştir.

TSPI ve oxLDL, CD36'nın ligandları olarak literatürde tanımlanmış olmasına rağmen bu ligandların CD36 aracılığı ile trombosit aktivasyonuna olan etkisi günümüze kadar iyi anlaşılamamıştır. Bu konu 3. ve 4. Bölüm'de deneysel çalışmalarla ayrıntılı olarak incelenerek CD36'nın fonksiyonu gösterilmiştir. TSPI ve oxLDL trombosit süspansiyonu içerisinde olduklarında hafif bir trombosit aktivasyonundan daha fazlasına neden olamamaktadır. Ancak bu ligandlar bir yüzeye bağlı (immobilize) olduklarında insan trombositlerini CD36 yoluyla güçlü bir şekilde aktive etmektedir. 3. Bölüm'de sunulduğu üzere immobilize LDL, trombosit adezyonu ve aktivasyonunu etkilememiş ancak TSP1 veya oxLDL stimule etmiştir. TSP1 ve oxLDL'ye bağlanan CD36 aracılığı ile trombositlerin adezyon ve sonrasında yayılarak şekil değiştirmesine $\mathrm{Ca}^{2+}$ akışı, P-selektin sekresyonu ve membranda fosfatidilserin oluşumu eşlik etmiştir. CD36'ya bağımlı sinyal yolağı, adenozin di fosfat (ADP) reseptörleri ve $\alpha_{I I b} \beta_{3}$ integrinlerin katkısı ile Src grubu protein kinaz ailesi ve Syk protein kinaz aktivasyonu üzerinden ilerleyerek trombosit aktivasyonuna neden olmaktadır. İmmobilize TSPI ve oxLDL, trombositlerin akış altında kollajene bağlı trombüs oluşumunu artırmaktadır. Bu çalışma, 4. Bölüm'de CD36 veya TSPI'in mutasyon ile elimine edildiği deney fareleri kullanılarak genişletilmiştir. CD36 ile trombositten elde edilen immobilize TSPI arasındaki etkileşimin, farelerde yüksek shear stres altında trombüs oluşumunu artırdığı tespit edilmiştir. Özet olarak burada elde edilen veriler, CD36 ve trombosit kaynaklı TSP1'in farelerde hemostaz ve trombozisde gizli ve yeni bir rolü olduğunu ve ayrıca kollajene bağlı trombüs oluşumunda ve trombüs stabilizasyonunda etkin olduğunu göstermektedir. 
Aterotrombozis, fatal kardiyovasküler hastalıkların önemli bir nedeni olduğu halde bu patolojik süreci incelemek için geliştirilmiş hayvan modelleri azdır. 5 . Bölüm'de, aterotrombozun altında yatan mekanizmaların çalışılması için yeni bir deneysel in vivo fare modeli geliştirilmiştir. Aterosklerotik plak üzerinde oluşan akut trombüsün intravital floresan mikroskop ile incelendiği bu modelde; Apoe-/ farelerde karotis arterlerinde plağın erozyonu/yırtılması lokal olarak ultrason uygulaması ile indüklenmektedir. Plak erozyonu sonucunda kollajen açığa çıkarak oklüziv olmayan trombüs oluşumuna yol açmaktadır. Bu bölümde, trombositlerdeki kollajen reseptörleri (glikoprotein VI) veya plazmada trombin oluşumu bloke edilmiş ve bu trombotik sürecin kollajene bağlı trombosit aktivasyonu ve doku faktörüne bağlı koagülasyona dayandığı gösterilmiştir. Ayrıca bu modelde, trombüs oluşumunun antitrombotik ajanlara duyarlı olduğu gösterilmiştir. Bahsedilen in vivo fare modeli, 6. Bölüm'de $P 2 Y_{12}$ reseptörlerinin aterotrombozdaki rolünü araştırmak için kullanılmıştır. Apoe $e^{-/-}$farelerde, tersinir (reverzibl) $\mathrm{P}_{2} \mathrm{Y}_{12}$ antagonistleri olan ticagrelor ve cangrelor, plak erozyonundan sonra trombüsün hem büyüklüğünün hem de stabilitesinin azalmasına sebep olmuştur. In vivo fare deneylerinin yanı sıra fare veya insan kanı, kollajen içeren aterosklerotik plak materyali ile kaplanmış yüzey üzerinden ex vivo olarak perfüze edilmiş ve yukarıda bahsedilen sonuçlar bir kez daha doğrulanmıştır. Bu sonuçlara göre, yüksek shear streste trombüs stabilizasyonu $\mathrm{P}_{2} \mathrm{Y}_{12}{ }^{\prime}$ ye bağımlı olup koagülasyon altında idame etmektedir. Sonuç olarak elde edilen verilerin var olan antitrombotik tedavinin gelişimi için anlamlı sonuçlar doğuracağı aşikardır.

İlaç özelliği taşıyan medikal sentetik ajanlarin yanı sıra kardiyovasküler sistem üzerinde olası koruyucu etkilerinden dolayı besinlerdeki çoklu doymamış n-3 yağ asitleri (PUFA) ve antioksidan polifenoller üzerine ilgi artmaktadır. Bu konunun incelenmesi için 7. Bölüm'de proaterojenik Apoe-/ farelerin kullanıldığı kontrollü diyet çalışması yapılmıştır. Apoe $e^{-/-}$fareler, yüksek yağ ve kolesterole ek olarak ceviz veya üzüm çekirdeği ekstresi içeren diyetlerle beslenmiştir. Bu bölümde, n-3 PUFA içeren ceviz yağı, n-3 PUFA ve antioksidan polifenoller içeren ceviz ve sadece antioksidan polifenoller içeren üzüm çekirdeği ekstresinin aterotromboza olan etkileri karşılaştırılmıştır. Deneysel hayvan çalışması sonucunda ceviz tüketiminin, plazma trigliserid, kolesterol ve protrombin seviyesini düşürmekte ve plazma antioksidan kapasitesini artırmakta olduğu görülmüştür. Buna, karaciğerde lipid birikiminde azalma ve CD36 exprese eden aterosklerotik plakların aortada belirgin bir şekilde azalması eşlik etmiştir. Bu etkilerin hiçbiri, ceviz yağı veya üzüm çekirdeği içeren yüksek yağlı diyetlerle provoke edilememiştir. Trombosit aktivasyonu, plazma trombin ve tam kanda trombüs oluşumu, diyetlerin hiçbirinde değişmemiştir. Sonuçlar genel olarak ele alındığında yüksek yağlı diyet tüketen proaterojenik farelerde, ceviz ile zenginleştirilmiş diyet, trombosit aktivasyonu ve koagülasyon üzerinde sınırlı bir etkiye sahip olmasına karşın plazmada lipid metabolizmasının azalmasına ve daha yavaş bir plak oluşumuna yol açmaktadır. 

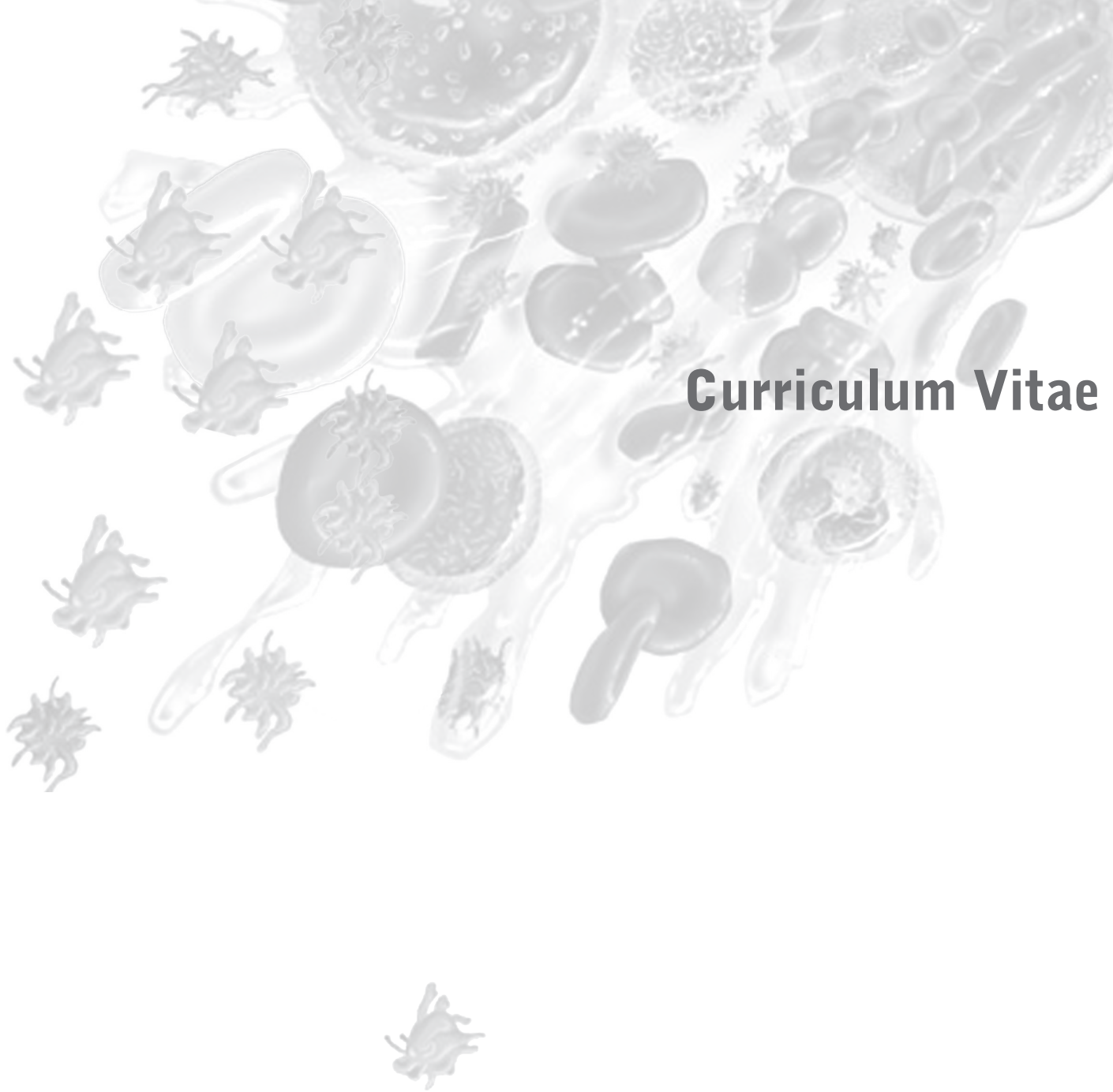

$\frac{16}{3} \frac{6}{5}$ 


\section{Curriculum Vitae}

Reyhan Nergiz-Unal was born in Ankara, Turkey on May $23^{\text {rd }}, 1980$. She completed secondary school at the 50.YIl Language-based High School in 1998, and later obtained her bachelor's degree in Nutrition and Dietetics in 2003 at the School of Health Sciences, Hacettepe University, Ankara (Turkey). Here, she obtained a student success award as well as an İhsan Doğramacı superior success award realized by Hacettepe University. While studying as a MSc student, she worked as nutritionist in the Acıbadem Hospital in Istanbul, and later worked as a research assistant at Division of Nutritional Biochemistry, Hacettepe University (Ankara) under the supervision of Prof. Dr. H. Tanju Besler. In 2006 she received her master's degree and continued to work as research assistant in the same department. In August 2007 she received a fellowship as talented PhD student from the Council of Higher Education of Turkey (YÖK). With this fellowship, she worked as PhD student in the Department of Biochemistry at the Cardiovascular Research Institute Maastricht (CARIM) of Maastricht University. The research performed, described in the present thesis, was supervised by Prof. Dr. J.W.M. Heemskerk and Dr. J.M.E.M. Cosemans. She obtained the status of Article 9 expert according to the Netherlands Law on Animal Experiments. During the PhD period, she visited congresses in Birmingham (United Kingdom), Wittenberg (Germany), Boston (USA) and Nürnberg (Germany), and obtained several prices. From August 2011, she is employed as talented postdoc with a YÖK fellowship by Hacettepe University. 


\section{List of Publications}

\section{Full Papers:}

1. Marijke J.E. Kuijpers, Karen Gilio, Sietse Reitsma, Reyhan Nergiz-Unal, Lenneke Prinzen, Sylvia Heeneman, Esther Lutgens, Marc A.M.J. van Zandvoort, Bernhard Nieswandt, Mirjam G.A. oude Egbrink, Johan W.M Heemskerk. Complementary roles of platelets and coagulation in thrombus formation on plaques acutely ruptured by targeted ultrasound treatment: a novel intravital model. J. Thromb. Haemost. 2009; 7: 152-161.

2. Reyhan Nergiz-Unal, Judith M.E.M. Cosemans, Marion A.H. Feijge, Paola E.J. van der Meijden, Robert F. Storey, J.J.J. (Hans) van Giezen, Mirjam G.A. oude Egbrink, Johan W.M. Heemskerk, Marijke J.E. Kuijpers. Stabilizing role of platelet $\mathrm{P} 2 \mathrm{Y}_{12}$ receptors in shear-dependent thrombus formation following plaque rupture. Plos One. 2010; 5: e10130.

3. Reyhan Nergiz-Unal, Timo Rademakers, Judith M.E.M. Cosemans, Johan W.M. Heemskerk. CD36 as a multiple-ligand signaling receptor in atherothrombosis. Cardiovasc. Hematol. Agents Med. Chem. 2011; 9: 42-55.

4. Reyhan Nergiz-Unal, Moniek M.E. Lamers, Roger van Kruchten, Joost J. F.P. Luiken, Judith M.E.M. Cosemans, Jan F.C. Glatz, Marijke J.E. Kuijpers, Johan W.M. Heemskerk. Signaling role of CD36 in platelet activation and thrombus formation on immobilized thrombospondin or oxidized LDL. J. Thromb. Haemost. 2011; in revision.

5. Reyhan Nergiz-Unal, Marijke J.E. Kuijpers, Sylvia Heeneman, Marion A.H. Feijge, Erik A.L. Biessen, Guido R.M.M. Haenen, H.Tanju Besler, Judith M.E.M. Cosemans, Johan W.M Heemskerk. Effect of dietary walnut on atherosclerosis and coagulant state in ApoE-deficient mice. 2011; submitted.

6. Reyhan Nergiz-Unal, Marijke J.E. Kuijpers, Irene Vroegrijk, Roger van Kruchten, Suzanne J.A. Korporaal, Maria Febbraio, Marc F. Hoylaerts, Marc Tjwa, Peter J. Voshol, Judith M.E.M. Cosemans, Johan W.M. Heemskerk. Subtle roles of platelet CD36 and thrombospondin-1 in murine thrombus formation on collagen. 2011; submitted.

7. Susanne De Witt, Judith M.E.M. Cosemans, Reyhan Nergiz-Unal, Martin H. Prins, Johan W.M Heemskerk. Murine models of arterial thrombosis, a meta-analysis. 2011; submitted.

8. Roger van Kruchten, Reyhan Nergiz-Unal, Karen Gilio, Edouard M. Bevers, Johan W.M Heemskerk. Calcium entry blockers to suppress thrombus formation of human platelets. 2011; submitted. 


\section{Published Abstracts:}

1. Reyhan Nergiz-Unal, Marijke J.E. Kuijpers, Imke C.A. Munnix, Jan F.C. Glatz, Johan W.M Heemskerk. Outside-in signaling induced by thrombospondin-1 enhances thrombus formation: involvement of CD36. J. Thromb. Haemost. 2009; Suppl. July 2009.

2. Reyhan Nergiz-Unal, Judith M.E.M. Cosemans, Paola E.J. van der Meijden, Marion A.H. Feijge, Mirjam G.A. oude Egbrink, Johan W.M. Heemskerk, Marijke J.E. Kuijpers. Thrombus stabilization by $\mathrm{P}_{2} \mathrm{Y}_{12}$ contributes to atherothrombosis and is restricted to high shear flow conditions. J. Thromb. Haemost. 2009; Suppl. July 2009.

3. Reyhan Nergiz-Unal, Moniek M.E. Lamers, Jan F.C. Glatz, Marijke J.E. Kuijpers, Johan W.M. Heemskerk. Role of CD36 in platelet activation and thrombus formation on immobilized thrombospondin and oxidized LDL. Hämostaseologie. 2010; 1/2010.

\section{List of Awards}

1. İhsan Doğramacı superior success award, School of Health Sciences, Hacettepe University, Ankara, Turkey, 2003.

2. Student success award, Department of Nutrition and Dietetics, Hacettepe University, Ankara, Turkey, 2003.

3. Fellowship for talented PhD student, Council of Higher Education (YÖK), Hacettepe University, Ankara, Turkey, 2007-2011.

4. Young investigator award, International Society on Thrombosis and Haemostasis (ISTH) at XXII ${ }^{\text {th }}$ Congress of ISTH, Boston, USA, 2009.

5. Poster award, first combined meeting of Gesellschaft für Thrombose- und Hämostaseforschung (GTH) \& Nederlandse Vereniging voor Trombose en Hemostase (NVTH), Nürnberg, Germany, 2010.

6. Asian-Pacific Scholarship, Japanese Society on Thrombosis and Hemostasis (JSTH) at XXIIIrd Congress of ISTH, Kyoto, Japan, 2011 


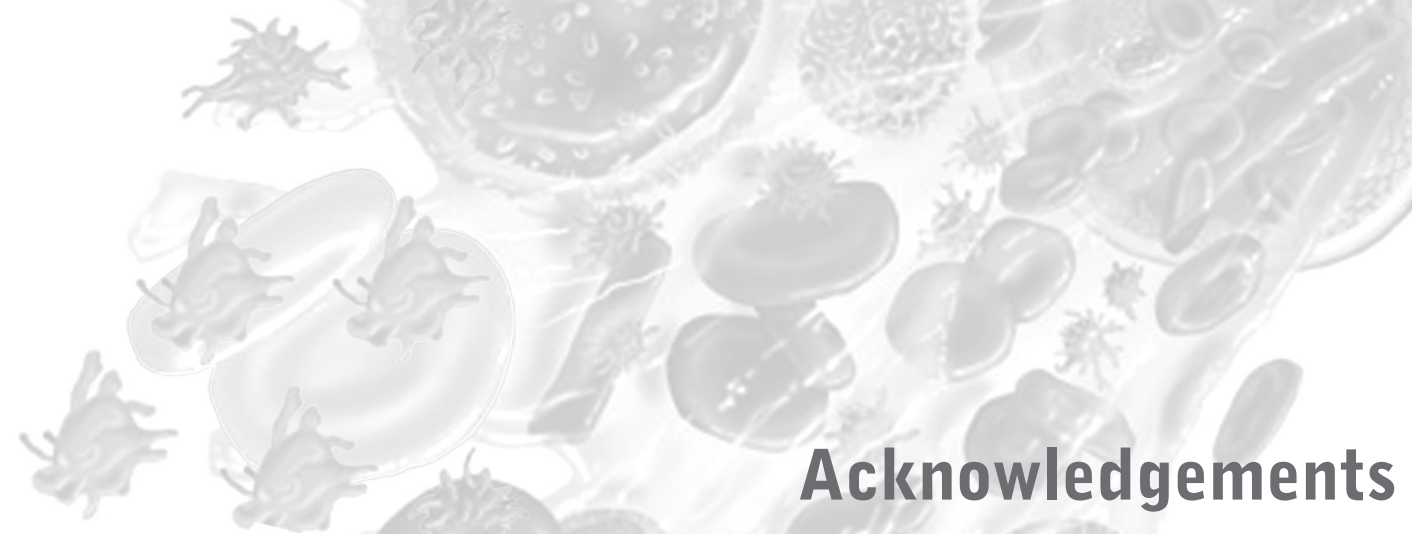

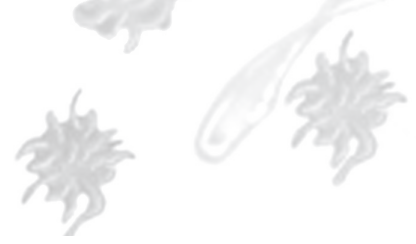
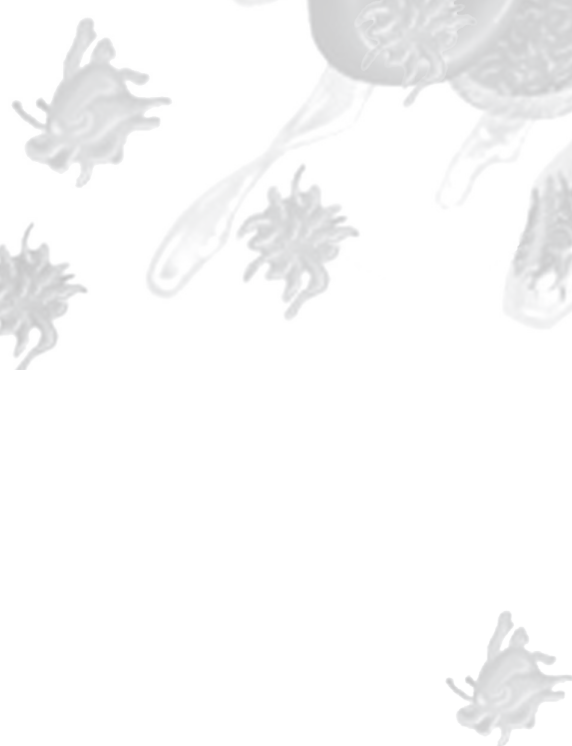

$\frac{16}{3}$ 


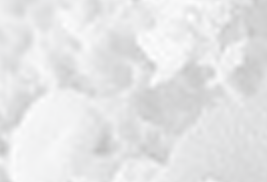

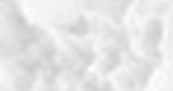

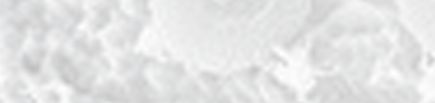

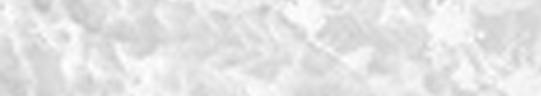

$\ln _{10}$

.

(3)
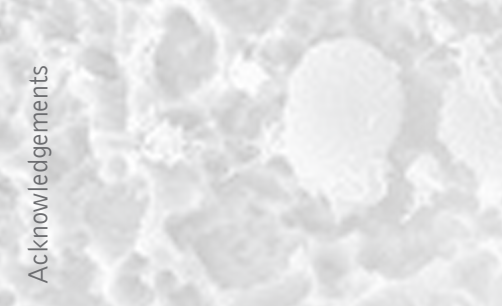

178

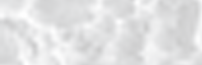

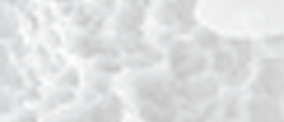

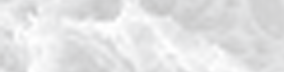

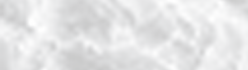

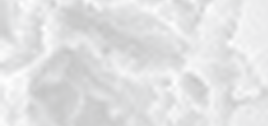

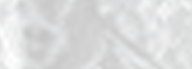

(4)

ans

$\cos 2$

$6 x^{2}-2(30)$

(3)

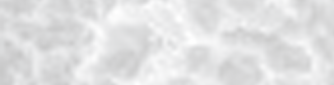

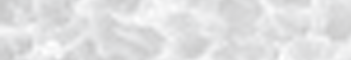

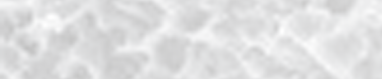

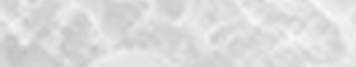

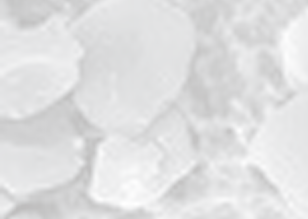




\section{Acknowledgements}

"Life is like riding a bicycle. To keep your balance you must keep moving" as Albert Einstein said. This expression has been so true for my life; especially when I found myself doing my PhD in Maastricht. I could not have been able to move forward without the support of some people in the Netherlands and Turkey. I will here thank all of you and promise to make it as brief as possible.

My first and foremost thanks must go to my supervisor Johan Heemskerk for giving me the opportunity to do a PhD in his laboratory, and for his huge amount of support, guidance and advice throughout. Thank you for always having your door open, and for your patience. It must have not been always easy to try to convert a nutritionist into a biochemist. Secondly, I am grateful to H. Tanju Besler for giving me the opportunity to do MSc in his laboratory, and supporting me to do PhD abroad. I am also grateful to Hacettepe University and the Council of Higher Education of Turkey (YÖK) for financial support.

Thanks to all my colleagues for a great working environment. Judith, thanks for all useful discussions, and practical advice during the last round of my PhD. Marion, it is difficult to express in a few sentences how grateful I am for your huge support over the years. Within the lab I must extend particular thanks to my "lab-teacher" Marijke for all the practical advice in my first animal experiments. Karen and Marisa, thank you for being such good friends as well as being great colleagues. I must also thank every other past and present member of the lab Michelle, Imke, Moniek, Roger, Saskia, Susanne, Frauke, Erik, Nadine, Paola and Rosje for providing support, advice and laughter when it was needed. Furthermore, to all the other colleagues who have been working at the Department of Biochemistry, thanks for contributing to my study by sharing materials, and experience with me. I would like to thank to all donors around the university who have kindly donated blood, and colleagues from Central Animal Facility (CPV) for enabling me to perform my research.

I am grateful to the members of the Assessment Committee A. Bast, E.A.L. Biessen, H. ten Cate, M. van Greevenbroek, S.J.A. Korporaal for the fast evaluation.

Outside work, I have received much support over the past 4 years from many people who cannot all be mentioned here. Many thanks to all people I have not named personally. Special thanks go to Sonia, Yeliz, Zeynep, Evren, İlkşan for always being there for me and for being such good friends, and to Mevlude, Mine, İnci for years of friendship.

Son olarak, beni hayata kazandıran değerli anneme, babama ve ailemin bütün bireylerine teşekkürlerimi sunuyorum. Thanks your interest in my life and for trying to understand exactly what I do at work (sometimes I struggled too... ()).

Birol, we leave the cloudy days behind, a new season starts and will continue forever in our own aura. I would never have made it this far without you. Biricik yol arkadaşım, çocukça bir heyecanla yüreğim ağzımda bekliyorum seninle yaşamayı...

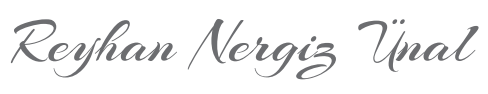

